\title{
WestVirginiaUniversity
}

THE RESEARCH REPOSITORY @ WVU

Graduate Theses, Dissertations, and Problem Reports

1999

\section{Trip generation rates for consolidated schools in West Virginia}

Amy Marie Balmer

West Virginia University

Follow this and additional works at: https://researchrepository.wvu.edu/etd

\section{Recommended Citation}

Balmer, Amy Marie, "Trip generation rates for consolidated schools in West Virginia" (1999). Graduate Theses, Dissertations, and Problem Reports. 963.

https://researchrepository.wvu.edu/etd/963

This Thesis is protected by copyright and/or related rights. It has been brought to you by the The Research Repository @ WVU with permission from the rights-holder(s). You are free to use this Thesis in any way that is permitted by the copyright and related rights legislation that applies to your use. For other uses you must obtain permission from the rights-holder(s) directly, unless additional rights are indicated by a Creative Commons license in the record and/ or on the work itself. This Thesis has been accepted for inclusion in WVU Graduate Theses, Dissertations, and Problem Reports collection by an authorized administrator of The Research Repository @ WVU. For more information, please contact researchrepository@mail.wvu.edu. 


\title{
Trip Generation Rates for Consolidated \\ Schools in West Virginia
}

\author{
Amy M. Balmer \\ Thesis \\ Submitted to the College of Engineering \\ and Mineral Resources \\ at West Virginia University
}

In Partial Fulfillment of the Requirements for The Degree of Master of Science in Civil Engineering

Ronald W. Eck, Ph.D., P.E., Chair

L. James French, III, Ph.D., P.E. David G. Williams, Ph.D.

Morgantown, West Virginia

1999

Keywords: Trip Generation, Traffic Projections, Traffic Impact Studies 


\section{Abstract \\ Trip Generation Rates for Consolidated Schools in West Virginia}

\section{Amy M. Balmer}

Currently, there are no trip generation rates for consolidated schools in West Virginia. A consolidated school is a public school that formed from the consolidation of other schools of the same type or a county-wide school. Because West Virginia is rural in nature and declining school-age population, the trip rates for consolidated schools would tend to be different than the national averages for traditional schools.

This research developed trip rates specific to consolidated high, middle, and elementary schools in West Virginia. In total, sixteen different schools in West Virginia were studied. Of the sixteen sites studied, seven were high schools, two were middle schools, four were elementary schools, one was an elementary-middle school combination, and two were middle-high school combinations. Trip rates for each type of school were calculated based on trips per employee, trips per students, and trips per 1000 SF GFA. The trip rates were based on weekday, am peak, and pm peak time periods. The number of bus trips, peaking characteristics, and parking characteristics of each site were analyzed.

The results of this study indicated that there are differences between ITE's (1997) national averages and results of this study. Study results are appropriate to predict the amount of traffic generated at consolidated high schools and consolidated elementary schools in West Virginia. In the cases of consolidated middle schools and consolidated combined schools, the existing ITE data should be used to predict the amount of traffic for new facilities. Also, the environment of the surrounding area should be analyzed to tailor the trip rates to the site in question. 


\section{Acknowledgments}

The author would like to take this opportunity to express appreciation for the many people who helped in the completion of this thesis. First of all, many thanks to Dr. Ronald W. Eck, her graduate advisor and committee chairperson, for his assistance and guidance in preparation of this thesis. The author also wishes to express appreciation to Jim French for his participation on the committee and the constructive comments and suggestions on the many draft versions. In addition to the two committee members mentioned previously, the author would like to express thanks to Dr. David Williams for his participation on the Examination Committee.

Additional thanks go to Jason Kratsas, Adam Patterson, and Jason Boyd for their help in data collection and data reduction. Of course, none of this work would have been completed without the support of the "Cellar Dwellers," friends, and family.

The full financial support and data collection provided by the Division of Highways, West Virginia Department of Transportation, sponsorship of this project is gratefully acknowledged. 


\section{Table of Contents}

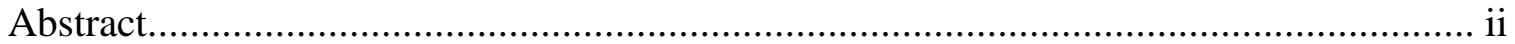

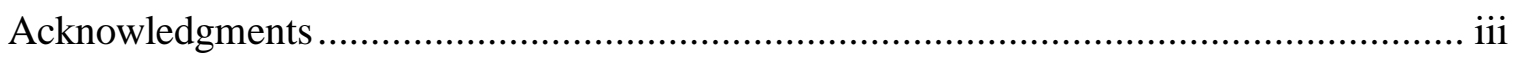

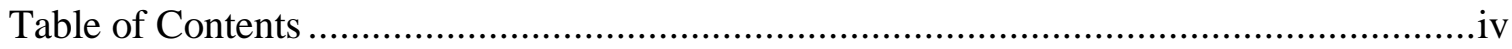

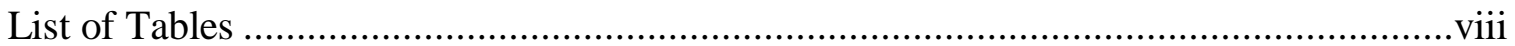

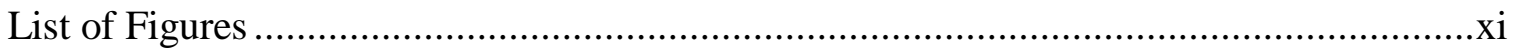

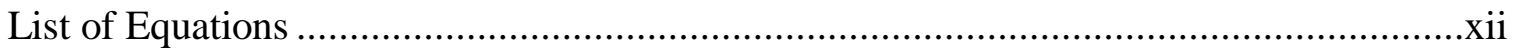

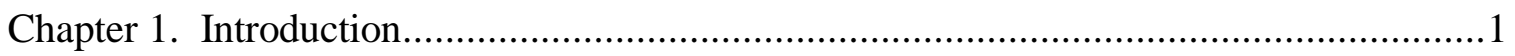

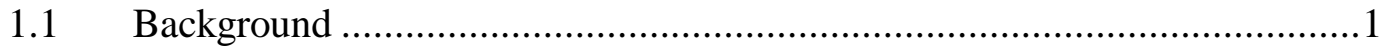

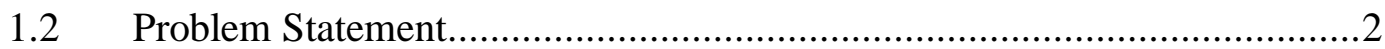

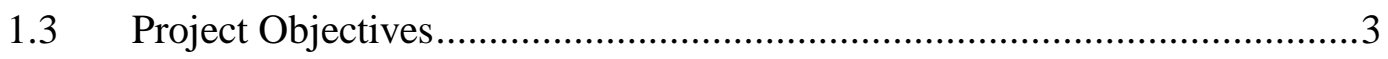

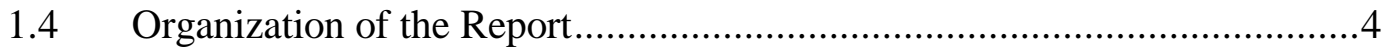

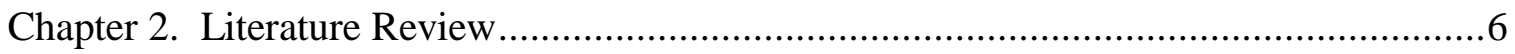

2.1 Introduction ..........................................................................

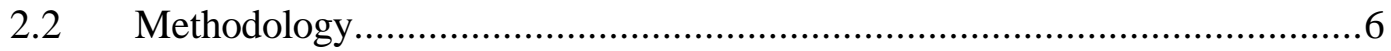

2.2.1 Site Definitions ................................................................. 7

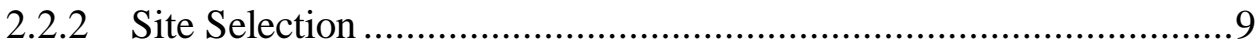

2.2.3 Data Collection ............................................................... 10

2.2.3.1 Types of Data and Traffic Counts..................................10

2.2.3.2 Sample Size ........................................................... 11

2.2.3.3 Socio-Economic Variables ............................................. 12

2.2.4 Average Trip Rate............................................................. 12

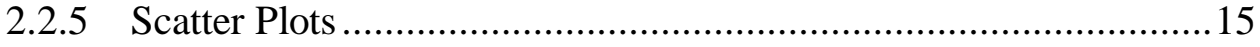

2.2.6 Single Variable Regression Analysis ........................................ 16

2.2.7 Correlation Coefficient (R) and Coefficient of

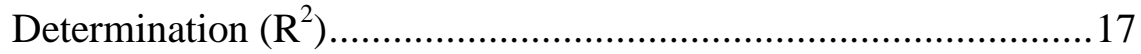

2.2.8 Multiple Variable Regression Analysis..................................... 18

2.2.9 Displaying and Reporting Results .........................................20

2.3 Site Specific Studies on Special Generators .........................................22 
2.3.1 High Schools ...............................................................................23

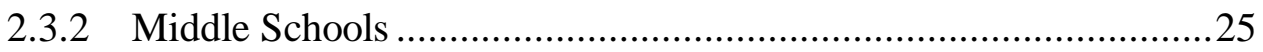

2.3.3 Elementary Schools..................................................................26

2.3.4 Comparison of Trip Rates by School Types ………......................27

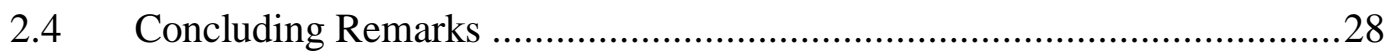

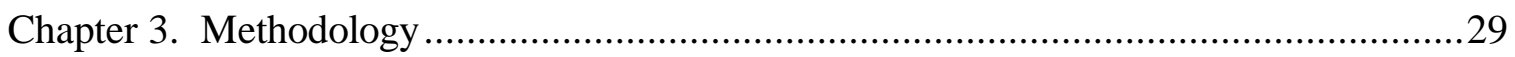

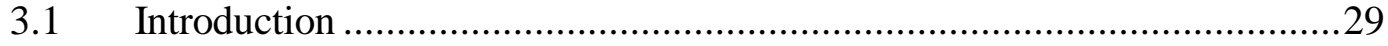

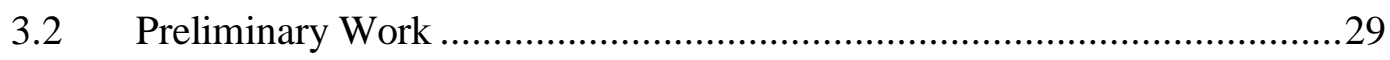

3.2.1 Land Use Selection ...................................................................29

3.2.2 Socio-Economic Variable Determination .........................................31

3.3 Site Identification and Selection............................................................... 31

3.3.1 Preliminary Site Identification........................................................31

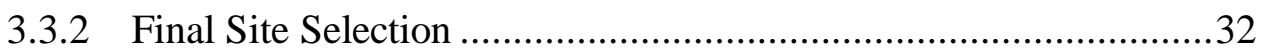

3.3.2.1 Number and Design of Access Points.................................32

3.3.2.2 Cut-Through Traffic..........................................................33

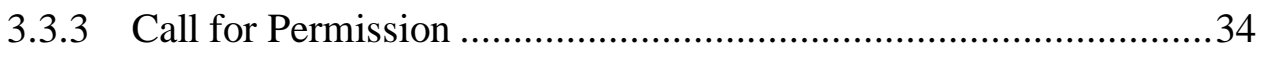

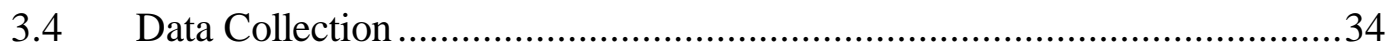

3.4.1 Socio-Economic Variable Collection................................................34

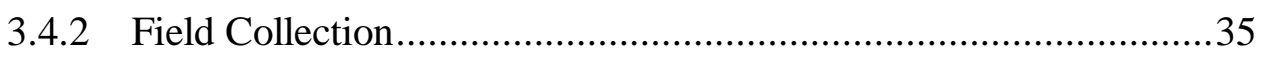

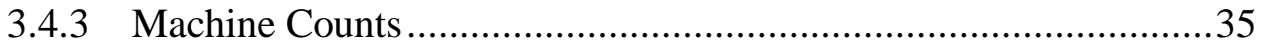

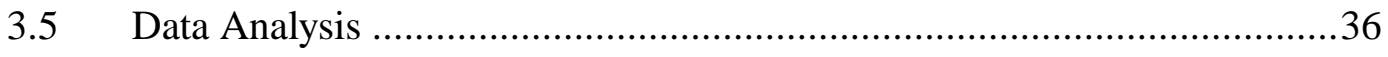

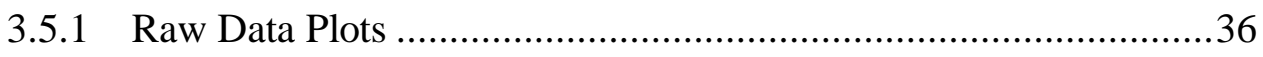

3.5.2 Number of Trips per Time Period ...................................................36

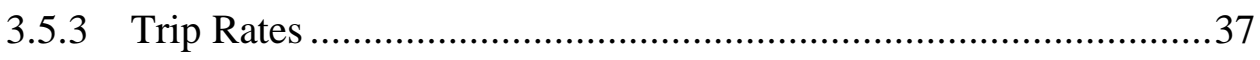

3.5.3.1 Trip Rates of an Individual Site ........................................... 37

3.5.3.2 Average Weighted Trip Rate for the Type of School ..........38

3.5.3.3 Regression Trip Rate Plot....................................................39

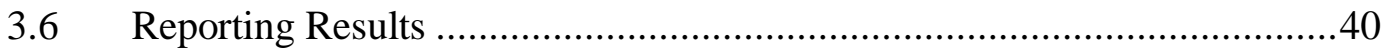


Chapter 4. Results for Consolidated High Schools .42

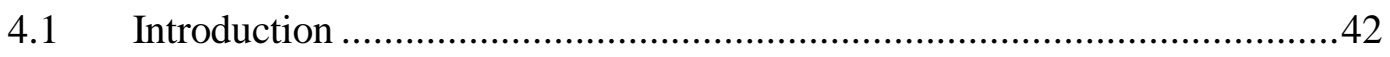

4.2 Consolidated High Schools ………………….....................................42

4.2.1 High School Sites Studied...........................................................43

4.2.2 Average Rates for Consolidated High Schools ...............................45

4.2.3 Comparison with Other Databases ..................................................49

4.2.4 Confidence Interval for High Schools.............................................53

4.2.5 Regression Results for High Schools...............................................54

4.2.6 Peaking Characteristics of High Schools .........................................55

4.2.7 Heavy Vehicle Traffic at High Schools ...........................................56

4.2.8 Recommendations for Use of High School Rates ..........................59

Chapter 5. Results for Consolidated Middle Schools ...........................................................61

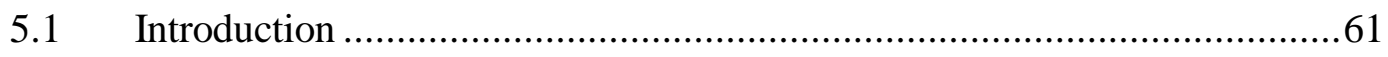

5.2 Consolidated Middle School Sites Studied ...................................................61

5.2.1 Average Rates for Consolidated Middle Schools ............................62

5.2.2 Comparison with Other Databases ..................................................64

5.2.3 Peaking Characteristics of Middle Schools.......................................67

5.2.4 Heavy Vehicle Traffic at Middle Schools .........................................68

5.2.5 Recommendations for Use of Middle School Rates........................68

Chapter 6. Results for Consolidated Elementary Schools..................................................70

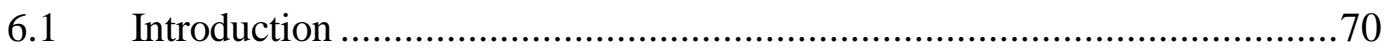

6.2 Elementary School Sites Studied............................................................

6.2.1 Average Rates for Consolidated Elementary Schools .....................71

6.2.2 Comparison with Other Databases .................................................75

6.2.3 Confidence Interval for Elementary Schools...................................78

6.2.4 Regression Results for Elementary Schools......................................79

6.2.5 Peaking Characteristics of Elementary Schools ................................8 80

6.2.6 Heavy Vehicle Traffic at Elementary Schools ..................................8 81 
6.2.7 Recommendations for Use of Elementary School Rates .82

Chapter 7. Results for Combined Consolidated School Sites .83

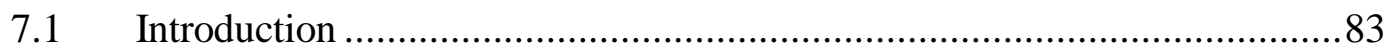

7.2 Combined Consolidated School Sites Studied ...................................... 83

7.2.1 Average Rates for Combined Consolidated School Sites ..............84

7.2.2 Comparison with Other School Types and Databases..................8 87

7.2.3 Peaking Characteristics of Combined School Sites......................89

7.2.4 Heavy Vehicle Traffic at Combined School Sites ........................90

7.2.5 Recommendations for Use of Combined School Site Rates...........91

Chapter 8. Overall Comparison of Consolidated School Types .....................................92

8.1 Comparison of Consolidated School Types .................................... 92

8.2 Parking Characteristics of Consolidated Schools...................................94

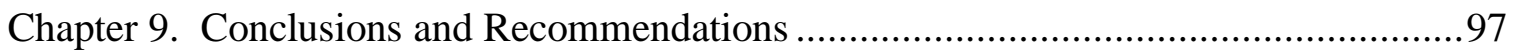

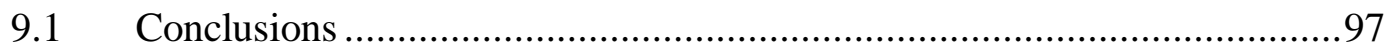

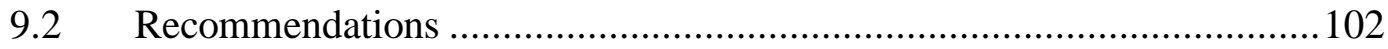

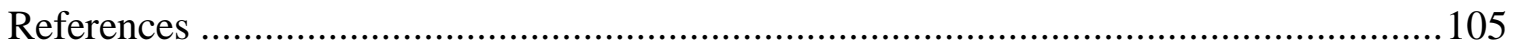

Appendix I - ITE Format Graphs for High Schools ............................................. 107

Appendix II - ITE Format Graphs for Elementary Schools....................................... 129

Appendix III - Study Data Points Plotted on ITE (1997) Graphs for High Schools ......... 139

Appendix IV - Study Data Points Plotted on ITE (1997) Graphs for Middle Schools ..... 161

Appendix V - Study Data Points Plotted on ITE (1997) Graphs for Elementary

Schools 168

Appendix VI- Study Data Points Plotted on ITE (1997) Graphs for Elementary-

Middle Schools

Appendix VII- Study Data Points Plotted on ITE (1997) Graphs for Middle-

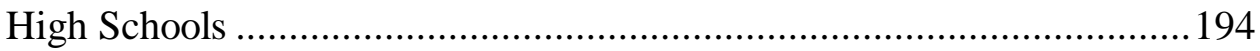

Vita 


\section{List of Tables}

3-1 Desired and Actual Project Sample Size ................................................................ 30

4-1 Comparison of SEV by High School Site .........................................................45

4-2a Comparison of Average Trip Rate per Employee for High Schools .......................47

4-2b Comparison of Average Trip Rate per Student for High Schools ............................47

4-2c Comparison of Average Trip Rate per 1000 SF GFA for High Schools ................48

4-3 Comparison of Student/Employee and Student/1000 SF GFA Ratios for

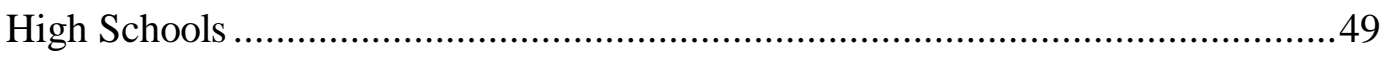

4-4a Comparison of High School Trip Rates per Employee with ITE (1997) .................50

4-4b Comparison of High School Trip Rates per Student with ITE (1997) ....................50

4-4c Comparison of High School Trip Rates per 1000 SF GFA with ITE

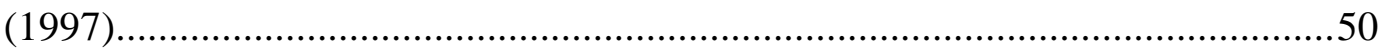

4-5 Comparison of This Study's Results with 1974 Study for High Schools ................52

4-6 Comparison of This Study's Results with 1994 North Carolina Study ...................53

4-7 Confidence Intervals for High Schools..............................................................54

4-8 Coefficient of Determination Values from 1999 WV Study for High

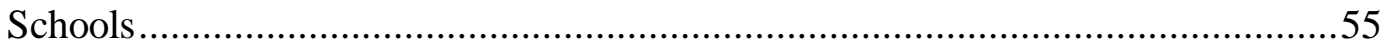

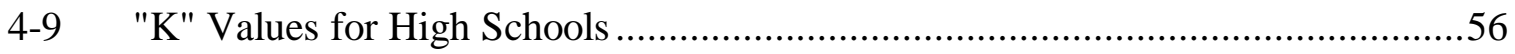

4-10 Number of Bus Trips at Each High School by Time of Day .................................58

4-11 Number of Students-per-Bus Trip at High Schools ...............................................58

5-1 Comparison of SEV by Middle School Site ......................................................61

5-2a Comparison of Average Trip Rate per Employee for Middle Schools ....................63

5-2b Comparison of Average Trip Rate per Student for Middle Schools........................63

5-2c Comparison of Average Trip Rate per 1000 SF GFA for Middle Schools ..............63

5-3 Comparison of Student/Employee and Student/1000 SF GFA Ratios

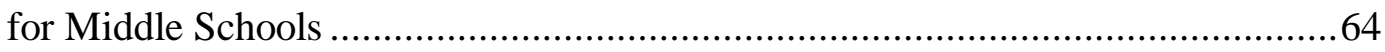

5-4a Comparison of Middle School Trip Rates per Student with ITE (1997) ................66

5-4b Comparison of Middle School Trip Rates per 1000 SF GFA with ITE (1997) ......66 
5-5 Comparison of 1999 Study Results with 1974 Study for Middle Schools..............66

5-6 "K" Values for Middle Schools.......................................................................67

5-7 Number of Bus Trips at Middle Schools by Time of Day ...................................68

5-8 Number of Students per Bus Trip at Middle Schools ........................................68

6-1 Comparison of SEV by Elementary School Site .......................................... 71

6-2a Comparison of Average Trip Rate per Employee for Elementary Schools.............72

6-2b Comparison of Average Trip Rate per Student for Elementary Schools ................72

6-2c Comparison of Average Trip Rate per 1000 SF GFA for Elementary

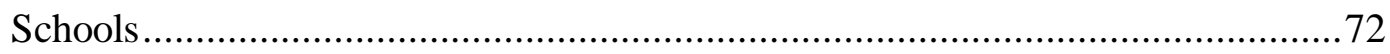

6-3 Comparison of Student/Employee and Student/1000 SF GFA Ratios for

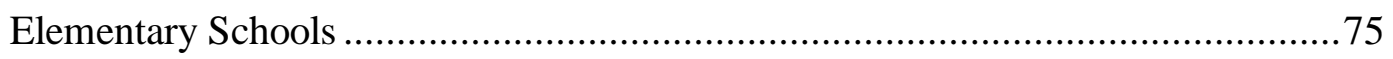

6-4a Comparison of Elementary School Trip Rates per Employee with ITE (1997) .....76

6-4b Comparison of Elementary School Trip Rates per Student with ITE (1997).........76

6-4c Comparison of Elementary School Trip Rate per 1000 SF GFA with

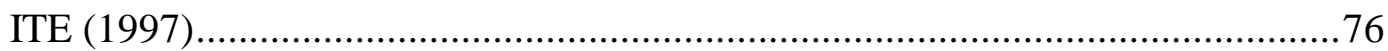

6-5 Comparison of 1999 Elementary Schools Excluding Site B with ITE ..................78

6-6 Comparison of 1999 Study Results with 1974 Study for Elementary

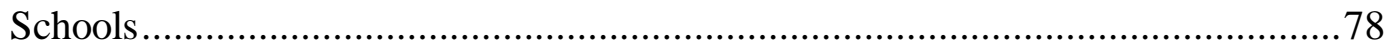

6-7 Confidence Intervals for Elementary Schools................................................ 79

6-8 Coefficient of Determination Values from 1999 WV Study for Elementary Schools80

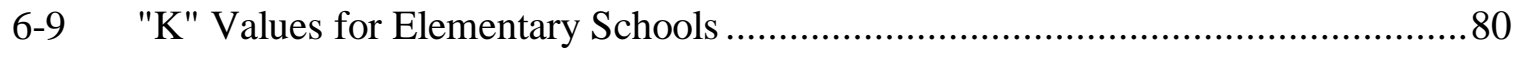

6-10 Number of Bus Trips at Elementary Schools by Time of Day............................81

6-11 Number of Students per Bus Trip at Elementary Schools ..................................82

7-1 Comparison of SEV by Combined School Site ............................................... 84

7-2a Comparison of Average Trip Rate per Employee for Combined School Sites .......85

7-2b Comparison of Average Trip Rate per Student for Combined School Sites..........85

7-2c Comparison of Average Trip Rate per 1000 SF GFA for Combined School Sites .85 
7-3 Comparison of Student/Employee and Students/1000 SF Ratios for

Combined Schools

7-4 Consequences for Using 1000 SF GFA Rates from Related Land Uses

for Predicting Traffic for Site C

7-5 Consequences for Using 1000 SF GFA Rates from Related Land Uses

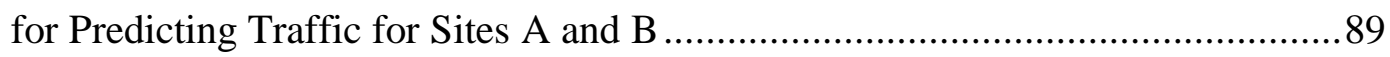

7-6 "K" Values for Combined Schools....................................................................90

7-7 Number of Bus Trips at Combined Schools by Time of Day .............................90

7-8 Number of Students per Bus Trip at Combined Schools ..................................91

8-1a Comparison of Consolidated School Weekday Trip Rates by School

Type

8-1b Comparison of Consolidated School AM Peak Trip Rates by School

Type

8-1c Comparison of Consolidated School PM Peak Trip Rates by School

Type

8-2 Comparison of Student/Employee and Students/1000 SF Ratios for

Consolidated Schools. .94

8-3a Parking Characteristics of High Schools ..................................................... 96

8-3b Parking Characteristics of Middle Schools..................................................96

8-3c Parking Characteristics of Elementary Schools .............................................. 96

8-3d Parking Characteristics of Combined Schools.................................................96

9-1 Comparison of This Study's Results with ITE for High Schools .........................99

9-2 Comparison of 1999 Elementary Schools Excluding Site B with ITE ................100 


\section{List of Figures}

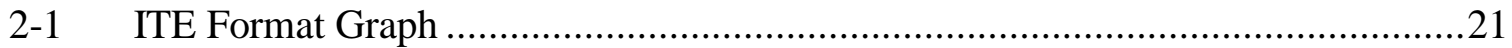

2-2 Comparison of High School Trip Rates ................................................... 25

2-3 Comparison of Middle School Trip Rates .....................................................26

2-4 Comparison of Elementary School Trip Rates ...............................................22 


\section{List of Equations}

2-1 Population Standard Deviation .....................................................................

2-2 Sample Standard Deviation ........................................................................

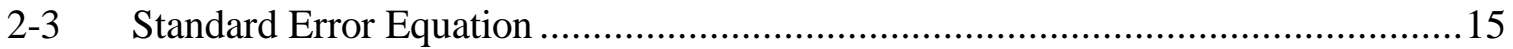

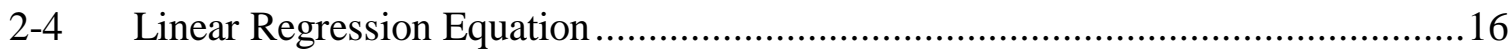

2-5 Logarithmic Regression Equation ....................................................................... 17

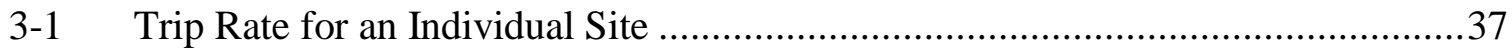

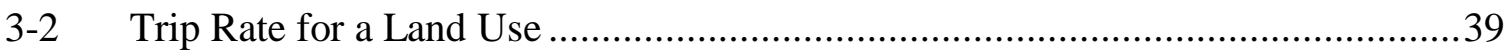




\section{Chapter 1. Introduction}

\subsection{Background}

Transportation planners and engineers are frequently asked to accommodate and approve new site developments. Highway agencies often have the responsibility for approving access plans for these developments and making traffic improvements in the surrounding area to accommodate the anticipated traffic volumes safely and efficiently. Planners and engineers charged with such responsibilities require trip generation data to assess the impact of new developments on existing traffic patterns.

The Institute of Transportation Engineers (ITE) broadly defines trip generation as determining "the number of trips generated for a particular land use" (ITE, 1997). According to ITE, and in general, the primary goal is to provide a means for predicting traffic for a future facility.

A review of literature indicates that a number of agencies and organizations, mainly in highly urbanized areas, have conducted trip generation studies and determined trip generation rates for a variety of land uses. The ITE (1997) publication, Trip Generation, represents a compilation of these data and is the foremost authority in determining the generation rates of specific land uses. According to ITE, the objectives of Trip Generation (ITE, 1997) include:

- Providing a consistent, user-friendly format for results

- Determining a statistical relationship between the socio-economic variables and number of trip ends 
- Organizing a database of information according to land use and independent variables

Predicting the traffic growth that will result from a new facility is a critical part of transportation planning. Accurate predictions lead to the formulation of appropriate traffic control and management strategies to accommodate increased traffic. Poor predictions can lead to congestion and safety problems which must be mitigated by government agencies. Alternatively, poor planning may also lead to costly overbuilding by the developer or by the public agency.

\subsection{Problem Statement}

For several decades, West Virginia Department of Transportation (WVDOT) planning and traffic engineering personnel have established a practice of using trip generation rates tailored to West Virginia. Logic suggests and experience has verified that tailored trip generation rates produce better results than rates based on national averages such as might be found in Trip Generation (ITE, 1997). In fact, the ITE publication recommends that local area studies be conducted because of dispersion in the collected data points.

During the 1970"s, West Virginia University studied several types of "special generators" in West Virginia (schools, shopping centers, hospitals, and certain industries) to estimate trip generation rates (Neumann and Deshpande, 1974). While these rates have served planners and engineers well, it is clear that demographic and socio-economic conditions and consequently, the trip generation characteristics of 
special generators have changed drastically in the last 25 years.

According to the West Virginia Department of Education, the school-age population has been declining at a rate of $2 \%$ annually (Cox, 1999). Declining schoolage population in many parts of the state has necessitated the consolidation of schools. By definition, a consolidated school is one which has been formed by the combination of several adjoining school districts (Webster, 1994). The consolidation typically occurs among a specific type of school, i.e. the consolidation of all high schools in a county into a single large high school. However, it also can occur among grade levels. Not only do these large schools serve many students but they have become important activity centers for their areas, attracting meetings, athletic events, and other functions not necessarily related to school activities. Because of the lack of current trip generation data on schools in West Virginia and the apparent complete lack of data on consolidated schools, there is a need for current trip generation data for consolidated schools in West Virginia.

\subsection{Project Objectives}

The overall goal of this project was to determine trip generation rates, peaking characteristics, and vehicle mix characteristics of the following types of consolidated schools in West Virginia:

- Consolidated Elementary Schools

- Consolidated Middle Schools

- Consolidated High Schools

- Combined Consolidated School Sites 
To accomplish this goal, several specific objectives were identified. Specific objectives were:

- Review literature from previous studies on trip generation for schools

- Design the experimental plan

- Identify and collect traffic and socio-economic variable data at selected schools

- Determine the traffic characteristics associated with consolidated schools

- Calculate trip generation statistics for typical time periods including:

- Average Rates and Standard Deviations

- Regression Equations and Coefficients of Determination

- Present results in a format that can be used by both WVDOT personnel and engineers and planners generally

\subsection{Organization the Report}

This report is divided into five chapters and two appendices. Chapter 1 contains background information, the problem statement, and project objectives. Chapter 2 summarizes the findings from a comprehensive literature review. Chapter 3 explains the methodology developed to carry out the goals of this research. Chapter 4 presents the results for consolidated high schools. Chapter 5 summarizes the results for consolidated middle schools. Chapter 6 presents the results for consolidated elementary schools and Chapter 7 presents the results for combined consolidated school sites. Chapter 8 contains an overall comparison of the consolidated school types. The conclusions and 
recommendations of this research project are contained in Chapter 9. There are seven important appendices which present graphical results from this and other studies. Appendices I and II contain the ITE format graphs developed from this research. Appendices III-VII present this study's data points plotted on the ITE (1997) graphs. 


\section{Chapter 2. Literature Review}

\section{$2.1 \quad$ Introduction}

A review of literature was undertaken to critically evaluate and learn from published research findings on trip generation characteristics of special generators in general and schools in particular. Objectives of this literature search were:

- To determine the methodology of trip generation studies including site selection, data collection requirements, data analysis, and displaying and reporting results

- To determine, for comparison purposes, the results of prior studies on traffic characteristics of schools in particular

Although many sources were reviewed, three emerged as the most useful, ITE's $\underline{\text { Trip Generation manual (1997), Neumann and Deshpande's (1974) West Virginia }}$

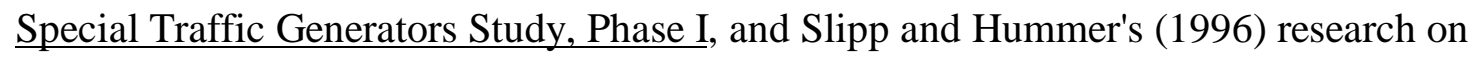
high schools in North Carolina.. The Trip Generation (ITE, 1997) manual provided useful definitions for specific land uses and trip generation rates. However, the ITE publication reports rates from the all over the United States, while this research focused on rates for West Virginia. Neumann and Deshpande (1974) provided trip generation results specific to West Virginia. Their results can be compared to national results as well as the results of this study.

\subsection{Methodology}

Review of the literature indicated that a successful trip generation research project (and valid trip generation rates) can result from following ITE's (1997) recommended methodology. In broad terms, the steps include: 
- Site Selection

- Data Collection

- Data Analysis

- Results Reporting

\subsubsection{Site Definitions}

When selecting sites for a comprehensive or specific land-use trip generation study, it is first necessary to identify and clearly classify the sites in the study into land use categories through phone surveys and site visits (Pehlke, 1994). A phone survey was recommended to obtain a general description of the site to see if it warrants further investigation as a possible research site. Data that can be obtained through phone surveys and site visits include the number and layout of entrances/exits and socioeconomic data. ITE (1997) gives clear descriptions of the land uses for which data are provided in Trip Generation. In the manual, ITE presents classifications and definitions for traditional high schools, middle schools, and elementary schools. These definitions were used in selecting sites for this research project. ITE does not include definitions for consolidated schools, combined elementary-middle schools and middle-high schools. Below are brief descriptions, as defined by ITE, of three subcategories of traditional schools that must be defined separately: elementary schools, middle schools, and high schools. Also included are the ITE generator category numbers (in parenthesis). Specific rates for the land uses will be discussed later in this chapter.

- Elementary schools (520) are defined by ITE as those that typically serve students of grades kindergarten through fifth or sixth grade. These are usually centrally 
located and have bus service for all students living beyond a specified distance from the school (ITE, 1997).

- Middle schools (522) are defined as those that serve students that have graduated from elementary school but have not yet entered high school (ITE, 1997).

- High schools (530) are facilities that serve students who have graduated from middle school. These typically serve students from ninth or tenth grades up to twelfth grade (ITE, 1997).

The focus of this research was trip generation rates for consolidated schools. Webster (Prentice Hall, 1994) defines a consolidated school as "a public school attended by pupils from several adjoining, especially rural, districts." In West Virginia, each county has a board of education to oversee the schools within that county. So, while students at a consolidated school will come from throughout the county, they do not typically come from adjoining counties. The definition used for consolidated schools specific to West Virginia was a public school recently formed from the consolidation of other schools of the same type or a county-wide school. Although not initially identified as a type of school to study, it became evident during the field data collection that there was an arrangement of schools that became classified as a combined consolidated school site. This type of school can be defined as a consolidated school that educates students from more than one school type. A combined consolidated school site can be housed in either one building or in separate buildings located on one campus. An example of a combined consolidated school site might be a combined consolidated school site would be a county-wide school serving grades 5 through 12 (middle school plus high school). 
For the purposes of this project, these definitions were used in conjunction with the ITE (1997) definition of the three types of schools. Note that the data compiled by ITE is not necessarily from consolidated schools. Since consolidated schools serve a larger, more rural area, the traffic generated by a consolidated school could be greater than that of a traditional school. Thus for transportation planning purposes, it is important to distinguish between a traditional school and a consolidated school.

\subsubsection{Site Selection}

Once a potential site has been classified, the literature (Pehlke, 1994) suggests visiting each site to examine the physical characteristics of the site to determine the suitability for counting. The West Virginia Special Generators report (Neumann and Deshpande, 1974) identifies requirements for sites to be counted adequately:

- Site must be a self-contained single land use with no through traffic

- Traffic can be counted at all entrances and exits

- Site should provide adequate off-street parking that is not shared by other nearby land uses

Neumann and Deshpande's research (1974) in West Virginia used pneumatic tube counters. In this case, the following requirements applied:

- Surfaces must be of asphalt or concrete composition and not gravel

- Throat must provide a straight section to ensure all tires on an axle cross the counter hose simultaneously, therefore giving one count per axle

- The site throat must extend a sufficient distance from the stop bar so that queued traffic does not reach the counter 


\subsubsection{Data Collection}

A good data collection plan will result in reliable, consistent information that provides the basis for valid, useful trip generation rates. ITE (1997) identifies multiple ways of collecting data for trip generation research. Researchers can obtain data from business owners or administrators, license plate surveys, ticket sales, parking pass information, and machine or manual traffic counts. Other data, such as socio-economic information, need to be obtained from the owner or manager of the site. Although there are many ways to collect data, the nature of this project was such that machine and manual counts were used to collect traffic data.

ITE does not set forth any specific requirements for the collection of data. It is reasonable to assume that portable traffic counting equipment should be placed at every access point or entrance to the study site. In their study of high schools, Slipp and Hummer (1996) collected machine counts for seven full days at each site. This is also supported by Arnold's research (1985) on mobile home parks which acquired machine counts for a minimum of seven days.

\subsubsection{Types of Data and Traffic Counts}

In addition to seven-day, twenty-four hour counts, Pehlke (1994) collected directional counts at fifteen-minute intervals for her study of commercial generators. The goal of performing the fifteen-minute count was to develop a Peak-Hour Factor (PHF) for the site. The use of machine counts for seven days is important in order to understand the temporal distribution of traffic at a site. It provides a single sample of every day of the week and five to seven samples of the hourly variations within a day. 
One example of this is that a restaurant may generate more traffic on a Friday or Saturday than on a Monday night; however, if only a three-day machine count was taken, the daily variation would not be captured. Furthermore, depending on the days selected, the average trip rate could be grossly over- or under-estimated. Clearly, for some land uses, the average trip rate could be influenced by the omission of a particular day-of-theweek.

In addition to machine counts, Pehlke (1994) used manual counts for vehicle classification and to check counter accuracy. In Tadi and Balbach's research (1994) on non-residential land uses, ten-hour manual counts were used to classify various types of vehicles such as single-unit trucks, buses, and multi-axle vehicles. This was necessary to "correct" the raw machine counts which do not count vehicles with 3 or more axles as a single vehicle. Pehlke (1994) also used manual counts during peak periods in her research for counter accuracy and vehicle classification.

\subsubsection{Sample Size}

One factor that was not discussed thoroughly in the existing literature was a procedure for determining the sample size for trip generation studies. Neumann and Deshpande (1974) presented an equation for finding a minimum sample size based on the student's t distribution. In this process, the standard deviation of the sample must be estimated. In reviewing the literature, it was noticed that most sample sizes were under ten observations per land use. However, ITE (1997) contained larger sample sizes due to the fact that the Trip Generation manual is a compilation of many sources. Slipp and Hummer's (1996) study contained under twenty observations. 


\subsubsection{Socio-Economic Variables}

The factors or characteristics through which travel activity is quantified into trip rates, are commonly referred to as the "socio-economic variables (SEVs)." They are usually basic predictable measures of the size of generator in question, with the implied assumption that the larger the facility, the more activity, and consequently more traffic will be produced. ITE (1997) and Neumann and Deshpande (1974) used SEVs including gross floor area (GFA), number of employees, and number of students. Slipp and Hummer (1996) studied many variables including GFA, number of employees (part-time and full-time), number of students, number of absences, number of early dismissals, and number of student drivers.

\subsubsection{Average Trip Rate}

The average of a data set is simply the sum of the observations of the sample divided by the total number of observations in the sample. For trip generation analysis, there are two averages which must be determined:

- Weighted average trip ends at a site per unit time (typically day or peak hour)

- Weighted average trip rate for a land use per SEV

The Average Trip Ends per day at an individual site can be determined by summing the number of trips divided by the number of days. However, in accordance with ITE's Trip Generation (1997), when determining the average for one land use (i.e. the combination of many individual sites) the average of the trips should be a weighted average. This weighted average trip rate is used in order to reduce variance within the 
data. For example, in the high school category, one site may have only 400 students while another may have 1300 students. The weighted average trip rate is calculated by summing the number of trip ends over all of the sites and dividing that by the sum of the independent variables.

The weighted average makes use of the vehicle trip end. A vehicle trip end, as defined by ITE's Trip Generation Update (1995) is a single or one-direction vehicle movement with either the origin or the destination (exiting or entering) inside a study site.

The average trip rate, as discussed earlier, is a weighted average trip rate for a particular land use. Expressed as a linear function, the weighted average trip rate is an equation that passes through the origin with a slope equal to the rate. ITE (1997) recommends using this only when the sample size is small and the standard deviation of the data is low; however, there is no threshold value cited for the standard deviation. Engineering judgement should be used in this case. If the standard deviation is not acceptable, scatter plots and/or regression analysis should be used to determine the trip rate. These two tools are described in the following sections.

The standard deviation measures the average variation from the calculated average of the set. When the standard deviation is small, it shows a smaller variance among the data collected. There are typically two equations for standard deviation depending on whether it is based on the observance of the entire population or just a portion (sample) of the population. Equations 2-1 and 2-2 represent the population standard deviation and sample standard deviation equations, respectively. 
Equation 2-1 Population Standard Deviation

$$
\sigma=\sqrt{\left(\frac{\varepsilon\left(x_{i}-x_{a v e}\right)^{2}}{n}\right)}
$$

Equation 2-2 Sample Standard Deviation

$$
\begin{aligned}
& S=\sqrt{\left(\frac{\varepsilon\left(x_{i}-x_{\text {ave }}\right)^{2}}{n-1}\right)} \\
& \text { where: } \quad \begin{aligned}
\sigma & =\text { Population Standard Deviation } \\
\mathrm{S} & =\text { Sample Standard Deviation } \\
\mathrm{x}_{\mathrm{i}} & =\text { Observed Value } \\
\mathrm{x}_{\mathrm{ave}} & =\text { Average of the } \mathrm{x}_{\mathrm{i}} \\
\mathrm{n} & =\text { Number of Observations }
\end{aligned}
\end{aligned}
$$

In the case of trip generation, the Sample Standard Deviation should be used since the collected data represent only a portion of the population. Note that since the weighted average is used instead of the true mean, the standard deviation calculated is not technically the true standard deviation of the mean (ITE, 1997).

Another use of the standard deviation and average of a data set is to determine the significance of the difference between two means. In the case of trip generation studies for West Virginia consolidated schools, the observed trip rates will be compared to national averages, as found in the ITE Trip Generation manual (1997). Equation 2-3 should be solved to determine if there are significant differences between the samples. If 
the difference in the sample means is larger than the standard error, there are differences in the samples (Dowdy and Wearden, 1991). 
Equation 2-3 Standard Error Equation

$$
Z=\frac{\mu_{1}-\mu_{2}}{\sqrt{\left(\frac{\sigma_{1}^{2}}{n_{1}}+\frac{\sigma_{2}^{2}}{n_{2}}\right)}}
$$

Where: $\quad Z=$ Normal Probability

$$
\begin{aligned}
& \mu=\text { Average of Sample } \\
& \sigma=\text { Standard Deviation of Sample } \\
& \mathrm{n}=\text { Number of Observations in Sample }
\end{aligned}
$$

\subsubsection{Scatter Plots}

Scatter plots provide a graphical means of viewing raw data from the trip generation study. In the specific case of trip generation, ITE's Trip Generation manual (1997) plots the independent variable (socio-economic variable) on the x-axis. The dependent variable, plotted on the y-axis, is the number of trip ends. Thus, each facility studied is represented on a land use scatter plot by a single point with coordinates (x, y). If the data points fall into a linear pattern, generalizations about the data may be made with respect to other sites in the same category via interpolation. However, in a majority of cases, a well-defined linear relationship is not present. In these situations, it is still possible to make generalizations using regression analysis (Dowdy and Wearden, 1991). Unlike the ITE (1997) data, the other sources reviewed did not make reference to the use of scatter plots. 


\subsubsection{Single Variable Regression Analysis}

Regression analysis can be defined as the function which best represents the data points by minimizing the differences between the function and the data points in the $y$ direction; this is the least squares method. Once this function is established, it is possible to predict the trip ends associated with any value of the socio-economic variable (within the limits defined by the range of SEVs studied) by reading the value on the line (Dowdy and Wearden, 1991). For example, if a new consolidated high school is being developed and if the size of the building is known, then the number of trips associated with that size facility could be determined by looking at the scatter plot with a regression line. ITE (1997) recommends use of the least squares method of regression. According to Dowdy and Wearden (1991), there are several assumptions with the regression analysis model:

- Means of the $\mathrm{y}$ values for each $\mathrm{x}$ value lie on a straight line (linear regression)

- For each x, the y values are independently and normally distributed

- For each $\mathrm{x}$, the $\mathrm{y}$ values have the same variance, $\sigma^{2}$

Least squares regression can be applied to any basic equation form. Although many basic forms exist, ITE (1997) recommends testing the linear and logarithmic forms and reporting only the one with the best fit. The general equations for these two forms are:

Equation 2-4 Linear Regression Equation

$$
\mathrm{T}=\mathrm{aX}+\mathrm{b}
$$


Equation 2-5 Logarithmic Regression Equation

$$
\begin{aligned}
& \operatorname{Ln}(T)=\operatorname{Ln}(X)+b \\
& \text { where: } \quad \begin{aligned}
T & =\text { Trip Ends } \\
X & =\text { Socio-economic Variable } \\
& a, b=\text { Parameters of the Regression Line Equation }
\end{aligned}
\end{aligned}
$$

ITE (1997) does not recommend reporting regression analysis for land use categories with less than 4 data points. ITE (1997) also states that a regression equation should be reported only when the number of trips increases with an increase in the independent variable.

\subsubsection{Correlation Coefficient (R) and Coefficient of Determination $\left(\mathrm{R}^{2}\right)$}

These coefficients can be used to gauge how well the regression line fits the data set. As such, they can answer two critical questions:

- To what extent does the independent variable explain the dependent variable?

- To what extent does the regression line fit or represent the raw data points?

To aid in answering these questions, two definitions prove useful:

- The Correlation Coefficient (R), as defined by Snedecor and Cochran (1989) is a measure of the closeness of linear relationship between the two variables. This value will always fall between -1 and 1 . As the absolute value of $r$ approaches 1 , the variables become increasingly correlated. If this value is positive, the regression line will have a positive slope, while a negative correlation will have a negative slope.

- The Coefficient of Determination $\left(\mathrm{R}^{2}\right)$ is a measure of how well the regression line 
fits the data set and is a positive value between 0 and 1. Schroeder (1986) explains this to be the percentage of total variation in the independent variable that is explained by the regression line, or the percentage of total variation in the dependent variable that is caused by the independent variable. He states

"...the regression coefficient (coefficient of determination) is more informative since it indicates by how much the dependent variable changes as the independent variable changes, whereas the correlation coefficient indicates only whether or not the two variables move in the same or opposite directions and the degree of linear slope.”

It should be noted that $\mathrm{R}^{2}$, the coefficient of determination, is the mathematical square of $\mathrm{R}$, the correlation coefficient.

With respect to the use of $\mathrm{R}^{2}$ in trip generation research, ITE (1997) reports only regression equations that have a $\mathrm{R}^{2}$ value greater that 0.5 . Values lower than 0.5 do not provide enough information about the trips associated with a particular land use to warrant being reported. Because of their importance in determining the correlation of the trip rates, $R$ and $R^{2}$ values were reported by Peyrebrune (1996), Slipp and Hummer (1996), Tadi and Balbach (1994), and Pehlke (1994). These values were not reported in Neumann and Deshpande (1974) or SANDAG (1996).

\subsubsection{Multiple Variable Regression Analysis}

Multiple variable regression is used when two or more variables are thought to affect the dependent variable independently and simultaneously. This tool can be valuable in obtaining a regression equation with a higher $R^{2}$. When a new variable is 
added to the equation, the $\mathrm{R}^{2}$ always increases. However, only independent variables that are independent of each other should be considered for use in multi-variable analysis. Otherwise, the equation will be double counting the effect of a single phenomenon to artificially make the equation seem more accurate. An example would be to predict trip ends at a household using a function that included both income and auto ownership. Since auto ownership is tied closely to income, the function is double counting the effect of a single phenomenon, that is, wealth. This could lead to false confidence in a particular variable equation that, in reality, does not explain the dependent variable well (Schroeder, 1986).

In the scope of trip generation, ITE (1997) does not use multiple regression analysis. In her study of shopping centers, Peyrebrune (1996) performed multivariable regression analysis. When examining more than one variable, the correlation was low. It was noted that the intent was not to form a relationship between SEVs but to set up a process and develop software for multivariable analysis.

Slipp and Hummer (1996) also used multivariable regression analysis. In their study of high schools in North Carolina, there was a high correlation $\left(\mathrm{R}^{2}=0.75\right)$ between the number of employees and number of parking spaces for weekdays. In the author's opinion, the two items were dependent on each other, and therefore, one would expect a correlation between the number of parking spaces and employees. Slipp and Hummer's (1996) use of multivariable regression analysis is thus inappropriate, and as stated previously, should be used only for SEVs which are independent. To be consistant with ITE and minimize the complexity of the equations, multiple variable regression analysis 
was not used in the statistical analysis of the data collected in this research.

\subsubsection{Displaying and Reporting Results}

ITE's Trip Generation (1997) provides a clear way of presenting trip generation analysis results. In Trip Generation, each land use is presented individually. Within each land use category, the rates per independent variable are reported for different time periods such as weekday, Saturday, Sunday, and the peak hour of generator. The data pages also contain the plot of SEV versus trip ends, the average trip rate equation, the best fit regression equation, and coefficient of determination. Also, ITE's method is universally understood due to the wide usage of the manual. Results presented in conformance with its procedure should provide the maximum usage and value to interested parties. Also, for comparison to other sources of trip generation results, information such as the number of studies, average number of independent variable, traffic directional distribution, weighted average trip rate, range of rates, and standard deviation are presented. ITE includes all of this information on one page. An example of the ITE format of presentation is shown in Figure 2-1. 


\section{High School \\ (530)}

\section{Average Vehicle Trip Ends vs: 1000 Sq. Feet Gross Floor Area \\ On a: Sunday}

Number of Studies: 18

Average 1000 Sq. Feet GFA: 217

Directional Distribution: $50 \%$ entering, $50 \%$ exiting

Trip Generation per 1000 Sq. Feet Gross Floor Area

\begin{tabular}{|c|c|c|}
\hline Average Rate & Range of Rates & Standard Deviation \\
\hline 1.72 & $0.30 \quad-\quad 8.19$ & 2.24 \\
\hline
\end{tabular}

\section{Data Plot and Equation}

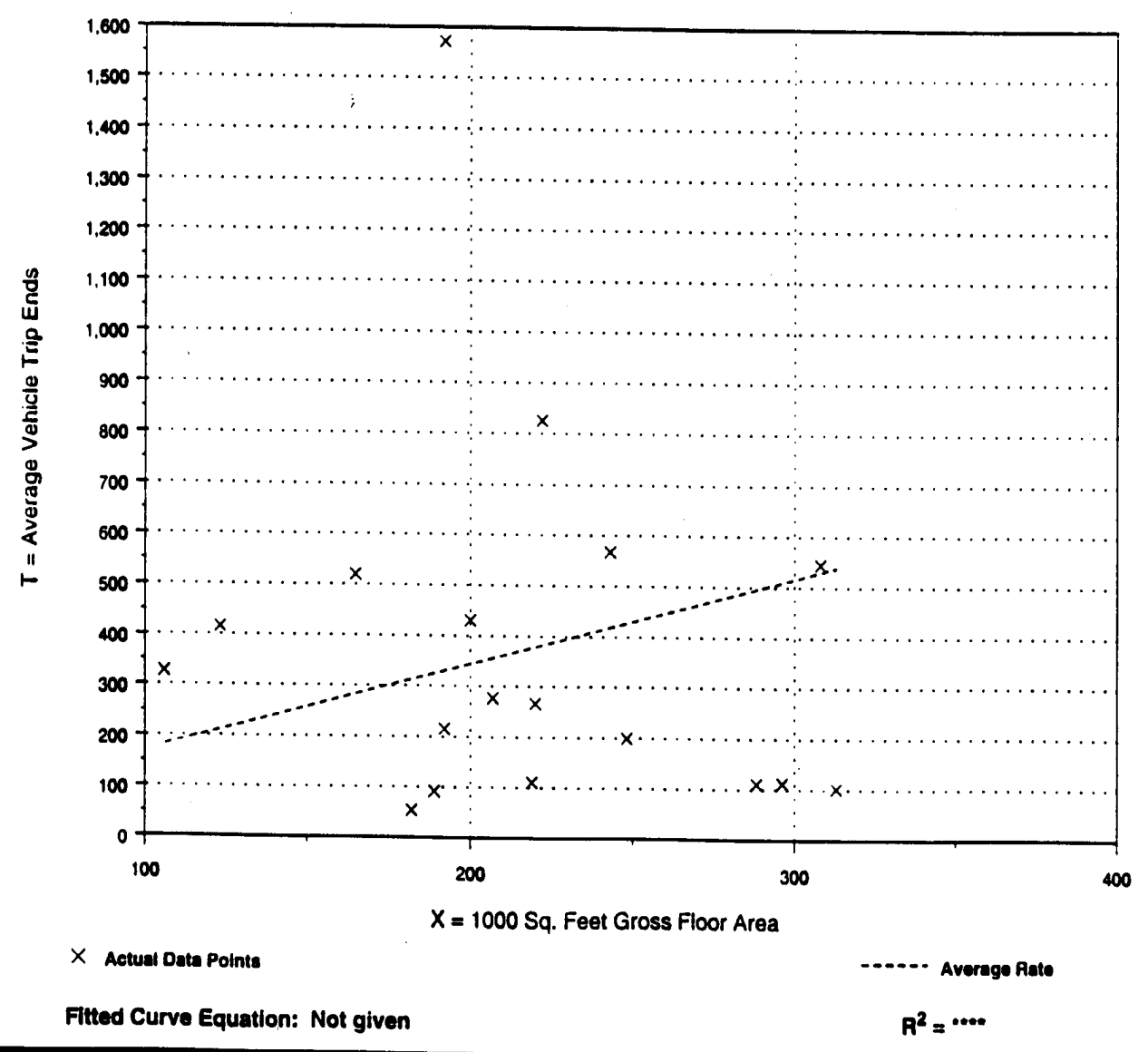

Figure 2-1 Example of ITE Format for Presenting Trip Generation Results (Source: ITE, 1997). 


\subsection{Site Specific Studies on the Trip Generation Characteristics of Schools}

As noted earlier, previous trip generation research focused on traditional types of schools, however, this research is concerned with consolidated schools. This section reviews that research with respect to two important issues: the SEVs used and the results of the research.

Schools can be classified as elementary, middle or junior high, and senior high schools, each category having different trip generation characteristics. Trips at schools are typically made by teachers and staff, buses, service vehicles, visitors, parents, and students. As such, the trip rate at each type of school is not expected to be uniform. For example, high schools may permit students to bring vehicles to school, thereby increasing the trip rate. If a parent were to drive a student to school, they would generate two trip ends each time they dropped off or picked up their child; whereas a student driver would create only one trip end in the morning and one in the evening. On the other hand, one would not expect student drivers at elementary or middle schools. There may also be "after-hour" activities at schools such as athletic programs and community events which generate traffic and defer some of the pm peak traffic until the off-peak. For these reasons, it is necessary to investigate the trip generation characteristics of each type of school individually.

The difference between rural schools and urban schools may affect the trip rates. For example, in an urban school, many students may walk to school and therefore not generate a driving trip end. In the rural case, most schools would be too far away for children to walk to school. Also, students may be largely served by bus since travel 
distances may be too far to drive to school.

It should be noted that the data from the literature reported here are from a variety of school types such as traditional, magnet, and community. There is no evidence that any sources report data for consolidated schools or combined consolidated school sites which were the focus of this study of schools in West Virginia.

\subsubsection{High Schools}

For each type of school, Trip Generation (ITE, 1997) reports results for socioeconomic variables such as students, employees, gross floor area, and acres. For high schools, ITE reports weekday, Saturday, and Sunday trip rates. Also reported in Trip Generation is peak hour of adjacent street traffic, one hour between 7 and 9 am, peak hour of adjacent street traffic, one hour between 4 and $6 \mathrm{pm}$, am peak hour of generator, and pm peak hour of generator for weekday. ITE also reports peak hour of generator for Saturday, and Sunday.

Slipp and Hummer (1996) report trip generation rates for North Carolina high schools for the following socio-economic variables students, employees, and gross floor area $(1000 \mathrm{SF})$. These peaks were reported for the weekday day, weekday peak hour of street am, street pm, generator am, and generator pm. Also reported are Saturday and Sunday rates for students during the day and peak hour of generator. One of their goals was to determine if there were significant differences between the national rates as reported by ITE (1997) and the rates for urbanized high schools in North Carolina. In their study, the previous works cited for school trip rates included the FHWA's Guidelines for Trip Generation Analysis, ITE's Trip Generation, $5^{\text {th }}$ Edition, and other 
works related to trip generation analysis but not exclusive to school trip generation. Their results showed that North Carolina schools had higher trip rate values than those in ITE. Another objective of Slipp and Hummer's study (1996) was to determine whether socio-economic variables other than students, employees, and gross floor area are good predictors of trip rates. Besides the standard ITE variables mentioned previously, they also examined number of full-time employees, number of part-time employees, number of buses, and number of parking spaces. Their results indicate that none of the new variables were good indicators of trip rates.

For other national data, SANDAG (1996) reports values for students, acres, and square footage. For high schools, the trip rates are 1.4 trips per student, 50 trips per acres, and 11 trips per 1000 SFGFA.

For each type of school, Neumann and Deshpande (1974) reported results for socio-economic variables such as students, employees, gross floor area, and acres. It was not mentioned specifically if the schools studied were consolidated.

When comparing West Virginia (Neumann and Deshpande, 1974)and ITE (1997) trip rates, Figure 2-2 shows that the trip rates are remarkably similar for each different socio-economic variable. The most noticeable difference is the trips per employee rate. West Virginia had a higher trips per employee rate than North Carolina high schools. 


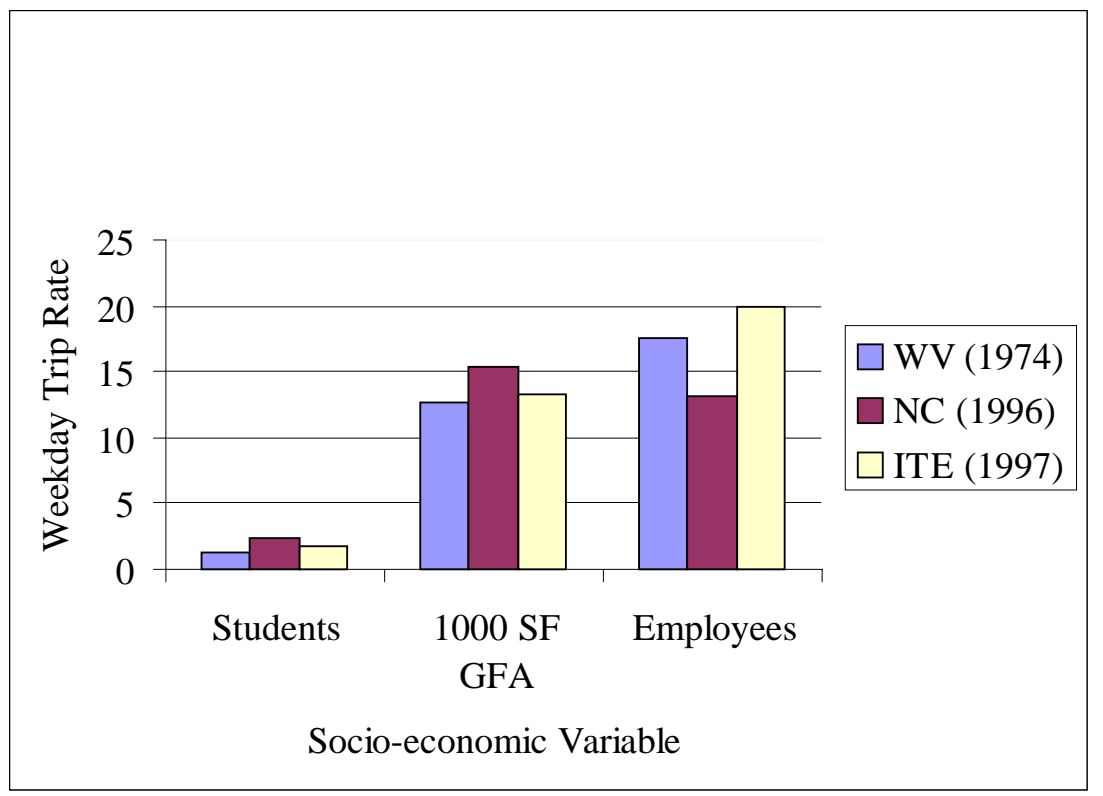

Figure 2-2 Comparison of High School Trip Rates

\subsubsection{Middle Schools}

Only three sources were located which identified trip generation rates for middle or junior high schools. Both ITE's Trip Generation (1997) and Neumann and Deshpande's (1974) West Virginia Special Generators study presented weekday rates for the number of students and gross floor area. Neumann and Deshpande (1974) also presented weekday rates for employees, acres, and Saturday and Sunday rates for acres. In SANDAG's report (1996) for middle or junior high schools, the trip rates were 1.0 per student and 40 per acre.

Figure 2-3 presents the data found in previous research for middle or junior high schools. When comparing the results of the West Virginia study to the ITE (nationwide) data (1997), slight differences in the trip rates were noted. The trip rates for West Virginia were lower than the national trip rates. The trip per student rate for ITE is 
almost double that of West Virginia but in absolute terms it is not that large.

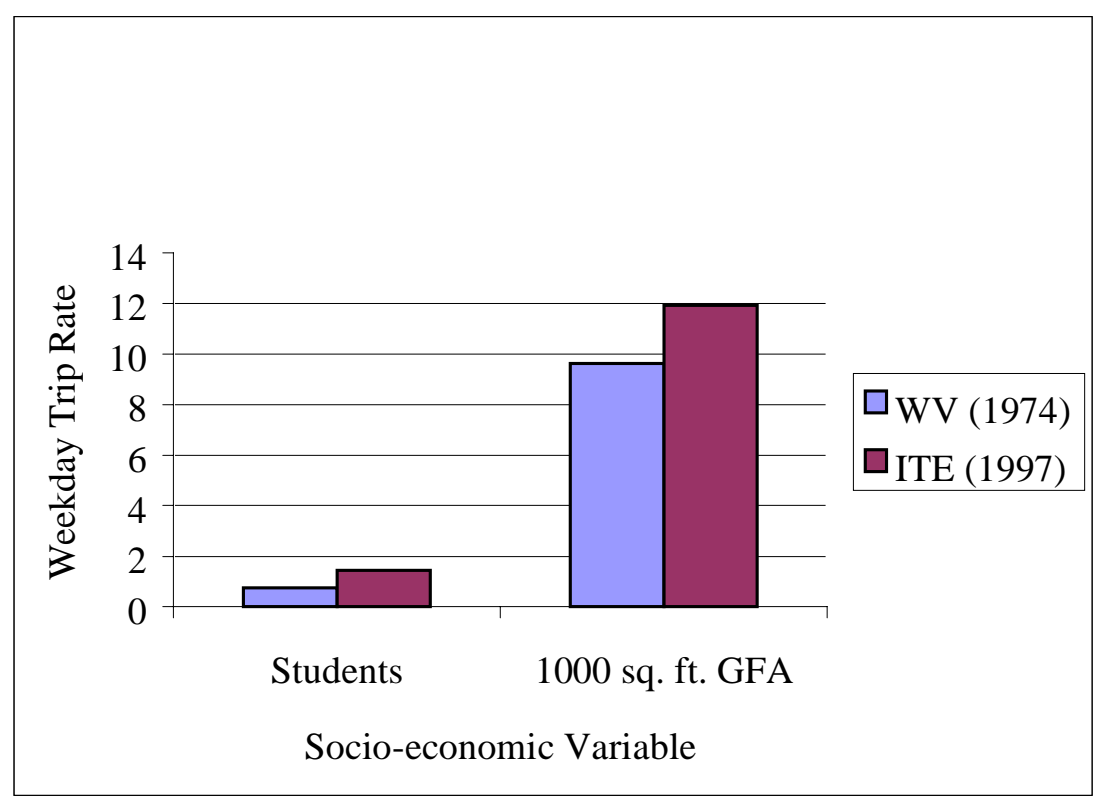

Figure 2-3 Comparison of Middle School Trip Rates

\subsubsection{Elementary Schools}

There are two interesting characteristics of elementary schools. The first is that students cannot drive themselves to school and some may walk. Elementary schools are more numerous and, as such, are more likely to be within the neighborhood they serve. The second characteristic is that some students may be dropped off and picked up by parents on their way to or from work, a practice which may not be as convenient in a rural area. Another characteristic reported by ITE is that about $60 \%$ of all elementary school students ride the bus to school.

ITE (1997) presents trip rate data by using the socio-economic variables students, employees, and 1000 SF GFA. They offer trip rates for weekday and peak hour of generators during the weekday. SANDAG (1996) offers trip rates for the socio- 
economic variables students, $1000 \mathrm{SF}$ gross leasable floor area, and acres. The trip rate for students was 1.4 trips per student. For the building size in GFA and property size in acres, the trip rates were 14, and 60, respectively. In Neumann and Deshpande's study (1974) of elementary schools in West Virginia, the socio-economic variables included students, 1000 SF GFA, and acres.

Figure 2-4 presents the data found in previous research for elementary schools. The difference between West Virginia and ITE trip rates is very noticeable especially in the cases of employees and 1000 SF GFA. However, the rates for West Virginia were developed using a sample size of 2 . Therefore, the validity of the trip rates is questionable. It is difficult to make comparisons with such a small sample size.

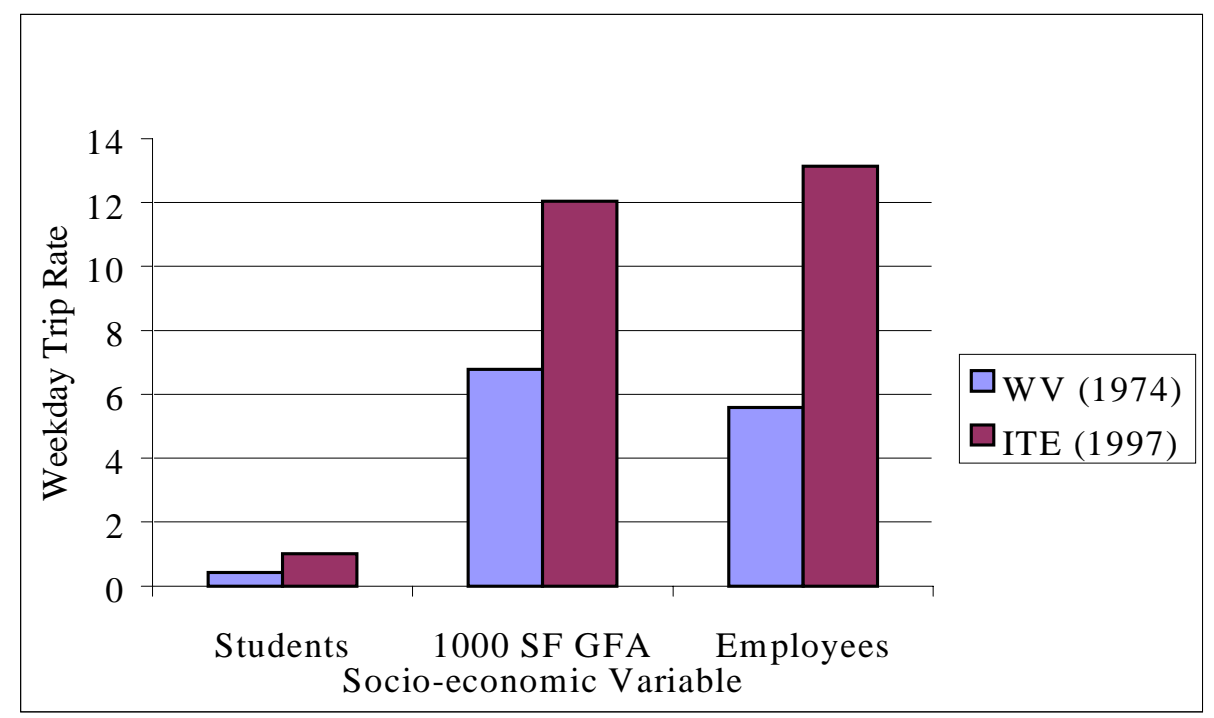

Figure 2-4 Comparison of Elementary School Trip Rates

\subsubsection{Comparison of Trip Rates by School Type}

It was also useful to compare the results among the different types of schools.

The trip rate per student was consistently around 2 trips per student for each type of 
school whether it is high school, middle school, or elementary school. When comparing the trips per 1000 SF GFA, high schools have a significantly higher value than middle and elementary schools. This is true for both the West Virginia (Neumann and Deshpande, 1974) and ITE data (1997). Also, the number of trips per employee in high schools is significantly different than those of elementary schools.

\subsection{Concluding Remarks}

A review of existing literature revealed a small body of trip generation research specifically on schools. Perhaps the most useful of these to practitioners and researchers was ITE's Trip Generation (1997). It provides the most comprehensive trip generation data available with respect to land uses considered and sample size. However, consolidated schools are not covered the published literature. Also, as was demonstrated in previous research, the existing West Virginia trip generation rates are lower than the national averages as reported by ITE. Thus, the results of the literature review support the objective of this project and confirm the need for the research, i.e., it is necessary to further investigate trip generation rates for consolidated schools in West Virginia. 


\section{Chapter 3. Methodology}

\subsection{Introduction}

The overall goal of this research was to determine reliable trip rates for consolidated schools in West Virginia. To accomplish this goal, a methodology was designed so that relevant information could be collected, analyzed, and presented. This chapter describes the experimental design, field data collection, and statistical analysis performed during this research project. Each of these areas will be described in detail in the following sections. Throughout the design and execution of the research methodology, consistency and agreement with the $6^{\text {th }}$ Edition of ITE $\underline{\text { Trip Generation }}$ (1997) was ensured.

\subsection{Preliminary Work}

\subsubsection{Land Use Selection}

This project was a comprehensive one that developed data for the West Virginia transportation planning and engineering community for at least the next 20 years. The following consolidated school types are expected to become and continue to be significant over this time and will require new or tailored trip generation rates to support transportation planning activities.

- Consolidated High Schools

- Consolidated Middle Schools

- Consolidated Elementary Schools

- Combined Consolidated School Sites

A preliminary sample size was selected for each school type based on discussions between the researchers and the WVDOH. These were based largely on judgements of 
the variability of sites within each land use. However, since West Virginia is a small state of less than 2 million in population and school consolidation is becoming more common, it was expected that the desired sample size might not be met for all school types. These preliminary estimates served as a guide for site selection. Table 3-1 shows the desired sample size along with the actual sample size attained for each school type.

Also, the table indicates that there was no desired sample size for combined consolidated school types since this was not part of the original study design. However, during the field data collection process through this research, it was recognized that it was not uncommon to find two types of consolidated schools at the same site. Thus, this arrangement of schools was felt to be appropriate for inclusion in the study.

As noted in Table 3-1, for all classes of generators, the sample sizes attained were smaller than the desired sample size. The desired sample size for this project was given by the West Virginia Department of Highways. This is due to the limited number of sites that could be feasibly collected and includes the elimination of sites due to mechanical counter failure. The following sites had to be eliminated due to counter failure:

- One high school in the Eastern panhandle

- One middle school in the central part of the state

- One elementary school in the Eastern panhandle

- One combined site in the central part of the state

Table 3-1 Desired and Actual Project Sample Size

\begin{tabular}{|c|c|c|}
\hline Generator & Desired Sample Size & Actual Sample Size \\
\hline Consolidated High Schools & 10 & 7 \\
\hline Consolidated Middle Schools & 10 & 2 \\
\hline Consolidated Elementary Schools & 10 & 4 \\
\hline Consolidated Elementary-Middle Schools & --- & 1 \\
\hline Consolidated Middle-High Schools & -- & 2 \\
\hline
\end{tabular}




\subsubsection{Socio-Economic Variable Determination}

The next step in the preliminary work was to determine the socio-economic variables to be collected for the schools. This process involved an extensive literature search and discussions with WVDOH personnel. The literature search identified three particularly relevant sources: ITE's Trip Generation (1997), the 1974 West Virginia Special Traffic Generators Study (Neumann and Deshpande, 1974) and Slipp and Hummer (1996). The SEVs documented in these sources were factors in the selection of SEVs for this study. The final SEV selection was a function of predictability of the SEV at the planning stage, uniformity with ITE's Trip Generation, and discussions with personnel in the Planning and Research Division of the WVDOT. For traditional schools, ITE (1997) studied trip rates per employee, student, and 1000 SF GFA. The 1974 WV Study (Neumann and Deshpande) studied the socio-economic variables employee, student, 10,000 SF GFA, and acres. The socio-economic variables selected and studied in this research were trip rates per employee, student, and 1000 SF GFA.

\subsection{Site Identification and Selection}

\subsubsection{Preliminary Site Identification}

Given the proposed sample sizes, over 30 different sites needed to be identified. As such, a comprehensive approach for locating potential sites was required. Several methods of locating sites were used.

A large number of sites were identified based on the personal knowledge of the research team and WVDOH traffic engineers and planners. A letter briefly describing project objectives and identifying land uses of interest was sent to each WVDOH District Engineer soliciting their help in identifying sites. Simple queries to colleagues 
from different parts of the state provided additional insight about sites in specific parts of the state. Through the letter and outreach to those from all parts of the state, good statewide coverage and representation was achieved.

In addition, the internet and telephone directories were used. The Internet's search engines and the West Virginia Department of Education home page permitted the location of potential sites throughout the state. Finally, the West Virginia Education Directory (1997) was a valuable. It listed all public schools in West Virginia, including location, principal name, and phone number.

\subsubsection{Final Site Selection}

Each site identified was field inspected to determine if it met the minimum requirements for inclusion in this study. The goals of the field inspection were to verify that the site met the requirements of the land use description, and to verify that the site was suitable for machine counting. The minimum requirements for machine counting at a site are the number and design of access points, whether or not the facility is free standing, and if the site possessed cut-through traffic.

\subsubsection{Number and Design of Access Points}

Site access is a critical element in determining whether a reliable count can be collected. In order to permit a reliable traffic count, successful sites had to meet certain requirements relative to access to the site. Site access had two important components with respect to this project:

1) Number of access points with the adjoining highway system

2) Throat lengths 
From a traffic counting standpoint, the ideal situation is a land use with a single access point with the highway system. However, typically, schools have more than one access point, with some having as many as three or four. Each point of access requires a machine counter. The availability of technicians and machine counters generally limited the number of drives that could be counted at any one site. Sites containing three or less drives were accepted.

Once a site was determined to have an acceptable number of access points, each point was examined for adequate throat length. A throat is a channelized portion of the driveway that provides a guideway for entering and exiting vehicles. With respect to machine counting, throats are important since they influence the way vehicles cross the pneumatic tube. In order for the counter to operate properly, the vehicles must cross the hose perpendicularly and should not stop over any point of it. If Vehicles turning from the adjacent street cross the counter before completing the turn they will not cross it perpendicularly. This can produce machine counts that are larger than actual volumes. Short throat lengths can also result in cars stopping on the hose while waiting to exit the facility. While a car is stopped on the hose, flow from the hose into the counter is blocked, resulting in a time period during which no cars in adjacent lanes are counted. Long throats or access roads to sites provide the opportunity to set the counter at a location where cars will not be turning and will maintain free flow.

\subsubsection{Cut-Through Traffic}

Potential sites were checked for the possibility of cut through traffic from adjacent streets or land uses. Sites serving cut-through traffic were eliminated from consideration, 
as the collected traffic data would include additional trips. Thus it is not possible to obtain an accurate count of the traffic generated by the site.

\subsubsection{Call for Permission}

Once a site was determined to be feasible, the responsible school official (e.g. the principal) was contacted for permission to use the site in the study. A key point in this call was the promise of confidentiality of the site in the project report. This is because some may believe that the socio-economic variable or traffic data could be used to determine sensitive information. For this reason, site names will not be revealed in this report, rather they will be generally labeled as to the type of school. For example, consolidated high schools will be listed as High School A, High School B, High School C, etc...

\subsection{Data Collection}

Data collection included the collection of the socio-economic variables and traffic count data from each site.

\subsubsection{Socio-Economic Variable Collection}

The socio-economic data were collected by contacting the school's principal, usually at the same time the call for permission was made. In addition to the SEV data, the principals were asked about student driving policies, the number of parking spaces available, number of bus trips, and after-school activities. In some cases, the principals offered other information such as the occurrence of community activities at the school and car-pooling. The SEV information was collected as close as possible to the time of traffic data collection. 


\subsubsection{Field Collection}

Mechanical traffic counters were utilized in the project to collect traffic data. Portable pneumatic tube traffic counters, which were used in this study, are advantageous due to their ability to count continuously for long periods of time; however, they do not provide vehicle classification data, an important consideration in pavement and geometric design. With these counters, each time a vehicle's axle crosses the tube, the air in the tube is displaced into the counter such that it triggers the counting mechanism. The counter records a single vehicle count after two axles are sensed. This method of counting is ideal for sites that attract only two-axle vehicles. In many trip generation studies, manual counts are made to determine the percentage of heavy vehicles (multi-axle vehicles) at a land use. In accordance with the original study plan, manual counts were made at the first few school studied. Manual counts were taken in conjunction with machine counts at three high schools, one middle school, and two elementary schools. It was noticed that schools do not typically attract large commercial vehicles such as tractor semi-trailer combinations and therefore manual counts were not necessary at every site. The largest vehicle used for design would be a school bus which has only two-axles. Therefore, manual counts were deemed not necessary and therefore were not acquired at the remainder of the school sites.

\subsubsection{Machine Counts}

The main consideration for the machine counting program was the duration of the count. For this project, a large number of sites had to be studied, thus long-term counts at each site were not possible. However, the duration of data collection must be long 
enough to obtain information about daily traffic patterns and characteristics. One full week of 24 one-hour counts per day was selected as a compromise. A full week of data gives five samples of the weekday peaks and trends, and provides a single sample of the variation by day of week. This yielded enough data to enable the researchers to report trip generation rates on a weekday, Saturday, and Sunday in the same manner as the ITE Trip Generation document (1997).

\subsection{Data Analysis}

The data analysis portion of the project followed the guidelines contained in ITE's Trip Generation (1997). The following steps were utilized in data analysis.

\subsubsection{Raw Data Plots}

The traffic count data were plotted versus time for each site. The plots were used to evaluate the daily variations and peaking characteristics of the traffic at each facility. The plots were also used to identify erroneous data or other special conditions that may have affected the counts. The main types of errors were battery failure for the counter and pneumatic tube failure. The raw data plots showed the researchers exactly when the failure occurred and if any data could be salvaged for the analysis. The special conditions that could be determined using the data plots were Friday night football games, activities during non-school hours, and any holidays that may have occurred during the week. Each principal was sent a copy of this plot, along with the adjusted counts in tabular form.

\subsubsection{Number of Trips per Time Period}

Once the raw counts for a site were corrected and all erroneous data were identified, the average weekday volume and the average peak hour volume were 
calculated. These were simple averages calculated using all five weekdays of the count. For Saturday and Sunday, only a single sample was collected, thus no averaging was required. The following flow rates were reported for each site:

- Average Vehicles per Weekday

- Average Vehicles per AM Peak Hour on a Weekday

- Average Vehicles per PM Peak Hour on a Weekday

- Average Vehicles per Saturday

- Average Vehicles per Sunday

\subsubsection{Trip Rates}

Trip rates for each land use were determined using the average vehicle per time period values presented in the previous section. In general, three trip rates were determined: the site specific trip rate, the average weighted trip rate for each land use, and the regression analysis based trip rate for each land use.

\subsubsection{Trip Rate of an Individual Site}

The trip rate of an individual site was determined using the following relationship: Equation 3-1 Trip Rate of an Individual Site

$$
R_{t i}=V_{a} / S E V
$$

where:

$$
\begin{aligned}
& \mathrm{R}_{\mathrm{ti}}=\text { Trip rate of an Individual Site } \\
& \mathrm{Va}=\text { Average Daily Volume (from Number of Trips per Time } \\
& \text { Period) }
\end{aligned}
$$

SEV = Socio-economic Variable 
For example, this relationship would provide the following trip rates, with respect to employees, for a consolidated high school:

- Weekday Trips/employee

- Weekday AM Peak Hour Trips/employee

- Weekday PM Peak Hour Trips/employee

- Saturday Trips/employee

- Saturday Peak Hour Trips/employee

- Sunday Trips/employee

- Sunday Peak Hour Trips/employee

Once the trip rates for all sites in a particular school category were found, the average and standard deviation for that category were computed. The consistency of the data set can be found by dividing the standard deviation by the average (known as the standard deviation to mean ratio). As the ratio increases, the set of rates becomes more inconsistent. It is important to note that obtaining high values for the standard deviation to average ratio does not necessarily indicate problems. This ratio is used as a measure of how much variation there is between the trip rates of a particular land use, and is an indicator of whether further investigation of this variation of the data is needed. Further investigation may reveal the presence of erroneous data or the need for further data collection.

\subsubsection{Average Weighted Trip Rate for the Type of School}

The trip rate for an entire type of school category, rather than just one of the sites, was found using the following relationship: 
Equation 3-2 Trip Rate for a Land Use

$$
R_{a w}=\sum V_{a i} / \sum S E V_{i}
$$

where: $\quad R_{a w}=$ Average weighted trip rate for land use

$\sum \mathrm{V}_{\mathrm{ai}}=$ Sum of average daily volumes from site 1 to site $\mathrm{i}$

$\Sigma \mathrm{SEV}_{\mathrm{I}}=$ Sum of SEVs from site 1 to site $\mathrm{i}$

Note that this is not simply the average of the trip rates for each of the sites. The weighted average is preferred because of the variation within each data set. ITE (1997) states, "data sets with a large variance will over-influence the average rate if they are not weighted."

\subsubsection{Regression Trip Rate Plot}

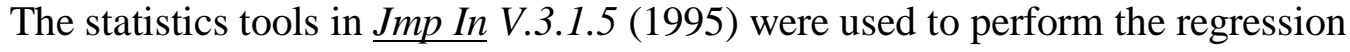
analysis. $\underline{\operatorname{Jmp} \text { In }}$ is a windows-based computer program developed by the SAS Institute, Inc. It is a statistical analysis program that has the capabilities of using statistical procedures to find the mean and standard deviation of a data set. Also, it is able to produce scatter plots and perform linear and logarithmic regression on a data set. Data was entered in a spreadsheet format by SEV and trip rate for each school type. The average traffic volume at each site was plotted versus a specific socio-economic variable in a scatter plot. $\underline{\operatorname{Imp} I n}$ then used the least squares methodology to determine the equation of a linear regression function and its $\mathrm{R}^{2}$ value. Regression was performed to determine the best-fit logarithmic relationship between an SEV and the average volume. The end result was two sets of regression lines, linear and logarithmic, with two separate 
$\mathrm{R}^{2}$ values for each SEV within each school type. Thus, for each SEV-Time period combination, two regression equations were reported: linear and logarithmic.

\subsection{Reporting Results}

It is anticipated that the results of this research will be used by engineers and planners in West Virginia and nationally. As such, a consistent, readily understandable format was required for reporting results. Due to its wide usage and acceptance, the ITE Trip Generation (1997) format was selected. It is likely to be the only format with which most potential users will be familiar. Furthermore, it provides the data necessary to perform traffic engineering analyses and designs, such as traffic impact studies or traffic signal warrant analysis. The ITE format requires the following information to be presented on a single page:

- Number of sites used for the land use

- Average value of the SEV for the sample

- Weighted average trip rate for the sample

- Trip rate range for the sample

- Standard deviation of the trip rates for the sample

- Data plot and equation, including:

- Graphical representation of weighted average trip rate

- $\quad$ Linear and logarithmic regression plot (highest $\mathrm{R}^{2}$ value controls)

- $\quad$ Equations of regression plots

- $\quad \mathrm{R}^{2}$ value of regression analysis 
An example of the ITE format was shown in Figure 2-1. A data sheet based on the ITE Trip Generation (1997) format was developed for each SEV of each land use for the following time periods:

- Weekday trips

- Weekday AM Peak Hour trips

- Weekday PM Peak Hour trips

- Saturday trips

- Saturday Peak Hour trips

- Sunday trips

- Sunday Peak Hour trips 


\section{Chapter 4. Results for Consolidated High Schools}

\subsection{Introduction}

As stated previously, this research focused on consolidated schools in West Virginia. By definition, a consolidated school was a public school recently formed from the consolidation of other schools of the same type or a county-wide school. In addition to the conventional consolidated school types of high schools, middle schools, and elementary schools, combined consolidated school sites were also studied. Three socioeconomic variables were collected for each site: number of employees, number of students, and 1000 SF gross floor area (GFA). Also, the number of parking spaces available and number of bus trips were collected for general information about each site. In the following chapters, each type of consolidated school is reported separately. Chapter 4 reports the results of the high schools. Chapter 5 reports the results of the middle schools and Chapter 6 reports the results of elementary schools. Chapter 7 reports the results of the combined consolidated school sites. Chapter 8 presents a comparison of trip rates among school type and the parking characteristics of consolidated schools.

\subsection{Consolidated High Schools}

Traffic data were collected at eight consolidated high schools. Of the eight data sets collected, one set of data was dismissed due to traffic counter failure; therefore the actual sample size was seven. In the sample, there were three county-wide schools and four consolidated schools. Each site is briefly described below. 


\subsubsection{High School Sites Studied}

High School A - This high school was located outside of a small town in central West Virginia. It was formed by the consolidation of all high schools in the county. Thus, it was the only high school in the county. This high school was located in a small county. Because of the location, most students must either ride the bus or find other vehicular means of transportation. Students were permitted to drive but had to obtain a permit from the school administration. In addition to the usual school-related extracurricular activities, this school had a community park located on its campus. The community park contains a picnic shelter and swimming pool.

High School B - This high school was located in the southeastern part of the state. It was the only high school in a large, sparsely populated county. Its rural location required students to either ride the bus or use other means of vehicular transportation. Students were permitted to drive to school. It should be noted that machine counts were not possible so traffic data were collected through the principal of the school. He was able to provide information based on parking pass information, number of bus trips, number of regular deliveries, and average number of daily visitors.

High School C - This county-wide consolidated high school was located in the northern part of the state. The location was rural in nature and therefore, students had to either ride the bus or use other means of vehicular transportation. Students were permitted to drive to school. It should be noted that the access drive was gated closed when school was not in session, on weekends, and when there were no activities on campus. Also, the school administration was unable to provide the building size for the data analysis. High School D - This high school located in southwestern West Virginia was formed by 
the consolidation of two rural high schools. This school serves part of a county in a rural setting, therefore, students must either ride the bus or use other means of vehicular transportation. Students were permitted to drive to school. In addition to the typical school functions, the campus also housed a county-wide vo-tech program during school hours.

High School E - This high school was located in the same county as High School D but serves a more urbanized area. It is located within a few miles of the central city area of one of the state's largest cities. The high school facility was built recently to accommodate the consolidation of two schools. Although the school was primarily for the residents of the city, it was located in a rural area just outside the urbanized area. Its only entrance was monitored on a continuous basis from a manned guardhouse. All visitors and students had to check-in and check-out with these guards. Students were permitted to drive to school.

High School F - This high school was located in the north-central part of the state and is not a county-wide school. It was formed by the consolidation of five rural high schools in the late 1970's. The unique aspect of this school was that students were not generally permitted to drive to school. This policy also applied to those students involved in afterschool activities. Students were permitted to drive under specific circumstances, such as mid-day doctor's appointments. As such, of the over 1000 students, less than 10 were permitted to drive on any given day. Since its consolidation, the administration developed an extensive bus service that included a late afternoon activity bus for student athletes and after-school activities. Because of the extensive bus service, students were not permitted to drive to school. In addition to the typical school activities, a county- 
wide vo-tech program is located on the campus.

High School G - This high school was located in the north-central area of the state. It was formed recently by the consolidation of two rural high schools and was not a countywide school. It was also a new facility in a rural area just outside of a small city. Because of the school's location, students were not able to walk to school. However, students were permitted to drive to school. In addition to the typical functions of a school, it also housed a Magnet program at night. This program offered evening college courses to the community.

To facilitate a comparison among the seven consolidated high schools studied, Table 4-1 provides the SEVs and parking information collected at each school.

Table 4-1 Comparison of SEV by High School Site

\begin{tabular}{|c|c|c|c|c||}
\hline High School & Employees & Students & 1000 SF GFA & Parking Spaces \\
\hline A & 73 & 1237 & 137 & 236 \\
\hline B & 49 & 440 & 88 & 150 \\
\hline C & 40 & 450 & --- & --- \\
\hline D & 120 & 1964 & 286 & 703 \\
\hline E & 202 & 2030 & 272 & 659 \\
\hline F & 86 & 1172 & 237 & 92 \\
\hline G & 94 & 1006 & 200 & 431 \\
\hline
\end{tabular}

\subsubsection{Average Rates for Consolidated High Schools}

The average trip rates and standard deviations for the seven sites are shown in Tables 4-2a, 4-2b, and 4-2c. The tables show that two sites had significantly lower trip rates than the other five sites. These low generators were High School B and High School C. Both of these sites were county-wide schools in largely rural, sparsely populated areas. These two facilities were also small; both had low student populations of approximately 450 students and under 50 employees. The other five schools had generally consistent results. The higher standard deviations for the am peak, pm peak, 
and weekday rates were caused primarily by these two smaller schools. One consistent attribute of the other 5 larger schools was that they usually were located near a more urbanized population centers. Consequently, these schools also served as community centers, offering opportunities such as vo-tech, Magnet programs, and recreational areas on the school site. High Schools B and C, because of their rural location and small size, did not serve this function. The additional roles increased the trip-making behavior at the more urban schools. Because of the differences between Sites B and C and the other five schools, Tables 4-2a, b, and c include trip rates and standard deviations if Sites B and C were to be excluded from the data set. As noticed in the Tables 4-2a, b, and c, when Sites $\mathrm{B}$ and $\mathrm{C}$ were excluded, the trip rates increased slightly and the standard deviation decreased dramatically in every case. The most noticeable difference was in the case of trip rate per employee on a weekday, which had an increase of approximately three trips per employee. The principal of Site B was unable to provide am peak, pm peak, and weekend data for his school.

Weekend trip data were collected at all schools with the exception of High Schools B and C. As stated previously, Site B data were collected from the principal of the school and the weekend traffic was unknown. The entrance of Site $\mathrm{C}$ was gated on the weekends and therefore no traffic data were collected. For weekends, the trip rates were consistent among the sites with the exception of High School D on Saturday. There is no reason to suspect that there is anything notably different about this high school. The cause for the high trip rate was likely related to school activities on the particular Saturday that the site was counted. 
Table 4-2a Comparison of Average Trip Rate per Employee for High Schools

\begin{tabular}{||c|c|c|c|c|c|c|c|c||}
\hline & & \multicolumn{7}{|c|}{ Average Trip Rate per Employee } \\
\hline Site & Employees & Weekday & AM Peak & PM Peak & Saturday & $\begin{array}{c}\text { Saturday } \\
\text { Peak }\end{array}$ & Sunday & $\begin{array}{c}\text { Sunday } \\
\text { Peak }\end{array}$ \\
\hline \hline A & 73 & 27.75 & 5.98 & 6.38 & 2.82 & 0.56 & 1.68 & 0.38 \\
\hline B & 49 & 4.61 & --- & --- & --- & --- & --- & --- \\
\hline C & 40 & 9.18 & 1.89 & 1.59 & --- & --- & --- & --- \\
\hline D & 120 & 35.41 & 8.10 & 6.23 & 21.38 & 3.09 & 1.80 & 0.36 \\
\hline E & 202 & 16.25 & 4.93 & 3.18 & 4.13 & 0.73 & 1.15 & 0.25 \\
\hline F & 86 & 33.98 & 4.87 & 5.32 & 7.29 & 1.30 & 1.97 & 0.23 \\
\hline G & 94 & 34.57 & 8.03 & 4.18 & 2.50 & 0.57 & 2.57 & 0.43 \\
\hline Weighted Average & 24.58 & 5.94 & 4.50 & 7.77 & 1.09 & 1.71 & 0.27 \\
\hline Standard Deviation & 12.95 & 2.33 & 1.87 & 7.92 & 1.07 & 0.51 & 0.08 \\
\hline \hline \multicolumn{2}{|l|}{} & & & & & & & \\
\hline \multicolumn{2}{|l|}{ Excluding B and C } & Weekday & AM Peak & PM Peak & Saturday & Sat. Peak & Sunday & Sun. Peak \\
\hline \hline \multicolumn{2}{|l|}{ Weighted Average } & 27.36 & 6.22 & 4.70 & 7.77 & 1.09 & 1.71 & 0.27 \\
\hline \multicolumn{2}{|l|}{ Standard Deviation } & 8.05 & 1.60 & 1.37 & 7.92 & 1.07 & 0.51 & 0.08 \\
\hline
\end{tabular}

Table 4-2b Comparison of Average Trip Rate per Student for High Schools

\begin{tabular}{|c|c|c|c|c|c|c|c|c|}
\hline & \multicolumn{7}{|c|}{ Average Trip Rate per Student } \\
\hline Site & Students & Weekday & AM Peak & PM Peak & Saturday & $\begin{array}{c}\text { Saturday } \\
\text { Peak }\end{array}$ & Sunday & $\begin{array}{c}\text { Sunday } \\
\text { Peak }\end{array}$ \\
\hline $\mathrm{A}$ & 1237 & 1.64 & 0.35 & 0.38 & 0.17 & 0.03 & 0.10 & 0.02 \\
\hline $\mathrm{B}$ & 440 & 0.51 & --- & --- & --- & --- & --- & --- \\
\hline $\mathrm{C}$ & 450 & 0.82 & 0.17 & 0.14 & --- & -- & --- & -- \\
\hline $\mathrm{D}$ & 1964 & 2.16 & 0.50 & 0.38 & 1.31 & 0.19 & 0.11 & 0.02 \\
\hline $\mathrm{E}$ & 2030 & 1.62 & 0.49 & 0.32 & 0.41 & 0.07 & 0.11 & 0.03 \\
\hline $\mathrm{F}$ & 1172 & 2.49 & 0.36 & 0.39 & 0.53 & 0.10 & 0.14 & 0.02 \\
\hline $\mathrm{G}$ & 1006 & 3.23 & 0.75 & 0.39 & 0.23 & 0.05 & 0.24 & 0.04 \\
\hline \multicolumn{2}{|c|}{ Weighted Average } & 1.97 & 0.46 & 0.35 & 1.00 & 0.09 & 0.13 & 0.02 \\
\hline \multicolumn{2}{|c|}{ Standard Deviation } & 0.94 & 0.20 & 0.10 & 0.46 & 0.06 & 0.06 & 0.01 \\
\hline \multicolumn{2}{|c|}{ Excluding $\mathrm{B}$ and $\mathrm{C}$} & Weekday & AM Peak & PM Peak & Saturday & Sat. Peak & Sunday & Sun. Peak \\
\hline \multicolumn{2}{|c|}{ Weighted Average } & 2.12 & 0.48 & 0.37 & 1.00 & 0.09 & 0.13 & 0.02 \\
\hline \multicolumn{2}{|c|}{ Standard Deviation } & 0.67 & 0.16 & 0.03 & 0.46 & 0.06 & 0.06 & 0.01 \\
\hline
\end{tabular}


Table 4-2c Comparison of Average Trip Rate per 1000 SF GFA for High Schools

\begin{tabular}{|c|c|c|c|c|c|c|c|c|}
\hline & \multicolumn{7}{|c|}{ Average Trip Rate per 1000 SF GFA } \\
\hline Site & 1000 SFGFA & Weekday & AM Peak & PM Peak & Saturday & $\begin{array}{c}\text { Saturday } \\
\text { Peak }\end{array}$ & $\overline{\text { Sunday }}$ & $\begin{array}{l}\text { Sunday } \\
\text { Peak }\end{array}$ \\
\hline$\overline{\mathrm{A}}$ & 137 & 14.79 & 3.19 & 3.40 & 1.50 & 0.30 & 0.90 & 0.20 \\
\hline $\mathrm{B}$ & 88 & 2.58 & -- & --- & --- & --- & $\overline{---}$ & --- \\
\hline $\mathrm{C}$ & --- & $\cdots$ & --- & --- & --- & --- & --- & --- \\
\hline $\mathrm{D}$ & 286 & 14.86 & 3.40 & 2.61 & 8.97 & 1.30 & 0.76 & 0.15 \\
\hline $\mathrm{E}$ & 272 & 12.07 & 3.66 & 2.36 & 3.07 & .54 & 0.85 & 0.19 \\
\hline $\mathrm{F}$ & 237 & 12.34 & 1.77 & 1.93 & 2.65 & 0.47 & 0.71 & 0.08 \\
\hline $\mathrm{G}$ & 200 & 16.25 & 3.77 & 1.97 & 1.18 & 0.27 & 1.21 & 0.20 \\
\hline \multicolumn{2}{|c|}{ Weighted Average } & 13.38 & 3.16 & 2.39 & .54 & 0.59 & 0.87 & 0.15 \\
\hline \multicolumn{2}{|c|}{ Standard Deviation } & 4.95 & 0.81 & 0.60 & 3.17 & 0.42 & 0.20 & 0.05 \\
\hline \multicolumn{2}{|c|}{ Excluding B and C } & Weekday & AM Peak & PM Peak & Saturday & Sat. Peak & Sunday & Sun. Pe \\
\hline \multirow{2}{*}{\multicolumn{2}{|c|}{ Weighted Average }} & 13.90 & 3.16 & 2.39 & "6.54 & 0.59 & 0.87 & 0.15 \\
\hline & & 1.79 & 0.81 & 0.60 & 3.17 & 0.42 & 0.20 & 0.05 \\
\hline
\end{tabular}


Table 4-3 presents the students-per-employee ratios and students-to-1000 SF GFA ratio for each site. These ratios are important since they may provide additional insight to the differences in trip rates between the seven sites studied. In general, the students-peremployee ratios for each site were similar with Sites A and D having the highest ratios. The students-to-1000 SF GFA ratios were similar with the exception of Site A which had the highest students-to-1000 SF GFA ratio of 9 students per 1000 SF GFA.

Table 4-3 Comparison of Student/Employee and Student/1000 SF Ratios for High Schools

\begin{tabular}{||c||c|c||}
\hline \hline Site & $\begin{array}{c}\text { Student/Employee } \\
\text { Ratio }\end{array}$ & $\begin{array}{c}\text { Student/1000 SF } \\
\text { Ratio }\end{array}$ \\
\hline \hline A & $16.9: 1$ & $9.0: 1$ \\
\hline B & $9.0: 1$ & $5.0: 1$ \\
\hline C & $11.3: 1$ & --- \\
\hline D & $16.4: 1$ & $6.9: 1$ \\
\hline E & $10.0: 1$ & $7.5: 1$ \\
\hline F & $13.6: 1$ & $5.0: 1$ \\
\hline G & $10.7: 1$ & $5.0: 1$ \\
\hline
\end{tabular}

\subsubsection{Comparison with Other Databases}

Tables 4-4 a, b, and c show how the trip generation results compare with the ITE Trip Generation (1997) rates. The table presents this study's weighted average trip rate (WV (1999)), ITE's weighted average trip rate (ITE (1997)), the significant difference (Sig Dif), and Standard Deviation to average ratio (S.D./Average). The significant difference is based on Equation 2-3, the standard error equation. If the "Z" value of this study's data and ITE's data was greater than a "Z" value of 1.96 which corresponds to a 95\% confidence interval, then there was a significant difference between the two studies. In comparison with the ITE rates, there were no statistically significant differences between this study and ITE. The rates per 1000 SF GFA and per student are remarkably similar, particularly for the am peak, pm peak, and weekday time periods. 
Table 4-4a Comparison of High School Trip Rates per Employee with ITE (1997)

\begin{tabular}{||c||c|c|c||c|c||}
\hline \multirow{2}{*}{$\begin{array}{l}\text { Time } \\
\text { Period }\end{array}$} & \multicolumn{2}{|c|}{ Trip Rate per Employee } & \multicolumn{2}{c||}{ S.D./Average } \\
\cline { 2 - 6 } & WV (1999) & ITE (1997) & Sig Dif & WV (1999) & ITE (1997) \\
\hline Weekday & 24.58 & 19.98 & $\mathrm{~N}$ & 0.53 & 0.42 \\
\hline AM Peak & 5.94 & 4.68 & $\mathrm{~N}$ & 0.39 & 0.62 \\
\hline PM Peak & 4.50 & 3.30 & $\mathrm{~N}$ & 0.42 & 0.64 \\
\hline Saturday & 7.77 & 6.65 & $\mathrm{~N}$ & 1.02 & 0.87 \\
\hline $\begin{array}{l}\text { Saturday } \\
\text { Peak }\end{array}$ & 1.09 & 1.23 & $\mathrm{~N}$ & 0.98 & 1.36 \\
\hline Sunday & 1.71 & 2.64 & $\mathrm{~N}$ & 0.30 & 1.30 \\
\hline $\begin{array}{l}\text { Sunday } \\
\text { Peak }\end{array}$ & 0.27 & 0.47 & $\mathrm{~N}$ & 0.30 & 2.23 \\
\hline
\end{tabular}

Table 4-4b Comparison of High School Trip Rates per Student with ITE (1997)

\begin{tabular}{|c|c|c|c|c|c|}
\hline \multirow{2}{*}{\begin{tabular}{|l} 
Time \\
Period \\
\end{tabular}} & \multicolumn{3}{|c|}{ Trip Rate per Student } & \multicolumn{2}{|c|}{ "S.D./Average } \\
\hline & WV (1999) & ITE (1997) & Sig Dif & WV (1999) & ITE (1997) \\
\hline Weekday & 1.97 & 1.97 & $\mathrm{~N}$ & 0.48 & 0.78 \\
\hline AM Peak & 0.46 & 0.42 & $\mathrm{~N}$ & 0.43 & 1.62 \\
\hline PM Peak & 0.35 & 0.30 & $\mathrm{~N}$ & 0.29 & 1.87 \\
\hline Saturday & 1.00 & 0.64 & $\mathrm{~N}$ & 0.46 & 1.41 \\
\hline $\begin{array}{l}\text { Saturday } \\
\text { Peak }\end{array}$ & 0.09 & 0.12 & $\bar{N}$ & 0.67 & 2.92 \\
\hline Sunday & 0.13 & 0.25 & $\mathrm{~N}$ & 0.46 & 2.20 \\
\hline $\begin{array}{l}\text { Sunday } \\
\text { Peak }\end{array}$ & 0.02 & 0.04 & $\mathrm{~N}$ & 0.50 & 5.50 \\
\hline
\end{tabular}

Table 4-4c Comparison of High School Trip Rates per 1000 SF GFA with ITE (1997)

\begin{tabular}{|l||c|c|c||c|c||}
\hline \multirow{2}{*}{$\begin{array}{l}\text { Time } \\
\text { Period }\end{array}$} & \multicolumn{2}{|c|}{ Trip Rate per 1000 SF GFA } & \multicolumn{2}{c||}{ S.D./Average } \\
\cline { 2 - 5 } & WV (1999) & ITE (1997) & Sig Dif & WV (1999) & ITE (1997) \\
\hline Weekday & 13.38 & 13.27 & $\mathrm{~N}$ & 0.37 & 0.57 \\
\hline AM Peak & 3.16 & 3.15 & $\mathrm{~N}$ & 0.26 & 0.78 \\
\hline \begin{tabular}{l} 
PM Peak \\
\hline Saturday
\end{tabular} & 2.39 & 2.21 & $\mathrm{~N}$ & 0.25 & 0.81 \\
\hline $\begin{array}{l}\text { Saturday } \\
\text { Peak }\end{array}$ & 0.54 & 4.33 & $\mathrm{~N}$ & 0.48 & 0.87 \\
\hline $\begin{array}{l}\text { Sunday } \\
\text { Sunday } \\
\text { Peak }\end{array}$ & 0.89 & 0.80 & $\mathrm{~N}$ & 0.71 & 1.36 \\
\hline
\end{tabular}


However, the trip rates per employee are much larger than the ITE rates; most noticeably for the weekday. Although no significant difference was detected, this study's rate for employees on a weekday was almost $25 \%$ higher than the ITE rate. Although it can not be confirmed through the investigation of ITE's rates and graphs, this suggests that the West Virginia schools studied have fewer employees per student than the schools in ITE's database. It should be noted that the schools in this study were all consolidated schools, whereas the ITE database represents many types of schools most of which are not consolidated schools. One important aspect of consolidated schools is the consolidation of resources including the consolidation of teachers and staff. This consolidation of employees while still serving the same population is the likely cause of the higher trip rates per employee yielded in this study.

Tables 4-4 a, b, and c provide a comparison of the variability of the sample. The ratio of standard deviation to weighted average was studied for each time period. ITE's Trip Generation (1997) considers any ratio less than 1.10 to be "good." Using ITE as a guide, the ratios for all variables indicate that the average trip rates calculated for consolidated high schools are acceptable for use. For the weekday periods in this study, these ratios indicate that the trip rates per 1000 SF GFA are more consistant than those for trips per employee and trips per student.

In comparing the ratio of standard deviation to weighted average to the ITE data, this study's ratios are much better than ITE's ratios in all but one case, that being the weekday trip rate per employee. The lower ratios are probably due to the fact that the schools in this study had a few things in common, they were all consolidated and all from West Virginia. Furthermore, they were all in somewhat rural locations and were all 
governed by the same state board of education. Also, it is evident that ITE has in general much better standard deviation to average ratios for the weekday time periods than it does for the weekend time periods. This is to be expected since weekend activity is much less structured. The ITE database has a more variable constituency, including different school types, sizes, and populations. This likely led to their higher standard deviation to weighted average ratio.

Table 4-5 shows how this study's results compared with the 1974 (Neumann and Deshpande) results. The rates reported in the 1974 West Virginia Special Generators (Neumann and Deshpande) study, were consistently lower than this study for the weekday, am peak, and pm peak in all cases. The results for this study are up to $150 \%$ greater than the 1974 results. It is interesting to note that the 1974 trip rates for $1000 \mathrm{SF}$ are lower than in this study.

Neumann and Deshpande (1974) studied three county-wide schools. One school studied in 1974 was studied also in this study, this was High School B. In 1974, this site had weekday rates of 6.49 trips per employee, 0.59 trips per student, and 4.46 trips per 1000 SF GFA. Referring to Tables 4-2 a, b, and c, it is noticeable that the 1999 rates are smaller in each case when compared to the previous rates. In 1974, Site B had 585 students and 53 employees whereas in 1999, Site B had 440 students and 49 employees. The reduction in the 1999 student population and number of employees would produce smaller trip rates than the 1974 study.

Table 4-5 Comparison of This Study's Results with 1974 Study for High Schools

\begin{tabular}{||l||c|c||c|c||c|c||}
\hline \hline \multirow{2}{*}{ Time Period } & \multicolumn{2}{c||}{ Trip Rate per Employee } & \multicolumn{2}{c|}{ Trip Rate per Student } & \multicolumn{2}{c||}{ Trip Rate per 1000 SF GFA } \\
\cline { 2 - 7 } & WV (1999) & WV (1974) & WV (1999) & WV (1974) & WV (1999) & WV (1974) \\
\hline Weekday & 24.58 & 17.52 & 1.97 & 1.22 & 13.38 & 12.68 \\
\hline AM Peak & 5.94 & 3.90 & 0.46 & 0.27 & 3.16 & 2.76 \\
\hline PM Peak & 4.50 & 1.96 & 0.35 & 0.14 & 2.39 & 1.41 \\
\hline \hline
\end{tabular}


In 1994, Slipp and Hummer conducted a comprehensive study of trip generation at high schools in urbanized counties of North Carolina. Table 4-6 presents a comparison of the 1999 West Virginia rates with the North Carolina rates. In general, the this study's trip rates are slightly lower and probably not significantly different than the 1994 North Carolina rates with the exception of trips per employee on a weekday and pm peak.

These differences can be attributed to the type of school studied by each research project. This study considered only consolidated high schools in West Virginia and the North Carolina study considered only urban schools.

Table 4-6 Comparison of This Study's Results with 1994 North Carolina Study

\begin{tabular}{||l||c|c||c|c||c|c||}
\hline \multirow{2}{*}{} & \multicolumn{2}{c||}{ Trip Rate per Employee } & \multicolumn{2}{c||}{ Trip Rate per Student } & \multicolumn{2}{c||}{ Trip Rate per 1000 SF GFA } \\
\cline { 2 - 7 } & WV (1999) & NC (1994) & WV (1999) & NC (1994) & WV (1999) & NC (1994) \\
\hline Weekday & 24.58 & 23.71 & 1.97 & 2.40 & 13.38 & 15.27 \\
\hline AM Peak & 5.94 & 6.06 & 0.46 & 0.61 & 3.16 & 3.90 \\
\hline PM Peak & 4.50 & 3.79 & 0.35 & 0.38 & 2.39 & 2.40 \\
\hline \hline
\end{tabular}

\subsubsection{Confidence Interval for High Schools}

Using the weekday rate, the standard deviation of 12.95 trips per employees and the average number of employees of 95 , yields a $67 \%$ confidence interval of $+/-1230$ vehicles per day. Using the same logic, the confidence intervals are presented in Table 47. These confidence intervals are quite large, and inclusion of High Schools B and C which yielded dramatically lower trip rates than the other five schools could impact the results of traffic impact studies and geometric studies. Therefore, it is advisable to determine, based on the location of the school and the intended "extra" uses of the school, whether the school will more closely resemble B and C, which had no extra uses or the other schools in the database. The trip rate can then be adjusted upwards or downwards as appropriate. 
Table 4-7 Confidence Intervals for High Schools

\begin{tabular}{|c|c|c|c|}
\hline \multirow[b]{2}{*}{ Time Period } & \multicolumn{3}{|c|}{ Vehicles per Day } \\
\hline & $\begin{array}{c}\text { Confidence Interval } \\
\text { per Employee }\end{array}$ & $\begin{array}{c}\text { Confidence Interval per } \\
\text { Student }\end{array}$ & $\begin{array}{c}\text { Confidence Interval per } \\
1000 \text { SF GFA }\end{array}$ \\
\hline Weekday & $+/-1230$ & $+/ /-1115$ & $+/-1005$ \\
\hline AM Peak & $+/-221$ & $+/-237$ & $+/-164$ \\
\hline PM Peak & $+/-178$ & $+/-119$ & $+/-122$ \\
\hline
\end{tabular}

\subsubsection{Regression Results for High Schools}

ITE Format Graphs for Consolidated High Schools were prepared. Included in Appendix I, they provide linear and logarithmic regression equations for each time period. Appendix III presents the 1999 WV data points plotted on ITE (1997) graphs. Table 4-8 compares the coefficient of determination $\left(\mathrm{R}^{2}\right)$ values for trips per employee, trips per student, and trips per 1000 SF GFA for this study. According to ITE, $\mathrm{R}^{2}$ values greater than 0.5 can be reported and those greater than 0.75 can be considered "good." In general, most of the weekday equations have $\mathrm{R}^{2}$ values that are considered "good." Of the three socio-economic variables, $1000 \mathrm{SF}$ has the highest $\mathrm{R}^{2}$ value for the weekday trip rate. The am and pm peaks are best represented by the trip rate per student which have the highest $\mathrm{R}^{2}$ values. The $\mathrm{R}^{2}$ values for Saturday, Sunday, and their peaks are not as good as the weekday values. However, when planning for a new facility, weekend traffic will generally not govern the design.

In the ITE database, only one case, weekday trips per employee, had a reported $\mathrm{R}^{2}$ value $\left(\mathrm{R}^{2}=0.51\right)$. All other values for the ITE database were below 0.50 and thus were not reported. 
Table 4-8 Coefficient of Determination Values for High Schools

\begin{tabular}{|c|c|c|c|c|c|c|}
\hline \multirow[b]{2}{*}{ Time Period } & \multicolumn{2}{|c|}{ Trip Rate per Employee } & \multicolumn{2}{|c|}{ Trip Rate per Student } & \multicolumn{2}{|c|}{ Trip Rate per 1000 SF GFA } \\
\hline & Linear & Logarithmic & Linear & Logarithmic & Linear & Logarithmic \\
\hline Weekday & 0.50 & 0.68 & 0.76 & 0.86 & 0.87 & 0.83 \\
\hline AM Peak & 0.72 & 0.81 & 0.80 & 0.86 & 0.53 & 0.46 \\
\hline PM Peak & 0.55 & 0.71 & 0.93 & 0.92 & 0.57 & 0.44 \\
\hline Saturday & 0.07 & 0.30 & 0.52 & 0.64 & 0.55 & 0.74 \\
\hline Saturday Peak & 0.10 & 0.33 & 0.55 & 0.62 & 0.60 & 0.78 \\
\hline Sunday & 0.36 & 0.46 & 0.13 & 0.10 & 0.44 & 0.56 \\
\hline Sunday Peak & 0.15 & 0.34 & 0.55 & 0.52 & 0.43 & 0.31 \\
\hline
\end{tabular}

\subsubsection{Peaking Characteristics for High Schools}

The " $\mathrm{K}$ " value is the percentage of the daily traffic that occurs in the peak hour, and was calculated by dividing the number of peak trips by the average number of weekday trips. Table 4-9 presents the "K" values by day of the week for each of the sites, and a weighted average " $K$ " value for the entire land use. The " $K$ " values calculated from this data set ranged from $0.12-0.30$, with the weekday and weekend weighted averages between $0.16-0.23$. For a high school, higher "K" values would be expected during the peaks because of the nature of a school. Students and employees arrive and depart at approximately the same times on a daily basis and there is typically not much traffic expected between the peak hours except for deliveries or visitors.

This study produced smaller " $K$ " values than expected for the peak hours. However, after reviewing the raw data, it was noticed that every school studied had high traffic volumes in the hours before and after what is considered the peak hour. So, it should be noted that the peak traffic volumes at a high school typically span more than one hour. If a "K" value was calculated for this time period, it would be evident that the most traffic at a school is during the hours before and after the peaks with hardly any 
traffic during the day.

Table 4-9 "K" Values for High Schools

\begin{tabular}{||c||c|c|c|c||}
\hline Site & AM Peak & PM Peak & Saturday & Sunday \\
\hline \hline A & 0.22 & 0.23 & 0.20 & 0.23 \\
\hline B & --- & --- & --- & --- \\
\hline C & 0.21 & 0.17 & --- & --- \\
\hline D & 0.23 & 0.18 & 0.14 & 0.20 \\
\hline E & 0.30 & 0.20 & 0.18 & 0.22 \\
\hline F & 0.14 & 0.16 & 0.18 & 0.12 \\
\hline G & 0.23 & 0.12 & 0.23 & 0.17 \\
\hline \hline $\begin{array}{c}\text { Weighted } \\
\text { Average }\end{array}$ & 0.23 & 0.17 & 0.16 & 0.19 \\
\hline
\end{tabular}

The weekday peak hours for the high schools were typically the same for every site. The am peak occurred between $7 \mathrm{am}$ and 8 am and the pm peak was $3 \mathrm{pm}$ to $4 \mathrm{pm}$. The only difference was in the pm peak for High School G, where their pm peak occurred between $2 \mathrm{pm}$ and $3 \mathrm{pm}$. Since the peaking characteristics of high schools are defined by students and employees arriving or leaving school, the peak volume hours can easily be predicted by knowing the time school starts and ends.

\subsubsection{Heavy Vehicle Traffic for High Schools}

The truck traffic at the high schools where manual counts were made was negligible. School buses are the primary heavy vehicle that needs to be considered in design and operations. Tables 4-10 and 4-11 present the bus data from each site. The table is based on the number of bus trips during the am, mid-day, and pm.

For high schools, all bus traffic occurred during the am and pm peaks with the exception of High School D, which had mid-day bus traffic. The bus traffic at Site D was due to the county-wide vo-tech center located on its campus. Students involved in votech usually spend half of their day at a traditional high school and the other half at the 
vo-tech center. Since there are a total of three high schools in this county, this creates additional bus traffic during the mid-day at High School D.

High School A had the highest number of buses, however, Table 4-11 indicates that each bus was only about one-half full. Considering that a bus can transport 44 students, the buses at Site A are not used to capacity or part of their fleet may include "mini-buses" which carry 22 students. High School F had no student driving except for special cases such as doctors appointments. It can be noticed in Tables 4-10 and 4-11 that Site F had the second highest number of buses and a students-per-bus ratio that did not exceed the bus capacity of 44 students.

Site $\mathrm{C}$ had the smallest number of buses and the second highest students per bus ratio. Since Site $\mathrm{C}$ is a county-wide school, the trip to school may be a long ride for some students. Instead of riding the buses, which typically do not take the most direct routes to school, students may choose to drive themselves. It was evident from Table 4-11, that Sites D, E, and G also had high students per bus ratios. These ratios were all over the bus capacity of 44 students per bus. The reason for this is that students were permitted to drive, and based on previous experience, school officials were able to reduce the number of buses needed. Thus the students-per-bus ratio increases.

These data are provided to permit the planner to make rough estimates of the bus traffic when the number of students are known. However, due to varying logistic plans between counties, these rates should be used only when the actual number of buses is not available from the school. 
Table 4-10 Number of Bus Trips at Each High School by Time of Day

\begin{tabular}{|c|c|c|c||}
\hline & \multicolumn{3}{|c||}{ Number of Bus Trips } \\
\hline Site & AM & Mid-Day & PM \\
\hline \hline A & 48 & 0 & 48 \\
\hline B & 11 & 0 & 11 \\
\hline C & 8 & 0 & 8 \\
\hline D & 26 & 26 & 31 \\
\hline E & 25 & 0 & 25 \\
\hline F & 32 & 0 & 32 \\
\hline G & 18 & 1 & 18 \\
\hline
\end{tabular}

Table 4-11 Number of Students-per-Bus at High Schools

\begin{tabular}{||c|c|c||}
\hline & \multicolumn{2}{|c|}{ Students per Bus } \\
\hline Site & AM & PM \\
\hline \hline A & 26 & 26 \\
\hline B & 40 & 40 \\
\hline C & $\mathbf{5 6}$ & $\mathbf{5 6}$ \\
\hline D & $\mathbf{7 6}$ & $\mathbf{6 3}$ \\
\hline E & $\mathbf{8 1}$ & $\mathbf{8 1}$ \\
\hline F & 37 & 37 \\
\hline G & $\mathbf{5 6}$ & 56 \\
\hline \hline Average & $\mathbf{5 3}$ & $\mathbf{5 1}$ \\
\hline
\end{tabular}

When designing a new school facility, a design vehicle has to be chosen to govern the geometric design. Typically, engineers use the guidelines developed by the American Association of State Highway and Transportation Officials (AASHTO) in A Policy on Geometric Design of Highways and Streets (1990) to choose an appropriate design vehicle. With respect to schools, a school bus is the largest vehicle that should be used for design. AASHTO (1990) identifies two types of bus design vehicles - the "BUS" and "A-BUS." By definition, the BUS is a single-unit bus that includes intercity and transit buses. The BUS has a wheelbase of 25 feet, width of 8.5 feet and an overall length of 40 feet. It also has a turning radius of 42 feet. The A-BUS is similar to the BUS, however it is articulated and has larger dimensions. However, neither type of bus as defined by 
AASHTO truly represents a school bus. From field measurements, it was determined that one type of bus used for school purposes had a smaller wheelbase, narrower width, and tighter turning radius that the AASHTO (1990) BUS. For the bus measured, the width was 7.2 feet with a wheelbase of 22 feet and an approximate turning radius of 35 feet. Other full-size buses manufactured by the Blue Bird Corporation had wheelbases as small as 20 feet (Blue, 1999). For new designs, the AASHTO BUS should be used, but it should be noted that school buses typically have smaller dimensions and a tighter turning radius.

\subsubsection{Recommendations for Use of High School Rates}

The trip generation results for consolidated high schools in this study are very similar to ITE's data for high schools except for the trip rates per employee, where the results from this study were $25 \%$ higher. For new schools, the size of the building is usually the known factor and will generally be used in traffic impact studies and design. For new facilities in West Virginia, the 1999 West Virginia data should be used in lieu of ITE (1997) but special attention must be given to the type of school is being planned. If a school is similar to High School B or C, that is, if it is a county-wide school in a predominantly rural area, a lower trip rate should be used.

While the average rates per 1000 SF GFA were generally the same for this study and for ITE (1997), this study revealed additional insight into consolidated schools. For schools that are located in large, sparsely populated districts, and that will not be used for additional community functions, the trip rate selected should be much less than the ITE average rate. In contrast, for consolidated schools that will be used for community functions as well as school functions, slightly higher than average rates should be 
selected. The extent to which rates should be lowered or raised should be determined on a case-by-case basis depending on local conditions.

This study yielded both quality equations and average trip rates. ITE's Trip Generation (1997) contains guidance in selecting between them when both are available. As pointed out earlier, either can be used, but the results must be tailored to each particular school depending on its location and function. 


\section{Chapter 5. Results for Middle Schools}

\section{$5.1 \quad$ Introduction}

Traffic data were collected at three consolidated middle schools. Of the three data sets collected, one set was dismissed due to traffic counter failure; therefore the actual sample size was two. The sites are briefly described below.

\subsection{Consolidated Middle School Sites Studied}

Middle School A - This middle school was located in the western part of the state. It was the only middle school in a sparsely populated county with an area of 319 square miles. Its rural location required students to either ride the bus or use other means of vehicular transportation. This middle school occupied a relatively new building.

Middle School B - This middle school was located in a developing area of southern West Virginia. It was formed in the early 1990's by the consolidation of two middle schools. Its location was in a suburban business area. Approximately $25 \%$ of the students walked to school.

To facilitate a comparison among the two consolidated middle schools studied, Table 5-1 provides the SEVs and parking information collected at each school.

Table 5-1 Comparison of SEV by Middle School Site

\begin{tabular}{|c|c|c|c|c|}
\hline Middle School & Employees & Students & 1000 SF GFA & Parking Spaces \\
\hline A & 53 & 400 & 71 & 50 \\
\hline B & 60 & 700 & 70 & 70 \\
\hline
\end{tabular}




\subsubsection{Average Rates for Consolidated Middle Schools}

The average trip rates and standard deviations for the two sites are shown in Tables 5-2a, b, and c. These tables show significant differences between the two sites, especially during the weekday time periods for "per employees" and "per 1000 SF GFA." Site B consistently had higher trip rates in every category when compared to Site A.

From Table 5-2c, it was noticed that the two sites have approximately the same size building but Site B's trip rate was double that of Site A. The higher trip rates may be attributed in part to the urbanized location of Site B, which encouraged "trip-chaining." Parents may have dropped their children off at school on their way to work, thus producing more trips at the school. Also, it was observed that the differences in Sites A and $\mathrm{B}$ for the pm peak were not as noticeable. This could indicate that parents were not picking their children up after school. This could be because the parents were still at work when school was dismissed. The second factor could been that children at the middle school age are less likely to need adult supervision for the few hours after school.

Differences were also noted in the population densities of the areas surrounding Sites A and B. Site B serves a geographic area with a denser population, and for most students, the school is close to their house. However, the rural setting of Site A, which had a low population density, combined with the fact that it serves an entire county, affected the trip rates. This indicated that most, if not all students, were not able to walk to school or ride the bus and parents were less likely to be driving past the school on their way to work or able to just "drop" them off. 
Table 5-2a Comparison of Average Trip Rate per Employee for Middle Schools

\begin{tabular}{||cc||c|c|c||}
\hline \multirow{2}{*}{ Site } & Employees & \multicolumn{3}{c||}{ Average Trip Rate per Employee } \\
\cline { 3 - 5 } & Weekday & AM Peak & PM Peak \\
\hline \hline A & 53 & 11.81 & 4.04 & 2.08 \\
\hline B & 60 & 20.98 & 6.87 & 3.55 \\
\hline \hline Weighted Average & 16.68 & 5.54 & 2.78 \\
\hline Standard Deviation & 6.48 & 2.00 & 1.04 \\
\hline
\end{tabular}

Table 5-2b Comparison of Average Trip Rate per Student for Middle Schools

\begin{tabular}{||cc||c|c|c||}
\hline \multirow{2}{*}{ Site } & Student & \multicolumn{3}{c||}{ Average Trip Rate per Student } \\
\cline { 3 - 5 } & Weekday & AM Peak & PM Peak \\
\hline \hline A & 400 & 1.57 & 0.54 & 0.28 \\
\hline B & 700 & 1.80 & 0.59 & 0.30 \\
\hline \hline Weighted Average & 1.71 & 0.57 & 0.29 \\
\hline Standard Deviation & 0.16 & 0.04 & 0.01 \\
\hline
\end{tabular}

Table 5-2c Comparison of Average Trip Rate per 1000 SF GFA for Middle Schools

\begin{tabular}{||c|c||c|c|c||}
\hline \multicolumn{2}{||c||}{} & \multicolumn{4}{c||}{ Average Trip Rate per 1000 SF GFA } \\
\cline { 3 - 5 } Site & 1000 SF GFA & Weekday & AM Peak & PM Peak \\
\hline \hline A & 71 & 8.87 & 3.04 & 1.56 \\
\hline B & 70 & 17.99 & 5.89 & 3.04 \\
\hline \hline \multicolumn{2}{||l|}{ Weighted Average } & 13.41 & 4.45 & 2.30 \\
\hline \multicolumn{2}{|l|}{ Standard Deviation } & 6.45 & 2.02 & 1.05 \\
\hline \hline
\end{tabular}


ITE does not report weekend rates for Middle Schools in their 1997 database. In an attempt to develop weekend trip rates, weekend data were collected for both sites. The amount of traffic at the sites was significantly lower than the weekday rates. The typical weekend traffic was at most $11 \%$ of the weekday traffic. Thus, the weekend traffic at middle schools was considered unimportant and not likely to enter into the highway or access design.

Table 5-3 presents the students-per-employee ratios and student-to-1000 SF GFA ratio for each site. These ratios are important since they provide additional insight to the differences in trip rates between the two sites studied. Table 5-3 indicates that Site B had a higher "students-per-employee" ratio. However, the "per employee" rates for Site B were high and this can be attributed to the urbanizing area which can lead to "tripchaining" and increased trip rates. Another factor to consider was that Site B had almost double the student population of Site A. While there was a large difference in the number of students, there is hardly a noticeable difference in the number of employees and building size. The similarities in building size combined with the difference in student populations can be easily noticed in Table 5-3.

Table 5-3 Comparison of Student/Employee and Student/1000 SF GFA Ratios for Middle Schools

\begin{tabular}{||c||c|c||}
\hline Site & $\begin{array}{c}\text { Student/Employee } \\
\text { Ratio }\end{array}$ & $\begin{array}{c}\text { Student/1000 SF } \\
\text { Ratio }\end{array}$ \\
\hline \hline A & $7.6: 1$ & $5.7: 1$ \\
\hline B & $11.7: 1$ & $10: 1$ \\
\hline
\end{tabular}

\subsubsection{Comparison with Other Databases}

Tables 5-4a and $\mathrm{b}$ show how these results compare with the ITE Trip Generation (1997) rates; Appendix IV contains the 1999 Consolidated Middle School data points on 
the ITE (1997) graphs. Note that ITE does not report trip rates per employee in their database for this land use. In comparison with ITE, no statistically significant differences were detected between this study and ITE. The $1999 \mathrm{WV}$ rates are slightly higher for the weekday and am peak in both cases. In contrast, the pm peak rates were approximately the same for "per student" and slightly lower for "per 1000 SF GFA." Although no significant difference was detected, the weekday trip rate per 1000 SF GFA was $13 \%$ higher than ITE's rate and the trip rate per student was $18 \%$ higher than ITE's rate. The trip rates per student for the am peak was $27 \%$ higher than ITE and there was no difference in the pm peak. For trip rate per 1000 SF GFA, the am peak was $21 \%$ higher than ITE and the pm peak was $6 \%$ lower than ITE's rate.

Tables 5-4a and $\mathrm{b}$ present the ratio of standard-deviation-to-weighted-average were studied for each time period to provide a comparison of the variability of the sample. The "per employee" ratios were 0.39 for weekdays, 0.36 for the am peak, and 0.37 for the pm peak. Using ITE as a guide, the ratios for the all variables indicate that the average trip rates calculated for consolidated middle schools are acceptable for use since the values were less than 1.10. However, this study's sample size was two sites and the standard deviation is of limited value in judging consistency or quality when $n=2$.

In comparing the ratios of standard-deviation-to-weighted-average to the ITE data, this study's ratios are much better than ITE's ratios for every case and time period. The smaller ratios in this study are probably due to the small standard deviation caused by the low sample size. Furthermore, the ITE database has a more variable constituency, having different school types, sizes, and populations. This likely led to ITE's higher, and in some cases, not acceptable for use, standard-deviation-to-weighted-average ratios. 
Table 5-4a Comparison of Middle School Trip Rates per Student with ITE (1997)

\begin{tabular}{|l||c|c|c||c|c||}
\hline \multirow{2}{*}{$\begin{array}{l}\text { Time } \\
\text { Period }\end{array}$} & \multicolumn{3}{|c||}{ Trip Rate per Student } & \multicolumn{2}{c||}{ S.D./Average } \\
\cline { 2 - 6 } & WV (1999) & ITE (1997) & Sig Dif & WV (1999) & ITE (1997) \\
\hline Weekday & 1.71 & 1.45 & $\mathrm{~N}$ & 0.09 & 0.97 \\
\hline AM Peak & 0.57 & 0.45 & $\mathrm{~N}$ & 0.07 & 1.67 \\
\hline PM Peak & 0.29 & 0.29 & $\mathrm{~N}$ & 0.03 & 1.93 \\
\hline
\end{tabular}

Table 5-4b Comparison of Middle School Trip Rates per 1000 SF GFA with ITE (1997)

\begin{tabular}{|l|c|c|c||c|c||}
\hline \multirow{2}{*}{$\begin{array}{l}\text { Time } \\
\text { Period }\end{array}$} & \multicolumn{2}{|c|}{ Trip Rate per 1000 SF GFA } & \multicolumn{2}{c||}{ S.D./Average } \\
\cline { 2 - 5 } & WV (1999) & ITE (1997) & Sig Dif & WV (1999) & ITE (1997) \\
\hline \hline Weekday & 13.41 & 11.92 & $\mathrm{~N}$ & 0.48 & 0.78 \\
\hline AM Peak & 4.45 & 3.68 & $\mathrm{~N}$ & 0.45 & 1.21 \\
\hline PM Peak & 2.30 & 2.45 & $\mathrm{~N}$ & 0.46 & 1.00 \\
\hline \hline
\end{tabular}

The rates reported in the West Virginia Special Generators (Neumann and Deshpande, 1974), were consistently lower than the 1999 study for the weekday, am peak, and pm peak in all cases. Table 5-5 shows how this study compares with the 1974 results. The rates determined for this study were up to $235 \%$ greater than the 1974 results. It should be noted that this was a comparison of two small sample sizes. The 1974 WV study had a sample size of three while the 1999 study had a sample size of two. Also, the schools in the 1974 study may not have been consolidated. It seems clear that the 1999 rates are truly higher than the 1974 rates for two reasons. The first indication was that the other schools studied typically had higher trips rates when compared to the 1974 study. Also, every entry in Table 5-5 is higher which indicates a trend in the 1999 trip rates.

Table 5-5 Comparison of 1999 Study Results with 1974 Study for Middle Schools

\begin{tabular}{||l||c|c||c|c||c|c||}
\hline \multirow{3}{*}{ Time Period } & \multicolumn{2}{|c|}{ Trip Rate per Employee } & \multicolumn{2}{c|}{ Trip Rate per Student } & \multicolumn{2}{c||}{ Trip Rate per 1000 SF GFA } \\
\cline { 2 - 5 } & WV (1999) & WV (1974) & WV (1999) & WV (1974) & WV (1999) & WV (1974) \\
\hline Weekday & 16.68 & 13.31 & 1.71 & 0.77 & 13.41 & 9.63 \\
\hline AM Peak & 5.54 & 2.99 & 0.57 & 0.17 & 4.45 & 2.17 \\
\hline PM Peak & 2.78 & 2.11 & 0.29 & 0.12 & 2.30 & 1.53 \\
\hline
\end{tabular}


Due to the small sample size of Consolidated Middle Schools, a regression analysis was not performed. Also, confidence intervals were meaningless with a sample size of 2 .

\subsubsection{Peaking Characteristics of Middle Schools}

Table 5-6 represents the " $K$ " values by day of the week for each of the sites, and a weighted " $K$ " value for the middle schools. The "K" values calculated from this data set range from $0.17-0.34$. The weekday averages were 0.33 for the am peak and 0.17 for the pm peak. After reviewing the raw data, it was noticed that each school had a definite peak hour in the am. However, the pm peak occurred and then was followed by two to three additional hours of high traffic volumes. So, the peak traffic volumes in the afternoon typically spanned for more than one hour at each site, thus, reducing the " $\mathrm{K}$ " value for the pm peak. The results for the "K" values are basically the same as the other types of school land uses in that the "K" values are higher during the am peak when compared to the pm peak and the peaks are spread over a few hours.

Table 5-6 "K" Values for Middle Schools

\begin{tabular}{||c||c|c||}
\hline Site & AM Peak & PM Peak \\
\hline \hline A & 0.34 & 0.18 \\
\hline B & 0.33 & 0.17 \\
\hline \hline Weighted Average & 0.33 & 0.17 \\
\hline
\end{tabular}

The am peak at Site A was from 7am to $8 \mathrm{am}$ and the pm peak was from $3 \mathrm{pm}$ to 4pm. Site B had a later starting time with a morning peak of $8 \mathrm{am}$ to $9 \mathrm{am}$ and in the afternoon, the pm peak was $3 \mathrm{pm}$ to $4 \mathrm{pm}$. Since the peaking characteristics of middle schools are defined by students and employees arriving or leaving school, the peak volume hours can be easily predicted by determining the school start and dismissal times. 


\subsubsection{Heavy Vehicle Traffic at Middle Schools}

As noted previously and similar to the other school types, there was not significant truck traffic at middle schools. School buses are the primary heavy vehicle that needs to be considered in design. Tables 5-7 and 5-8 present the bus trip data from the two middle schools studied.

Site A had students per bus ratios that were smaller than the capacity of a bus, which is 44 students. However, Site B had students per bus ratios that were approximately double the capacity of a school bus. As noted previously, Site B is located in an area where $25 \%$ of the student population is able to walk to school, since bus service for these students is not provided for these students, the students per bus ratio was increased.

Table 5-7 Number of Bus Trips at Middle Schools by Time of Day

\begin{tabular}{||c||c|c||}
\hline \multicolumn{1}{|c||}{ Site } & \multicolumn{2}{c|}{ Number of Bus Trips } \\
\cline { 2 - 3 } A & AM & PM \\
\hline \hline B & 14 & 14 \\
\hline
\end{tabular}

Table 5-8 Number of Students per Bus Trip at Middle Schools

\begin{tabular}{||c||c|c||}
\hline \multirow{2}{*}{ Site } & \multicolumn{2}{|c|}{ Students per Bus Trip } \\
\cline { 2 - 3 } & AM & PM \\
\hline \hline A & 29 & 29 \\
\hline B & $\mathbf{7 0}$ & $\mathbf{8 8}$ \\
\hline \hline Average & $\mathbf{5 0}$ & $\mathbf{5 9}$ \\
\hline
\end{tabular}

\subsubsection{Recommendations for Use of Middle School Rates}

The weighted average trip rates for consolidated middle schools are very similar to ITE's results. For new schools, the size of the building is usually the known factor and will generally be used in traffic impact studies and design. Due to the small sample size of this study, Trip Generation (ITE, 1997) should be used for new consolidated middle 
schools. The rates can be tailored to the specific case through the results of this study. If a school is similar to Site A, that is if it is a county-wide school in a predominately rural area with a low population, a 25\% smaller trip rate than ITE should be used for the weekday. In contrast, if the new school is more similar to Site B, that is if it is located in a more densely populated urban/suburban area, then a 50\% higher trip rate should be used for the weekday. 


\section{Chapter 6. Results for Elementary Schools}

\subsection{Introduction}

Traffic data were collected at five consolidated elementary schools. Of the five collected, one set of data was dismissed due to traffic counter failure; therefore the sample size was four. Each site is briefly described below.

\subsection{Elementary School Sites Studied}

Elementary School A - This elementary school was located in a developing area of the eastern panhandle in West Virginia. In recent years, the population of this county has increased significantly. The location of the school was not conducive for students to walk to school. Consequently, students were required to either ride the bus or be dropped off by parents.

Elementary School B - This elementary school was located in a small city in the Ohio River Valley and is not considered a "true" consolidated elementary school. Because of recent consolidation activities in other schools within the county, this elementary school was moved to a new facility that was located in a residential area and thus many children walked to school.

Elementary School C - This elementary school was located in a small city in northcentral West Virginia that had a large professional workforce in the area. It was formed by the consolidation of three smaller neighborhood schools and had a channelized pulloff area with a special school entrance to accommodate drop-offs. It was located in a residential area and thus, it was possible for children to walk to school.

Elementary School D - This elementary school was established in the late 1970's and was located in the same county as Elementary School C. Its location was in a suburban 
business area. Students could not walk to school and were either bused or dropped off by parents.

To facilitate a comparison among the four consolidated elementary schools studied, Table 6-1 provides the SEVs and parking information collected at each school. Table 6-1 Comparison of SEV by Elementary School Site

\begin{tabular}{|c|c|c|c|c|}
\hline Elementary School & Employees & Students & 1000 SF GFA & Parking Spaces \\
\hline A & 65 & 529 & 66 & 100 \\
\hline B & 58 & 317 & 58 & 80 \\
\hline C & 78 & 750 & 87 & 100 \\
\hline D & 65 & 570 & 62 & 70 \\
\hline
\end{tabular}

\subsubsection{Average Rates for Consolidated Elementary Schools}

The average trip rates and standard deviations for the four sites are shown in Tables 6-2a, 6-2b, and 6-2c. Also included in these tables are the weighted averages and the standard deviations if Site B were to be excluded from the data set. This was included to illustrate the differences when the possibly non-consolidated school was excluded.

Tables 6-2a, b, and c show that Elementary School A had lower rates than the other three sites. There was barely a difference between the socio-economic variables of Elementary School A and Elementary School D, however, there was a significant difference in their trip rates. In each case, the trip rates for Site A were only one-half of the trip rates for Site D. As previously mentioned, Elementary School A was located in the eastern panhandle. In recent years, this area has seen a dramatic rise in commuting activity to the Washington, D.C area. 
Table 6-2a Comparison of Average Trip Rate per Employee for Elementary Schools

\begin{tabular}{|c|c|c|c|c|}
\hline & & \multicolumn{3}{|c|}{ Average Trip Rate per Employee } \\
\hline Site & Employees & Weekday & AM Peak & PM Peak \\
\hline A & 65 & 14.60 & 4.10 & 3.27 \\
\hline B & 58 & 32.19 & 8.65 & 7.10 \\
\hline $\mathrm{C}$ & 78 & 26.73 & 7.10 & 7.10 \\
\hline $\mathrm{D}$ & 65 & 34.92 & 8.56 & 6.03 \\
\hline \multicolumn{2}{|c|}{ Weighted Average } & 26.96 & 7.06 & 5.90 \\
\hline \multicolumn{2}{|c|}{ Standard Deviation } & 9.01 & 2.12 & 1.81 \\
\hline \multicolumn{2}{|c|}{ Excluding Site B } & Weekday & AM Peak & PM Peak \\
\hline \multicolumn{2}{|c|}{ Weighted Average } & 25.50 & 6.62 & 5.57 \\
\hline \multicolumn{2}{|c|}{ Standard Deviation } & 10.22 & 2.27 & 1.98 \\
\hline
\end{tabular}

Table 6-2b Comparison of Average Trip Rate per Student for Elementary Schools

\begin{tabular}{|c|c|c|c|c|}
\hline \multirow[b]{2}{*}{ Site } & \multirow[b]{2}{*}{ Students } & \multicolumn{3}{|c|}{ Average Trip Rate per Student } \\
\hline & & Weekday & AM Peak & PM Peak \\
\hline A & 529 & 1.79 & 0.50 & 0.40 \\
\hline B & 317 & 5.89 & 1.58 & 1.30 \\
\hline $\mathrm{C}$ & 750 & 2.78 & 0.74 & 0.74 \\
\hline $\mathrm{D}$ & 570 & 3.98 & 0.98 & 0.69 \\
\hline \multicolumn{2}{|c|}{ Weighted Average } & 3.31 & 0.87 & 0.73 \\
\hline \multicolumn{2}{|c|}{ Standard Deviation } & 1.76 & 0.46 & 0.37 \\
\hline \multicolumn{2}{|c|}{ Excluding Site B } & Weekday & AM Peak & PM Peak \\
\hline \multicolumn{2}{|c|}{ Weighted Average } & 2.87 & 0.74 & 0.63 \\
\hline \multicolumn{2}{|c|}{ Standard Deviation } & 1.10 & 0.24 & 0.18 \\
\hline
\end{tabular}

Table 6-2c Comparison of Average Trip Rate per 1000 SF GFA for Elementary Schools

\begin{tabular}{|c|c|c|c|c|}
\hline & & \multicolumn{3}{|c|}{ 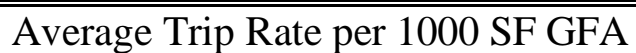 } \\
\hline Site & 1000 SF GFA & Weekday & AM Peak & PM Peak \\
\hline A & 66 & 14.47 & 4.06 & 3.24 \\
\hline B & 58 & 32.35 & 8.69 & 7.13 \\
\hline $\mathrm{C}$ & 87 & 23.97 & 6.37 & 6.37 \\
\hline $\mathrm{D}$ & 62 & 36.61 & 8.98 & 6.33 \\
\hline \multicolumn{2}{|c|}{\begin{tabular}{|l||} 
Weighted Average \\
\end{tabular}} & 26.33 & 6.90 & 5.77 \\
\hline \multicolumn{2}{|c|}{ Standard Deviation } & 9.78 & 2.29 & 1.72 \\
\hline \multicolumn{2}{|c|}{ Excluding Site B } & Weekday & AM Peak & PM Peak \\
\hline \multicolumn{2}{|c|}{ Weighted Average } & 24.72 & 6.42 & $\overline{\overline{5.40}}$ \\
\hline \multicolumn{2}{|c|}{ Standard Deviation } & 11.11 & 2.46 & 1.80 \\
\hline
\end{tabular}


Parents may not be able to drop their children off on their way to work because of the need to leave for work long before students are due at school and because they may not be headed towards the school since their job is in another city. Therefore, many of the children may rely on bus transportation or may share rides with other families; thus accounting for the lower trip rates.

Elementary School $\mathrm{C}$ also had noticeably low trip rates. This could be due to its residential setting and children being able to walk to school. It was also evident that Elementary School B had the lowest number of students and yet the highest "per student" trip rates. The high trip rate could be an indication that there are less students relative to the other schools (in terms of employees and 1000 SF GFA, see Table 6-3). Also, the differences may be due to the fact that this school is not considered a consolidated school. Because of the differences between Sites A and C and the other two schools, a higher standard deviation results.

There was a slight difference between the am peak and pm peak for each time period. This may be due to parents who are able to drop their children off at school but unable to pick them up. The am start time for Sites $\mathrm{A}$ and $\mathrm{C}$ was 8:30 am and dismissal was at 3:30 pm. Site D had a start time of 8:50 am and dismissal time of 3:20 pm. These start and dismissal times suggest that the peak traffic would be spread over two hours. The start time for Site B was at 8:00 am and the dismissal time was at 2:45 pm. This onthe-hour start time would indicate that all peak traffic would occur in the one hour before the school start time. The pm peak would tend to be more spread-out than the am peak because of after-school activities or teachers staying after hours to finish work.

When comparing the differences between the weighted average rates including 
Site B and excluding Site B, it was noticed that the trip rates excluding Site B were lower in every case. These differences can be attributed to the fact that Site B is not a consolidated school whereas the other two sites were consolidated.

ITE does not report weekend rates for Elementary Schools in their 1997 database. In an attempt to develop weekend trip rates, weekend data were collected for Sites A and B. The amount of traffic at these sites was significantly lower than weekday rates. The typical weekend traffic was at most $8 \%$ of the weekday traffic. Thus, the weekend traffic was considered unimportant in designing for the transportation needs of the school.

Typically schools consolidate because of reduced populations or financial constraints. So, when schools consolidate, it also means that resources such as employees and buildings are consolidated while still serving the same student population. Table 6-3 presents the student-to-teacher ratios and student-to-1000 SF GFA ratio for each site. These ratios provide insight to the differences noted in the trip rates among the sites. From Table 6-3, it is noticeable that Site B had the highest students per employee ratio, this would make the "per employee" rates low if all else were equal. On a per student basis, Site B also had a smaller building relative to the other schools. In turn, this would make the "per 1000 SF" rates low if all else were equal. Perhaps this explains why "per student" rates are so high for Elementary School B. In general, Site A had the lowest trip rates of the four sites studied. 
Table 6-3 Comparison of Student/Employee and Student/1000 SF Ratios for Elementary Schools

\begin{tabular}{||c||c|c||}
\hline Site & $\begin{array}{c}\text { Student/Employee } \\
\text { Ratio }\end{array}$ & $\begin{array}{c}\text { Student/1000 SF } \\
\text { Ratio }\end{array}$ \\
\hline \hline A & $8.1: 1$ & $8.1: 1$ \\
\hline B & $5.5: 1$ & $5.5: 1$ \\
\hline C & $9.6: 1$ & $8.6: 1$ \\
\hline D & $8.8: 1$ & $9.2: 1$ \\
\hline
\end{tabular}

\subsubsection{Comparison with Other Databases}

Tables 6-4 a, b, and c show how these results compare with the ITE's Trip Generation (1997) rates. It should be noted that the rates in Tables 6-4a, b, and c include Site B. In comparison with ITE, statistically significant differences were detected between this study and ITE. The WV trip rates were approximately double the ITE trip rates in each case. Referring back to Tables 6-2 a, b, and c, it is noticeable that Site A had rates similar to ITE's Trip Generation (1997). The differences in weighted average trip rates could be due to the school locations in combination with the commuting patterns and job types. 
Table 6-4a Comparison of Elementary School Trip Rates per Employee with ITE (1997)

\begin{tabular}{||l||c|c|c||c|c||}
\hline \multirow{2}{*}{$\begin{array}{l}\text { Time } \\
\text { Period }\end{array}$} & \multicolumn{3}{c|}{ Trip Rate per Employee } & \multicolumn{2}{c||}{ S.D./Average } \\
\cline { 2 - 6 } & WV (1999) & ITE (1997) & Sig Dif & WV (1999) & ITE (1997) \\
\hline Weekday & 26.96 & 13.13 & Y & 0.33 & 0.46 \\
\hline AM Peak & 7.06 & 3.71 & Y & 0.30 & 0.63 \\
\hline PM Peak & 5.90 & 3.5 & Y & 0.31 & 0.78 \\
\hline
\end{tabular}

Table 6-4b Comparison of Elementary School Trip Rates per Student with ITE (1997)

\begin{tabular}{|l||c|c|c||c|c||}
\hline \multirow{2}{*}{$\begin{array}{l}\text { Time } \\
\text { Period }\end{array}$} & \multicolumn{3}{c|}{ Trip Rate per Student } & \multicolumn{2}{c||}{ S.D./Average } \\
\cline { 2 - 6 } & WV (1999) & ITE (1997) & Sig Dif & WV (1999) & ITE (1997) \\
\hline \hline Weekday & 3.31 & 1.02 & Y & 0.53 & 1.05 \\
\hline AM Peak & 0.87 & 0.30 & Y & 0.53 & 1.87 \\
\hline PM Peak & 0.73 & 0.26 & Y & 0.52 & 2.04 \\
\hline \hline
\end{tabular}

Table 6-4c Comparison of Elementary School Trip Rates per 1000 SF GFA with ITE (1997)

\begin{tabular}{||c||c|c|c||c|c||}
\hline \multirow{2}{*}{$\begin{array}{l}\text { Time } \\
\text { Period }\end{array}$} & \multicolumn{2}{|c|}{ Trip Rate per 1000 SF GFA } & \multicolumn{2}{c||}{ S.D./Average } \\
\cline { 2 - 4 } & WV (1999) & ITE (1997) & Sig Dif & WV (1999) & ITE (1997) \\
\hline \hline Weekday & 26.33 & 12.03 & Y & 0.37 & 0.58 \\
\hline AM Peak & 6.90 & 3.36 & Y & 0.33 & 0.72 \\
\hline PM Peak & 5.77 & 3.12 & Y & 0.30 & 0.75 \\
\hline \hline
\end{tabular}

All of the elementary schools studied were located in and around urban areas, none of the schools were located in remote or rural settings. In addition, there were many professional type jobs located in the vicinity of schools B, C, and D. When parents can tailor their schedule to coordinate dropping off and picking up their children, and the school can be conveniently accessed as part of the commute, "trip-chaining" occurs. That is, parents are able to drop their children off at school while on their way to work. This increased the trip rates for Sites B, C, and D. Site A was unique because it was located in an area with many work opportunities; however, there were more manufacturing jobs than professional jobs. Also, this area was becoming home to a significant number of commuters to Washington, D.C. Many of the parents who hold professional jobs and would normally keep the same hours as their children must leave 
earlier for work because of the commuting distance. This irregularity in work schedule is not conducive to delivering children to and from school. Thus, these children must either ride the bus or be taken to school by other parents.

Tables 6-4 a, b, and c provide a comparison of the variability of the sample, using the ratio of standard deviation to weighted average, for each time period to compare the differences between trip rate per employee, per student, and per 1000 SF GFA. Using ITE as a guide, the ratios for all the variables indicate that the average trip rates calculated for elementary schools are acceptable for use. For the weekday periods in this study, these ratios indicate that the trip rates per employee are slightly better than those for trips per 1000 SF GFA and trips per student.

In comparing this study's standard-deviation-to-weighted-average ratio with ITE's data, this study's ratios are consistently better than ITE's ratios during every time period. In the cases of am peak and pm peak, the ITE data produces ratios which are greater than 1.10; meaning that the ITE results are not good according to their definition. The smaller ratios for this study were probably due to the fact that the schools in this study had two common characteristics in that they were all consolidated and located in suburban areas. All of the schools were also governed by the same state board of education. In contrast, the ITE database represents a wide variety of elementary schools from all over the U.S. and Canada. This likely led to their higher standard-deviation-toweighted-average ratio.

Table 6-5 presents the Elementary School data with the exclusion of Site B compared to ITE (1974). As expected, the trip rates for this study were higher than the 1997 ITE data. 
Table 6-5 Comparison of 1999 Elementary Schools Excluding Site B with ITE

\begin{tabular}{||l||c|c||c|c||c|c||}
\hline \multirow{3}{*}{ Time Period } & \multicolumn{2}{|c|}{ Trip Rate per Employee } & \multicolumn{2}{c||}{ Trip Rate per Student } & \multicolumn{2}{c||}{ Trip Rate per 1000 SF GFA } \\
\cline { 2 - 7 } & $1999 \mathrm{WV}$ & $1997 \mathrm{ITE}$ & $1999 \mathrm{WV}$ & $1997 \mathrm{ITE}$ & $1999 \mathrm{WV}$ & 1997 ITE \\
\hline Weekday & 25.50 & 13.13 & 2.87 & 1.02 & 24.72 & 12.03 \\
\hline AM Peak & 6.62 & 3.71 & 0.74 & 0.30 & 6.42 & 3.36 \\
\hline PM Peak & 5.57 & 3.50 & 0.63 & 0.26 & 5.40 & 3.12 \\
\hline
\end{tabular}

The rates in the 1974 West Virginia Special Generators Study (Neumann and Deshpande, 1974), are significantly lower than the 1999 study for the weekday, am peak, and pm peak in all cases. Table 6-6 shows how this study's results compare with the 1974 results. The results for this study are up to $1088 \%$ greater than the 1974 results. It should be noted that the 1974 study had a small sample size of two elementary schools, which were located in sparsely populated areas of the state. Also, it should be noted that the elementary schools in the 1974 study were not consolidated schools.

Table 6-6 Comparison of 1999 Study Results with 1974 Study for Elementary Schools

\begin{tabular}{||l||c|c||c|c||c|c||}
\hline \multirow{3}{*}{ Time Period } & \multicolumn{2}{|c|}{ Trip Rate per Employee } & \multicolumn{2}{c||}{ Trip Rate per Student } & \multicolumn{2}{c||}{ Trip Rate per 1000 SF GFA } \\
\cline { 2 - 7 } & $1999 \mathrm{WV}$ & $1974 \mathrm{WV}$ & $1999 \mathrm{WV}$ & $1974 \mathrm{WV}$ & $1999 \mathrm{WV}$ & $1974 \mathrm{WV}$ \\
\hline Weekday & 26.96 & 5.55 & 3.31 & 0.43 & 26.33 & 6.75 \\
\hline AM Peak & 7.06 & 1.03 & 0.87 & 0.08 & 6.90 & 1.25 \\
\hline PM Peak & 5.90 & 0.94 & 0.73 & 0.07 & 5.77 & 1.14 \\
\hline
\end{tabular}

\subsubsection{Confidence Interval for Elementary Schools}

Using the weekday rate, the standard deviation of 9.01 trips per employee and the average number of employees of 67 , yields a $67 \%$ confidence interval of $+/-604$ vehicles per day. Using the same logic, Table 6-7 represents the confidence intervals for elementary schools. The confidence intervals are quite large, and the inclusion of Elementary School A which yielded lower trip rates than the other three schools could impact the results of traffic impact studies. Therefore, it is advisable to determine, based on location of the school, whether the school will more closely resemble Site A or the 
other schools in the database. That is, the planner or engineer should make an assessment about whether the school location will be conducive to trip-chaining. The trip rate can then be adjusted either upwards or downward as appropriate.

Table 6-7 Confidence Intervals for Elementary Schools

\begin{tabular}{|c|c|c|c|}
\hline & \multicolumn{3}{|c|}{ Vehicles per Day } \\
\hline Time Period & \begin{tabular}{|c} 
Confidence Interval \\
per Employee
\end{tabular} & $\begin{array}{c}\text { Confidence Interval per } \\
\text { Student }\end{array}$ & $\begin{array}{c}\text { Confidence Interval per } \\
1000 \text { SF GFA }\end{array}$ \\
\hline Weekday & $+/-604$ & $+/-954$ & $+/-665$ \\
\hline AM Peak & $+/-142$ & $+/-251$ & $+/-156$ \\
\hline PM Peak & $+/-121$ & $+/-203$ & $+/-117$ \\
\hline
\end{tabular}

\subsubsection{Regression Results of Elementary Schools}

The ITE format graphs for Elementary Schools, located in Appendix II, provide linear and logarithmic regression equations for each time period. Appendix V contains the 1999 data points plotted on the ITE (1997) graphs. Table 6-8 compares the coefficient of determination $\left(\mathrm{R}^{2}\right)$ values for trips per employee, trips per student, and trips per 1000 SF GFA for this study. According to ITE, $\mathrm{R}^{2}$ values greater than 0.5 can be reported and those greater than 0.75 can be considered "good." By examining Table 6-8, it is clear that no $\mathrm{R}^{2}$ values are considered "good" by ITE's definition. As discussed previously, this lack of correlation can be attributed to the great variation between the trip rates of Sites B and D even though they have approximately the same socio-economic variables. Another factor that may have affected the regression equations and $\mathrm{R}^{2}$ values would be the small sample size. A small number of observations gives the regression line a lack of direction and therefore results in poor $\mathrm{R}^{2}$ values.

It should be noted that the sample size for elementary schools is less than six sites. Therefore, according to ITE criteria, the regression results would not be reported regardless of the $\mathrm{R}^{2}$ value. The regression information is presented for information 
purposes only. In the ITE database, only one case, weekday trips per student, had a

reportable $\mathrm{R}^{2}$ value. That value is 0.61 . All other values for the ITE database are below 0.50 and therefore not reported.

Table 6-8 Coefficient of Determination Values from 1999 WV Study for Elementary Schools

\begin{tabular}{||l||c|c||c|c||c|c||}
\hline \multirow{2}{*}{\multicolumn{1}{|c||}{}} & \multicolumn{2}{c||}{ Trip Rate per Employee } & \multicolumn{2}{c||}{ Trip Rate per Student } & \multicolumn{2}{c||}{ Trip Rate per 1000 SF GFA } \\
\cline { 2 - 7 } & Linear & Logarithmic & Linear & Logarithmic & Linear & Logarithmic \\
\hline Time Period & 0.05 & 0.03 & 0.05 & 0.01 & 0.03 & 0.02 \\
\hline Weekday & 0.06 & 0.04 & 0.04 & 0.01 & 0.05 & 0.03 \\
\hline PM Peak & 0.31 & 0.17 & 0.18 & 0.04 & 0.37 & 0.20 \\
\hline \hline
\end{tabular}

\subsubsection{Peaking Characteristics of Elementary Schools}

Table 6-9 presents the " $\mathrm{K}$ " values by day of the week for each of the sites, and a weighted average " $\mathrm{K}$ " value for the elementary schools. The " $\mathrm{K}$ " values calculated from this data set range from $0.17-0.28$. The weekday averages were 0.21 for the pm peak and 0.25 for the am peak. As with any type of school, higher "K" values were expected because of the nature of a school, having definite peaks for the am and pm. This study produced smaller "K" values than expected for the peak hours. However, after reviewing the raw data, it was noticed that each school had high traffic volumes in the hours preceding and following what is considered the peak hour. There was also a high traffic volume around the noon hour for kindergarten dismissal and arrival. It was concluded that the peak traffic volumes at elementary schools typically span more than one hour. Table 6-9 "K" Values for Elementary Schools

\begin{tabular}{||c||c|c||}
\hline \hline Site & AM Peak & PM Peak \\
\hline \hline A & 0.28 & 0.22 \\
\hline B & 0.27 & 0.22 \\
\hline C & 0.21 & 0.24 \\
\hline D & 0.25 & 0.17 \\
\hline Weighted Average & 0.25 & 0.21 \\
\hline
\end{tabular}


The weekday peak hours for elementary schools were similar. The am peak for sites $\mathrm{A}$ and $\mathrm{C}$ occurred between 8am and 9am and their pm peak was between $3 \mathrm{pm}$ and $4 \mathrm{pm}$. On the other hand, Sites B and D had their am peak from 7am to $8 \mathrm{am}$ and the pm peak between $2 \mathrm{pm}$ and $3 \mathrm{pm}$. Since the peaking characteristics of elementary schools are defined by students and employees arriving or leaving school, the peak volume hours can easily be predicted by determining the school start and dismissal times.

\subsubsection{Heavy Vehicle Traffic at Elementary Schools}

It should be noted that there was not significant truck traffic at elementary schools. School buses are the primary heavy vehicle that needs to be considered in design. Tables 6-10 and 6-11 present the bus trip data from each site studied.

All sites had students-per-bus ratios that were either at or just below the capacity of a bus which is 44 students. Site A had the highest number of buses and the lowest students-per-bus ratio. Although it is unknown whether the schools studied used only full-sized buses, this under-capacity could be attributed to the use of mini-buses which carry only 22 students. Sites C and D, which are located in the same county, have the highest number of buses compared to the other schools. It should be noted that Site C does not have mid-day buses because it does not have kindergarten classes.

Table 6-10 Number of Bus Trips at Elementary School by Time of Day

\begin{tabular}{||c||c|c|c||}
\hline \multicolumn{1}{|c||}{ Site } & \multicolumn{3}{c||}{ Number of Bus Trips } \\
\cline { 2 - 4 } & AM & Mid-Day & PM \\
\hline \hline A & 20 & 5 & 20 \\
\hline B & 9 & 6 & 11 \\
\hline C & 17 & 0 & 17 \\
\hline D & 17 & 2 & 17 \\
\hline
\end{tabular}


Table 6-11 Number of Students per Bus at Elementary Schools

\begin{tabular}{||c||c|c||}
\hline \multirow{2}{*}{\multicolumn{1}{|c||}{ Site }} & \multicolumn{2}{c||}{ Students per Bus Trip } \\
\cline { 2 - 3 } & AM & PM \\
\hline \hline A & 26 & 26 \\
\hline B & 35 & 29 \\
\hline C & 44 & 44 \\
\hline D & 34 & 34 \\
\hline \hline Average & 35 & 33 \\
\hline
\end{tabular}

\subsubsection{Recommendations for Use of Elementary School Rates}

The results for elementary schools in this study are considerably different than ITE's results. For new schools, the size of the building is usually the known factor and will generally be used in traffic impact studies and design. For new West Virginia facilities, the rates from this study should be used in lieu of ITE, with adjustments made to the average trip rate depending on what type of school is being planned. If the school is to be located in an area where people live close to where predominantly professional jobs are located, the trip rates will be higher because of trip-chaining. An estimate that is approximately equal to the weighted average trip rate (excluding Site B) is appropriate. If there is a mix of job types such as mining, manufacturing, and limited professionaltype jobs, an estimate that is approximately one-half of this study's weighted average trip rate (excluding Site B) would provide a good estimate of the trip rate.

ITE's Trip Generation (1997) sets guidelines in selecting equations and average trip rates to be used for planning purposes. This study includes linear regression equations and logarithmic regression equations in Appendix II. However, because of the low sample size and poor correlation, neither of these should be selected for use under any circumstance. 


\section{Chapter 7. Results for Combined Consolidated School Sites}

\subsection{Introduction}

Traffic data were collected at three combined school sites. As mentioned in Chapter 2, a combined consolidated school site is a consolidated school site that contains more than one school type in either the same building or different buildings on the same campus. For example, a combined consolidated school site is the combination of an elementary school and middle school. Each site is briefly described below.

\subsection{Combined Consolidated School Sites Studied}

Combined School Site A - The site consisted of a middle school and a high school and was formed by the consolidation of all middle schools and high schools in the county. This combined school site was located in central West Virginia in a county with an area of 511 square miles. Both the middle school and high school served the entire county. This site was interesting in that each school had a separate building, on a single campus. Because of the sparse population of the county, most students either rode the bus or found other vehicular means of transportation. Students were permitted to drive to school. Combined School Site B - This single-building school consisted of a middle school and high school and was located in the north-central part of the state. It was formed by the consolidation of all middle schools and high schools in the county. This school was located in a county with an area of 452 square miles. Because of its rural location, most students either rode the bus or found other vehicular means of transportation. Students were permitted to drive to school.

Combined School C - This single-building school consisted of an elementary school and a middle school and was located in the eastern part of the state. It was formed by the 
consolidation of all elementary schools and middle schools in the county, which had an area of 417 square miles. Because of its rural location, children were either bused to school or dropped off by parents.

To facilitate a comparison among the three combined consolidated school sites studied, Table 7-1 provides the SEVs and parking information collected at each school.

Table 7-1 Comparison of SEV by Combined School Site

\begin{tabular}{|c|c|c|c|c||}
\hline Combined School & Employees & Students & 1000 SF GFA & Parking Spaces \\
\hline $\mathrm{A}-\mathrm{MS} / \mathrm{HS}$ & 148 & 1533 & 193 & 280 \\
\hline $\mathrm{B}-\mathrm{MS} / \mathrm{HS}$ & 90 & 1012 & 87 & 200 \\
\hline $\mathrm{C}-\mathrm{ES} / \mathrm{MS}$ & 63 & 564 & 64 & 80 \\
\hline
\end{tabular}

\subsubsection{Average Rates for Combined Consolidated School Sites}

The average trip rates and standard deviations for the three sites are shown in Tables 7-2a, 7-2b, and 7-2c. Since sites A and B were both middle-high school combinations, it was expected that they would have similar trip rates. In fact, sites $\mathrm{A}$ and B had similar weekday, am peak, and pm peak trip rates for "per employee" and "per student." However, there were noticeable differences in the trip rates "per 1000 SF GFA.” This was likely caused by the fact that Site A had a separate building for each school, while at site B both schools occupied a single building. In order to alleviate traffic congestion, Site B's middle school and high school did not have the same start time and dismissal times. This led to the lower peak rates because the peaks were spread out over a few hours. 
Table 7-2a Comparison of Average Trip Rate per Employee for Combined School Sites

\begin{tabular}{||c|c||c|c|c||}
\hline \multirow{2}{*}{ Site-School Type } & \multirow{2}{*}{ Employees } & \multicolumn{3}{c||}{ Average Trip Rate per Employee } \\
\hline & & Weekday & AM Peak & PM Peak \\
\hline \hline A - MS/HS & 148 & 21.54 & 3.36 & 2.49 \\
\hline B - MS/HS & 90 & 19.47 & 4.97 & 3.15 \\
\hline C - ES/MS & 63 & 16.16 & 5.96 & 2.31 \\
\hline \hline \multicolumn{2}{|r|}{ Weighted Average } & 19.80 & 4.38 & 2.65 \\
\hline \multicolumn{2}{|r|}{ Standard Deviation } & 2.71 & 1.31 & 0.44 \\
\hline
\end{tabular}

Table 7-2b Comparison of Average Trip Rate per Student for Combined School Sites

\begin{tabular}{||c|c||c|c|c||}
\hline \multirow{2}{*}{ Site-School Type } & \multicolumn{1}{|c||}{ Students } & \multicolumn{3}{c||}{ Average Trip Rate per Student } \\
\hline & & Weekday & AM Peak & PM Peak \\
\hline \hline A - MS/HS & 1533 & 2.08 & 0.32 & 0.24 \\
\hline B - MS/HS & 1012 & 1.73 & 0.44 & 0.28 \\
\hline C - ES/MS & 564 & 1.80 & 0.67 & 0.26 \\
\hline \hline \multicolumn{2}{||r|}{ Weighted Average } & 1.92 & 0.42 & 0.26 \\
\hline \multicolumn{2}{|r|}{ Standard Deviation } & 0.18 & 0.17 & 0.02 \\
\hline
\end{tabular}

Table 7-2c Comparison of Average Trip Rate per 1000 SF GFA for Combined School Sites

\begin{tabular}{||c|c||c|c|c||}
\hline \hline \multirow{2}{*|}{ Site-School Type } & \multicolumn{1}{|c||}{1000 SF GFA } & \multicolumn{3}{c||}{ Average Trip Rate per 1000 SF GFA } \\
\hline & & Weekday & AM Peak & PM Peak \\
\hline \hline A - MS/HS & 193 & 16.52 & 2.58 & 1.91 \\
\hline B - MS/HS & 87 & 20.26 & 5.17 & 3.28 \\
\hline C - ES/MS & 64 & 15.99 & 5.90 & 2.29 \\
\hline \hline \multicolumn{2}{|c|}{ Weighted Average } & 17.36 & 3.85 & 2.33 \\
\hline \multicolumn{2}{|c|}{ Standard Deviation } & 2.33 & 1.75 & 0.71 \\
\hline
\end{tabular}


As mentioned previously, Site C consisted of an elementary school and middle school. This site was inherently different than Site A and B because students were not driving, but instead were more likely to be driven to school by parents. In general, daily trip rates were lower than Sites A and B while the peaks were slightly higher to approximately the same.

Compared to other types of schools, there were no noticeable differences in the amount of traffic in the evenings. This would indicate that the schools were not used more for after-hour activities such as public meetings or other types of activities. In general, the traffic was less than expected during after-school hours.

Weekend trip rates were calculated for Site B. The weekend trip rates were significantly lower than the weekday rates. The typical weekend traffic was at most $15 \%$ of the weekday traffic. Thus, weekend traffic was considered negligible.

Table 7-3 presents the student-per-teacher ratios and the student-to-1000-SF GFA ratio for each site. The most important differences noted were be between Sites A and B since they served the same school grades. Sites A and B had similar student-to-teacher ratios, however, the student-to-1000-SF GFA ratio was significantly different. Remembering that Site A had two buildings and Site B has one building, the gross floor area of Site A was much larger than Site B. This would make the "per 1000 SF GFA" rates low, if all else were equal. This could perhaps explain why the "per employee" and "per student" rates for Site A are slightly higher than Site B.

Table 7-3 Comparison of Student/Employee and Students/1000 SF Ratios for Combined School Sites

\begin{tabular}{||c||c|c||}
\hline Site & Student/Employee Ratio & Student/1000 SF Ratio \\
\hline \hline A & $10.4: 1$ & $7.9: 1$ \\
\hline B & $11.2: 1$ & $11.7: 1$ \\
\hline C & $9.0: 1$ & $8.9: 1$ \\
\hline
\end{tabular}




\subsubsection{Comparison with Other School Types and Databases}

In order to relate the combined school sites with other school types, such as elementary, middle, and high school, the combination school data points were plotted along with the other school types results on the ITE . For instance, Site C (an elementary school and middle combination school was plotted on both the elementary school plots and middle school plots located in Appendix VI. Likewise, Sites A and B were plotted on both the middle school and high school plots. These plots are located in Appendix VII.

In comparing Site $\mathrm{C}$ with elementary schools, it was evident that the rates for the combined school sites were higher than the ITE (1997) average for both the weekday and am peak time periods; while the pm peak was slightly lower than ITE except for the "per student" trip rate. Compared to the 1999 WV data, Site C had fewer trips than the elementary school weighted averages. In comparison with the middle schools, Site C was greater than the ITE average for the weekday and am peak in all categories and lower than the ITE average for the pm peaks. When comparing the 1999 data to the combined consolidated school site data, Site C, no differences were noted with the middle school data.

For new facilities, the socio-economic variable 1000 SF GFA should be used for determining the trip rate. If the ITE elementary schools rates were used for design, a rate slightly higher than ITE should be used for weekday and am peak. A slightly lower rate should be used for the pm peak. Table 7-4 compares the consequences of using $1000 \mathrm{SF}$ GFA rates from related land uses to predict traffic for Site C. 
Table 7-4 Consequences of Using 1000 SF GFA Rates from Related Land Uses for Predicting Traffic for Site C

\begin{tabular}{||c||c|c|c||}
\hline \multicolumn{1}{|c||}{ Related Land Use } & \multicolumn{3}{c||}{ Error } \\
\cline { 2 - 4 } & Weekday & AM Peak & PM Peak \\
\hline \hline Elementary Schools ITE & 250 too low & 100 too low & 52 too high \\
\hline Middle Schools ITE & 256 too low & 140 too low & 10 too low \\
\hline Elementary Schools WVSG & 651 too high & 63 too high & 219 too high \\
\hline Middle Schools WVSG & 163 too high & 91 too high & No error \\
\hline
\end{tabular}

As a result of this analysis, it is recommended that elementary-middle school combination sites be estimated using the ITE data for middle schools. Also, it should be noted that the ITE graphs for middle schools show four data points that are unlike the other points. These points have a higher number of trips than the rest of the data points and thus caused the average rate line to be "pulled" closer to those points. It was noticed that the combination school point was more like the typical points on the middle school graphs.

In comparing Sites A and B to middle schools, it was evident that the average rate for middle/high combination schools was about the same as the ITE for "per student" and "per employee." The combination school rates were much higher for the "1000 SF GFA" category. It was also noted that the ITE average was almost equal to the 1999 middle school results. When comparing the combination sites with the 1999 high school data, it was noticed that the averages were approximately the same for the weekday and am peak time periods and slightly lower for the pm peaks for both the ITE data and the 1999 high school data. Table 7-5 compares the consequences of using 1000 SF GFA rates from related land uses to predict traffic for Sites A and B. 
Table 7-5 Consequences of Using 1000 SF GFA Rates from Related Land Uses for Predicting Traffic for Sites A and B

\begin{tabular}{||c||c|c|c||}
\hline \multicolumn{1}{|c||}{ Related Land Use } & \multicolumn{3}{c||}{ Error } \\
\cline { 2 - 4 } & Weekday & AM Peak & PM Peak \\
\hline \hline Middle Schools ITE & 806 too low & 42 too high & 15 too high \\
\hline High Schools ITE & 617 too low & 32 too low & 18 too low \\
\hline Middle Schools WVSG & 600 too low & 150 too high & 6 too low \\
\hline High Schools WVSG & 602 too low & 31 too low & 7 too high \\
\hline
\end{tabular}

As a result of this analysis, it was concluded that high schools would be a better predictor of middle-high school trip rates. Since the 1999 WV results for consolidated high schools are very similar to the ITE results, the ITE database should be used for future predictions. Because of the small sample sizes and dated results, the Neumann and Deshpande (1974) research should not be used for combined consolidated sites.

\subsubsection{Peaking Characteristics of Combined School Sites}

Table 7-6 represents the "K" values by weekday for each of the sites, and a weighted average " $K$ " value for the combined school sites. The " $K$ " values calculated from this data set ranged from $0.12-0.37$. The weekday averages were 0.22 for the am peak and 0.13 for the pm peak. The "K" values for Site A were especially small and as mentioned previously, this was caused by the staggered arrival/dismissal times at each school. This spreads the peak traffic over more than one hour, thus reducing the "K" value or percentage of daily traffic occurring during the peak period.

Students and employees arrive and depart at approximately the same times on a daily basis and there is typically not much traffic between the peak hours except for visitors and deliveries. This study produced smaller " $\mathrm{K}$ " values than expected for the peak hours when compared to the typical ITE "K" values for schools. However, after reviewing the raw data, it was noticed that each school had high traffic volumes in the 
hours preceding and following what is considered the peak hour. So, it should be noted that the peak traffic volumes at combined school sites typically span more than one hour. Table 7-6 "K" Values for Combined Schools

\begin{tabular}{||c||c|c||}
\hline Site & AM Peak & PM Peak \\
\hline \hline A & 0.16 & 0.12 \\
\hline B & 0.26 & 0.16 \\
\hline C & 0.37 & 0.14 \\
\hline Weighted Average & 0.22 & 0.13 \\
\hline
\end{tabular}

The am weekday peak hour was 7-8 am for each site and the pm peak hour was 3$4 \mathrm{pm}$. Since the peaking characteristics of schools are defined by students and employees arriving or leaving school, the peak volume hours can easily be predicted by determining the school start and dismissal times.

\subsubsection{Heavy Vehicle Traffic at Combined School Sites}

As with the other types of schools, significant truck traffic was not expected at the combined schools. School buses are the primary heavy vehicle that needs to be considered in design. Tables 7-8 and 7-9 present the bus trip data from each site.

Sites A and C had students-per-bus ratios that were below the 44-student capacity of a bus. Site B had a ratio of 56 students per bus. However, it should be noted that some of the students may not be riding the bus in the am and pm because of the county's vo-tech program. In conjunction with students driving to school, the ratio would be higher because some students do not ride the bus and use other means of transportation. Table 7-7 Number of Bus Trips at Combined School Sites by Time of Day

\begin{tabular}{||c||c|c|c||}
\hline \multirow{2}{*}{\multicolumn{1}{|c||}{ Site }} & \multicolumn{3}{c|}{ Number of Bus Trips } \\
\cline { 2 - 4 } & AM & Mid-Day & PM \\
\hline \hline A & 36 & --- & 36 \\
\hline B & 18 & 4 & 18 \\
\hline C & 14 & 2 & 14 \\
\hline
\end{tabular}


Table 7-8 Number of Students per Bus Trip at Combined School Sites

\begin{tabular}{||c||c|c||}
\hline \multirow{2}{*}{ Site } & \multicolumn{2}{c|}{ Students per Bus Trip } \\
\cline { 2 - 3 } & AM & PM \\
\hline \hline A & 43 & 43 \\
\hline B & $\mathbf{5 6}$ & $\mathbf{5 6}$ \\
\hline C & 40 & 40 \\
\hline \hline Average & $\mathbf{4 6}$ & $\mathbf{4 6}$ \\
\hline
\end{tabular}

\subsubsection{Recommendations for Use of Combined School Site Rates}

In this study, one elementary/middle school and two middle/high school sites were studied. As such, this sample size is too small to make general conclusions about combined consolidated schools. This analysis focused on the consequences, in terms of traffic projection errors, that would have resulted from using related school land uses as a surrogate for the combined school. It was determined that in these particular cases, the 1000 SF GFA ITE rates for middle schools should be used, but for weekday and am peak period, a higher rate should be used. For middle/high school combinations, ITE rates for high schools should be used for estimating trip rates, but for the weekday time periods, a higher number should be used. 


\section{Chapter 8. Overall Comparison of Consolidated Schools}

\subsection{Comparison of Consolidated School Types}

Tables 8-1a, b, and c present a comparison between school type and trip rate for consolidated schools. When comparing among types of schools, it was noticed that elementary schools had the highest trip rates in all cases and time periods. In the cases of per employee and per 1000 SF GFA, the differences between elementary schools and the other school types were substantial. In the per student and per 1000 SF GFA cases, high schools, middle schools, and combined school sites had similar rates for each time period. However, the per employee rates were different for high schools, middle schools, and combined school sites. For the weekday and pm peak, the consolidated high schools had higher trip rates than middle schools and combined school sites. This difference can be attributed to the fact that students were able to drive to school. This would increase the number of trips and thus the trip rate. Another factor would be that high schools have more extra-curricular activities. 
Table 8-1a Comparison of Consolidated School Weekday Trip Rates by School Type

\begin{tabular}{|c|c|c|c|}
\hline & \multicolumn{3}{|c|}{ Weekday Trip Rate } \\
\hline School Type & per Employee & per Student & per 1000 SF GFA \\
\hline High School & 24.58 & 1.97 & 13.38 \\
\hline Middle School & 16.68 & 1.71 & 13.41 \\
\hline Elementary School & 26.96 & 3.31 & 26.33 \\
\hline Elem (w/o Site B) & 25.50 & 2.87 & 24.72 \\
\hline Combined School & 19.80 & 1.92 & 17.38 \\
\hline
\end{tabular}

Table 8-1b Comparison of Consolidated School AM Peak Trip Rates by School Type

\begin{tabular}{|c|c|c|c|}
\hline & \multicolumn{3}{|c|}{ Am Peak Trip Rate } \\
\hline School Type & per Employee & per Student & per 1000 SF GFA \\
\hline High School & 5.94 & 0.46 & 3.16 \\
\hline Middle School & 5.54 & 0.57 & 4.45 \\
\hline Elementary School & 7.06 & 0.87 & 6.90 \\
\hline Elem (w/o Site B) & 6.62 & 0.74 & 6.42 \\
\hline Combined School & 4.38 & 0.42 & 3.85 \\
\hline
\end{tabular}

Table 8-1c Comparison of Consolidated School PM Peak Trip Rates by School Type

\begin{tabular}{|c|c|c|c|}
\hline & \multicolumn{3}{|c|}{ PM Peak Trip Rate } \\
\hline School Type & per Employee & per Student & per 1000 SF GFA \\
\hline "High School & 4.50 & 0.35 & 2.39 \\
\hline Middle School & 2.78 & 0.29 & 2.30 \\
\hline Elementary School & 5.90 & 0.73 & 5.77 \\
\hline Elem (w/o Site B) & 5.57 & 0.63 & 5.40 \\
\hline Combined School & 2.65 & 0.26 & 2.33 \\
\hline
\end{tabular}

As previously mentioned, the ratios of students per employee and students per

1000 SF GFA can provide insight to the differences in trip rates among the school types.

Table 8-2 compares the students-per-employee and students-per-1000 SF ratios. As expected, elementary schools had the lowest student to employee ratios when compared to the other school types. This can be attributed to the typical small class size and nurturing nature of an elementary school. Also as expected, high schools and combined school sites (which consist of two middle/high school combinations) had high student per 
employee ratios. In general, as students go to higher grade levels, the student per employee ratio becomes larger. Another point to note is that as students move to a different category of school, the trend indicated that there are less students per building area. The elementary schools had the highest student/1000 SF ratio because of the typical types of facilities. Elementary schools typically have classrooms, offices, a cafeteria, and gymnasium. However, as students get older, their educational needs change and thus there may be other rooms such as band rooms, auditoriums, and swimming pools.

Table 8-2 Comparison of Students/Employee and Students/1000 SF Ratios for Consolidated Schools

\begin{tabular}{||c||c|c||}
\hline School Type & Student/Employee Ratio & Student/1000 SF Ratio \\
\hline \hline High School & $12.6: 1$ & $6.4: 1$ \\
\hline High (w/o Sites B and C) & $13.5: 1$ & $6.7: 1$ \\
\hline Middle School & $9.7: 1$ & $7.9: 1$ \\
\hline Elementary School & $8.0: 1$ & $7.9: 1$ \\
\hline Elem (w/o Site B) & $8.8: 1$ & $8.7: 1$ \\
\hline Combined School & $10.2: 1$ & $9.5: 1$ \\
\hline
\end{tabular}

\subsection{Parking Characteristics of Consolidated Schools}

The parking characteristics were of interest to give a better understanding for the driving and parking situation at each school. The fundamental relationship between parking and trip generation can be explained as when parking is provided at a site, trips will be generated at that site. The data collected about parking characteristics included the number of parking spaces and driving policy. In addition to these items, some principals were able to give more detailed information about the number of teacher drivers and car-poolers and the number of student drivers.

Tables 8-3a, b, c, and d present the parking characteristics of each type of consolidated school studied. As indicated in Table 8-3a, high schools had enough 
parking to accommodate employees. Also, there were extra spaces to accommodate visitors and some student drivers. As mentioned previously, Site F does not permit students to drive to school and thus does not need extra spaces to accommodate student drivers. High School Site C was unable to provide parking information and thus was not in Table 8-3a. When compared to the other types of schools, the tables indicated that there was more extra parking available at the high schools studied. This may be due to the need for extra parking for activities such as football games, vo-tech, and Magnet programs. For the middle schools, the data indicated that Site A did not have enough parking for teachers. As with middle schools, elementary schools provided enough parking for the employees and visitors. For the combined school sites, Sites A and B were middle/high school combinations and students were permitted to drive. Combined Site $\mathrm{C}$ was an elementary/middle school combination and had a few spaces in excess of those needed for employees.

In general, high school type sites, whether purely high school or a combination of middle and high schools, need enough parking to accommodate employees, some student drivers, and reoccurring extra-curricular activities such as football games or community meetings. In contrast, middle and elementary schools do not need as many parking spaces as high schools. The need is based on the number of employees and visitors at the school. 
Table 8-3a Parking Characteristics of High Schools

\begin{tabular}{|c|c|c|c|c|}
\hline High School & Employees & Students & Parking Spaces & Student Drivers? \\
\hline Site A & 73 & 1237 & 236 & Y \\
\hline Site B & 49 & 440 & 150 & Y \\
\hline Site D & 120 & 1964 & 703 & Y \\
\hline Site E & 202 & 2030 & 659 & Y \\
\hline Site F & 86 & 1172 & 92 & N \\
\hline Site G & 94 & 1006 & 431 & Y \\
\hline
\end{tabular}

Table 8-3b Parking Characteristics of Middle Schools

\begin{tabular}{|c|c|c|c|}
\hline Middle School & Employees & Students & Parking Spaces \\
\hline Site A & 53 & 400 & 50 \\
\hline Site B & 60 & 700 & 70 \\
\hline
\end{tabular}

Table 8-3c Parking Characteristics of Elementary Schools

\begin{tabular}{|c|c|c|c|}
\hline Elementary School & Employees & Students & Parking Spaces \\
\hline Site A & 65 & 529 & 100 \\
\hline Site B & 58 & 317 & 80 \\
\hline Site C & 78 & 750 & 100 \\
\hline Site D & 65 & 570 & 70 \\
\hline
\end{tabular}

Table 8-3d Parking Characteristics of Combined School Sites

\begin{tabular}{|c|c|c|c||}
\hline Combined School & Employees & Students & Parking Spaces \\
\hline Site A & 148 & 1533 & 280 \\
\hline Site B & 90 & 1012 & 200 \\
\hline Site C & 63 & 564 & 80 \\
\hline
\end{tabular}




\section{Chapter 9. Conclusions and Recommendations}

\subsection{Conclusions}

The overall goal of this research was to study the trip generation characteristics of consolidated schools in West Virginia and to develop trip rates for three consolidated school types - high schools, middle schools, and elementary schools. However, a fourth school type was added to the study, combined consolidated school sites. As mentioned previously, the definition used for consolidated schools specific to West Virginia was a public school recently formed from the combination of other schools of the same type or a county-wide school. A combined consolidated school can be defined as a consolidated school site that is attended by students from more than one school type. A combined consolidated school can be housed in either one building or separate buildings located on one campus. Consolidated schools are inherently different from traditional schools because of the consolidation of resources, buildings, teachers, and students.

After reviewing the existing literature, it was found that no trip rates for consolidated schools existed and that the West Virginia trip rates determined by Neumann and Deshpande (1974) were out-dated. Although ITE (1997) provided current trip rates for schools, the trip rates were developed from many types of schools and locations throughout the United States and Canada and not necessarily consolidated schools. With the ever-decreasing school-age population in West Virginia, the number of counties considering consolidating schools is increasing and current trip rates are needed.

In total, sixteen different schools in West Virginia were examined. At each school, machine counts were performed and socio-economic information was collected. Of the sixteen sites studied, seven were high schools, two were middle schools, four were 
elementary schools, one was an elementary-middle school combination, and two were middle-high school combinations. The socio-economic variables collected were number of employees, number of students, and gross floor area of the building. In addition to the independent variables, information on the number of parking spaces available on-site, number of daily bus trips, and re-occurring events at each facility were collected. Manual counts of heavy vehicles were collected at six schools. As a result of this pilot study, it was concluded that schools generated a negligible amount of heavy commercial traffic. The heavy vehicle of primary interest was the school bus.

After the data were collected, site trip rates, weighted average trip rates, and regression analysis were analyzed for each land use. Also, the data were plotted in the traditional ITE format graph. These plots were generated for each socio-economic variable and time period studied with the exception of middle schools which had only two observations.

The range of weekday trip rates for consolidated high schools was 4.61-34.57 trips per employee, 0.51-3.23 trips per student, and 2.58-16.25 trips per 1000 SF GFA. Table 9-1 compares the weighted trip rates with ITE's Trip Generation (1997) for High Schools. As noticed in the table, the 1999 West Virginia rates developed in this study are higher than ITE's rates, with the exception of trip rate per student on a weekday where the two rates are equal. The high school rates were developed from the data collection of seven consolidated schools. The conclusion of the consolidated high school analysis was that the 1999 West Virginia data are appropriate for use in the planning and design of parking and access for future consolidated high schools. This conclusion was based on the acceptable $\mathrm{R}^{2}$ values, small standard deviation to average ratios, and low standard 
deviations. It is important that proposed schools be classified properly and these rates should only be used when the school is classified as a consolidated high school. In addition to the proper classification, special attention should be paid to whether the school is a county-wide school, located in a rural area, and if the school serves community functions. If the school is a county-wide school located in a rural area, the trip rate used should be lower than the average trip rate developed in this study. In the case of a consolidated school in an urban area and which serves community functions, a slightly higher rate than the average developed in this study should be used. With the exception of one school that did not permit student drivers, these rates were developed from schools permitting students to drive to school. If it is known that a new consolidated high school will not permit students to drive to campus, then the trip rate developed from this study should be reduced to account for this policy. The extent to which the rates are raised or lowered should be decided on a case-by-case basis depending on the local conditions.

This study yielded both quality equations, having acceptable $\mathrm{R}^{2}$ values of greater than 0.50 , and average trip rates with small standard deviations. ITE's Trip Generation (1997) contains guidance in selecting between them when both are available. As pointed out earlier, either can be used, but the results must be tailored to each particular school depending on its location and function.

Table 9-1 Comparison of This Study's Results with ITE for High Schools

\begin{tabular}{|c|c|c|c|c|c|c|}
\hline \multirow[b]{2}{*}{ Time Period } & \multicolumn{2}{|c|}{ Trip Rate per Employee } & \multicolumn{2}{|c|}{ Trip Rate per Student } & \multicolumn{2}{|c|}{ Trip Rate per 1000 SF GFA } \\
\hline & WV (1999) & ITE (1997) & WV (1999) & ITE (1997) & WV (1999) & ITE (1997) \\
\hline Weekday & 24.58 & 19.98 & 1.97 & 1.97 & 13.38 & 13.27 \\
\hline AM Peak & 5.94 & 4.68 & 0.46 & 0.42 & 3.16 & 3.15 \\
\hline PM Peak & 4.50 & 3.30 & 0.35 & 0.30 & 2.39 & 2.21 \\
\hline
\end{tabular}


Because of the small sample size for consolidated middle schools, neither the trip rates or the equations developed in this study should be used. For new consolidated middle school facilities, the rates presented in ITE's Trip Generation (1997) manual should be used. However, an adjustment for school-type should be made. If a countywide school is located in a predominately rural area, ITE's rate should be reduced by $25 \%$. In contrast, if a school is located in an urbanized area, a trip rate $50 \%$ higher than ITE should be used.

The range of weekday trip rates for consolidated elementary schools was 14.6034.92 trips per employee, 1.79-5.89 trips per student, and 14.47-36.61 trips per $1000 \mathrm{SF}$ GFA. Table 9-2 presents the results for consolidated elementary schools and indicates that the West Virginia rates were significantly different than the ITE (1997) rates. For new consolidated elementary school facilities, the 1999 West Virginia data should be used. However, adjustments should be made depending on the environment in which the school is being developed. Where trip-chaining is expected, a rate that is approximately equal to the weighted average trip rate (excluding Site B) developed in this study is appropriate. Where there is no significant trip-chaining, an estimate that is approximately one-half of this study's weighted average trip rate (excluding Site B) would be appropriate. Although this research produced quality trip rates, it is not advisable to use the equations developed because of the small sample size and poor $\mathrm{R}^{2}$ values.

Table 9-2 Comparison of 1999 Elementary Schools Excluding Site B with ITE

\begin{tabular}{||l||c|c||c|c||c|c||}
\hline \multirow{2}{*}{ Time Period } & Trip Rate per Employee & \multicolumn{2}{c||}{ Trip Rate per Student } & \multicolumn{2}{|c||}{ Trip Rate per 1000 SF GFA } \\
\cline { 2 - 7 } & $1999 \mathrm{WV}$ & 1997 ITE & $1999 \mathrm{WV}$ & $1997 \mathrm{ITE}$ & $1999 \mathrm{WV}$ & $1997 \mathrm{ITE}$ \\
\hline Weekday & 25.50 & 13.13 & 2.87 & 1.02 & 24.72 & 12.03 \\
\hline AM Peak & 6.62 & 3.71 & 0.74 & 0.30 & 6.42 & 3.36 \\
\hline PM Peak & 5.57 & 3.50 & 0.63 & 0.26 & 5.40 & 3.12 \\
\hline \hline
\end{tabular}


For combined consolidated schools, the sample size was too small to make general conclusions. This analysis focused on the consequences, in terms of traffic projection errors, that would have resulted from using related school land uses as a surrogate for the combined school. It was determined that, for elementary-middle consolidated combined school sites, if the ITE (1997) rates for middle schools based on the trips per 1000 SF GFA were used, the weekday and am peak period would have produced a smaller trip rate. For middle-high school combinations, if the ITE rates for high schools were used for estimating trip rates, the weekday time periods would have produced a smaller trip rate.

When comparing among types of schools, it was noticed that elementary schools had the highest trip rates in all cases and time periods. In the cases of per employee and per 1000 SF GFA, the differences between elementary schools and the other school types were substantial. In the per student and per 1000 SF GFA cases, high schools, middle schools, and combined schools had similar rates for each time period. However, the per employee rates were different for high schools, middle schools, and combined schools. For the weekday and pm peak, the consolidated high schools had higher trip rates than middle schools and combined schools. This difference can be attributed to the fact that students were able to drive to school. This would increase the number of trips and thus the trip rate. Another factor would be that high schools have more extra-curricular activities.

The peaking characteristics of the four types of consolidated schools were different than what was originally expected. For each type of school, higher "K" values were expected because of the nature of schools. Students and employees arrive and 
depart at approximately the same times on a daily basis and there is typically not much traffic expected between the peak hours except for deliveries and visitors. However, when reviewing the raw data, it was noticed that every school studied had high traffic volumes in the hours before and after what is considered the peak hour. In conclusion, it should be noted that the peak traffic period typically spans more than one hour.

Although the number of bus trips was not chosen as a socio-economic variable, an analysis of bus trip capacity was conducted. The conclusion of the bus trip analysis indicated that elementary schools, middle schools, and elementary-middle school sites typically did not have a students-per-bus ratio of over 44 with the exception of one middle school. However, this middle school was in an area where students were able to walk to school. In contrast, the high schools typically had students-per-bus ratios over 44. This was attributed to student drivers who did not use the bus service.

Similar to the number of bus trips, the parking characteristics of each site were not chosen as a socio-economic variable. The conclusions of the parking characteristics among the types of school were that each type of school offered enough parking spaces for employees and a few extra spaces for visitors. In addition to the employee and visitor parking at high schools, there were some extra spaces for student drivers or school functions such as football games. However, it was unknown if the high schools had enough parking on-site for every student driver and visitors for school functions.

\section{$9.2 \quad$ Recommendations}

Because of the small sample sizes for middle schools and combined school types, it is recommended that data be collected at additional sites to develop usable rates specifically for consolidated schools in West Virginia. Also, it would be desirable to 
collect data at sites in particular parts of the state for each type of school. Collecting trip generation data from consolidated high schools in the northern panhandle, eastern panhandle, and southern part of the state would be desirable. For consolidated middle schools, the eastern panhandle, northern panhandle, and central area of the state would be desirable. Additional consolidated elementary school trip generation data in the northern panhandle, central and southern areas of the state would be desirable. For consolidated combined schools, additional data collected in the eastern and northern panhandles and southern area of the state is recommended.

It is also recommended that a trip generation study be undertaken to determine if traditional schools in West Virginia are more similar to the West Virginia consolidated school rates developed in this study than the national rates developed by ITE (1997). A study to compare the trip rates of traditional schools in West Virginia to the trip rates of consolidated schools in West Virginia and trip rates published in ITE (1997) may provide some insight to trip generation at schools in West Virginia. In general, differences between school trip rates in West Virginia compared to the rest of the nation could be determined. More specifically, differences in trip rates for traditional schools and consolidated schools in West Virginia could be determined.

Very limited manual counts were conducted to determine the vehicle classification (and magnitude of the trips) associated with schools. It was concluded that there was not significant heavy vehicle traffic, other than school buses, at the sites. However, manual counts that include occupancy counts would provide additional insight to determine the extent of car-pooling by faculty and teachers. Also, manual counts at each site could include interviewing parents who drop-off or pick-up their children at 
school. A few quick questions concerning their trip-making behaviors may lead to a quantification and a better understanding of the trip-chaining phenomenon.

Some of the schools in this study offered activities not directly related to the education of students. For example, one high school offered a Magnet program for college-age adults and another school had a community recreational area on-site. Most schools also had various after-hours activities such as sports practice, club meetings, and activities at night. A trip generation study that also focuses on the frequency and magnitude of the activities may provide a better understanding of how these types of activities affect the trip generation characteristics of schools. 


\section{References}

American Association of State Highway and Transportation Officials (AASHTO), $\underline{A}$ Policy on Geometric Design of Highways and Streets, Washington, D.C. 1990.

Arnold Jr., E.D., “Trip Generation at Special Sites,” ITE Journal, March, 1985, pp.15-19.

Blue Bird Corporation, "Blue Bird TC/2000 School Bus Specifications," http://www.blue-bird.com/tc2000 spec.html (1999).

Cox, Michael, West Virginia Department of Education, Phone Interview on March 18, 1999.

Dowdy, Shirley and Stanley Wearden, Statistics for Research Second Edition, John Wiley \& Sons, New York, NY, 1991.

Institute of Transportation Engineers (ITE), Trip Generation $6^{\text {th }}$ Edition, Washington, D.C., 1997.

Institute of Transportation Engineers (ITE), Trip Generation: 1995 Update to the $5^{\text {th }}$ Edition, Washington, D.C., 1995.

$\underline{\text { Jmp In }}$, Version 3.1.5, SAS Institute, Inc. 1995.

Neumann E.S. and G.K. Deshpande, West Virginia Special Traffic Generators Study, Phase I, Department of Civil Engineering, West Virginia University, Morgantown, WV, 1974.

Pehlke, Linda Olson, "Membership Warehouse Club Trip Generation Study,” ITE Journal, Septemeber, 1994, pp. 14-19.

Peyrebrune, Joan C., "Trip Generation Characteristics of Shopping Centers,” $\underline{\text { ITE }}$ Journal, June, 1996, pp.46-50.

SANDAG, "A (not so) Brief Guide of Vehicular Traffic Generation Rates for the San Diego Region," http://www.sandag.cog.ca.us/ftp/html/trans/tg.htm (1996).

Schroeder, Larry D., Understanding Regression Analysis: an Introductory Guide, Sage Publications, Beverly Hills, CA, 1986.

Slipp, Peter R.M., "Trip Generation Rates for High Schools in Urbanized Counties of North Carolina," Thesis for Masters of Science, North Carolina State University, Raleigh, NC, 1994.

Slipp, Peter R.M. and Joseph E. Hummer, “Trip Generation Rate Update for Public High Schools," ITE Journal, June, 1996, pp. 34-40. 
Snedecor, George W. and William G. Cochran, Statistical Methods Eighth Edition, Iowa State University Press, Ames, IA, 1989.

Tadi, Ramakrishna R. and Paul Balbach, "Truck Trip Generation Characteristics of Nonresidential Land Uses," ITE Journal, July, 1994, pp. 43-47.

Webster's New World Dictionary, Prentice Hall, New York, NY, 1994.

West Virginia Education Directory, West Virginia Department of Education, Charleston, WV, 1997. 


\section{Appendix I}

ITE Format Graphs

for High Schools 


\section{High Schools}

Average Vehicle Trip Ends V/S; Employees

On a: Weekday

Number of Studies: 7

Average SEV Value: 94.86

Directional Distribution: Not Studied

Trip Generation per Employee

\begin{tabular}{|ccc|}
\hline Average Rate & Range of Rates & Standard Deviation \\
\hline 24.58 & $4.61-35.41$ & 12.95 \\
\hline
\end{tabular}

Data Plot

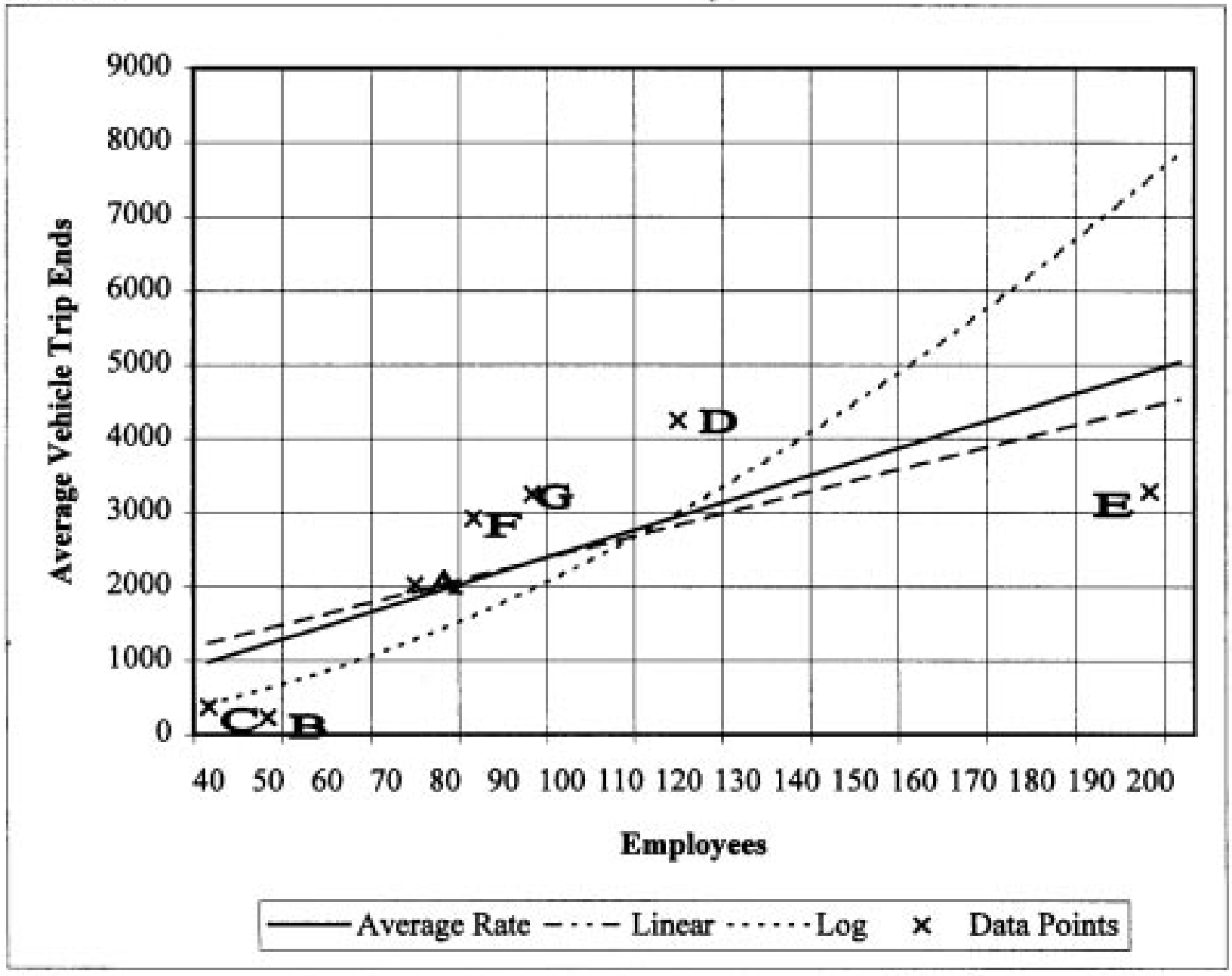

Linear Equation

Trip Ends=437.46+19.97(Employees)

$r^{2}=0.50$

Log Equation

Trip Ends -0.54 (Employees) $)^{1.30}$

$r^{2}=0.68$

(Equations with $r^{2}<0.5$ are not recommended for use) 


\section{High Schools}

Average Vehicle Trip Ends V/S: Employees

On a: Weekday AM Peak

Number of Studies: 6

Average SEV Value: 102.5

Directional Distribution: Not Studied

Trip Generation per Employee

\begin{tabular}{|ccc|}
\hline Average Rate & Range of Rates & Standard Deviation \\
\hline 5.94 & $1.89-8.10$ & 2.33 \\
\hline
\end{tabular}

\section{Data Plot}

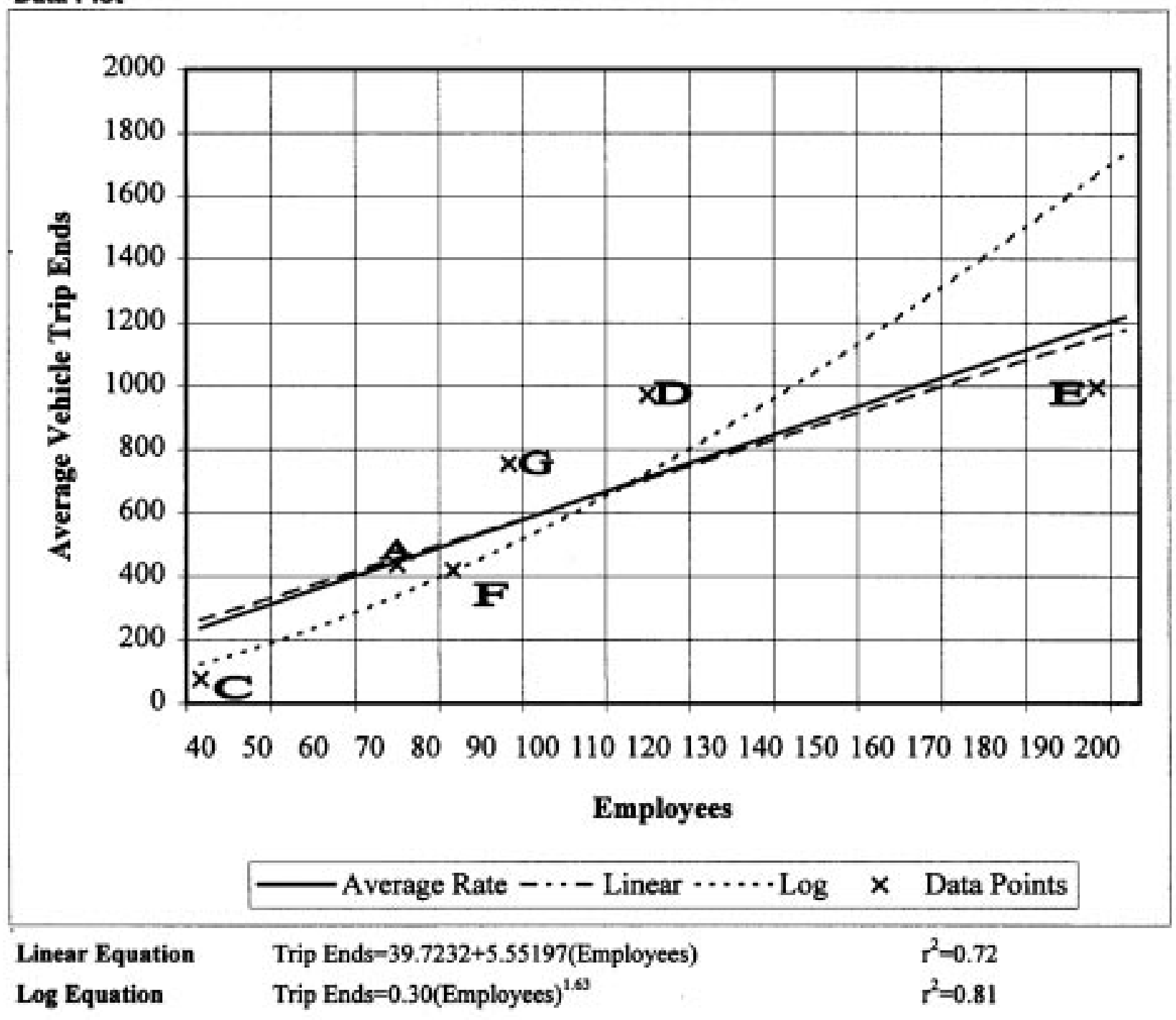




\section{High Schools}

Average Vehicle Trip Ends V/S: Employees

On a: Weekday PM Peak

Number of Studies: 6

Average SEV Value: 102.5

Directional Distribution: Not Studied

Trip Generation per Employee

\begin{tabular}{|ccc|}
\hline Average Rate & Range of Rates & Standard Deviation \\
\hline 4.50 & $1.59-6.37$ & 1.87 \\
\hline
\end{tabular}

\section{Data Plot}

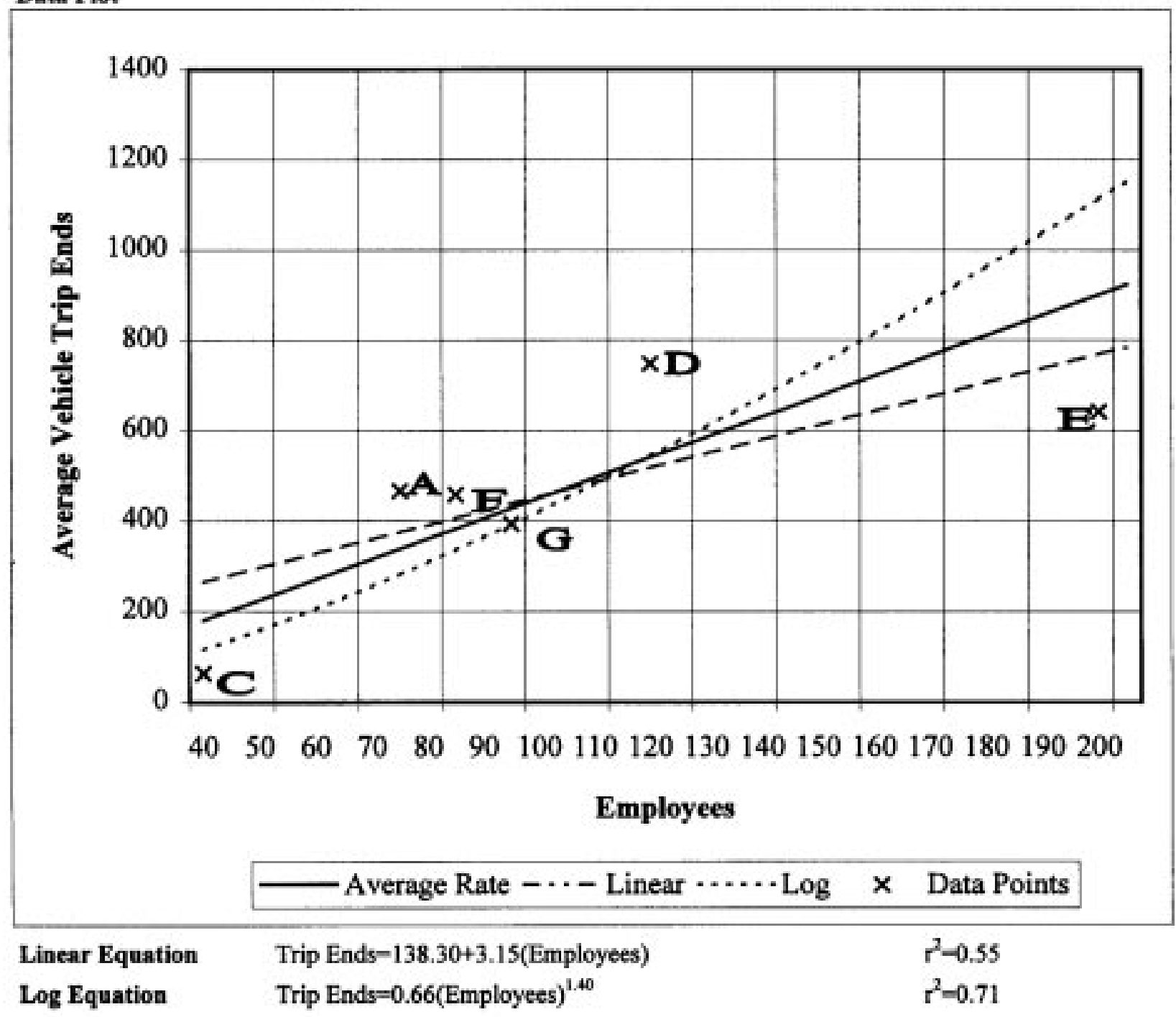




\section{High Schools}

Average Vehicle Trip Ends V/S: Employees

On a: Saturday

Number of Studies: 5

Average SEV Value: 115

Directional Distribution: Not Studied

Trip Generation per Employee

\begin{tabular}{|ccc|}
\hline Average Rate & Range of Rates & Standard Deviation \\
\hline 7.77 & $2.50-21.38$ & 7.92 \\
\hline
\end{tabular}

Data Plot

Caution - Use Carefully - Small Sample Slze

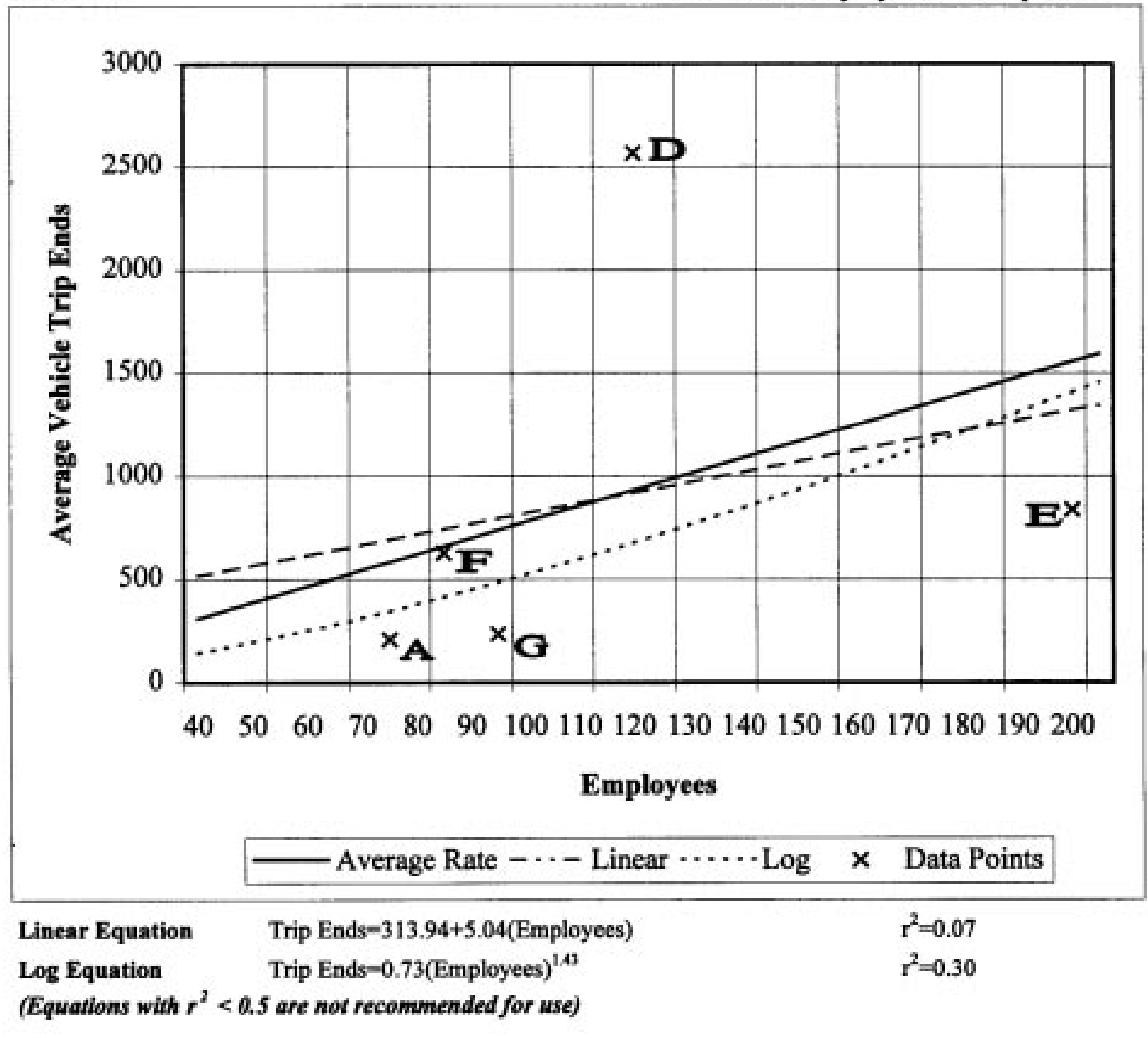




\section{High Schools}

Average Vehicle Trip Ends V/S: Employees

On a: Saturday Peak

Number of Studies: 5

Average SEV Value: 115

Directional Distribution: Not Studied

Trip Generation per Employee

\begin{tabular}{|ccc|}
\hline Average Rate & Range of Rates & Standard Deviation \\
\hline 1.09 & $0.56-3.09$ & 1.07 \\
\hline
\end{tabular}

Data Plot

Caution - Use Carefully - Small Sample Slze

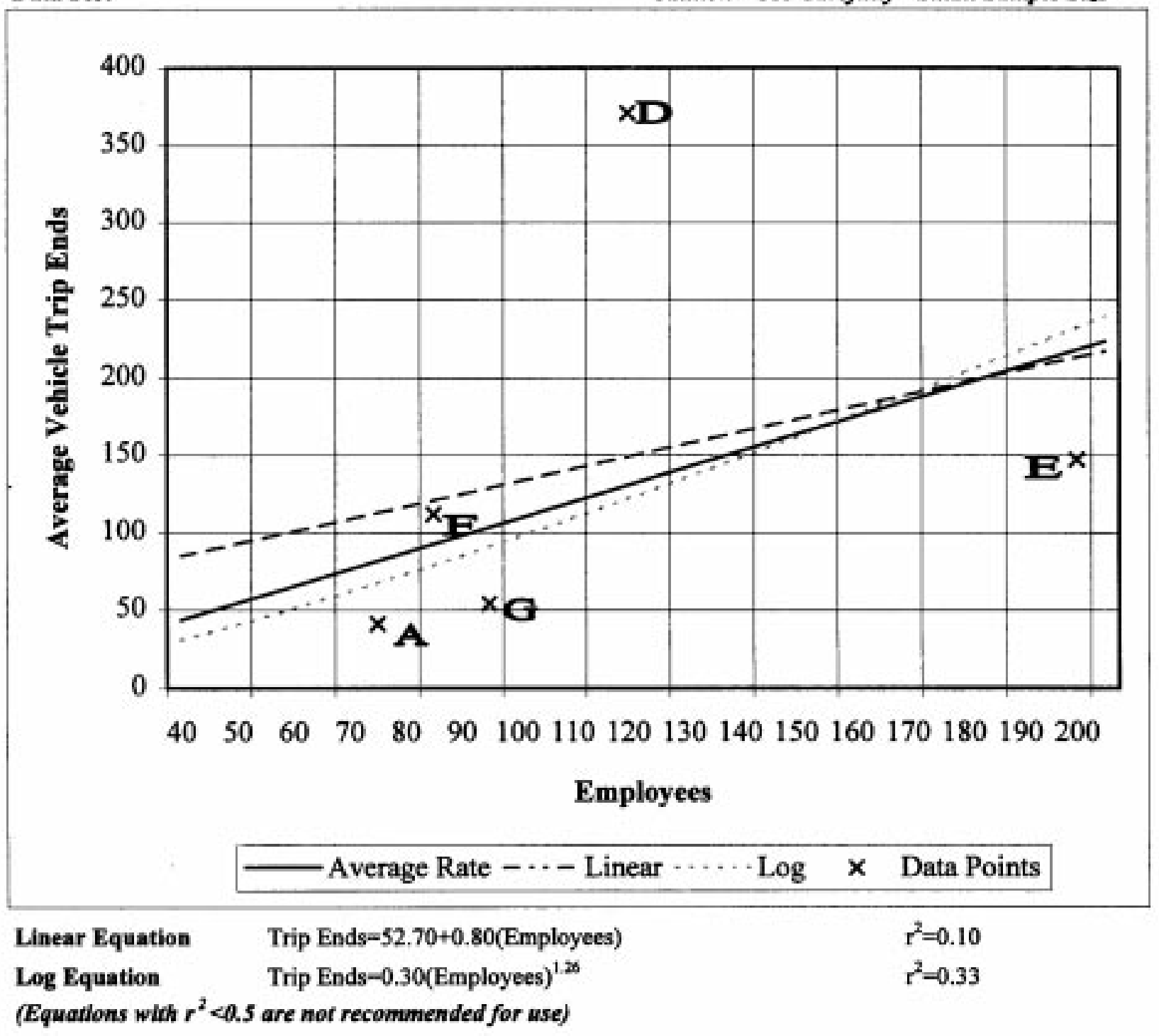




\section{High Schools}

Average Vehicle Trip Ends V/S: Employees

On a: Sunday

Number of Studies: 5

Average SEV Value: 115

Directional Distribution: Not Studied

Trip Generation per Employee

\begin{tabular}{|clc|}
\hline Average Rate & Range of Rates & Standard Deviation \\
\hline 1.71 & $1.15-2.57$ & 0.51 \\
\hline
\end{tabular}

Data Plot

Caution - Use Carefully - Small Sample Size

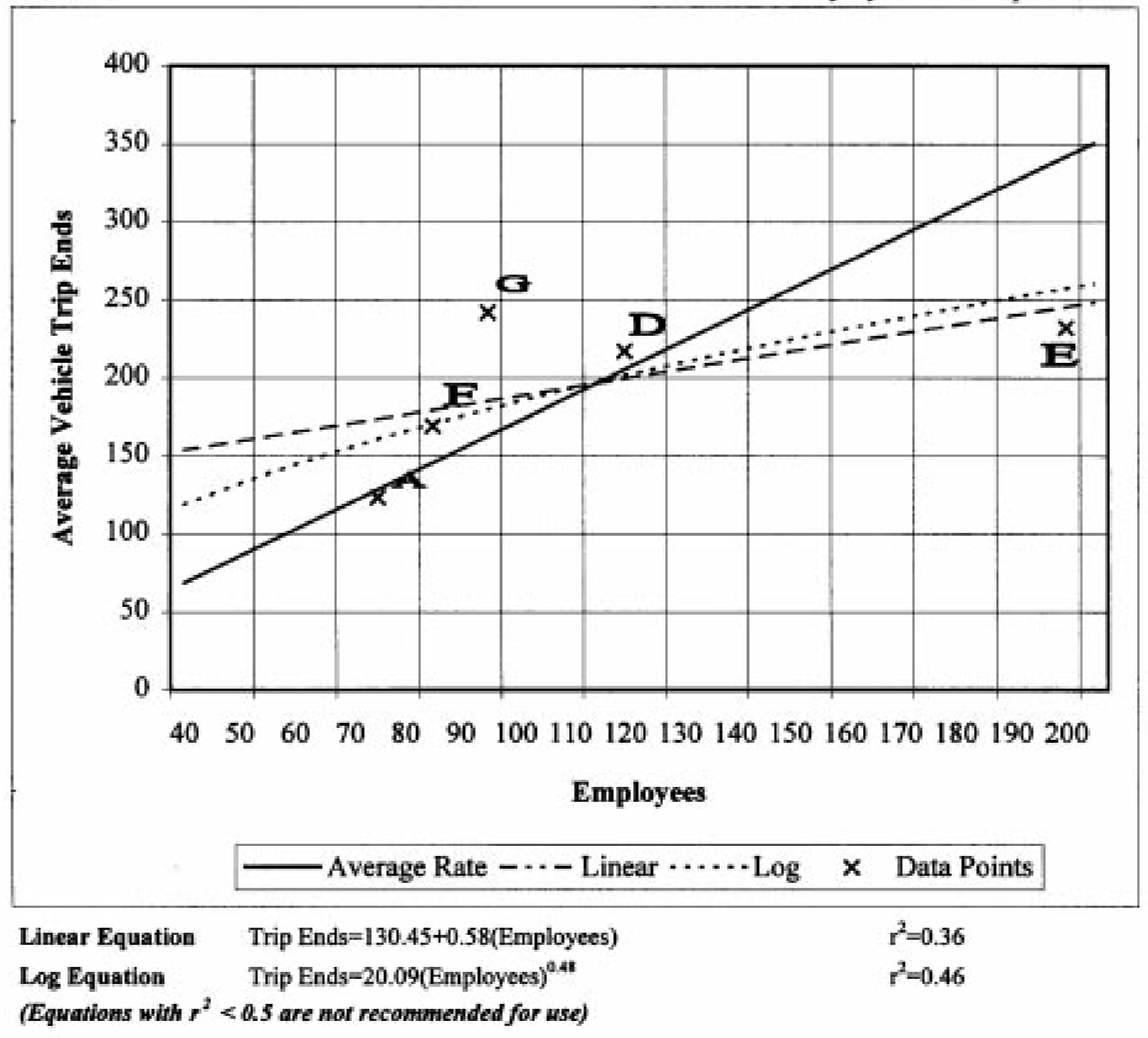




\section{High Schools}

Average Vehicle Trip Ends V/S: Employees

On a: Sunday Peak

Number of Studies: 5

Average SEV Value: 115

Directional Distribution: Not Studied

Trip Generation per Employee

\begin{tabular}{|clc|}
\hline Average Rate & Range of Rates & Standard Deviation \\
\hline 0.27 & $0.23-0.43$ & 0.08 \\
\hline
\end{tabular}

Data Plot

Caution - Use Carefully - Small Sample Size

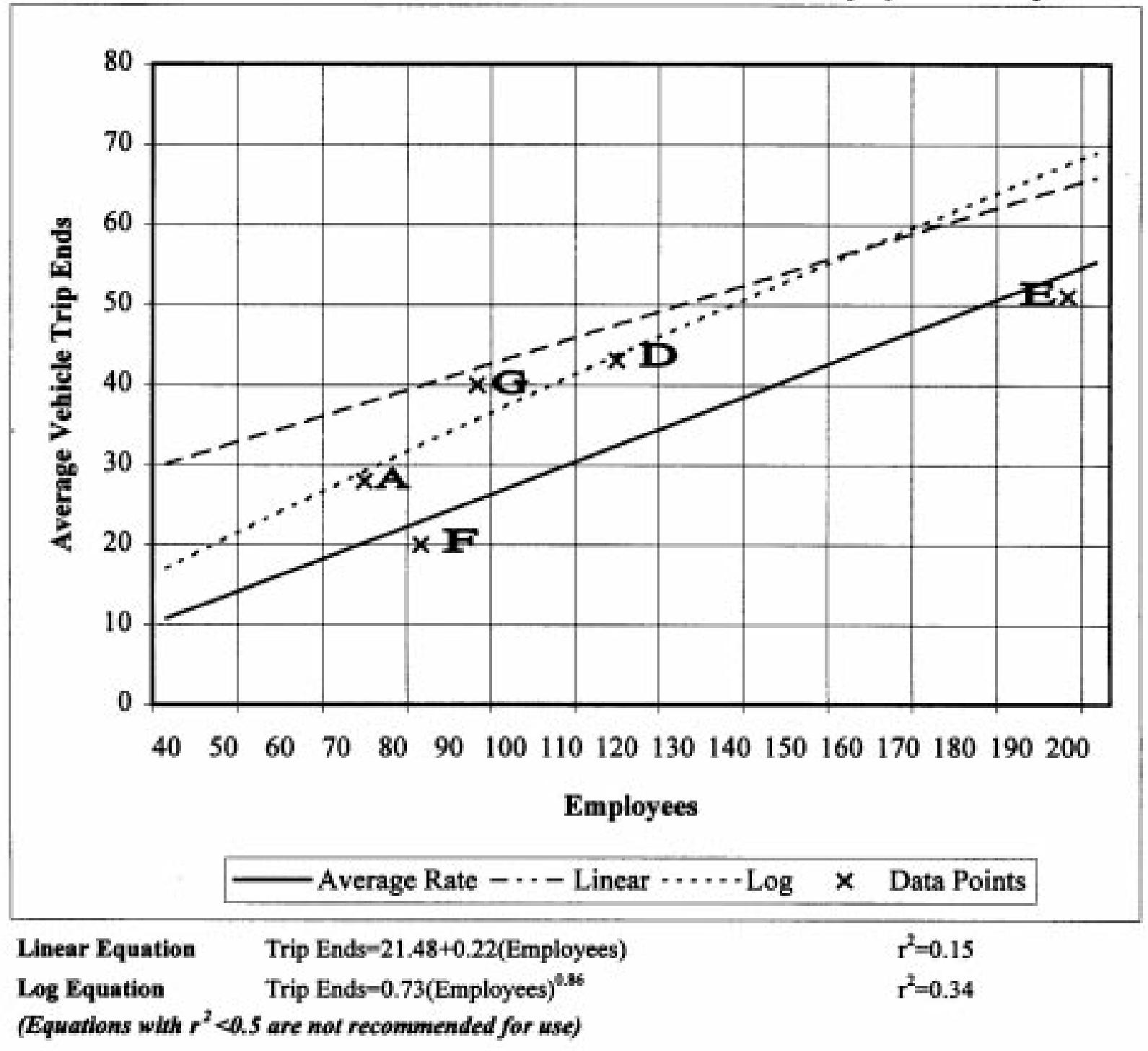




\section{High Schools}

Average Vehicle Trip Ends V/S: Students

On a: Weekday

Number of Studies: 7

Average SEV Value: 1185.57

Directional Distribution: Not Studied

Trip Generation per Student

\begin{tabular}{|ccc|}
\hline Average Rate & Range of Rates & Standard Deviation \\
\hline 1.97 & $0.51-3.23$ & 0.94 \\
\hline
\end{tabular}

Data Plot

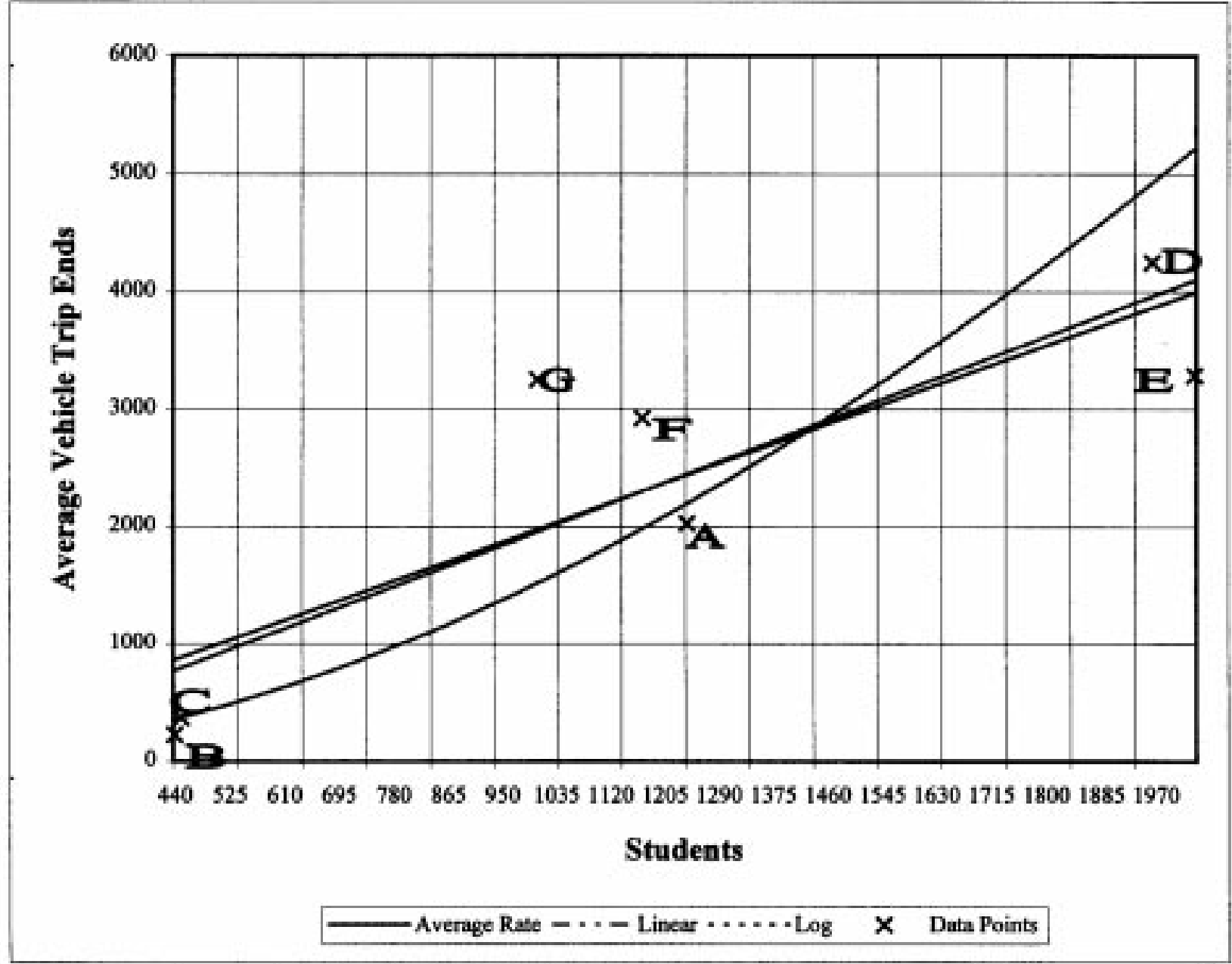

$\begin{array}{lll}\text { Linear Equation } & \text { Trip Ends }=145.61+2.09 \text { (Students) } & r^{2}=0.76 \\ \text { Log Equation } & \text { Trip Ends }=0.01 \text { (Students) }{ }^{1.76} & r^{2}=0.86\end{array}$




\section{High Schools}

Average Vehicle Trip Ends V/S: Students

On a: Weekday AM Peak

Number of Studies: 6

Average SEV Value: 1309.83

Directional Distribution: Not Studied

Trip Generation per Student

\begin{tabular}{|ccc|}
\hline Average Rate & Range of Rates & Standard Deviation \\
\hline 0.46 & $0.17-0.75$ & 0.2 \\
\hline
\end{tabular}

\section{Data Plot}

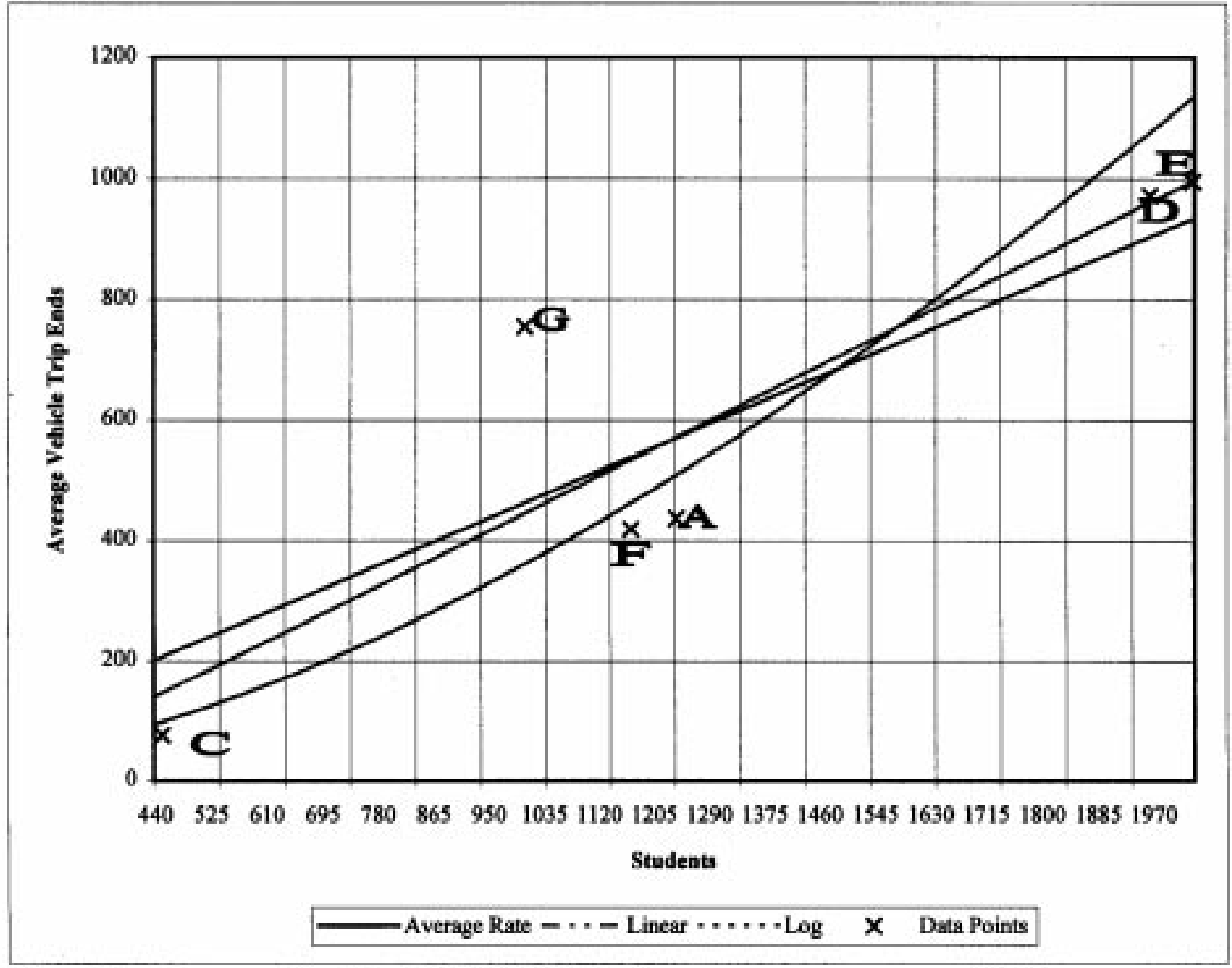

Linear Equation

Log Equation
Trip Ends $=95.24+0.54$ (Students)

Trip Ends $=0.005$ (Students) ${ }^{1.65}$ $r^{2}=0.80$

$r^{2}=0.86$ 


\section{High Schools}

Average Vehicle Trip Ends V/S: Students

On a: Weekday PM Peak

Number of Studies: 6

Average SEV Value: 1309.83

Directional Distribution: Not Studied

Trip Generation per Student

\begin{tabular}{|ccc|}
\hline Average Rate & Range of Rates & Standard Deviation \\
\hline 0.35 & $0.14-0.39$ & 0.10 \\
\hline
\end{tabular}

\section{Data Plot}

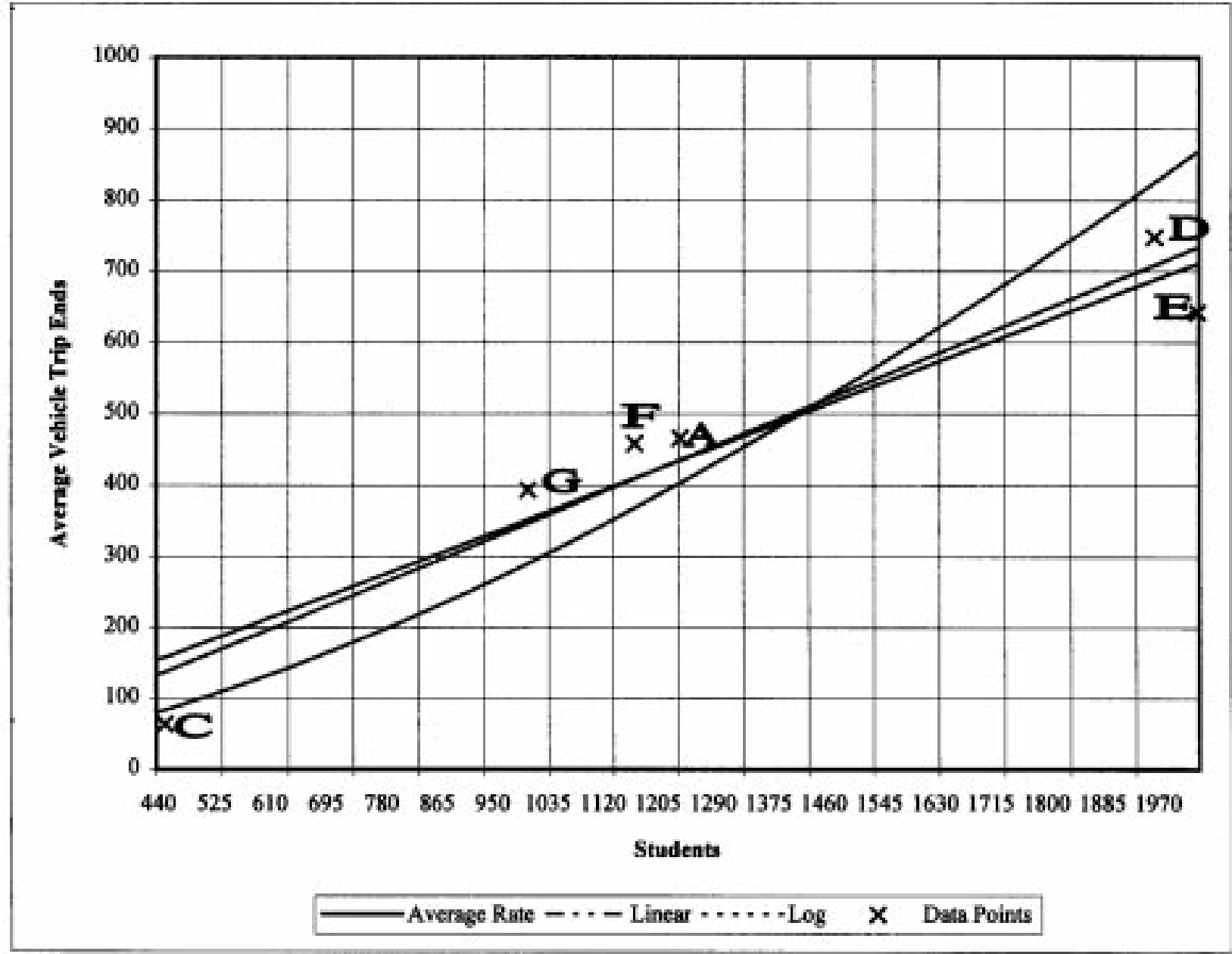

Linear Equation

Log Equation
Trip Ends $-32.78+0.38$ (Students)

Trip Ends -0.006 (Students) $^{1.36}$

$$
r^{2}=0.93
$$

$r^{2}=0.92$ 


\section{High Schools}

Average Vehicle Trip Ends V/S: Students

On a: Saturday

Number of Studies: 5

Average SEV Value: 1481.8

Directional Distribution: Not Studied

Trip Generation per Student

\begin{tabular}{|ccc|}
\hline Average Rate & Range of Rates & Standard Deviation \\
\hline 1.00 & $0.17-1.31$ & 0.46 \\
\hline
\end{tabular}

Data Plot

Caution - Use Carefully - Small Sample Slze

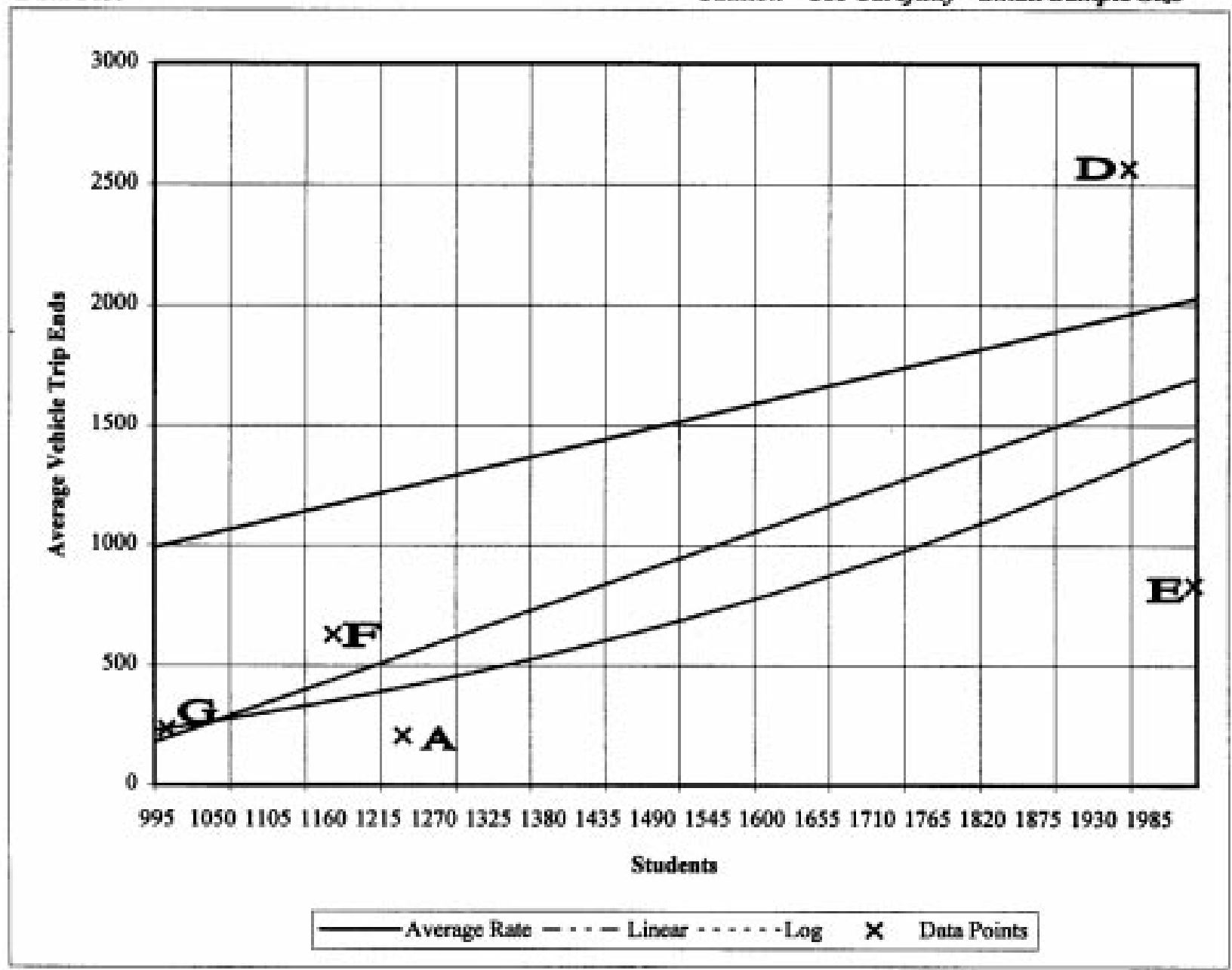

Linear Equation

Trip Ends $=1271.90+1.46$ (Students)

$r^{2}=0.52$

-Log Equation

Trip Ends -4.29 (Students) $^{2.58}$

$r^{2}=0.64$ 


\section{High Schools}

Average Vehicle Trip Ends V/S: Students

On a: Saturday Peak

Number of Studies: 5

Average SEV Value: 1481.8

Directional Distribution: Not Studied

Trip Generation per Student

\begin{tabular}{|ccc|}
\hline Average Rate & Range of Rates & Standard Deviation \\
\hline 0.09 & $0.03-0.19$ & 0.06 \\
\hline
\end{tabular}

Data Plot

Caution - Use Carefully - Small Sample Size

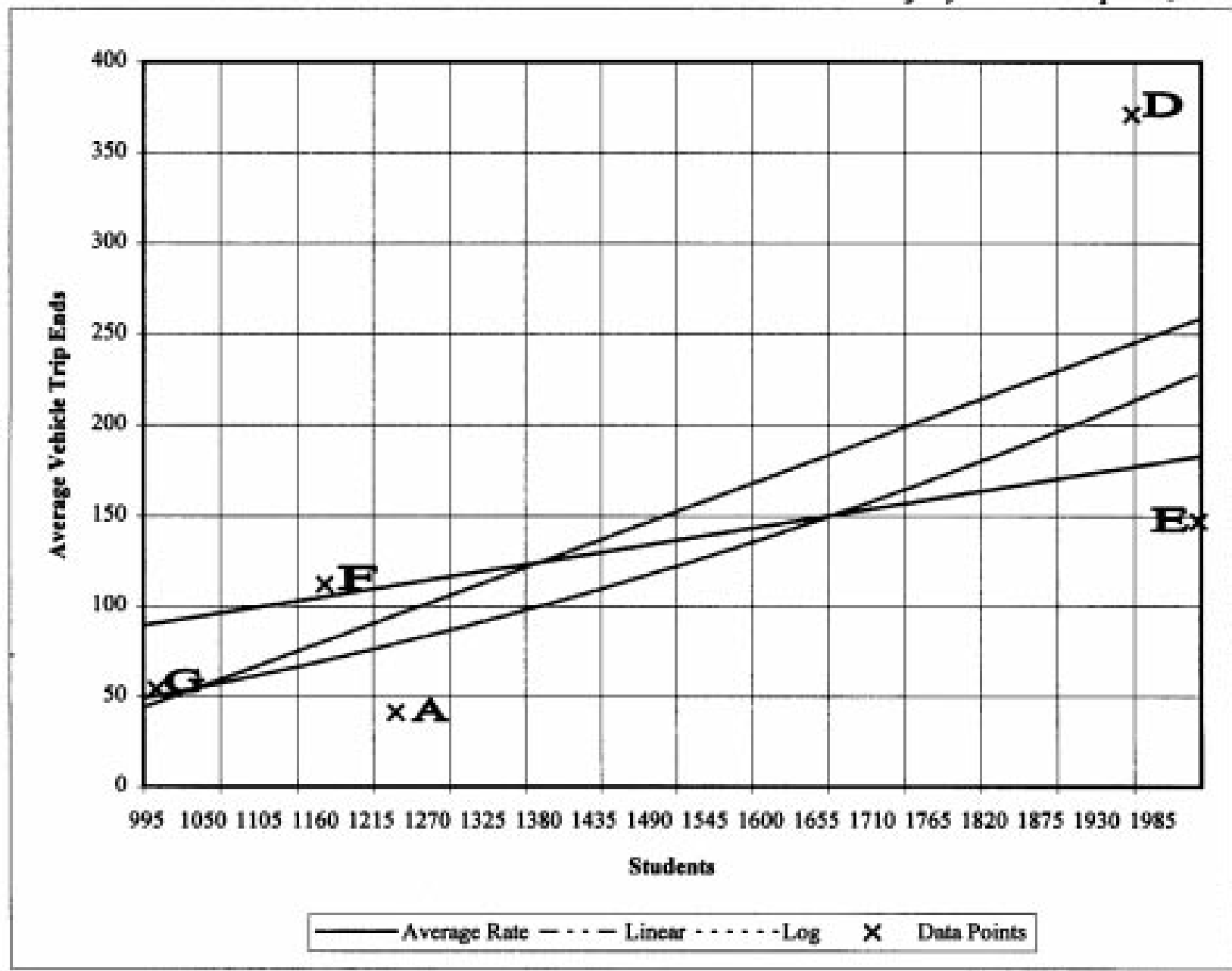

Linear Equation

Log Equation
Trip Ends $=-161.05+0.21$ (Students)

Trip Ends=1.77(Students) ${ }^{2.15}$

$$
r^{2}-0.55
$$

$r^{2}=0.62$ 


\section{High Schools}

Average Vehicle Trip Ends V/S: Students

On a: Sunday

Number of Studies: 5

Average SEV Value: 1481.8

Directional Distribution: Not Studied

Trip Generation per Student

Average Rate

0.13
Range of Rates $0.10-0.24$

Standard Deviation 0.06

Data Plot

Caution - Use Carefully - Small Sample Size

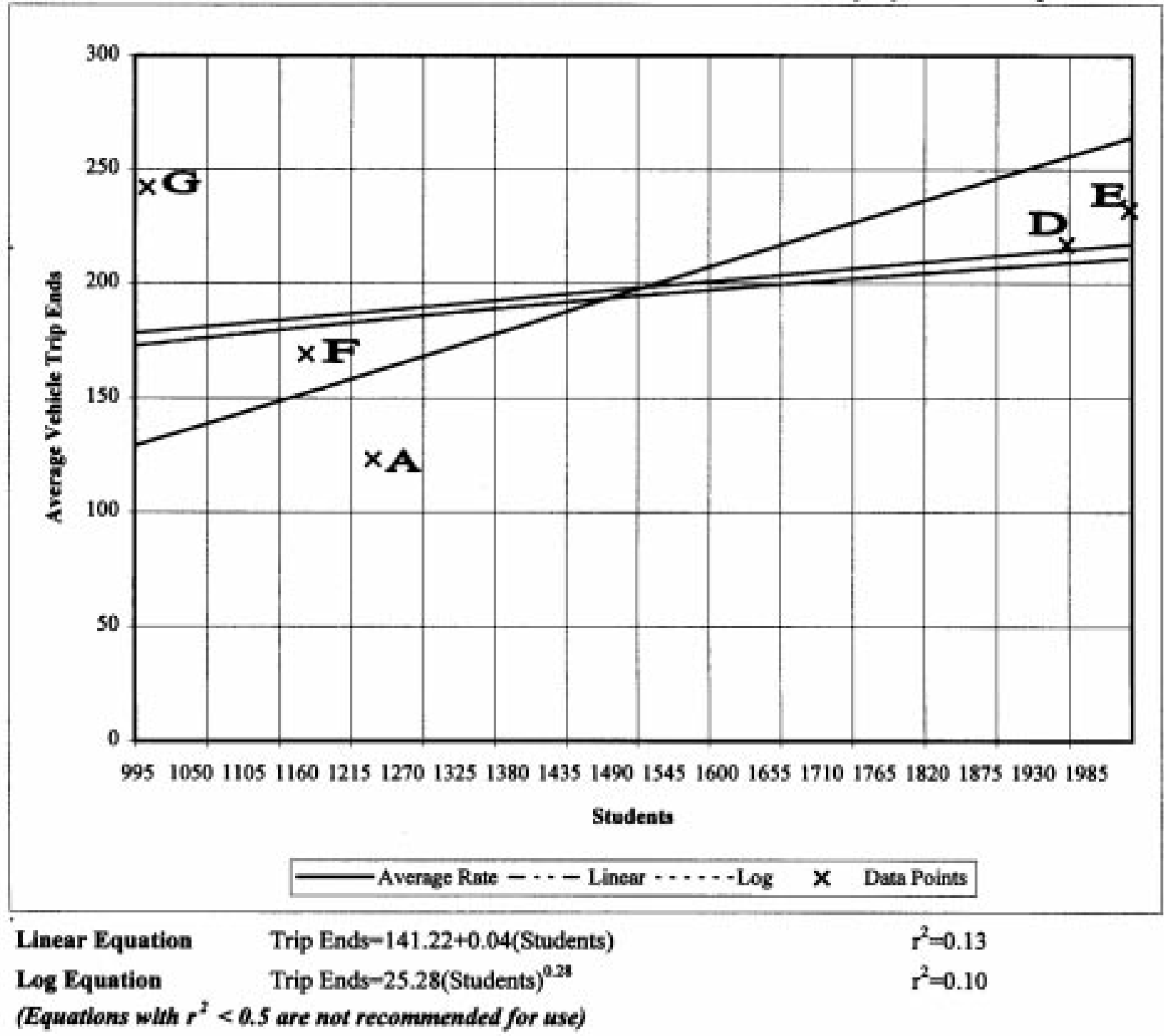




\section{High Schools}

Average Vehicle Trip Ends V/S: Students

On a: Sunday Peak

Number of Studies: 5

Average SEV Value: 1481.8

Directional Distribution: Not Studied

Trip Generation per Student

Average Rate

Range of Rates

Standard Deviation

0.02 $0.02-0.04$ 0.01

Data Plot

Caution - Use Carefully - Small Sample Size

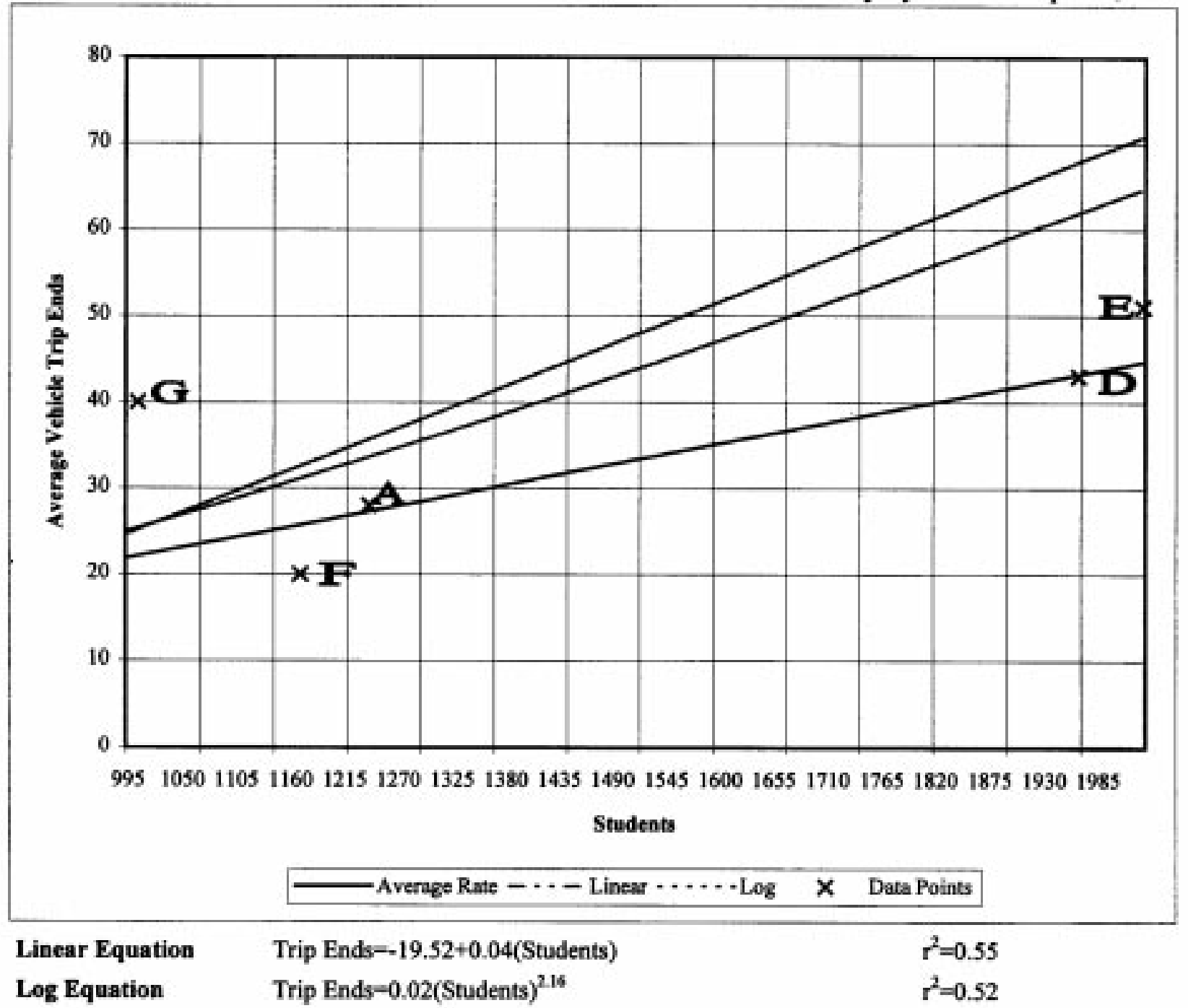




\section{High Schools}

Average Vehicle Trip Ends V/S: 1000 SF GFA

On a: Weekday

Number of Studies: 6

Average SEV Value: 203.17

Directional Distribution: Not Studied

Trip Generation per 1000 SF GFA

\begin{tabular}{|ccc|}
\hline Average Rate & Range of Rates & Standard Deviation \\
\hline 13.38 & $2.58-14.86$ & 4.95 \\
\hline
\end{tabular}

Data Plot

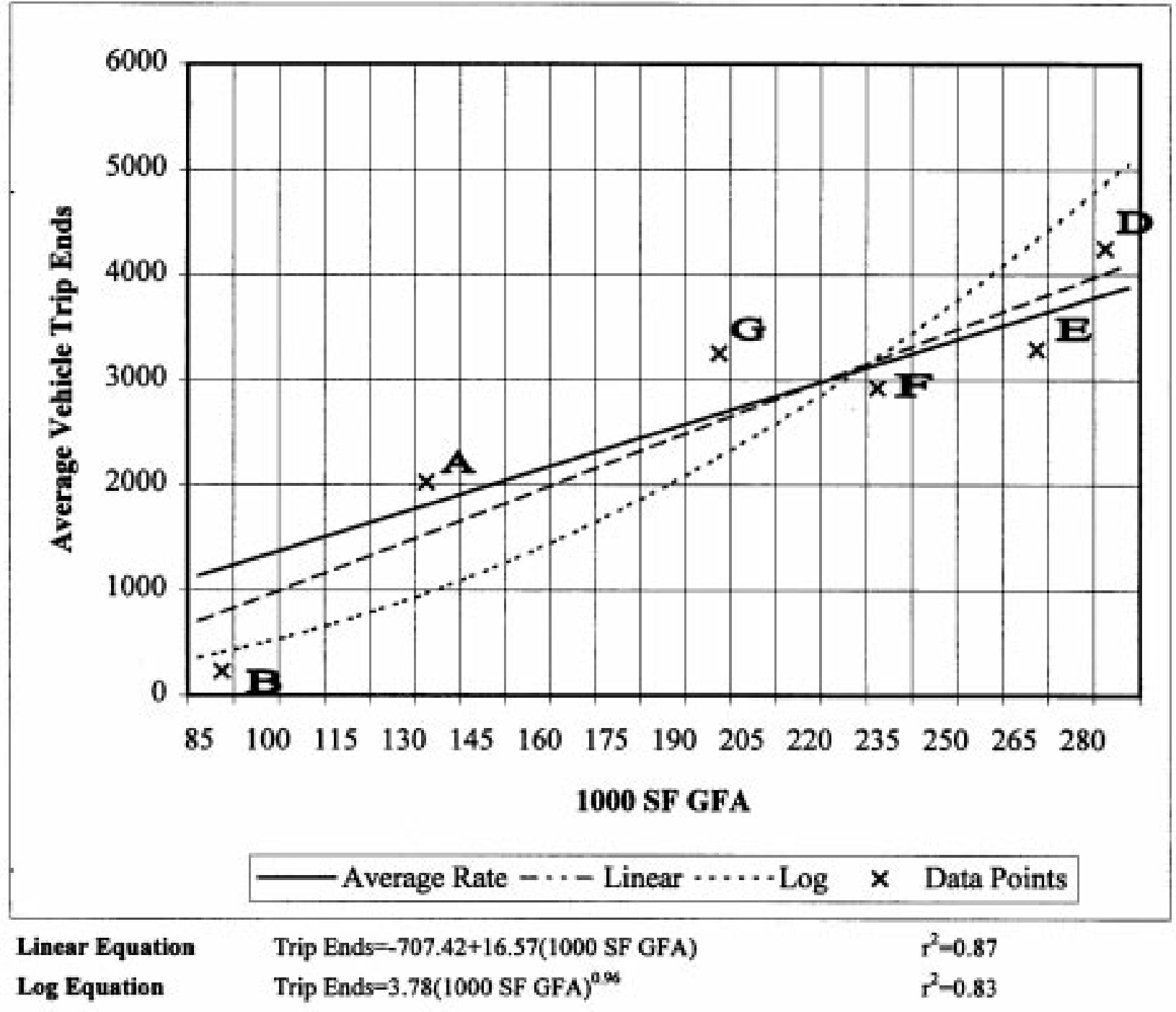




\section{High Schools}

Average Vehicle Trip Ends V/S: 1000 SF GFA

On a: Weekday AM Peak

Number of Studies: 5

Average SEV Value: 226.2

Directional Distribution: Not Studied

Trip Generation per 1000 SF GFA

\begin{tabular}{|ccc|}
\hline Average Rate & Range of Rates & Standard Deviation \\
\hline 3.16 & $1.79-3.77$ & 0.81 \\
\hline
\end{tabular}

Data Plot

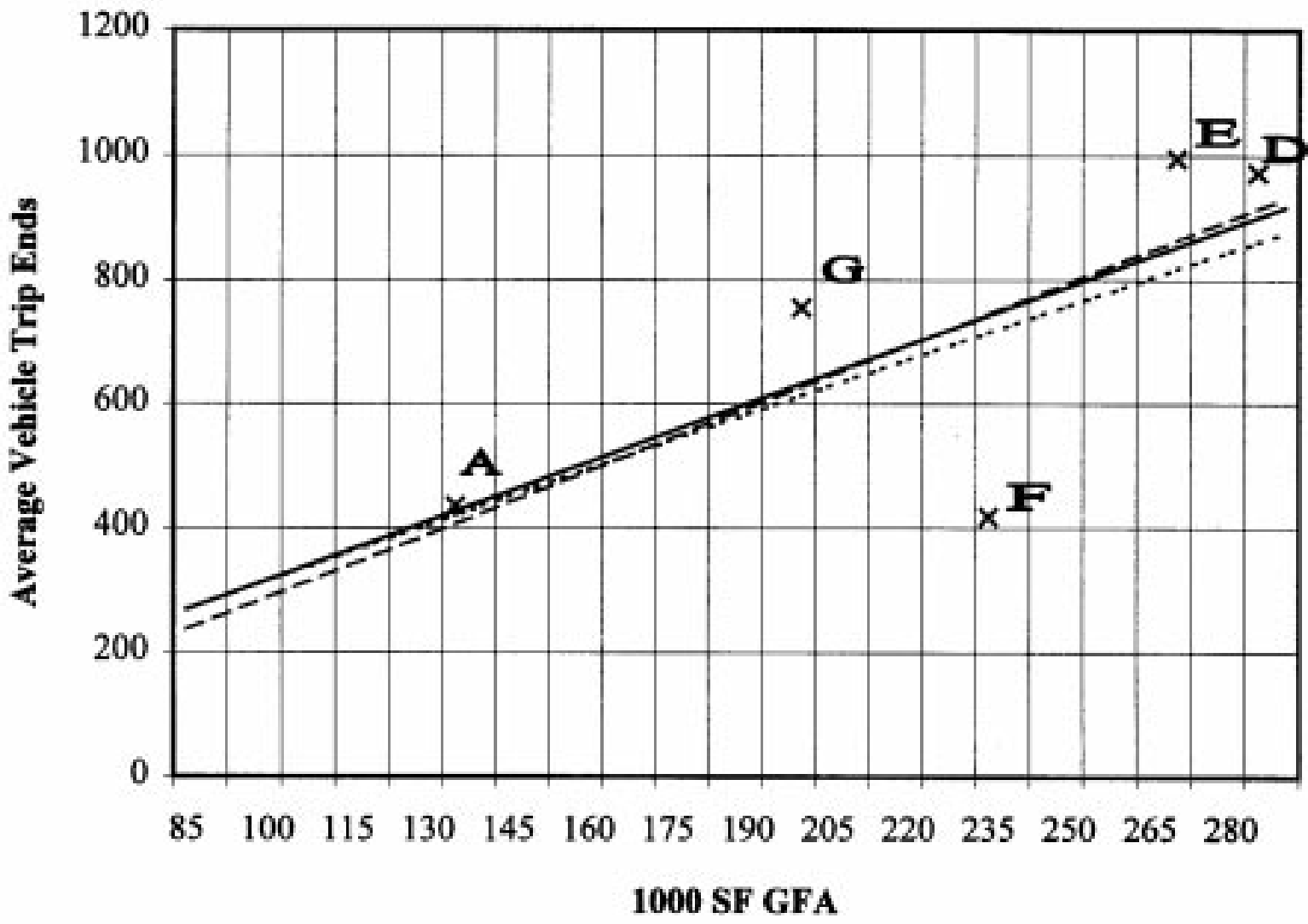

$$
\text { Average Rate }-\cdots \text { - Linear } \cdots \cdots \cdot \log \times \text { Data Points }
$$

Linear Equation

Log Equation

(Equations with $r^{2}=0.53$

$r^{2}=0.46$ 


\section{High Schools}

Average Vehicle Trip Ends V/S: 1000 SF GFA

On a: Weekday PM Peak

Number of Studies: 5

Average SEV Value: 226.2

Directional Distribution: Not Studied

Trip Generation per 1000 SF GFA

\begin{tabular}{|ccc|}
\hline Average Rate & Range of Rates & Standard Deviation \\
\hline 2.39 & $1.93-3.40$ & 0.60 \\
\hline
\end{tabular}

Data Plot

Caution - Use Carefully - Small Sample Size

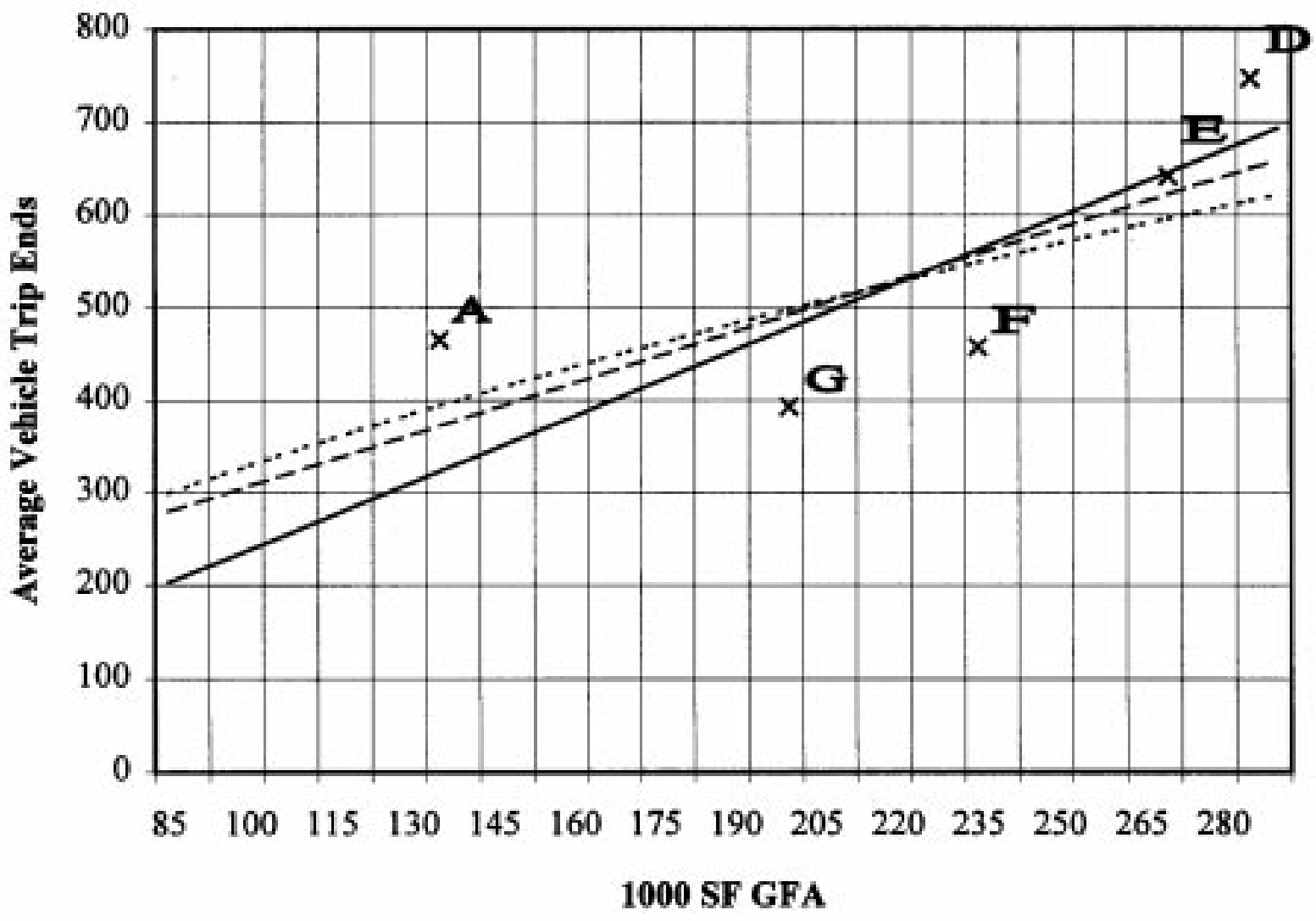

- Average Rate $-\cdots$ - Linear $\cdots \cdots \log \times$ Data Points

$\begin{array}{lll}\text { Linear Equation } & \text { Trip Ends=121.94+1.85(Employees) } & r^{2}=0.57 \\ \text { Log Equation } & \text { Trip Ends=21.15(1000 SF GFA) })^{0.60} & r^{2}=0.44\end{array}$

(Equations with $r^{2}<0.5$ are not recommended for use) 


\section{High Schools}

Average Vehicle Trip Ends V/S: 1000 SF GFA

On a: Saturday

Number of Studies: 5

Average SEV Value: 226.2

Directional Distribution: Not Studied

Trip Generation per 1000 SF GFA

\begin{tabular}{|ccc|}
\hline Average Rate & Range of Rates & Standard Deviation \\
\hline 6.54 & $1.50-8.97$ & 3.17 \\
\hline
\end{tabular}

Data Plot

Caution - Use Carefully - Small Sample Size

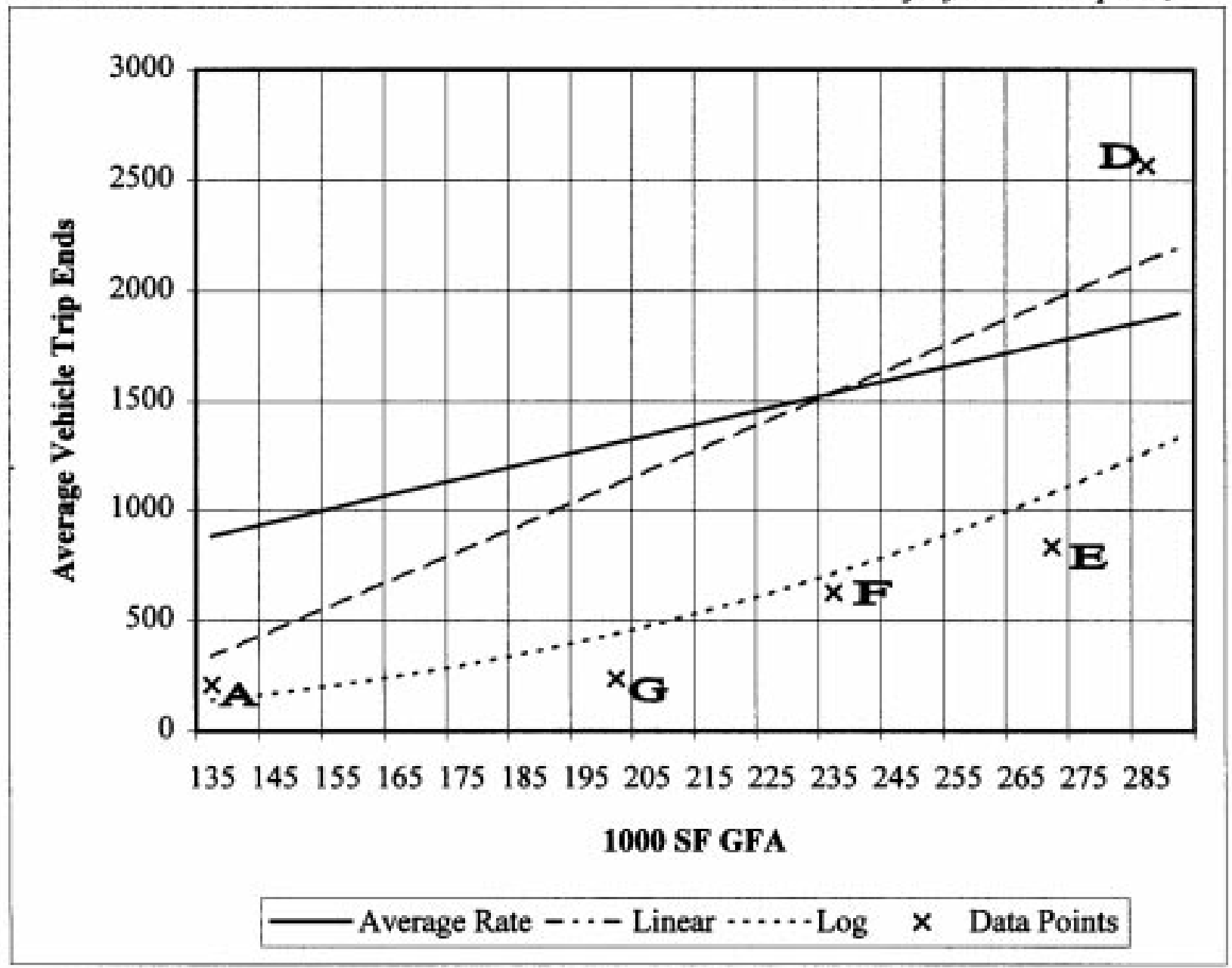

Linear Equation

Log Equation
Trip Ends $=-1280.6+11.99(1000$ SF GFA)

Trip Ends $-6.25 \times 10^{-5}(1000 \text { SF GFA })^{298}$ $r^{2}=0.55$

$r^{2}=0.74$ 


\section{High Schools}

Average Vehicle Trip Ends V/S: 1000 SF GFA

On a: Saturday Peak

Number of Studies: 5

Average SEV Value: 226.2

Directional Distribution: Not Studied

Trip Generation per 1000 SF GFA

Average Rate

0.59
Range of Rates $0.27-1.30$
Standard Deviation 0.42

Data Plot

Caution - Use Carefully - Small Sample Size

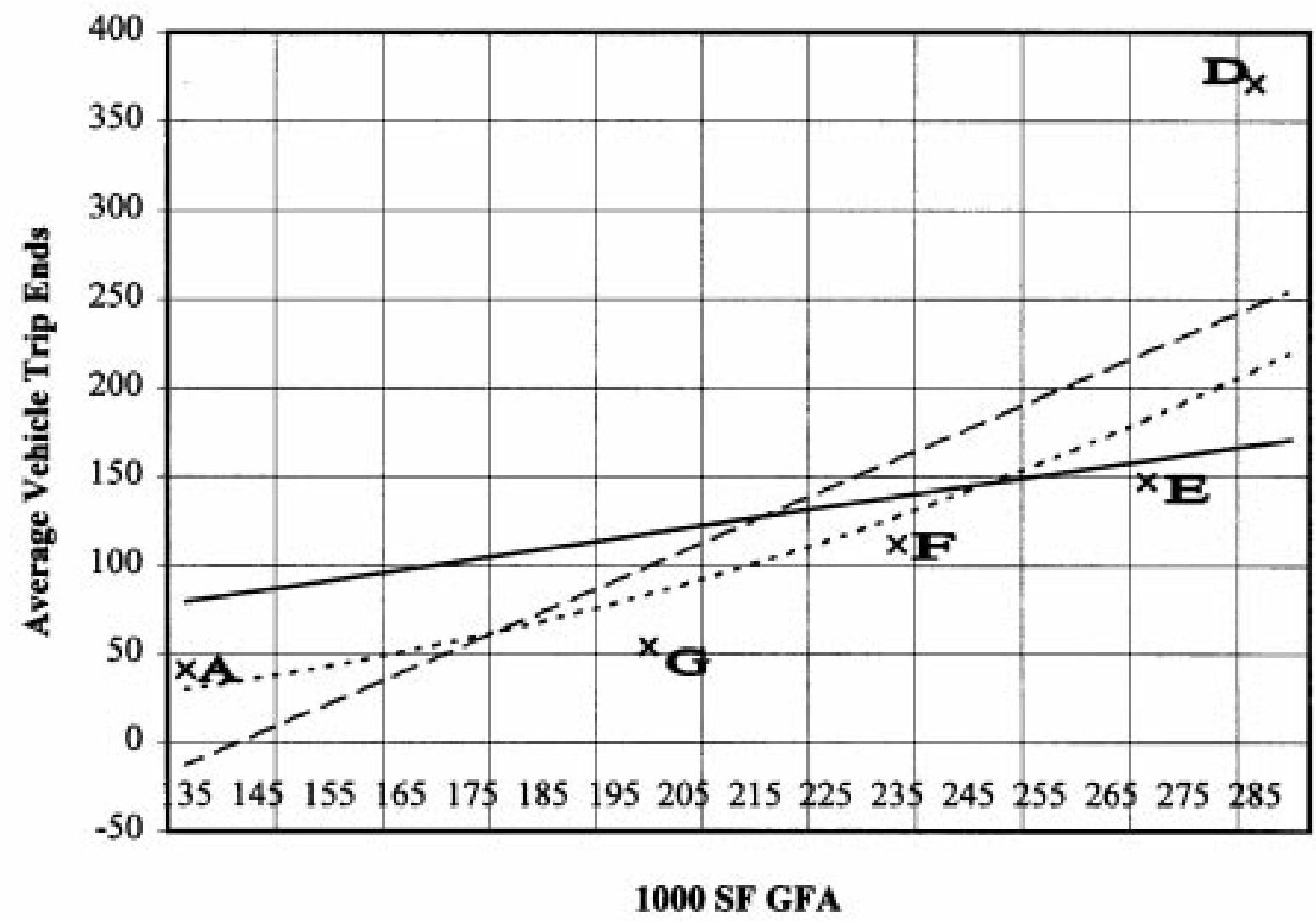

- Average Rate $-\cdots$ - Linear $\cdots \cdots$ Log $\times$ Data Points

Linear Equation

Log Equation
Trip Ends $=245.93+1.73$ (1000 SF GFA)

Trip Ends $=8.78 \times 10^{-5}(1000 \text { SF GFA })^{260}$ $r^{2}=0.60$

$r^{2}=0.78$ 


\section{High Schools}

Average Vehicle Trip Ends V/S: 1000 SF GFA

On a: Sunday

Number of Studies: 5

Average SEV Value: 226.2

Directional Distribution: Not Studied

Trip Generation per 1000 SF GFA

\begin{tabular}{|ccc|}
\hline Average Rate & Range of Rates & Standard Deviation \\
\hline 0.87 & $0.71-1.21$ & 0.20 \\
\hline
\end{tabular}

Data Plot

Caution - Use Carefully - Small Sample Size

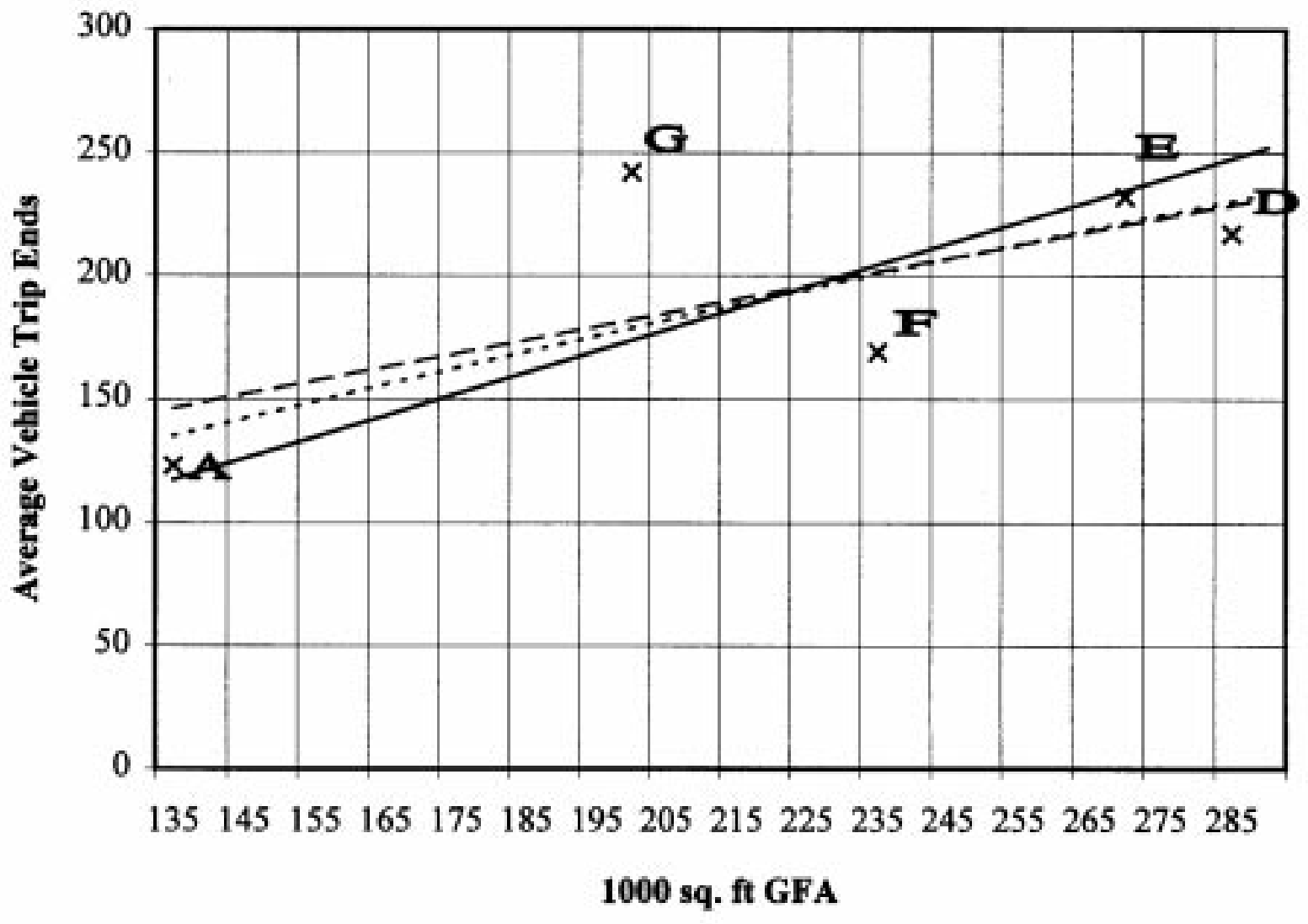

- Average Rate $-\cdots$ - Linear $\cdots \cdots$ Log $\times$ Data Points

$\begin{array}{lcc}\text { Linear Equation } \quad \text { Trip Ends }=72.27+0.55(1000 \text { SF GFA) } & r^{2}=0.44 \\ \text { Log Equation } \quad \text { Trip Ends }=4.10(1000 \text { SF GFA })^{0.71} & r^{2}=0.56 \\ \text { (Equations with } r^{2}<0.5 \text { are not recommended for use) } & \end{array}$




\section{High Schools}

Average Vehicle Trip Ends V/S: 1000 SF GFA

On a: Sunday Pcak

Number of Studies: 5

Average SEV Value: $\mathbf{2 2 6 . 2}$

Directional Distribution: Not Studied

Trip Generation per 1000 SF GFA

\begin{tabular}{|ccc|}
\hline Average Rate & Range of Rates & Standard Deviation \\
\hline 0.15 & $0.08-0.20$ & 0.05 \\
\hline
\end{tabular}

Data Plot

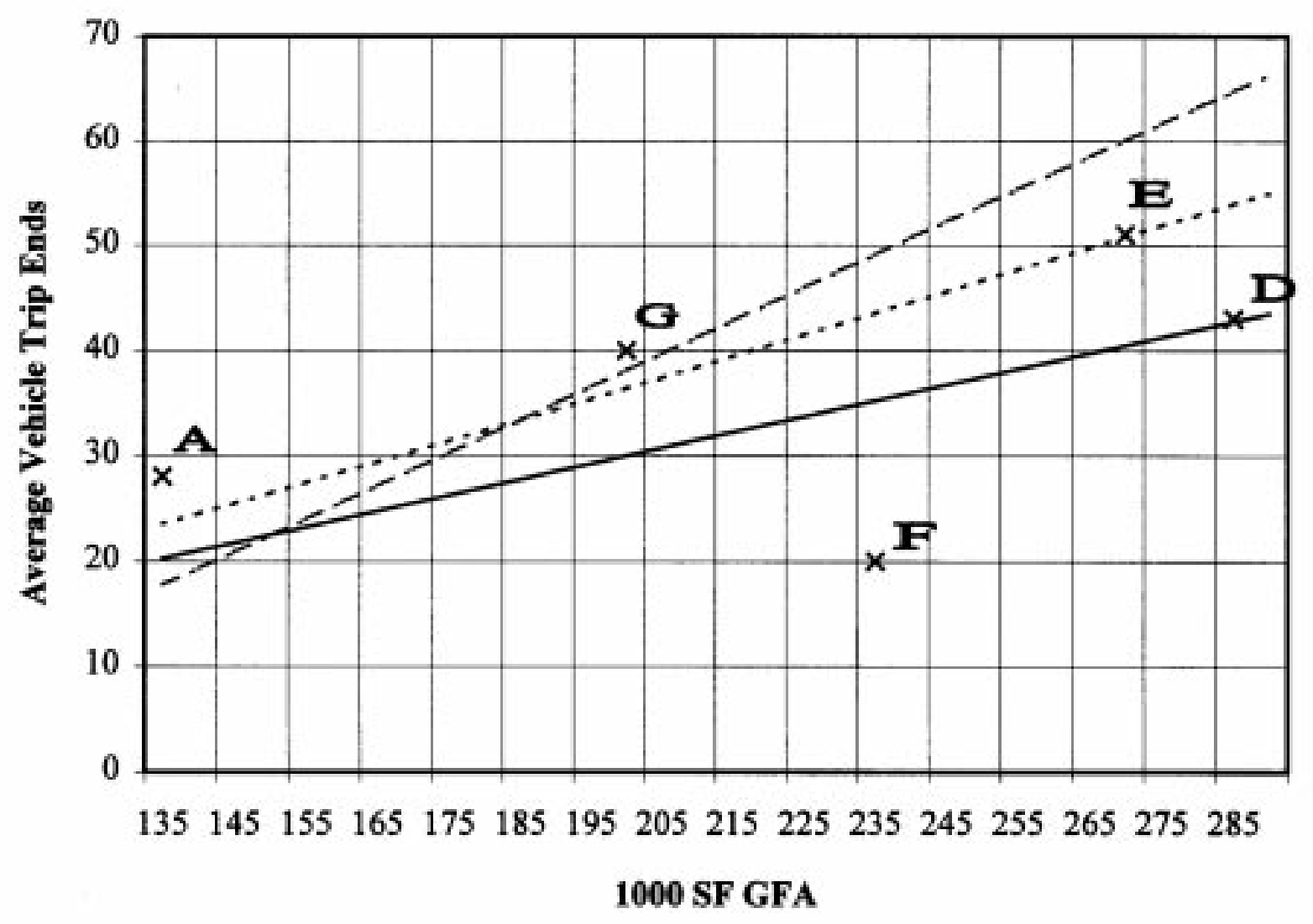

- Average Rate $-\cdots-$ Linear $\cdots \cdots$ Log $\times$ Data Points

\begin{tabular}{lcc}
\hline Linear Equation & Trip Ends $=24.63+0.31(1000 \mathrm{SF}$ GFA $)$ & $\mathrm{r}^{2}=0.43$ \\
Log Equation & Trip Ends $=0.10(1000 \mathrm{SF} \text { GFA })^{1.11}$ & $\mathrm{r}^{2}=0.31$ \\
(Equations with $r^{2}<0.5$ are not recommended for use) &
\end{tabular}


Appendix II

ITE Format Graphs

for Elementary Schools 


\section{Elementary Schools}

Average Vehicle Trip Ends V/S: 1000 SF GFA

On a: Weekday PM Peak

Number of Studies: 4

Average SEV Value: 68

Directional Distribution: Not Studied

Trip Generation per 1000 SF GFA

\begin{tabular}{|ccc|}
\hline Average Rate & Range of Rates & Standard Deviation \\
\hline 5.77 & $3.24-7.13$ & 1.72 \\
\hline
\end{tabular}

Data Plot

Caution - Use Carefully - Small Sample Stze

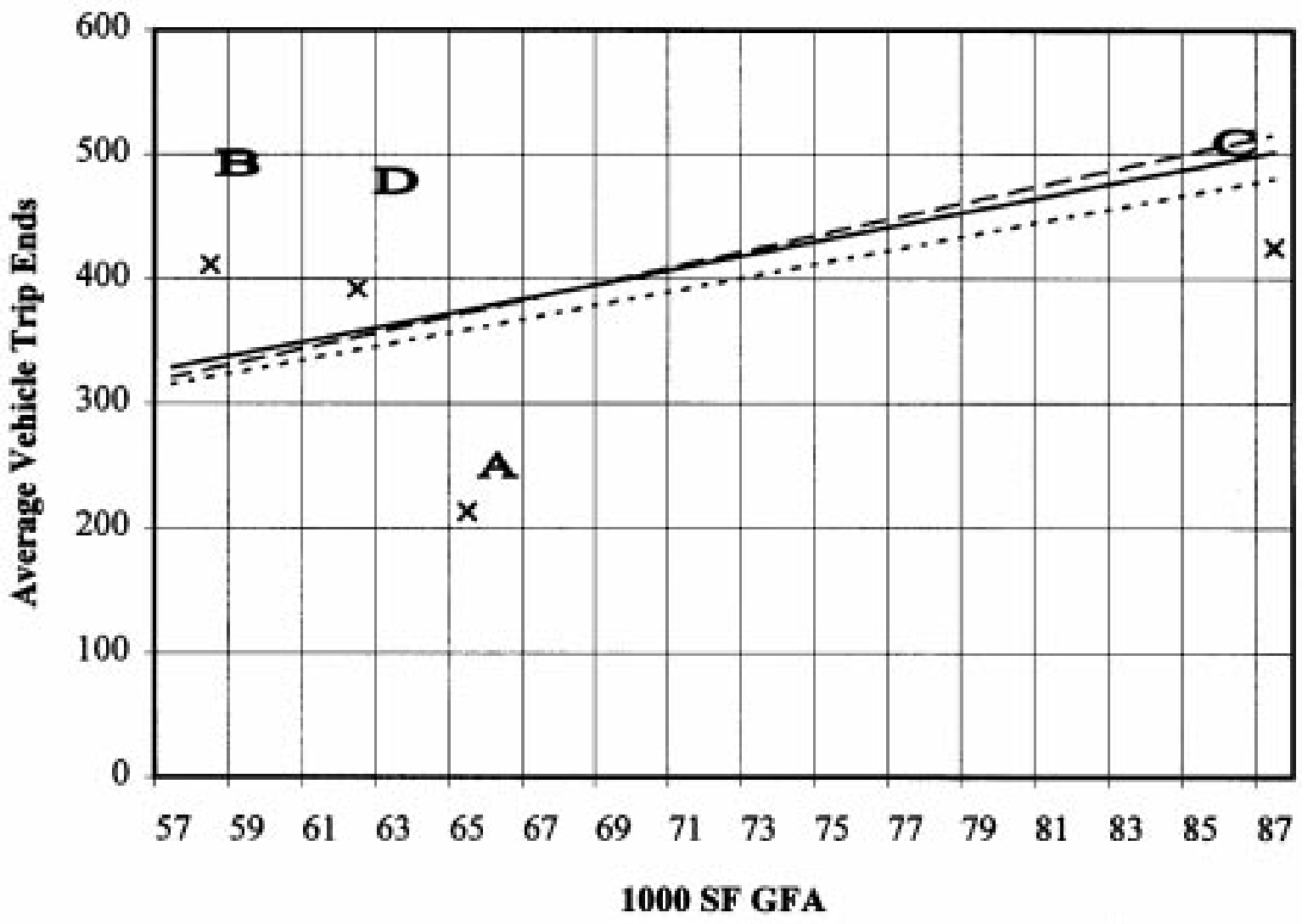

Average Rate $-\cdots$ - Linear $\cdots \cdots$ Log $\times$ Data Points

Linear Equation

Log Equation $\quad$ Trip Ends $=5.58(1000$ SF GFA)
(Equations with $r^{2}<0.5$ are not recommended for use) $r^{2}=0.37$

$r^{2}=0.20$ 


\section{Elementary Schools}

Average Vehicle Trip Ends V/S: 1000 SF GFA

On a: Weekday AM Peak

Number of Studies: 4

Average SEV Value: 68

Directional Distribution: Not Studied

Trip Generation per 1000 SF GFA

\begin{tabular}{|ccc|}
\hline Average Rate & Range of Rates & Standard Deviation \\
\hline 6.90 & $4.06-8.98$ & 2.29 \\
\hline
\end{tabular}

Data Plot

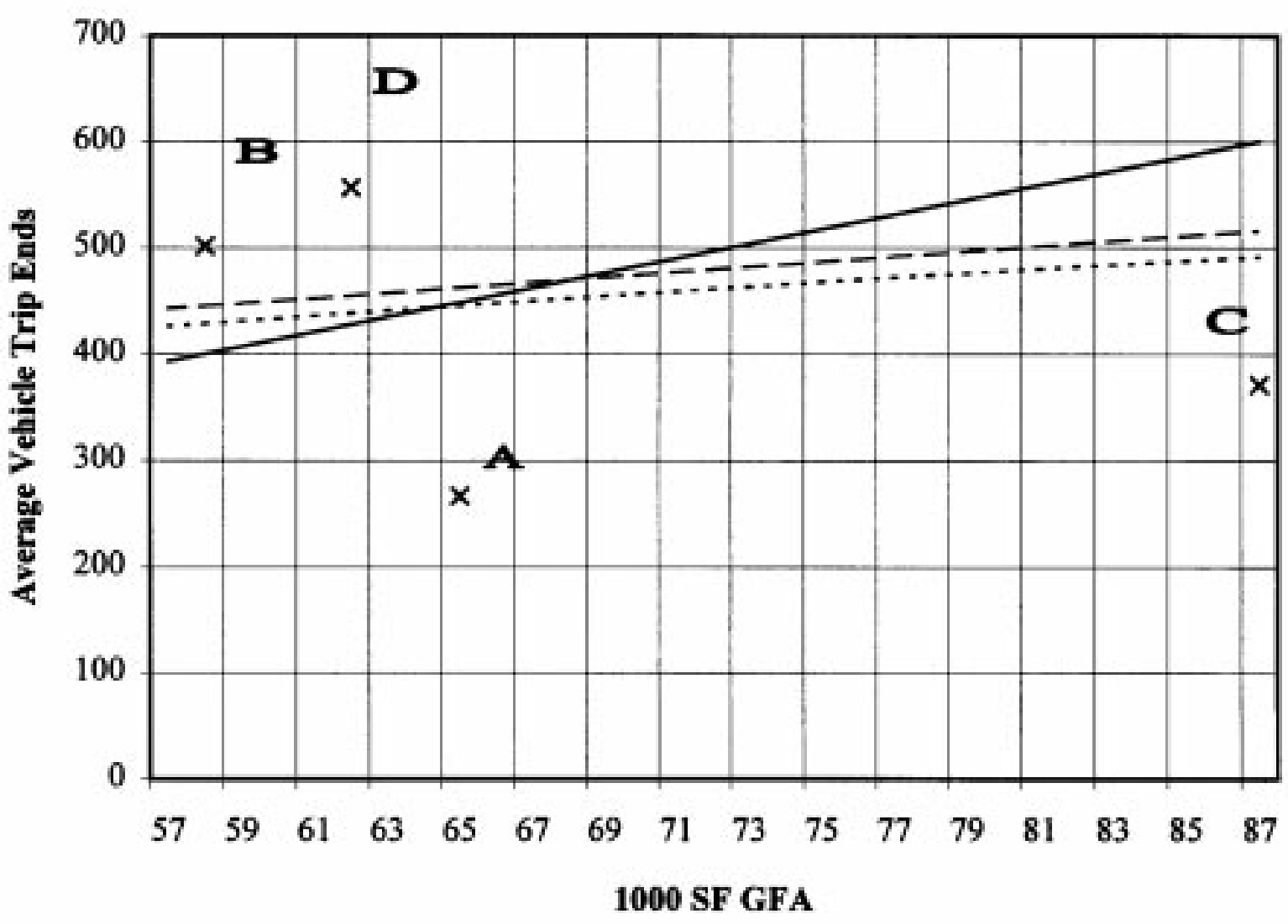

- Average Rate - -.- Linear $\cdots \cdots$ Log $\times$ Data Points

Linear Equation

Log Equation

(Equations with
Trip Ends $-303.40+2.44(1000$ SF GFA)

Trip Ends $=108.85(1000 \text { SF GFA })^{0.4}$

$r^{2}-0.05$

$r^{2}=0.03$ 


\section{Elementary Schools}

Average Vehicle Trip Ends V/S: 1000 SF GFA

On a: Weekday

Number of Studies: 4

Average SEV Value: 68

Directional Distribution: Not Studied

Trip Generation per 1000 SF GFA

\begin{tabular}{|ccc|}
\hline Average Rate & Range of Rates & Standard Deviation \\
\hline 26.33 & $14.47-36.60$ & 9.78 \\
\hline
\end{tabular}

Data Plot

Caution - Use Carefully - Small Sample Stze

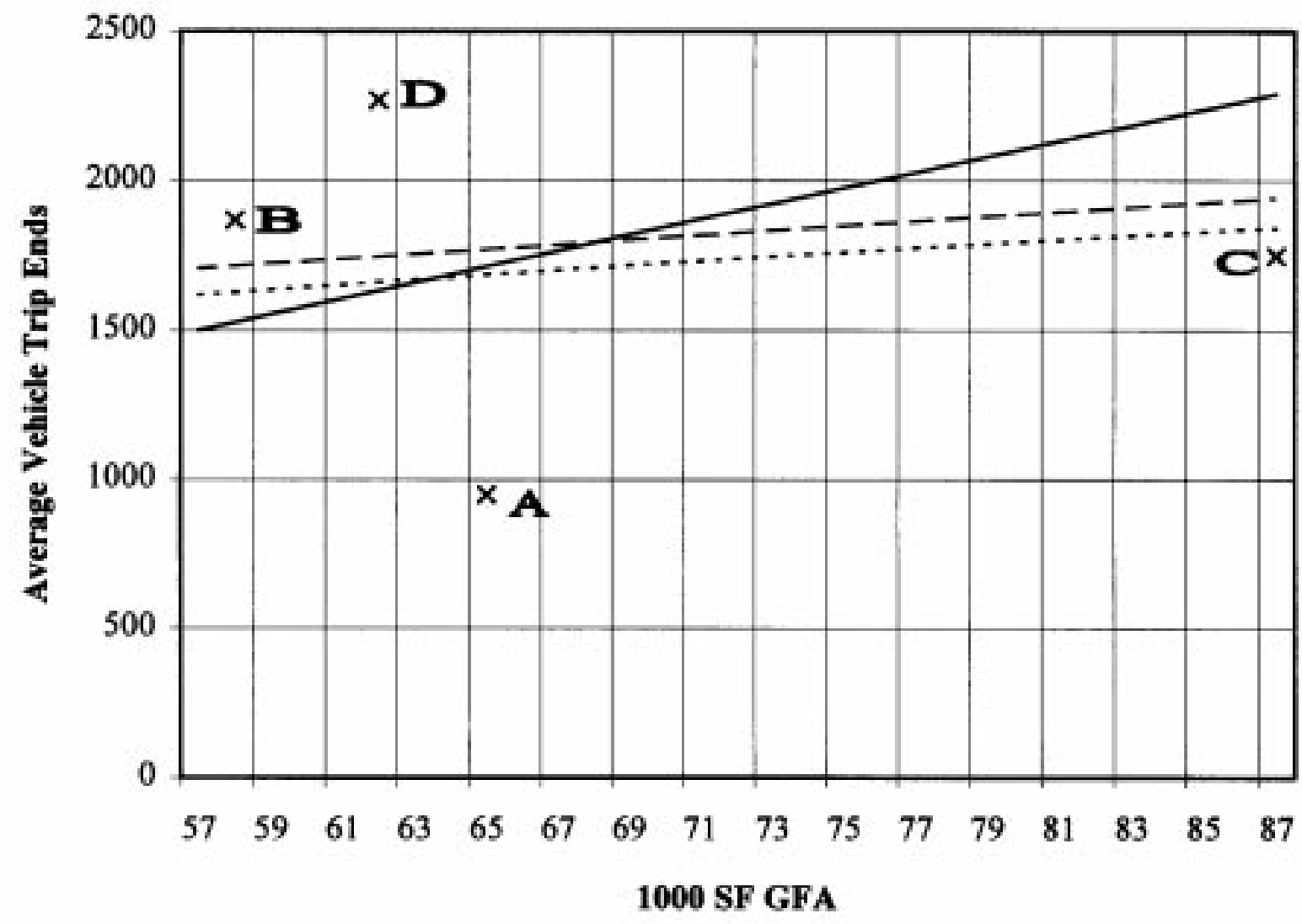

Average Rate $-\cdots$ - Linear $\cdots \cdots \cdot \log \times$ Data Points

Linear Equation

Log Equation $\quad$ Trip Ends $=478.19(1000 \mathrm{SF} \mathrm{GFA}$
(Equatlons with $r^{2}<0.5$ are not recommended for use) $r^{2}=0.03$

$r^{2}=0.02$ 


\section{Elementary Schools}

Average Vehicle Trip Ends V/S: Students

On a: Weekday PM Peak

Number of Studies: 4

Average SEV Value: 542

Directional Distribution: Not Studied

Trip Generation per Student

\begin{tabular}{|ccc|}
\hline Average Rate & Range of Rates & Standard Deviation \\
\hline 0.73 & $0.40-1.30$ & 0.37 \\
\hline
\end{tabular}

Data Plot

Caution - Use Carefully - Small Sample Size

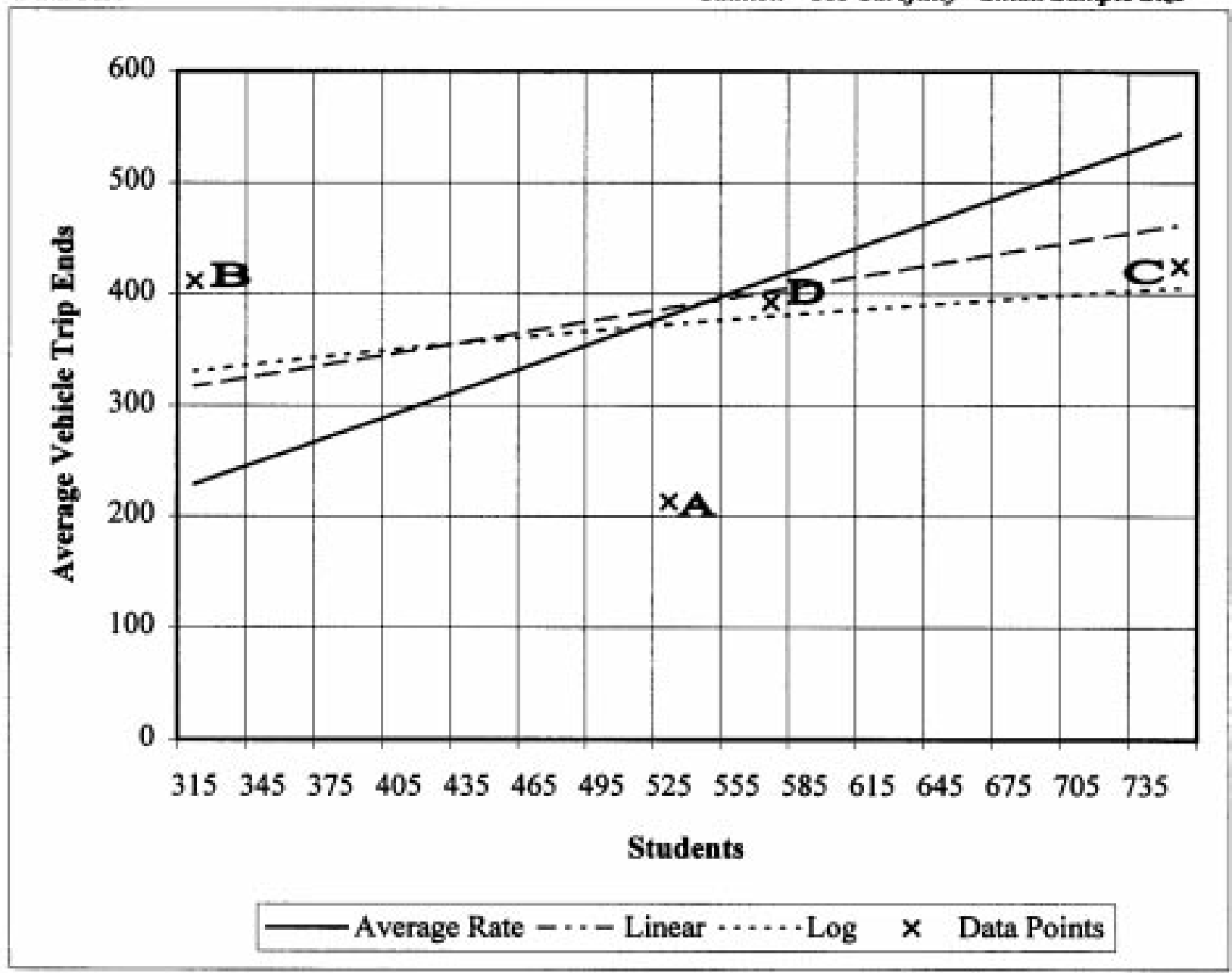

Linear Equation

Trip Ends $=212.04+0.33$ (Students)

$r^{2}=0.18$

Log Equation

Trip Ends=85.63(Students) ${ }^{0.23}$

$r^{2}=0.04$

(Equations with $r^{2}<0.5$ are not recommended for use) 


\section{Elementary Schools}

Average Vehicle Trip Ends V/S: Students

On a: Weekday AM Peak

Number of Studies: 4

Average SEV Value: 542

Directional Distribution: Not Studied

Trip Generation per Student

\begin{tabular}{|ccc|}
\hline Average Rate & Range of Rates & Standard Deviation \\
\hline 0.87 & $0.49-1.58$ & 0.46 \\
\hline
\end{tabular}

Data Plot

Caution - Use Carefully - Small Sample Size

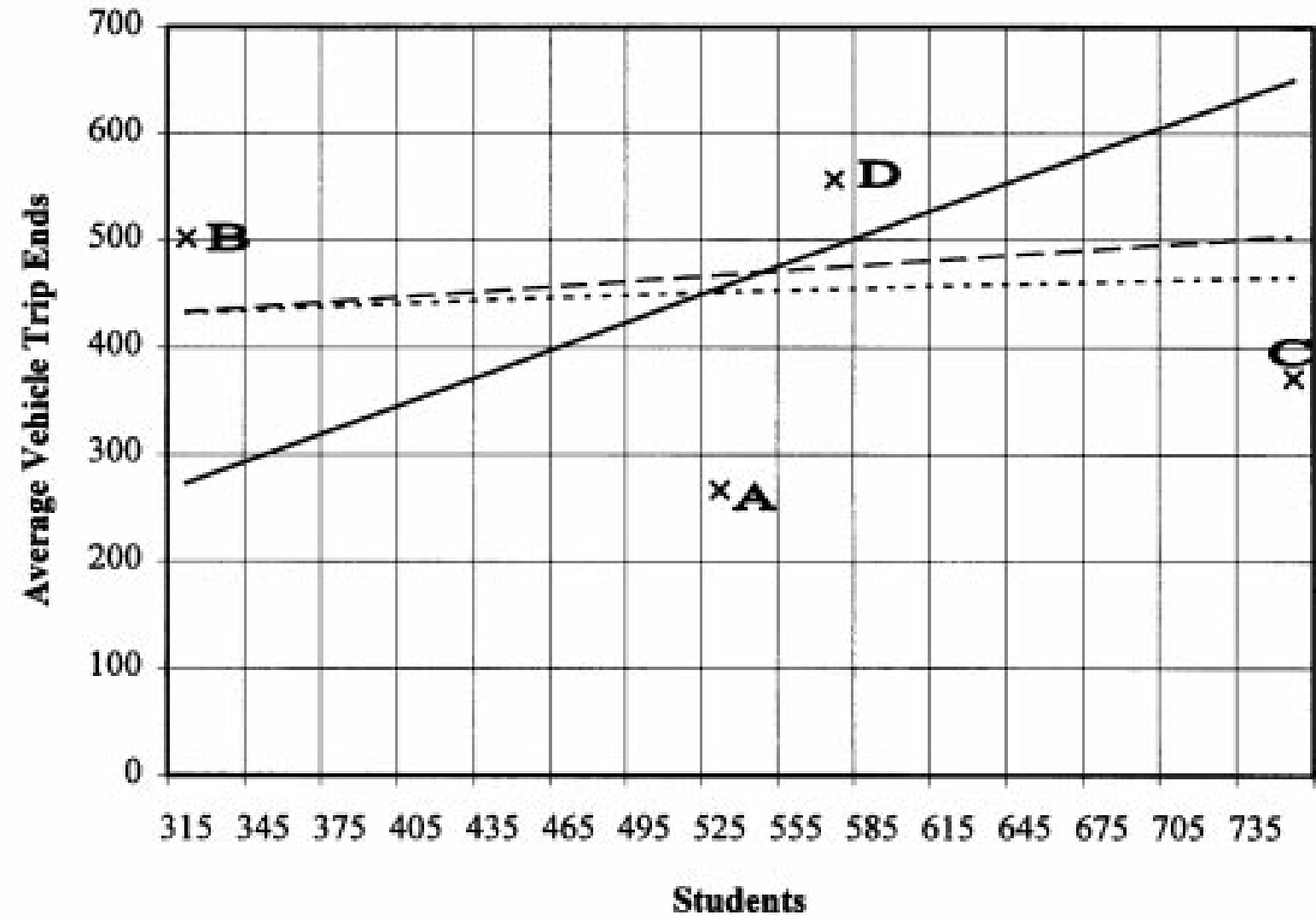

$$
\text { Average Rate }-\cdots \text { - Linear } \cdots \cdot \text { Log } \times \text { Data Points }
$$

Linear Equation

Log Equation

(Equations with $r^{2}<0.5$ are not recommended for use) $r^{2}=0.04$

$r^{2}=0.01$ 


\section{Elementary Schools}

Average Vehicle Trip Ends V/S: Students

On a: Weekday

Number of Studies: 4

Average SEV Value: 542

Directional Distribution: Not Studied

Trip Generation per Student

\begin{tabular}{|ccc|}
\hline Average Rate & Range of Rates & Standard Deviation \\
\hline 3.31 & $1.79-5.89$ & 1.76 \\
\hline
\end{tabular}

Data Plot

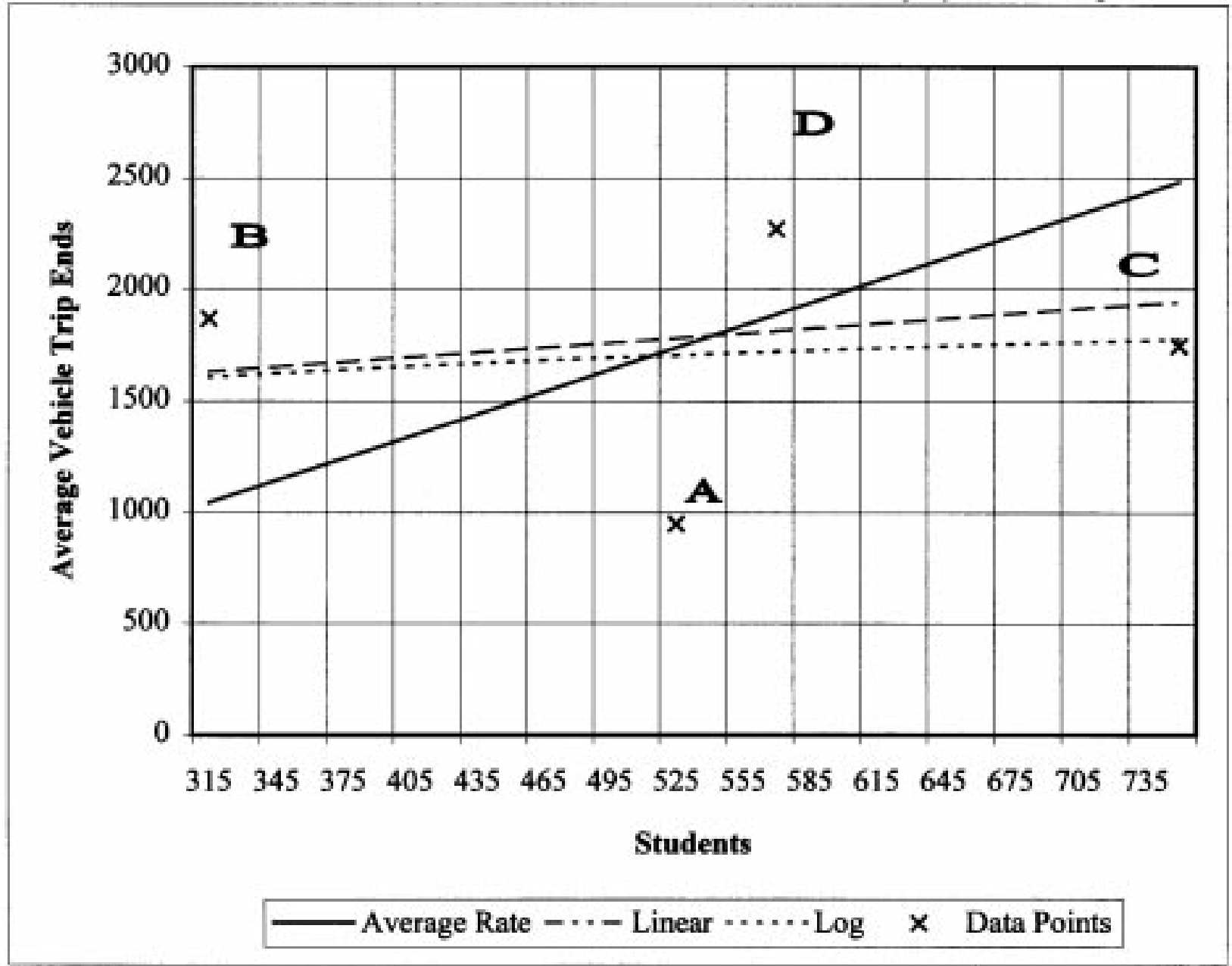

Linear Equation

Trip Ends=1401.83+0.72(Students)

$r^{2}=0.05$

Log Equation

Trip Ends $=820.57$ (Students) ${ }^{0.12}$

$r^{2}=0.01$

(Equations with $r^{2}<0.5$ are not recommended for use) 


\section{Elementary Schools}

Average Vehicle Trip Ends V/S: Employees

On a: Weekday PM Peak

Number of Studies: 4

Average SEV Value: 67

Directional Distribution: Not Studied

Trip Generation per Employee

\begin{tabular}{|ccc|}
\hline Average Rate & Range of Rates & Standard Deviation \\
\hline 5.90 & $3.27-7.10$ & 1.81 \\
\hline
\end{tabular}

Data Plot

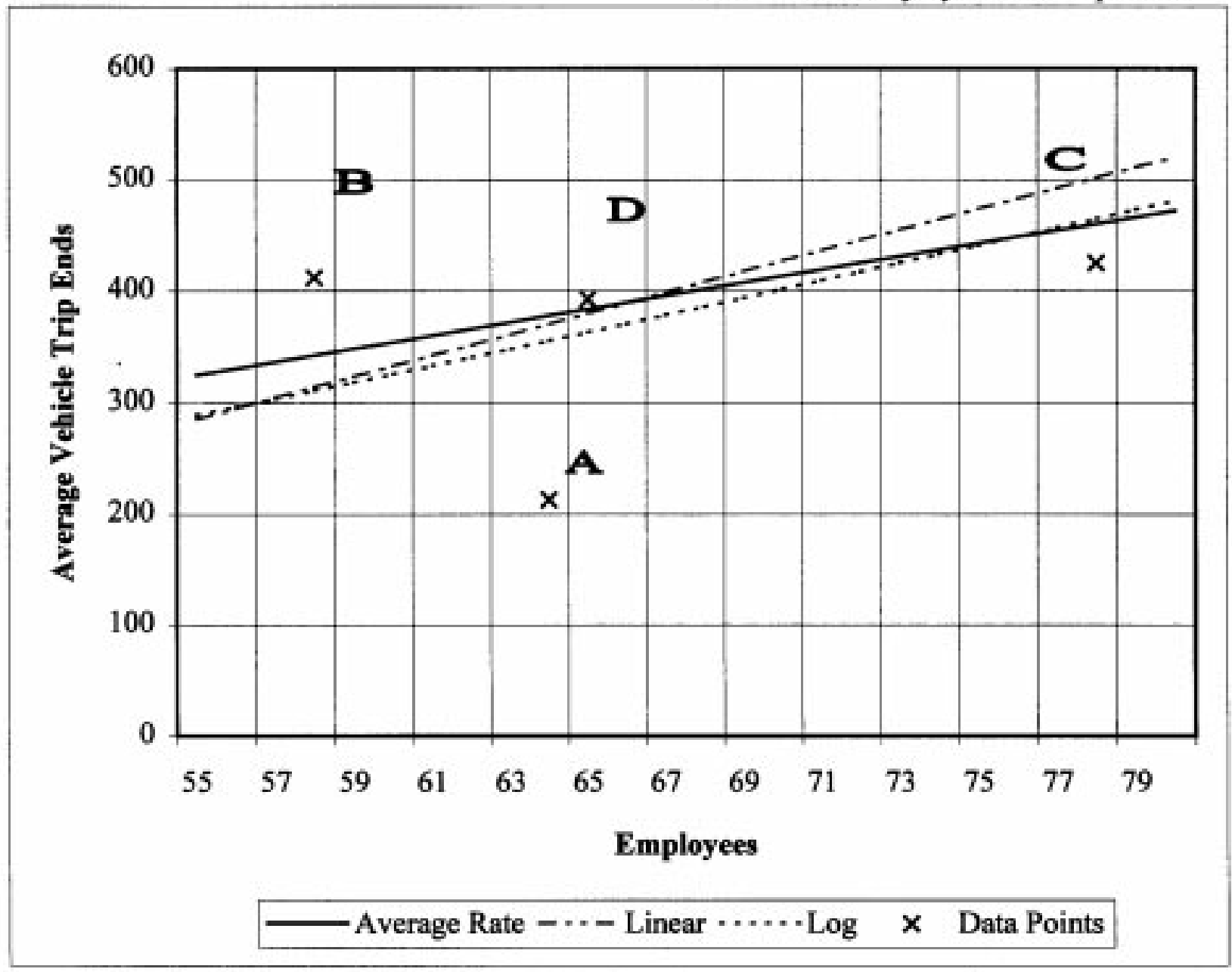

Linear Equation

Trip Ends $=-231.65+9.40$ (Employees)

$r^{2}=0.31$

Log Equation

Trip Ends $=1.25$ (Employees) (1.36 $^{1.3}$

$r^{2}=0.17$

(Equations with $r^{2}<0.5$ are not recommended for use) 


\section{Elementary Schools}

Average Vehicle Trip Ends V/S: Employees

On a: Weekday AM Peak

Number of Studies: 4

Average SEV Value: 67

Directional Distribution: Not Studied

Trip Generation per Employee

\begin{tabular}{|ccc|}
\hline Average Rate & Range of Rates & Standard Deviation \\
\hline 7.06 & $4.10-8.65$ & 2.12 \\
\hline
\end{tabular}

\section{Data Plot}

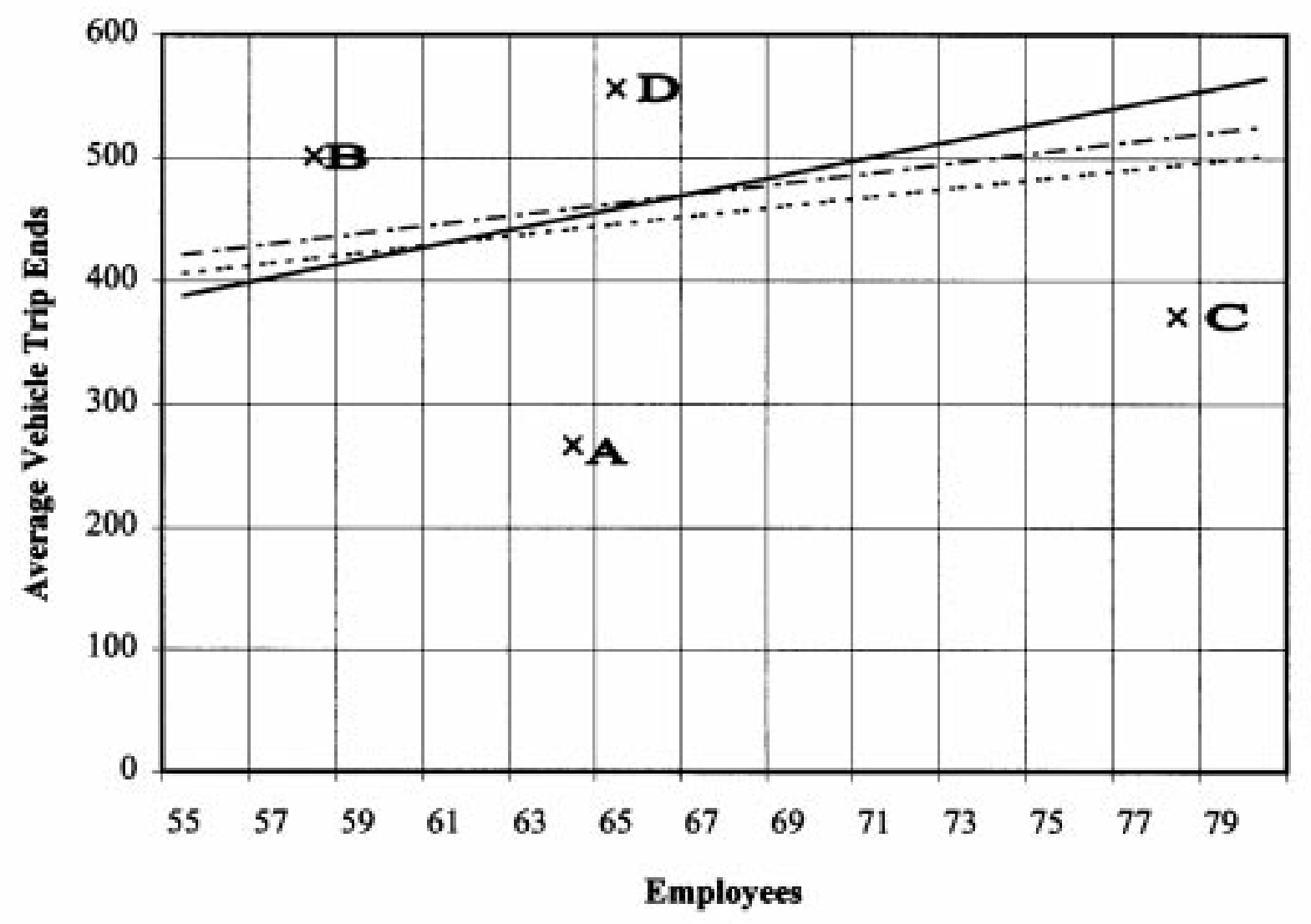

Average Rate $\cdots$ - Linear $\cdots \cdot$ Log $\times$ Data Points

$\begin{array}{lcc}\text { Linear Equation } \quad \text { Trip Ends-191.84+4.18(Employees) } & r^{2}=0.06 \\ \text { Log Equation } \quad \text { Trip Ends-42.10(Employees) } & r^{0.57}=0.04 \\ \text { (Equations with } r^{2}<0.5 \text { are not recommended for use) } & \end{array}$




\section{Elementary Schools}

Average Vehicle Trip Ends V/S: Employees

On a: Weekday

Number of Studies: 4

Average SEV Value: 67

Directional Distribution: Not Studied

Trip Generation per Employee

\begin{tabular}{|ccc|}
\hline Average Rate & Range of Rates & Standard Deviation \\
\hline 26.96 & $14.6-34.92$ & 9.01 \\
\hline
\end{tabular}

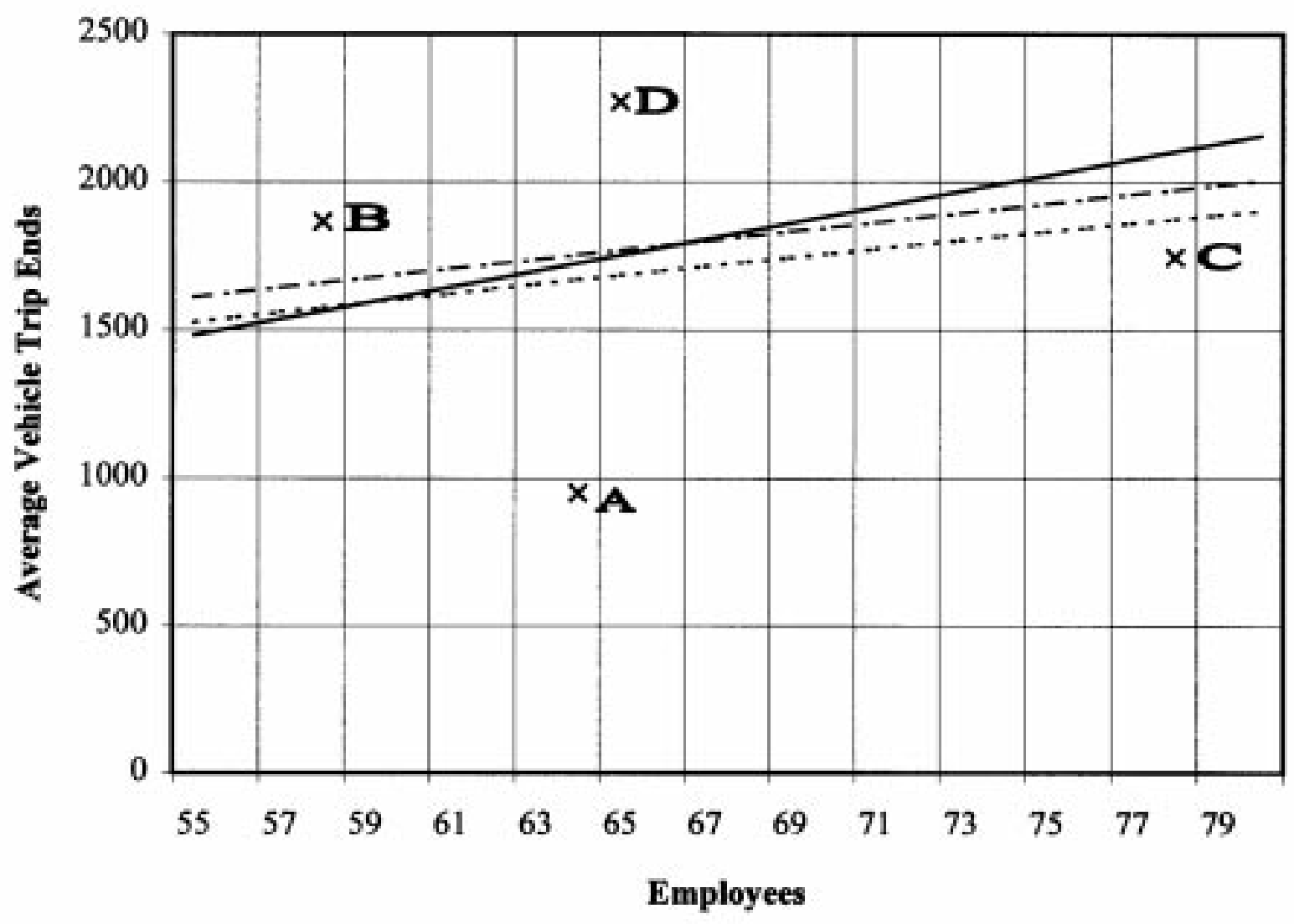

-Average Rate $-\cdots-$ Linear $\cdots \cdots \log \times$ Data Points

$\begin{array}{lll}\text { Linear Equation } & \text { Trip Ends }-748.68+15.70 \text { (Employees) } & r^{2}=0.05 \\ \text { Log Equation } & \text { Trip Ends-145.47(Employees) } & r^{0.99} \\ \end{array}$

(Equations with $r^{2}<0.5$ are not recommended for use) 
Appendix III

\section{Study Data Points Plotted on ITE (1997) Graphs}

\section{For High Schools}




\section{High School \\ (530)}

\section{Average Vehicle Trip Ends vs: 1000 Sq. Feet Gross Floor Area \\ On a: Sunday, \\ Peak Hour of Generator}

Number of Studies: 18

Average $1000 \mathrm{Sq}$. Feet GFA: 217

Directional Distribution: $33 \%$ entering, $67 \%$ exiting

Trip Generation per 1000 Sq. Feet Gross Floor Area

\begin{tabular}{|cccc|}
\hline Average Rate & Range of Rates & Standard Deviation \\
\hline 0.30 & 0.06 & -1.79 & 0.67 \\
\hline
\end{tabular}

\section{Data Plot and Equation}

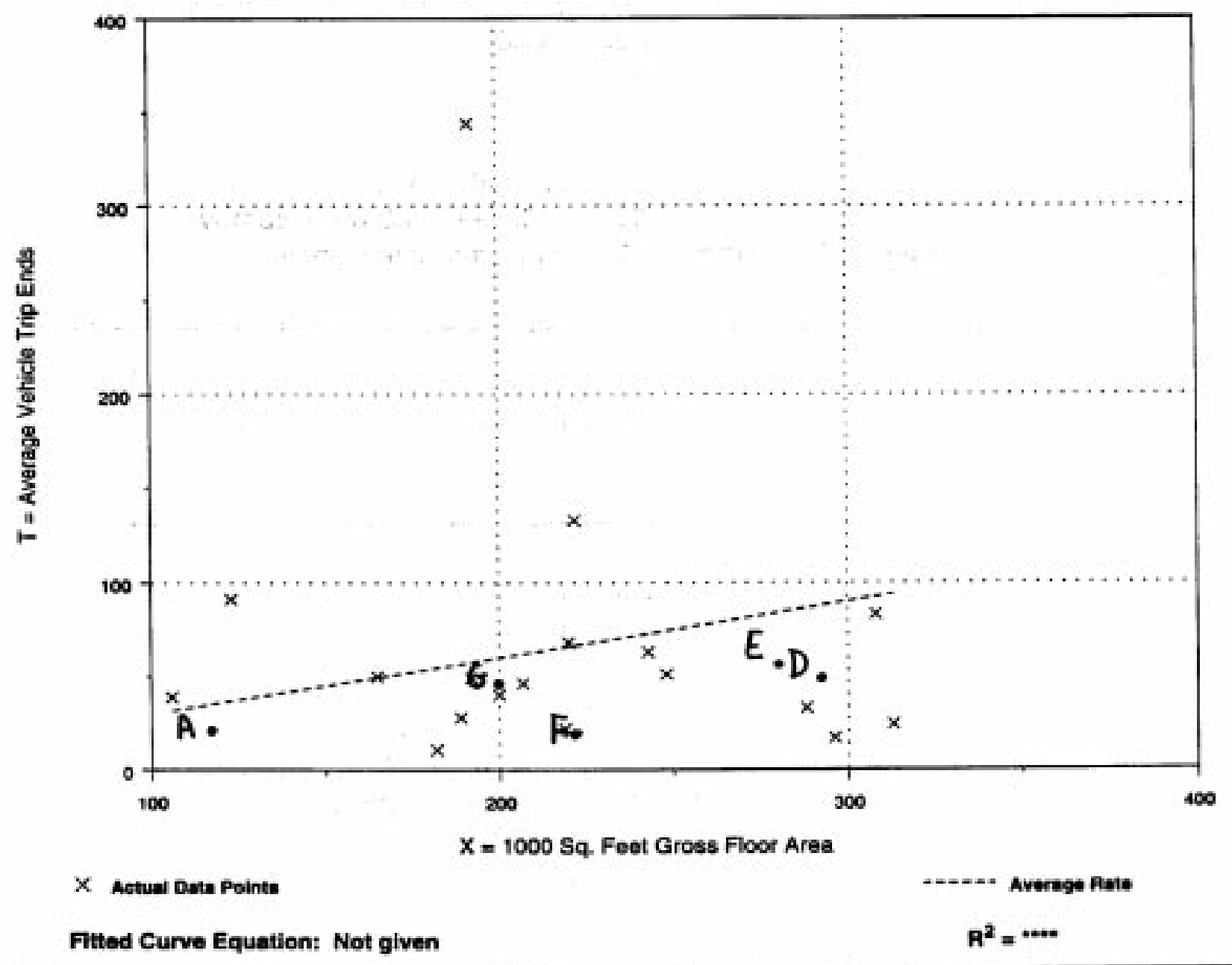




\title{
High School \\ (530)
}

\section{Average Vehicle Trip Ends vs: 1000 Sq. Feet Gross Floor Area \\ On a: Sunday}

\author{
Number of Studies: 18 \\ Average $1000 \mathrm{Sq}$. Feet GFA: 217 \\ Directional Distribution: $50 \%$ entering, $50 \%$ exiting
}

\section{Trip Generation per 1000 Sq. Feet Gross Floor Area}

\begin{tabular}{|cccc|}
\hline Average Rate & Range of Rates & Standard Deviation \\
\hline 1.72 & 0.30 & 8.19 & 2.24 \\
\hline
\end{tabular}

\section{Data Plot and Equation}

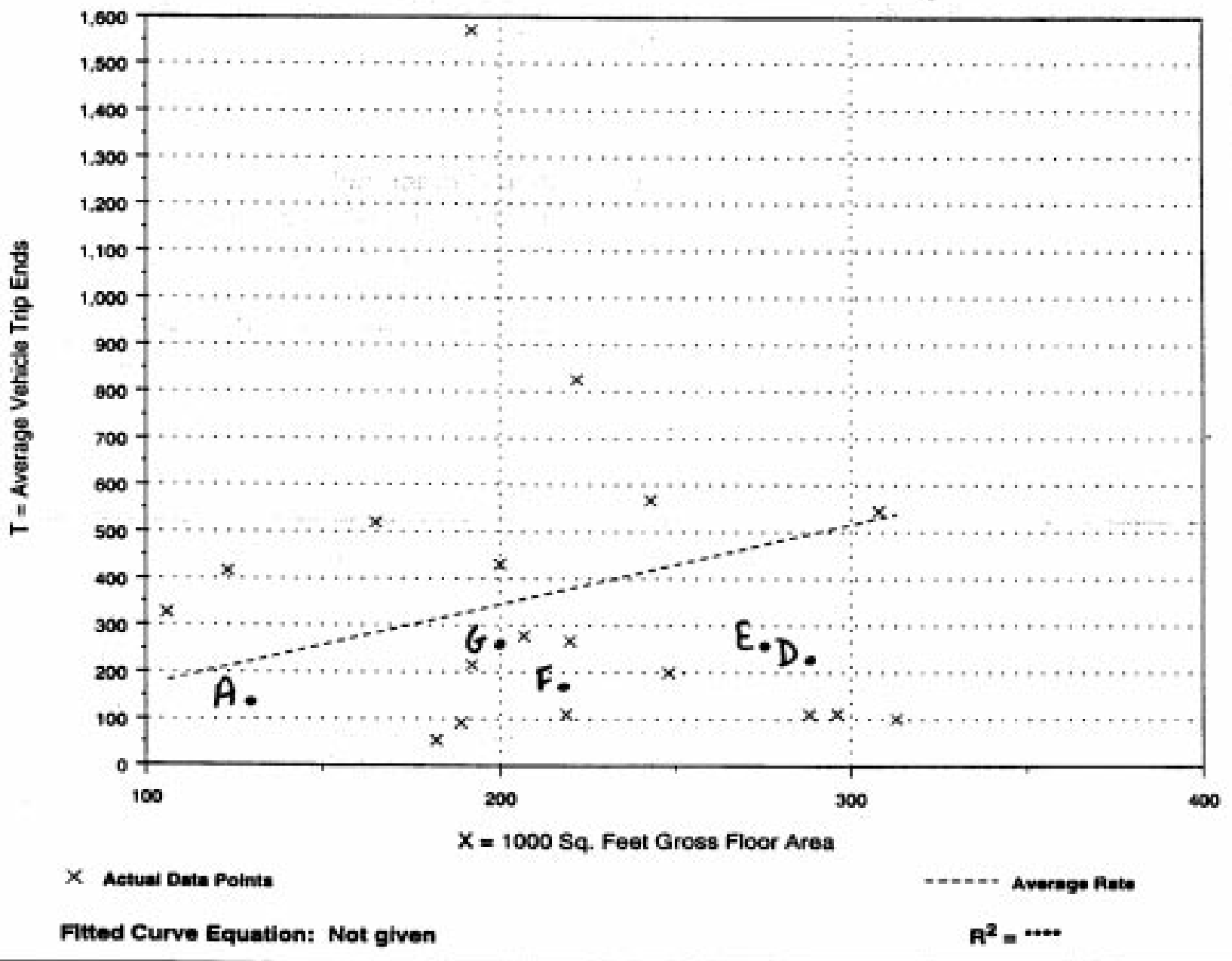




\section{High School (530)}

\section{Average Vehicle Trip Ends vs: 1000 Sq. Feet Gross Floor Area \\ On a: Saturday, \\ Peak Hour of Generator}

Number of Studies: 18

Average $1000 \mathrm{Sq}$. Feet GFA: 217

Directional Distribution: $74 \%$ entering, $26 \%$ exiting

\section{Trip Generation per 1000 Sq. Feet Gross Floor Area}

\begin{tabular}{|cllc|}
\hline Average Pate & Range of Rates & Standard Deviation \\
\hline 0.80 & 0.08 & 2.08 & 1.09 \\
\hline
\end{tabular}

\section{Data Plot and Equation}

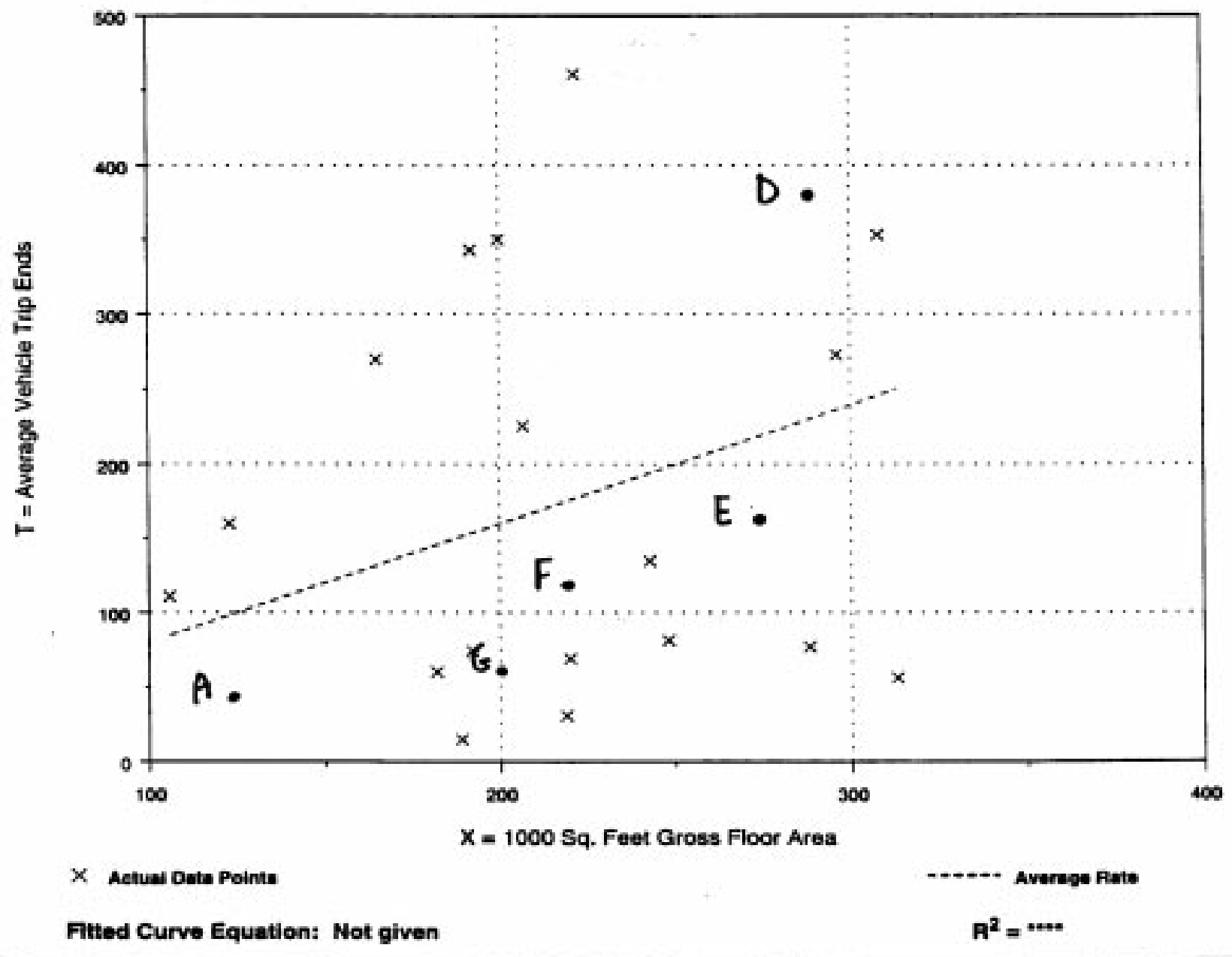




\section{High School (530)}

Average Vehicle Trip Ends vs: 1000 Sq. Feet Gross Floor Area

On a: Saturday

Number of Studies: 18

Average $1000 \mathrm{Sq}$. Feet GFA: 217

Directional Distribution: $50 \%$ entering, $50 \%$ exiting

Trip Generation per 1000 Sq. Feet Gross Floor Area

\begin{tabular}{|clcc|}
\hline Average Rate & Range of Rates & Standard Deviation \\
\hline 4.33 & $0.31-8.85$ & 3.76 \\
\hline
\end{tabular}

\section{Data Plot and Equation}

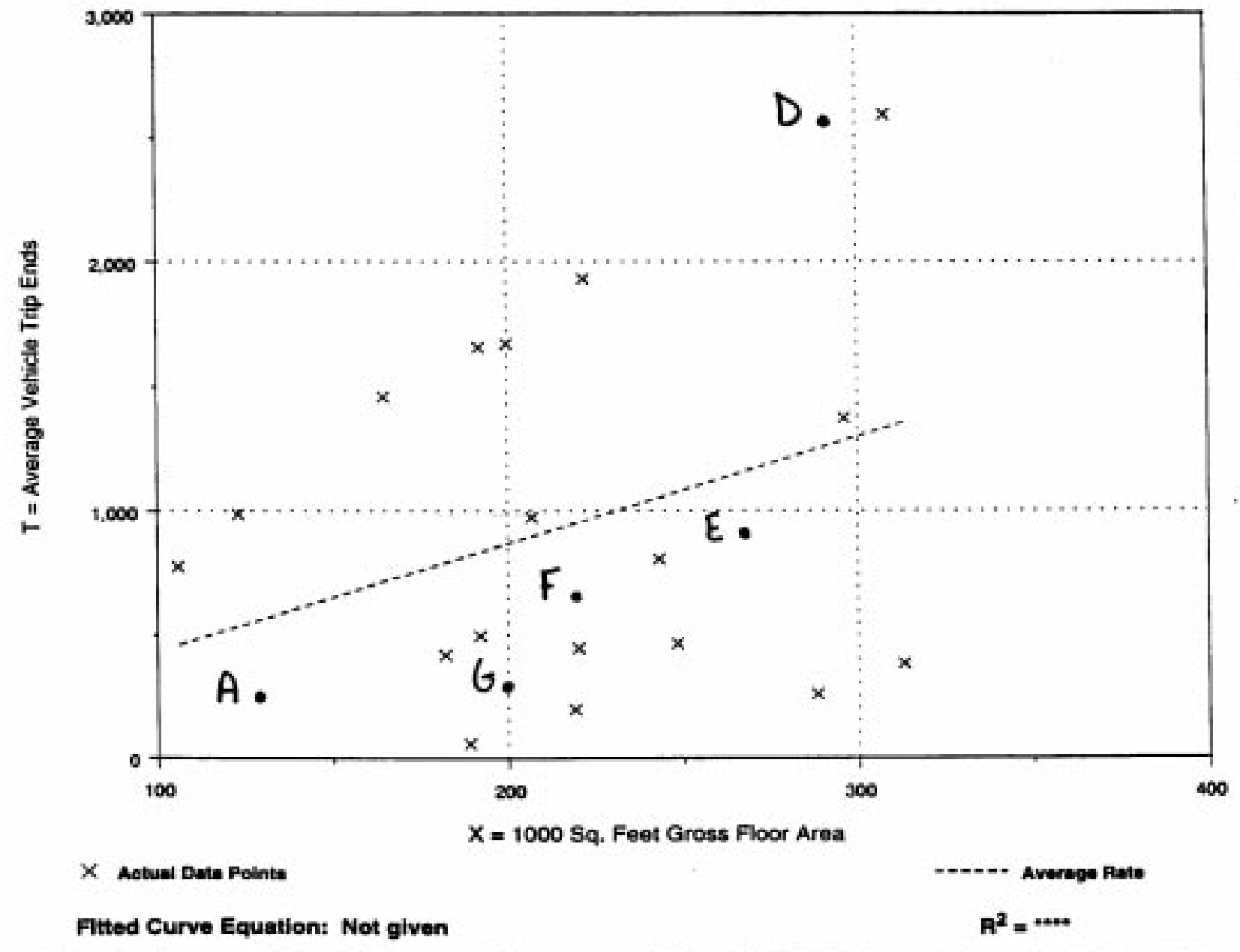




\section{High School (530)}

\section{Average Vehicle Trip Ends vs: 1000 Sq. Feet Gross Floor Area \\ On a: Weekday, \\ P.M. Peak Hour of Generator}

Number of Studies: 38

Average $1000 \mathrm{Sq}$. Feet GFA: 187

Directional Distribution: $30 \%$ entering, $70 \%$ exiting

Trip Generation per 1000 Sq. Feet Gross Floor Area

\begin{tabular}{|cccc|}
\hline Average Rate & Range of Rates & Standard Deviation \\
\hline 2.21 & $0.98-5.14$ & 1.78 \\
\hline
\end{tabular}

\section{Data Plot and Equation}

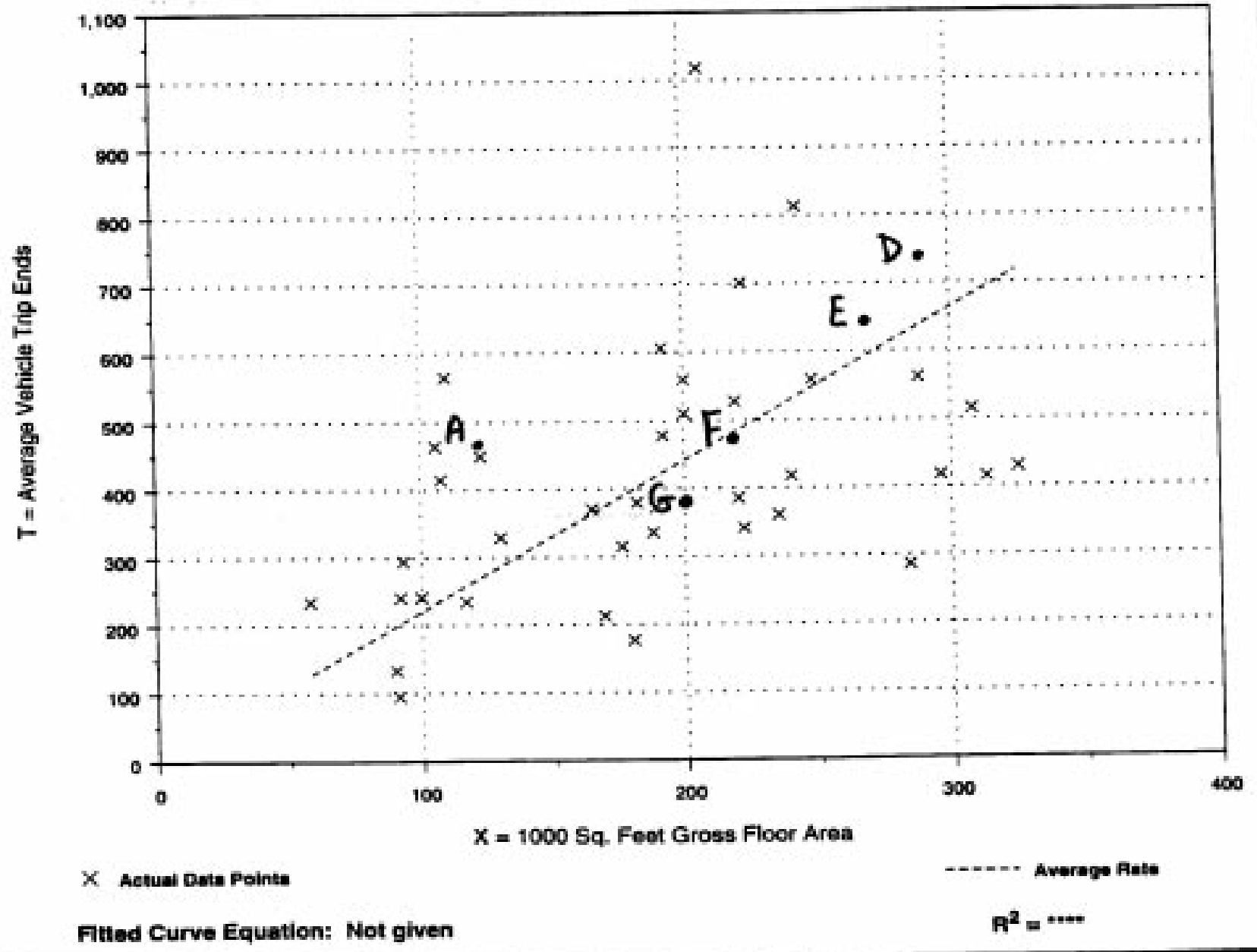




\section{High School (530)}

\section{Average Vehicle Trip Ends vs: 1000 Sq. Feet Gross Floor Area \\ On a: Weekday,}

A.M. Peak Hour of Generator

Number of Studies: 38

Average $1000 \mathrm{Sq}$. Feet GFA: 187

Directional Distribution: $72 \%$ entering, $28 \%$ exiting

\section{Trip Generation per 1000 Sq. Feet Gross Floor Area}

\begin{tabular}{|cccc|}
\hline Average Rate & Range of Rates & Standard Deviation \\
\hline 3.15 & $0.51 \quad-9.86$ & 2.47 \\
\hline
\end{tabular}

\section{Data Plot and Equation}

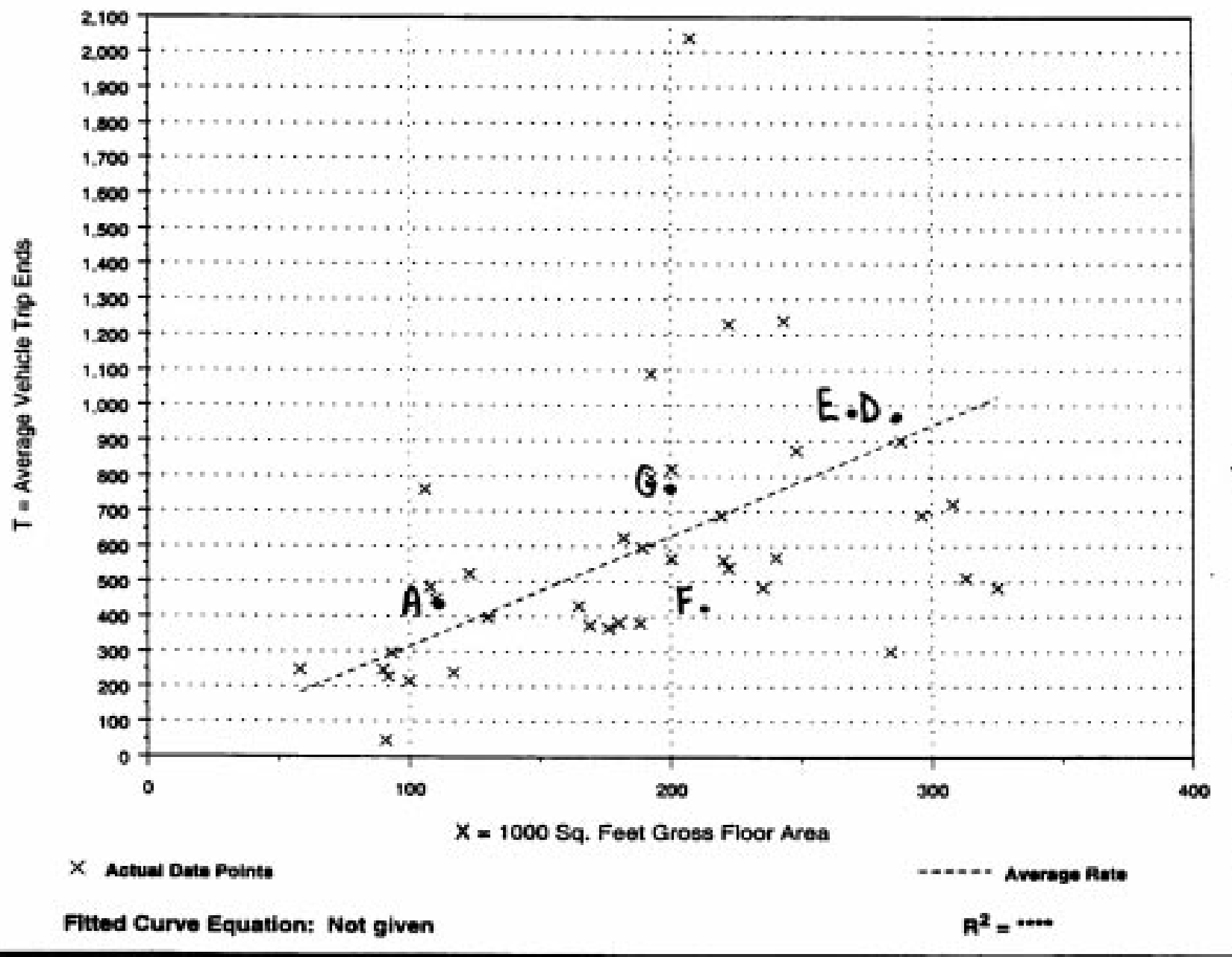




\section{High School \\ (530)}

\section{Average Vehicle Trip Ends vs: 1000 Sq. Feet Gross Floor Area \\ On a: Weekday}

Number of Studies: 38

Average $1000 \mathrm{Sq}$. Feet GFA: 187

Directional Distribution: $50 \%$ entering, $50 \%$ exiting

Trip Generation per 1000 Sq. Feet Gross Floor Area

\begin{tabular}{|ccc|}
\hline Average Pate & Range of Rates & Standard Deviation \\
\hline 13.27 & $4.00 \quad 34.06$ & 7.51 \\
\hline
\end{tabular}

\section{Data Plot and Equation}

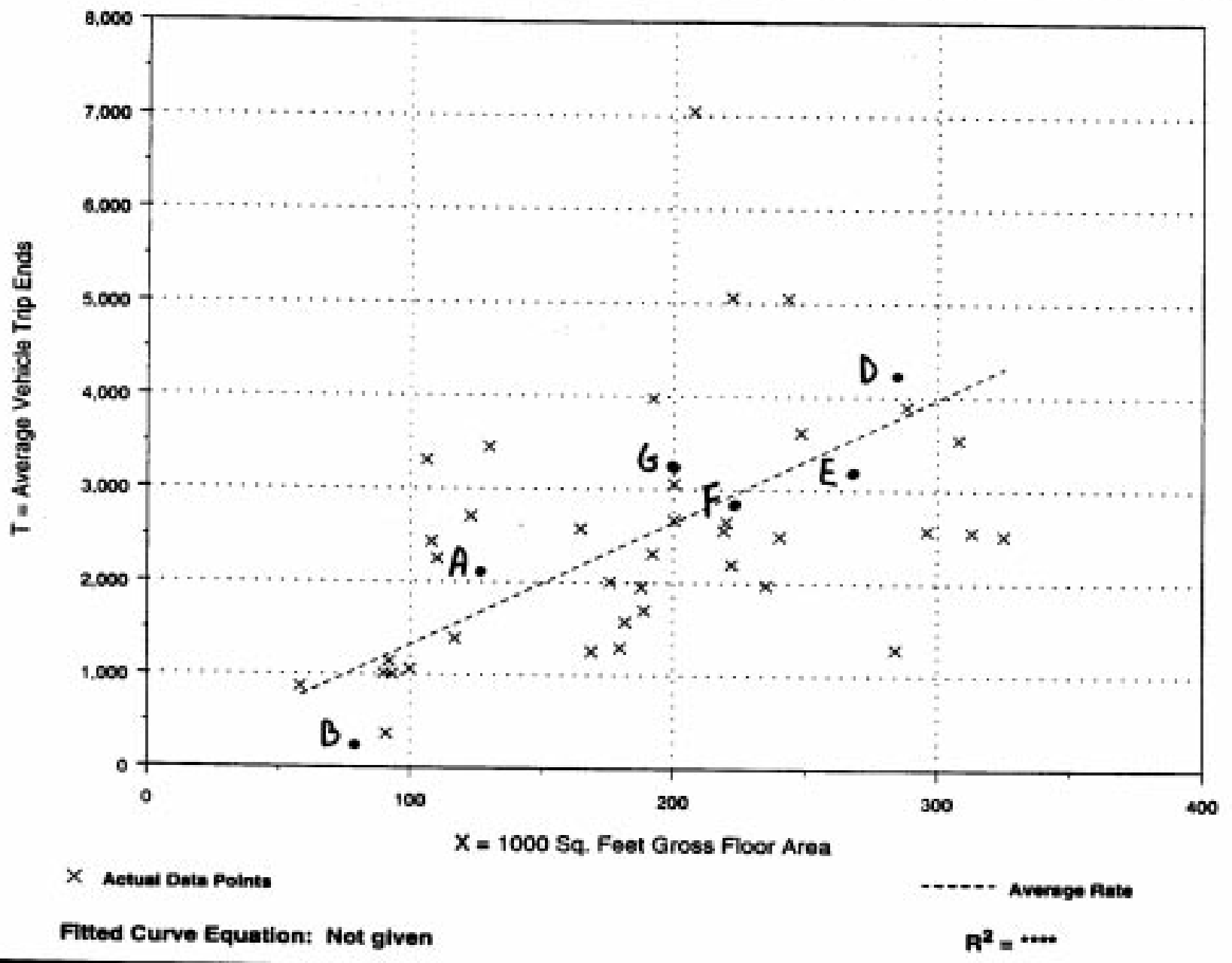




\section{High School}

(530)

\section{Average Vehicle Trip Ends vs: Students \\ On a: Sunday, \\ Peak Hour of Generator}

Number of Studies: 18

Average Number of Students: 1,481

Directional Distribution: $33 \%$ entering, $67 \%$ exiting

\section{Trip Generation per Student}

\begin{tabular}{|ccc|}
\hline Averago Rate & Range of Rates & Standard Deviation \\
\hline 0.04 & $0.01 \quad 0.20$ & 0.22 \\
\hline
\end{tabular}

\section{Data Plot and Equation}

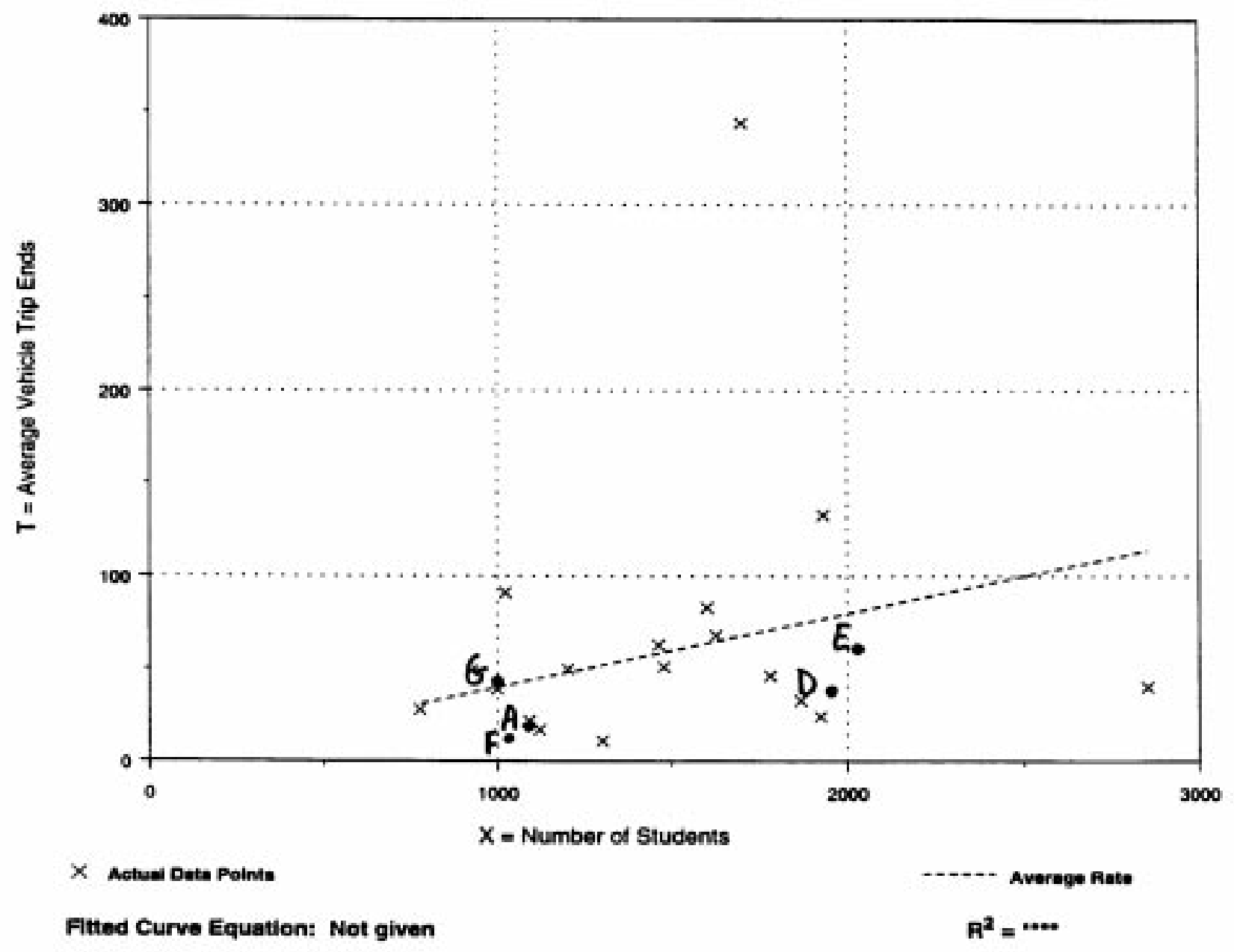




\section{High School \\ (530)}

\section{Average Vehicle Trip Ends vs: Students \\ On a: Sunday}

Number of Studies: 18

Average Number of Students: 1,481

Directional Distribution: $50 \%$ entering, $50 \%$ exiting

\section{Trip Generation per Student}

\begin{tabular}{|ccc|}
\hline Average Rate & Range of Pates & Standard Deviation \\
\hline 0.25 & $0.04 \quad 0.92$ & 0.55 \\
\hline
\end{tabular}

\section{Data Plot and Equation}

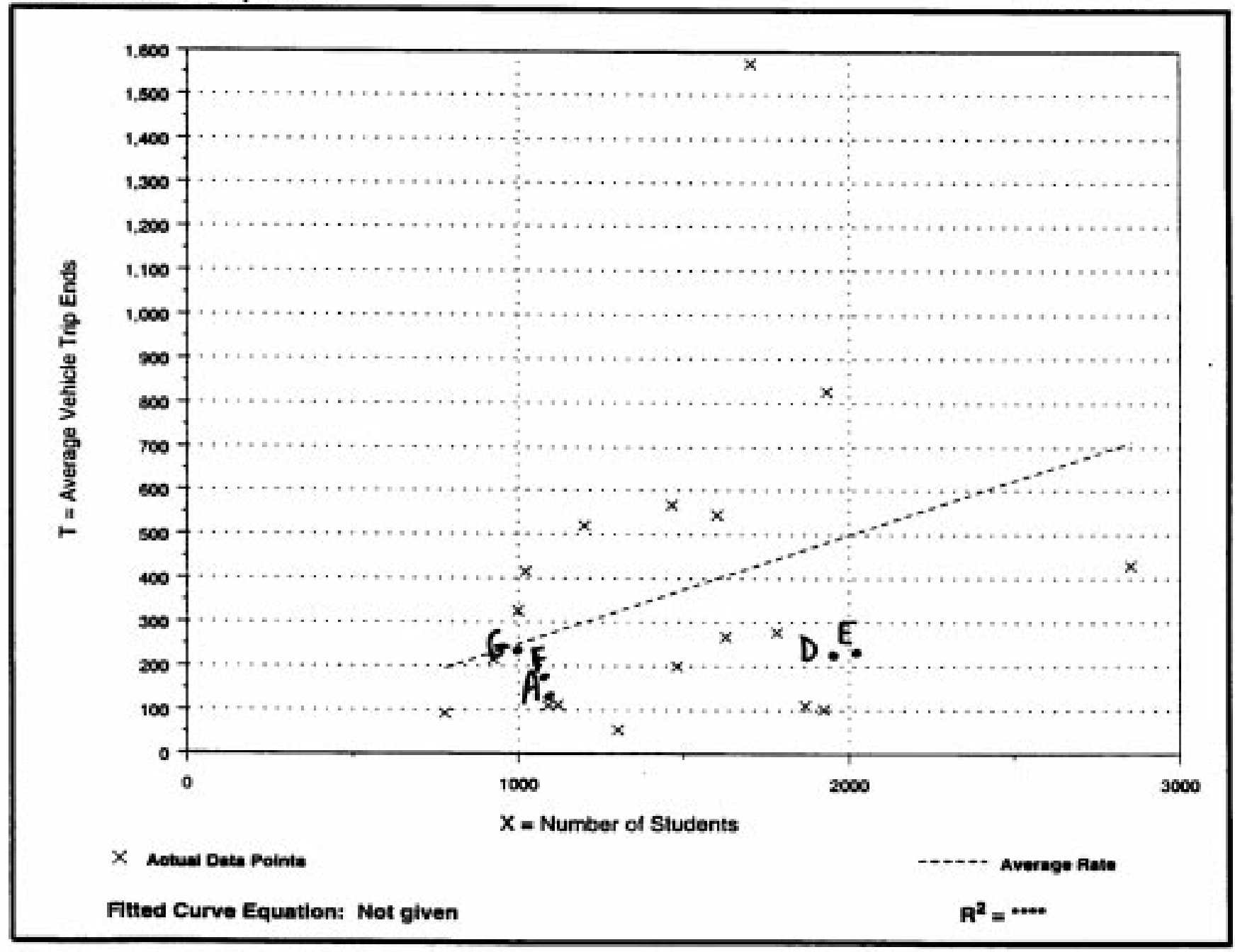




\title{
High School (530)
}

\section{Average Vehicle Trip Ends vs: Students \\ On a: Saturday, \\ Peak Hour of Generator}

\author{
Number of Studies: 18 \\ Average Number of Students: 1,481 \\ Directional Distribution: $74 \%$ entering, $26 \%$ exiting
}

Trip Generation per Student

\begin{tabular}{|cccc|}
\hline Average Rate & Range of Rates & Standard Deviation \\
\hline 0.12 & 0.02 & 0.24 & 0.35 \\
\hline
\end{tabular}

\section{Data Plot and Equation}

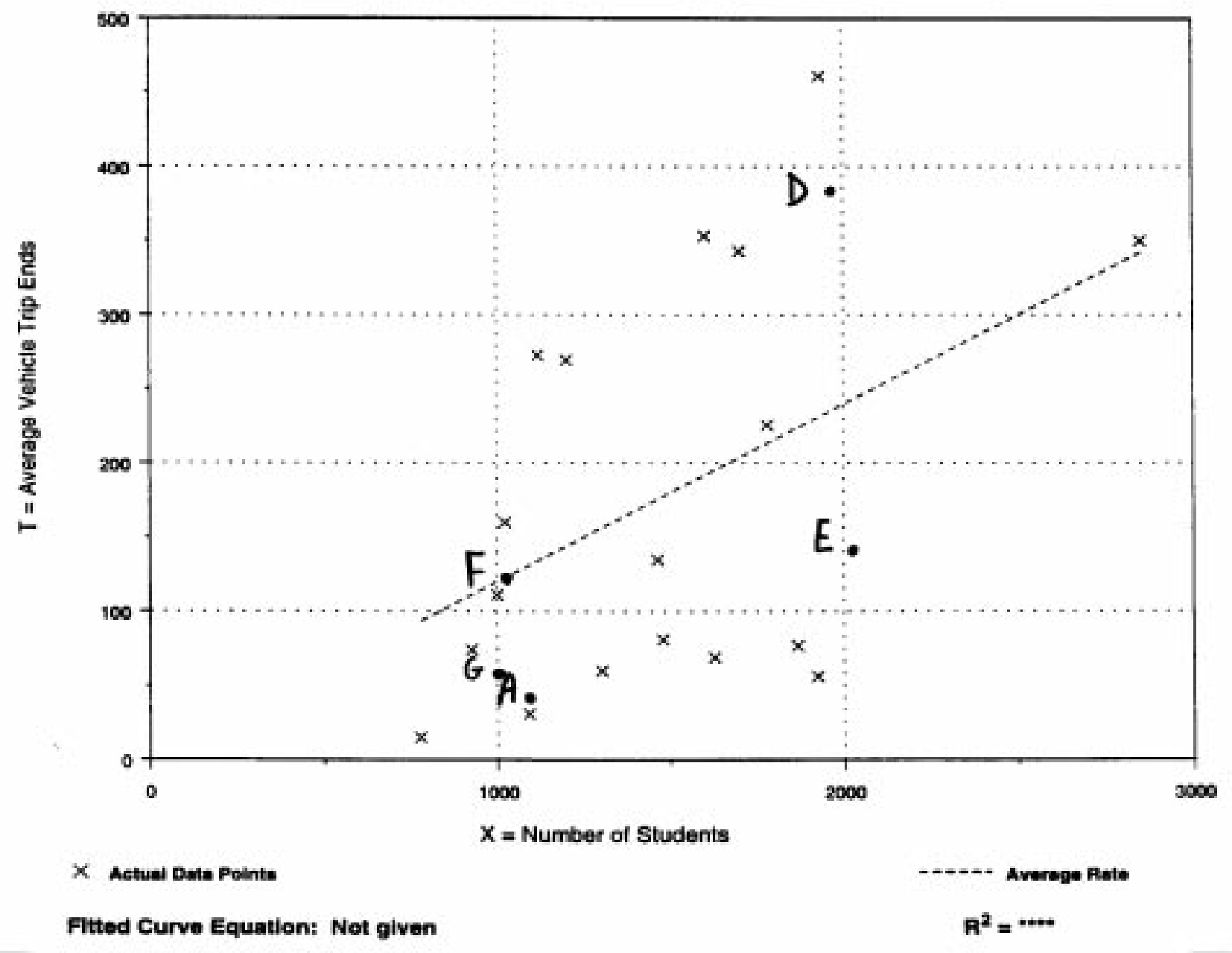




\section{High School \\ (530)}

\section{Average Vehicle Trip Ends vs: Students \\ On a: Saturday}

Number of Studies: 18

Average Number of Students: 1,481

Directional Distribution: $50 \%$ entering, $50 \%$ exiting

\section{Trip Generation per Student}

\begin{tabular}{|clcc|}
\hline Average Rate & \multicolumn{2}{c|}{ Range of Rates } & Standard Deviation \\
\hline 0.64 & $0.08-1.62$ & 0.90 \\
\hline
\end{tabular}

\section{Data Plot and Equation}

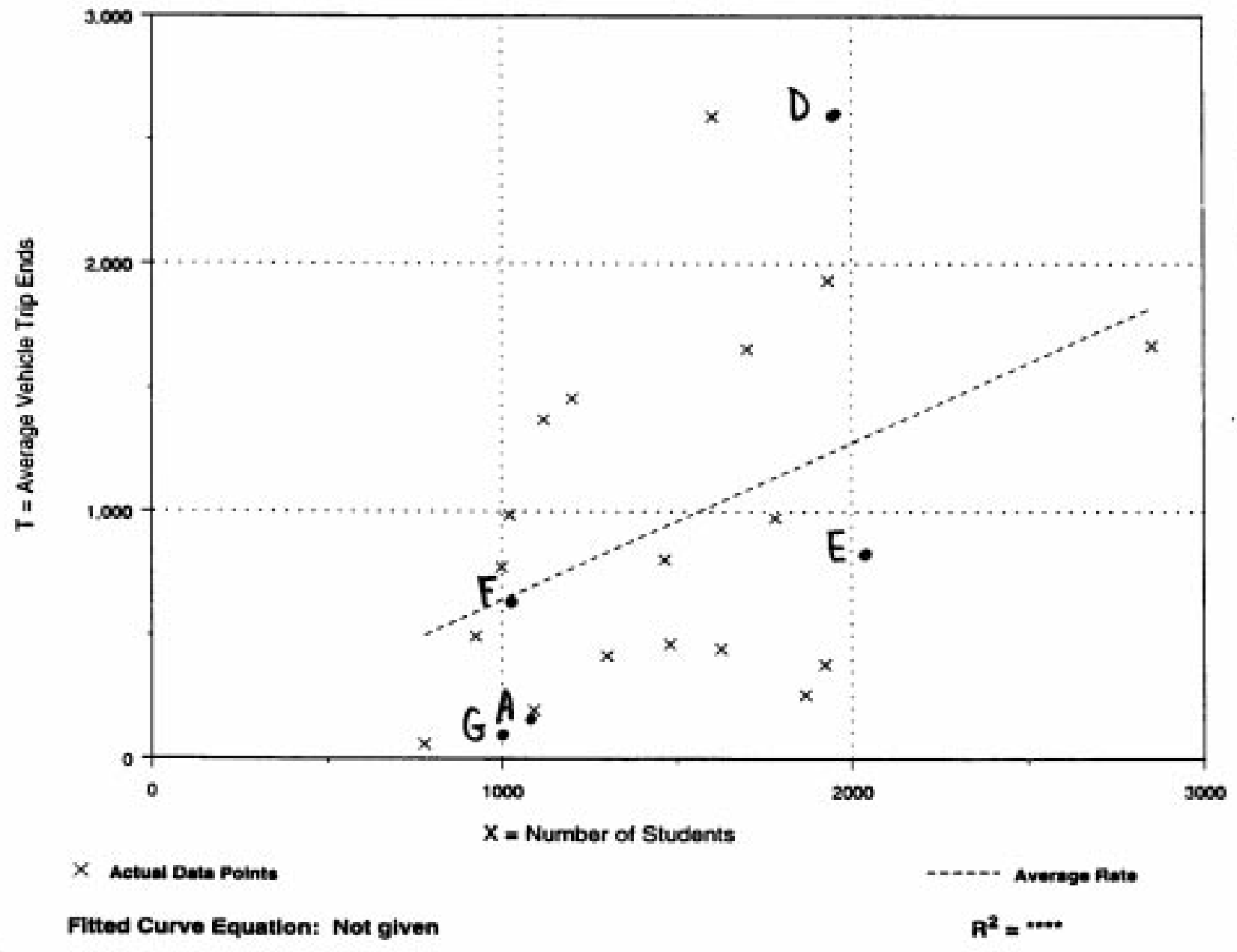




\title{
High School (530)
}

\section{Average Vehicle Trip Ends vs: Students \\ On a: Weekday, \\ P.M. Peak Hour of Generator}

\author{
Number of Studies: 54 \\ Average Number of Students: 1,253 \\ Directional Distribution: $31 \%$ entering, $69 \%$ exiting
}

\section{Trip Generation per Student}

\begin{tabular}{|c|c|c|}
\hline Average Rate & Range of Rates & Standard Deviation \\
\hline 0.30 & $0.10-0.57$ & 0.56 \\
\hline
\end{tabular}

\section{Data Plot and Equation}

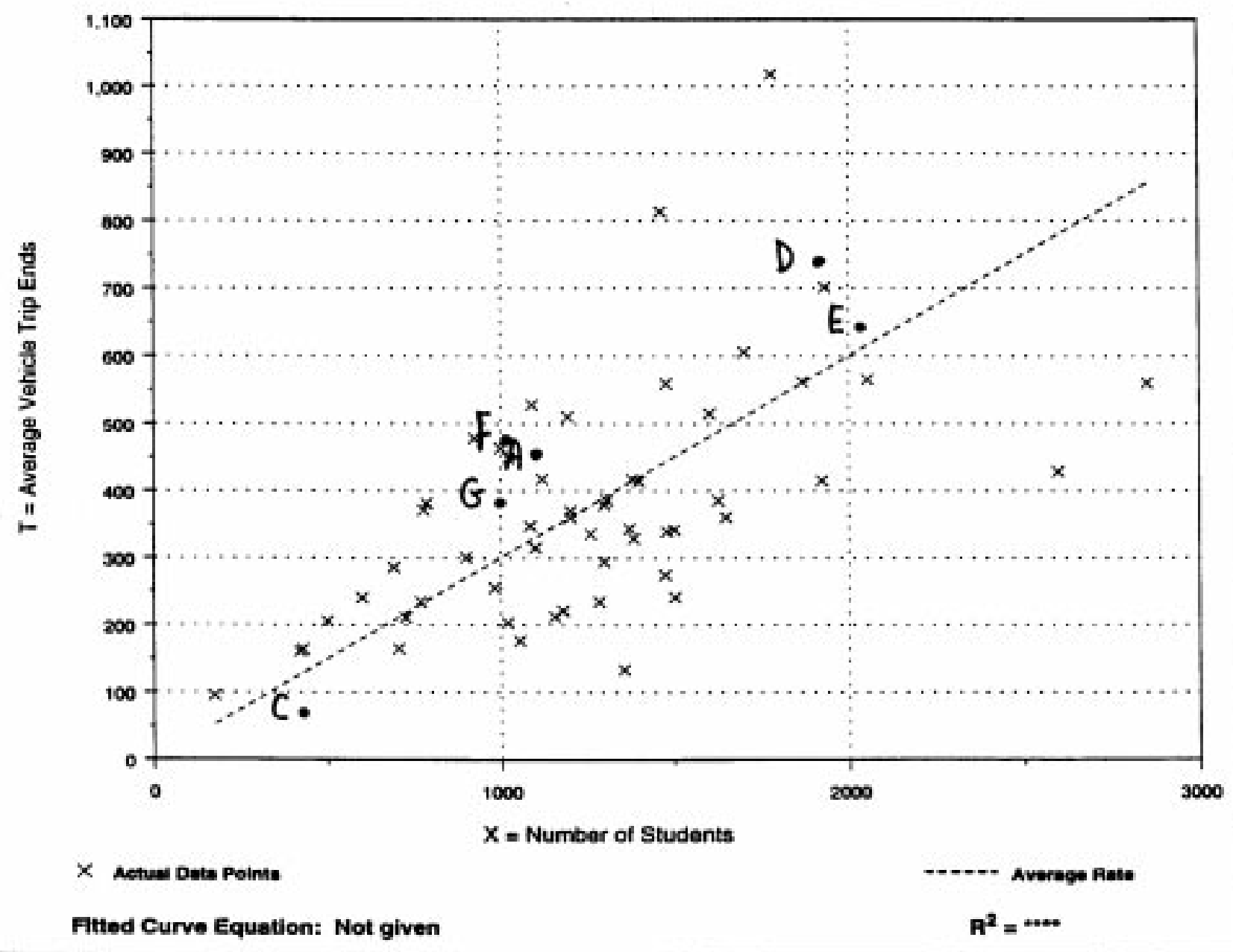




\section{High School}

(530)

\section{Average Vehicle Trip Ends vs: Students \\ On a: Weekday, \\ A.M. Peak Hour of Generator}

Number of Studies: 54

Average Number of Students: 1,253

Directional Distribution: $71 \%$ entering, $29 \%$ exiting

\section{Trip Generation per Student}

\begin{tabular}{|clcc|}
\hline Average Rate & Range of Rates & Standard Deviation \\
\hline 0.42 & $0.14 \cdot 1.15$ & 0.68 \\
\hline
\end{tabular}

\section{Data Plot and Equation}

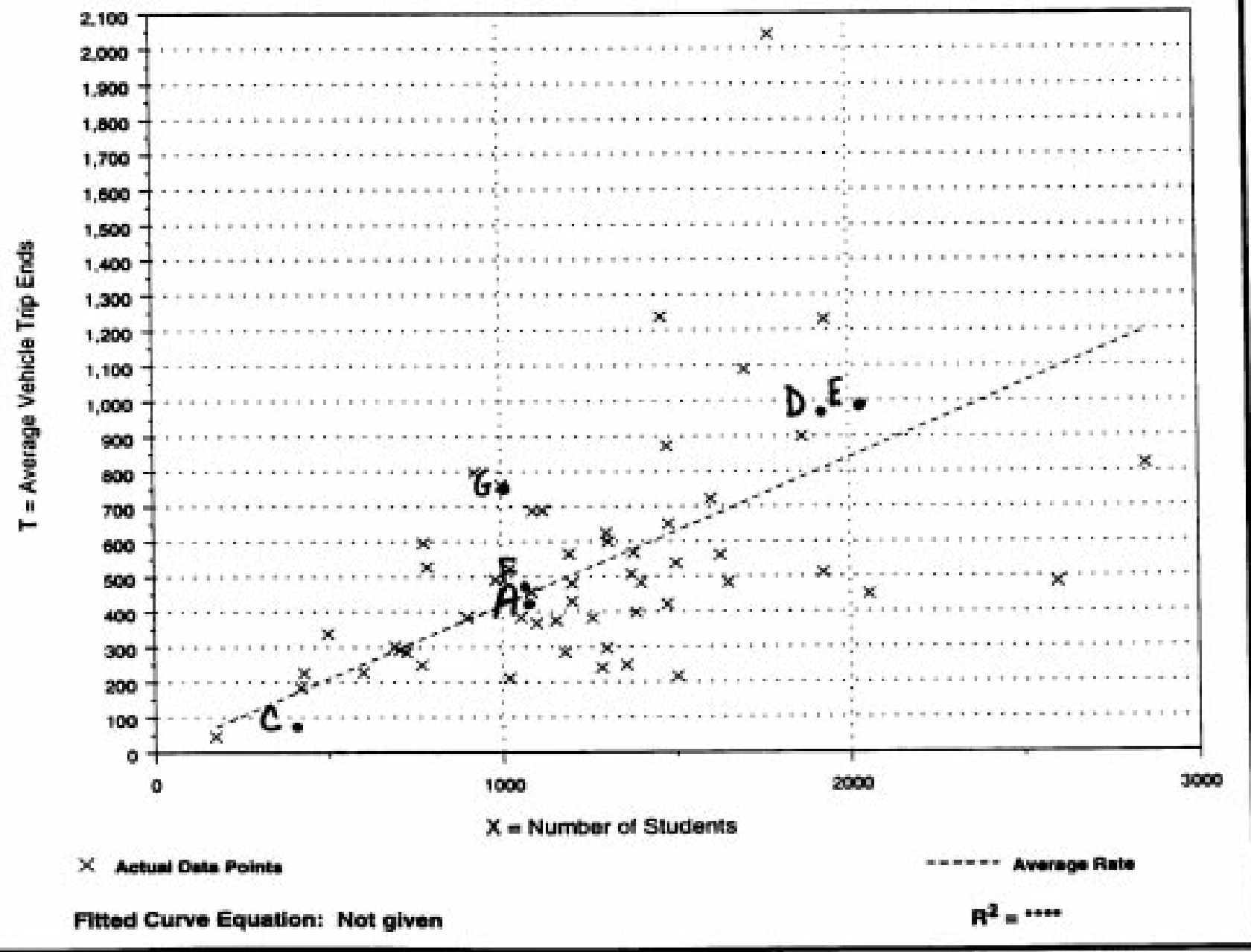




\section{High School}

(530)

\section{Average Vehicle Trip Ends vs: Students \\ On a: Weekday}

Number of Studies: 45

Average Number of Students: 1,309

Directional Distribution: $50 \%$ entering, $50 \%$ exiting

Trip Generation per Student

\begin{tabular}{|clcc|}
\hline Average Rate & Range of Rates & Standard Deviation \\
\hline 1.79 & 0.71 & -3.96 & 1.54 \\
\hline
\end{tabular}

\section{Data Plot and Equation}

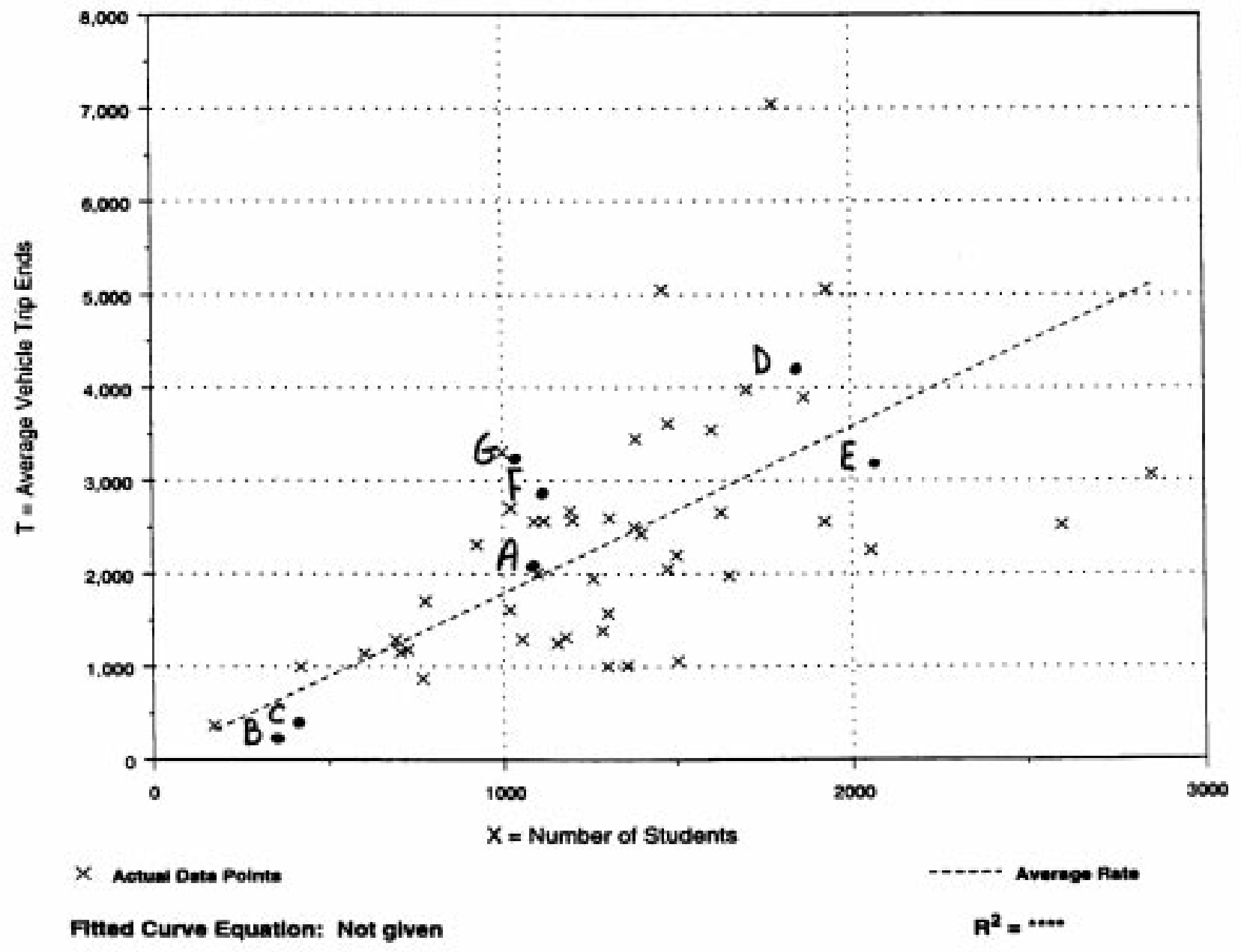




\section{High School (530)}

\section{Average Vehicle Trip Ends vs: Employees \\ On a: Sunday, \\ Peak Hour of Generator}

Number of Studies: 18

Avg. Number of Employees: 142

Directional Distribution: $33 \%$ entering, $67 \%$ exiting

Trip Generation per Employee

\begin{tabular}{|clc|}
\hline Average Rate & Range of Rates & Standard Deviation \\
\hline 0.47 & $0.09-2.25$ & 0.84 \\
\hline
\end{tabular}

\section{Data Plot and Equation}

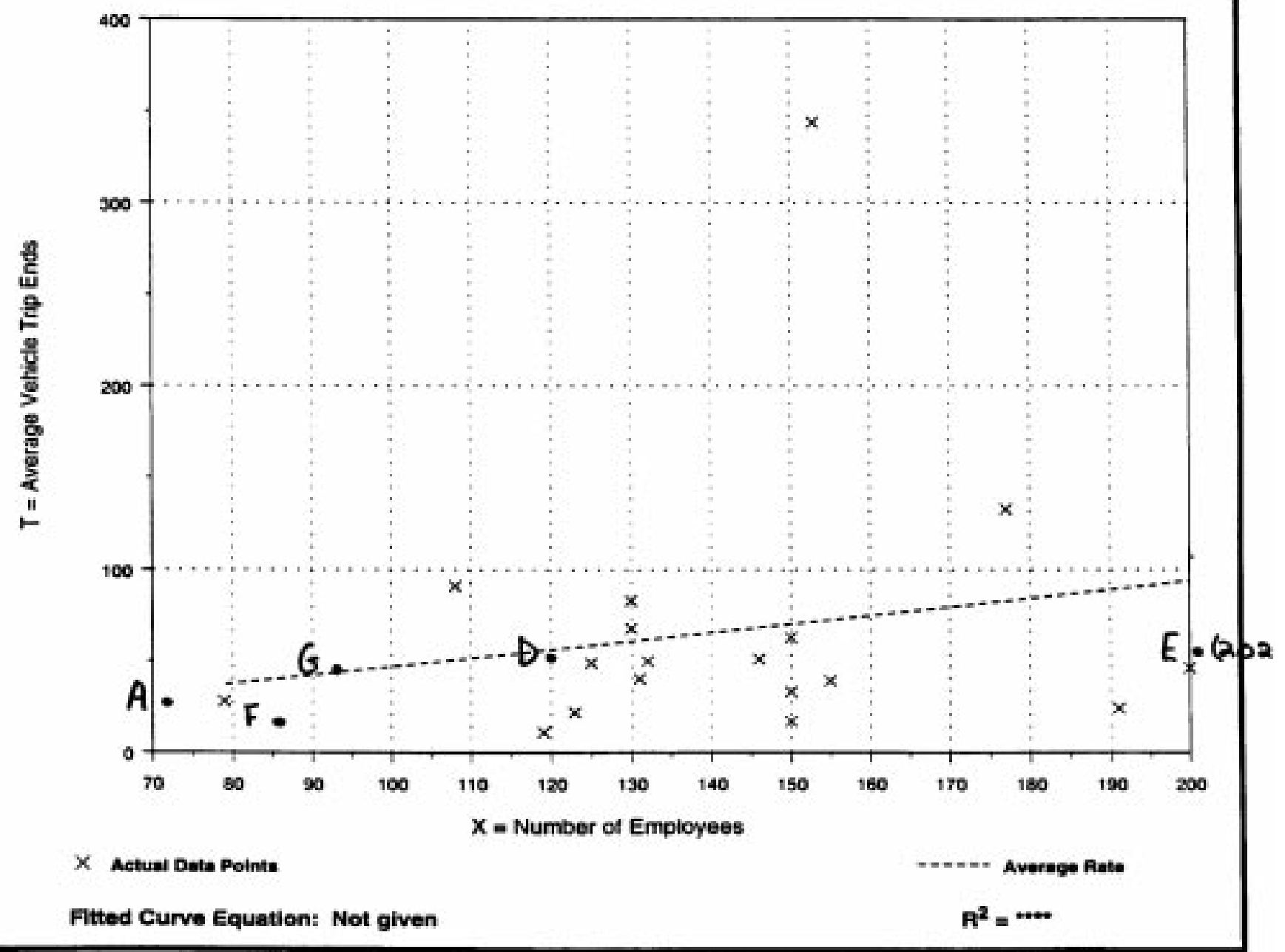




\section{High School \\ (530)}

\section{Average Vehicle Trip Ends vs: Employees \\ On a: Sunday}

Number of Studies: 18

Avg. Number of Employees: 142

Directional Distribution: $50 \%$ entering, $50 \%$ exiting

\section{Trip Generation per Employee}

\begin{tabular}{|ccc|}
\hline Average Rate & Range of Pates & Standard Deviation \\
\hline 2.64 & $0.45 \quad \cdot 10.27$ & 2.88 \\
\hline
\end{tabular}

\section{Data Plot and Equation}

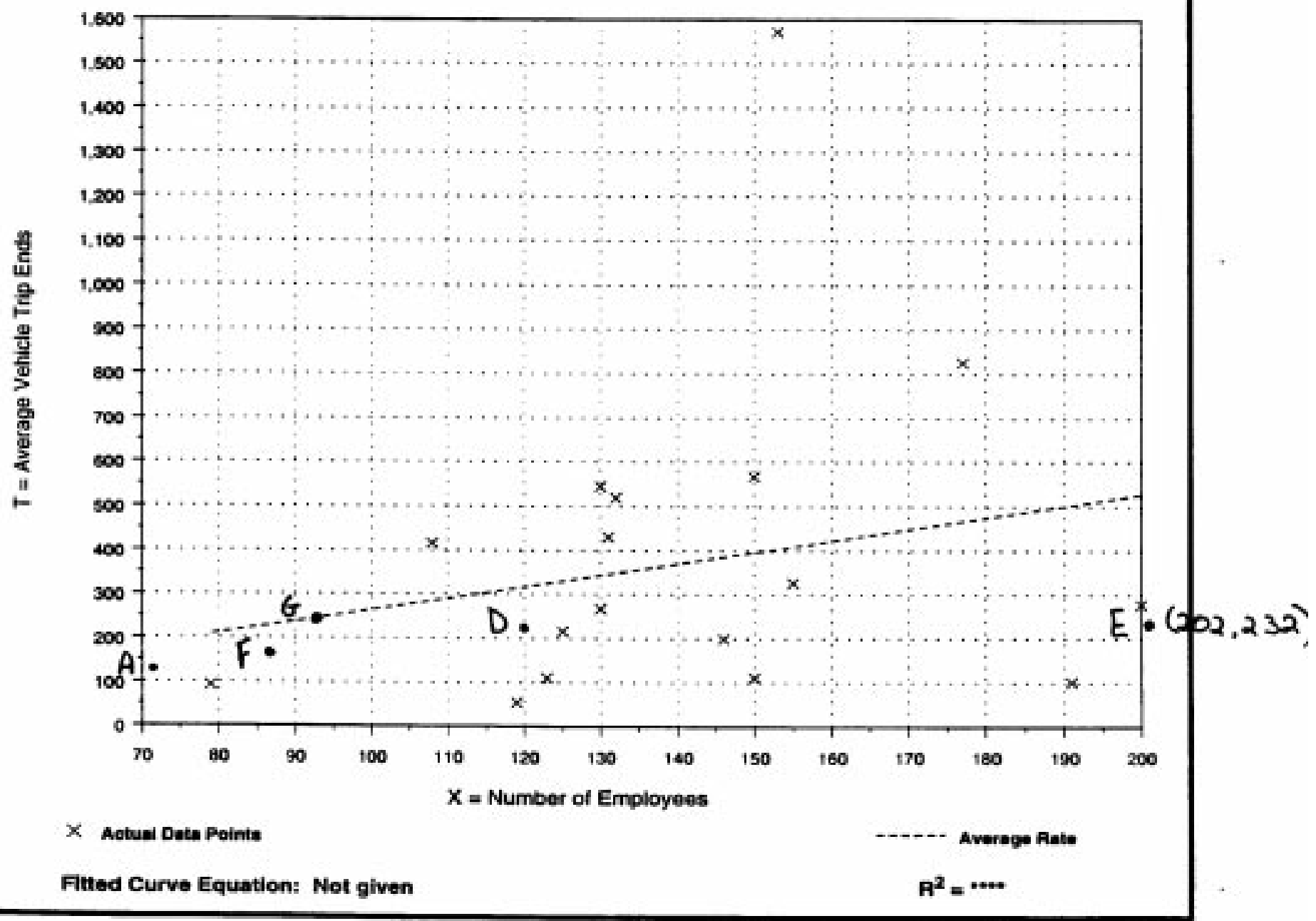




\section{High School \\ (530)}

\section{Average Vehicle Trip Ends vs: Employees \\ On a: Saturday, \\ Peak Hour of Generator}

Number of Studies: 18

Avg. Number of Employees: 142

Directional Distribution: $74 \%$ entering, $26 \%$ exiting

\section{Trip Generation per Employee}

\begin{tabular}{|cccc|}
\hline Average Rate & Range of Rates & Standard Deviation \\
\hline 1.23 & 0.19 & $\cdot 2.72$ & 1.41 \\
\hline
\end{tabular}

\section{Data Plot and Equation}

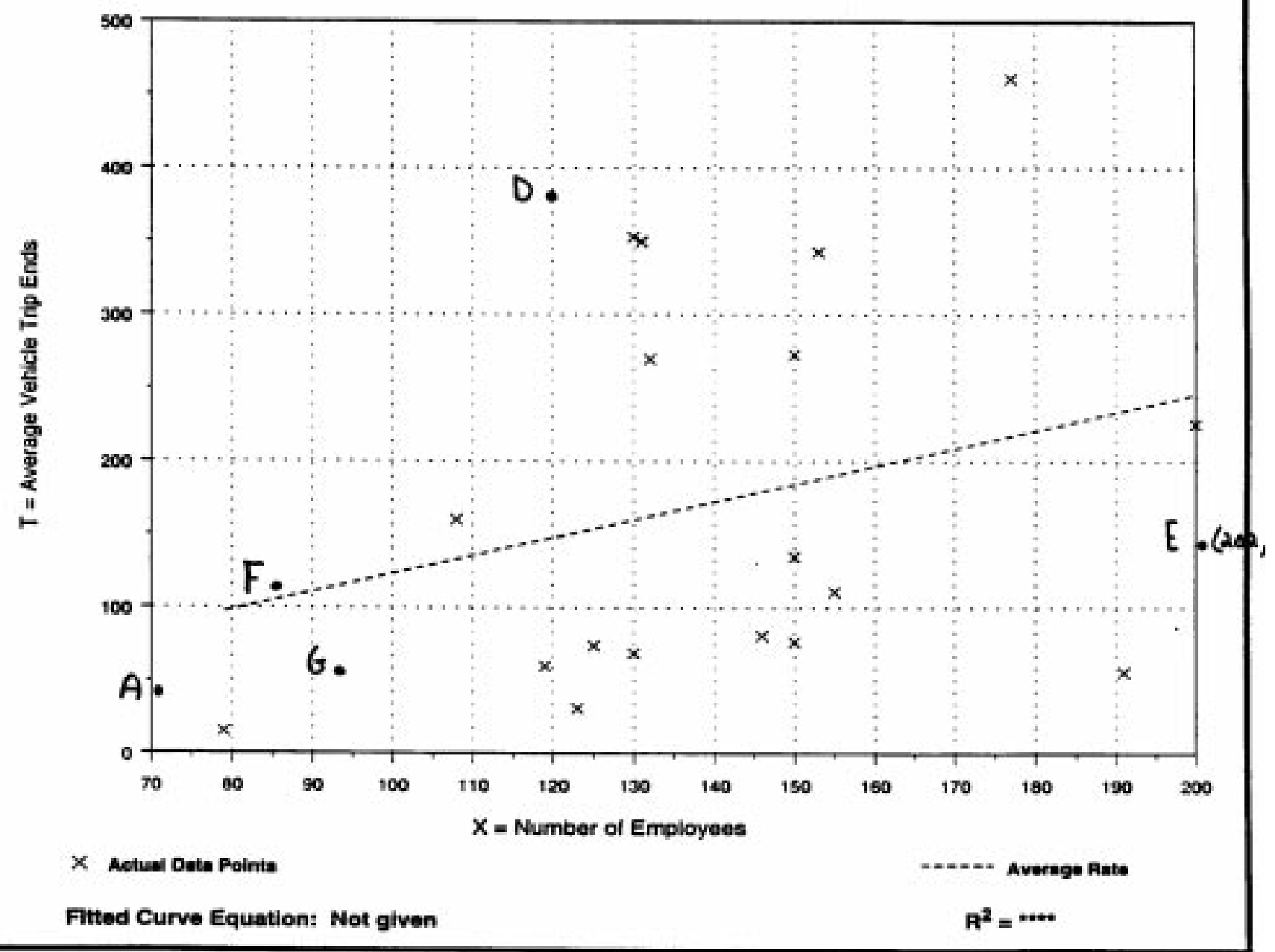




\title{
High School (530)
}

\section{Average Vehicle Trip Ends vs: Employees \\ On a: Saturday}

\author{
Number of Studies: 18 \\ Avg. Number of Employees: 142 \\ Directional Distribution: $50 \%$ entering, $50 \%$ exiting
}

\section{Trip Generation per Employee}

\begin{tabular}{|ccc|}
\hline Average Pate & Range of Rates & Standard Deviation \\
\hline 6.65 & $0.75 \cdot 19.95$ & 5.42 \\
\hline
\end{tabular}

\section{Data Plot and Equation}

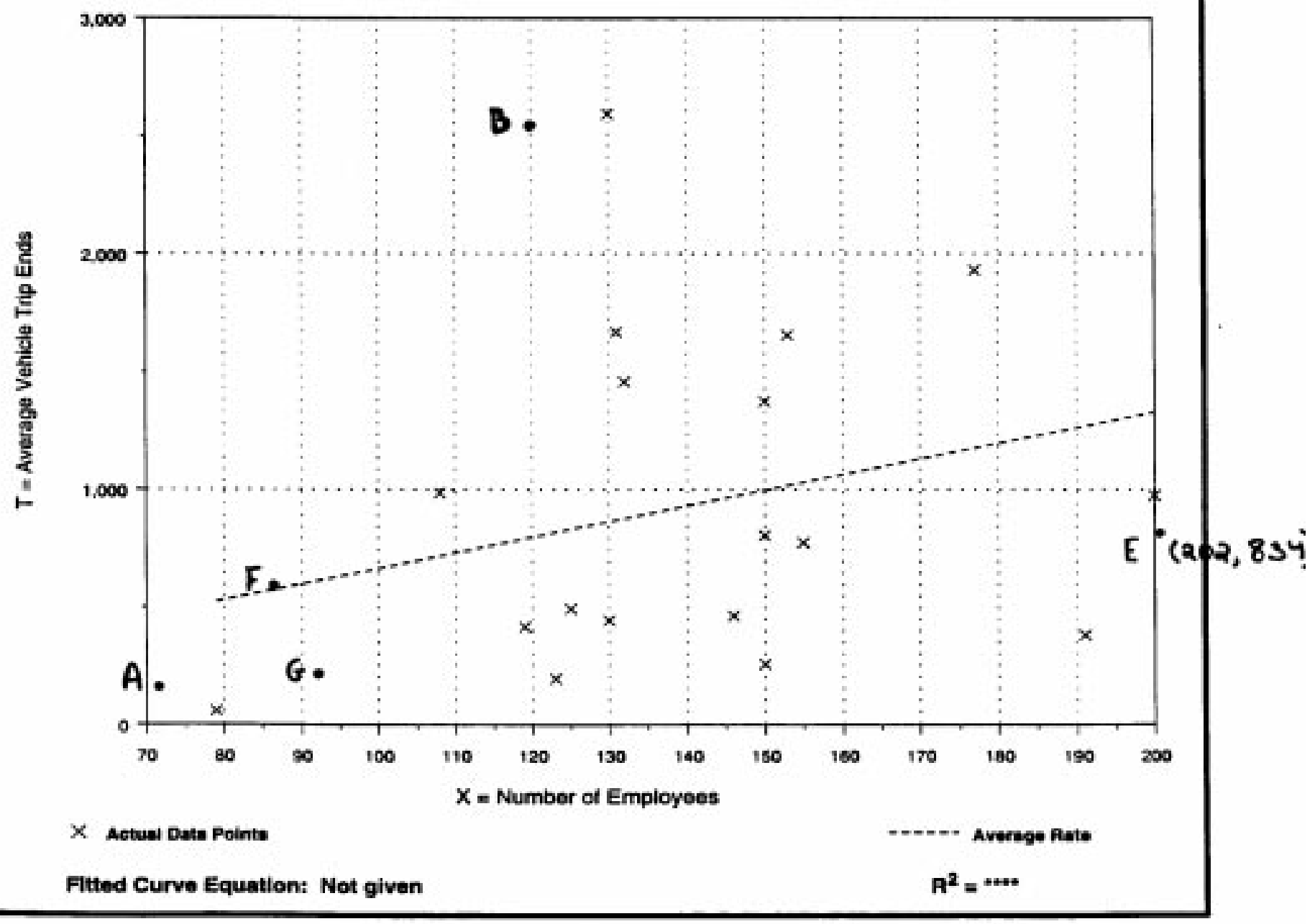




\section{High School \\ (530)}

\section{Average Vehicle Trip Ends vs: Employees \\ On a: Weekday, \\ P.M. Peak Hour of Generator}

Number of Studies: 45

Avg. Number of Employees: 117

Directional Distribution: $30 \%$ entering, $70 \%$ exiting

\section{Trip Generation per Employee}

\begin{tabular}{|cccc|}
\hline Average Rate & Range of Rates & Standard Deviation \\
\hline 3.30 & $1.13 \cdot 6.98$ & 2.10 \\
\hline
\end{tabular}

\section{Data Plot and Equation}

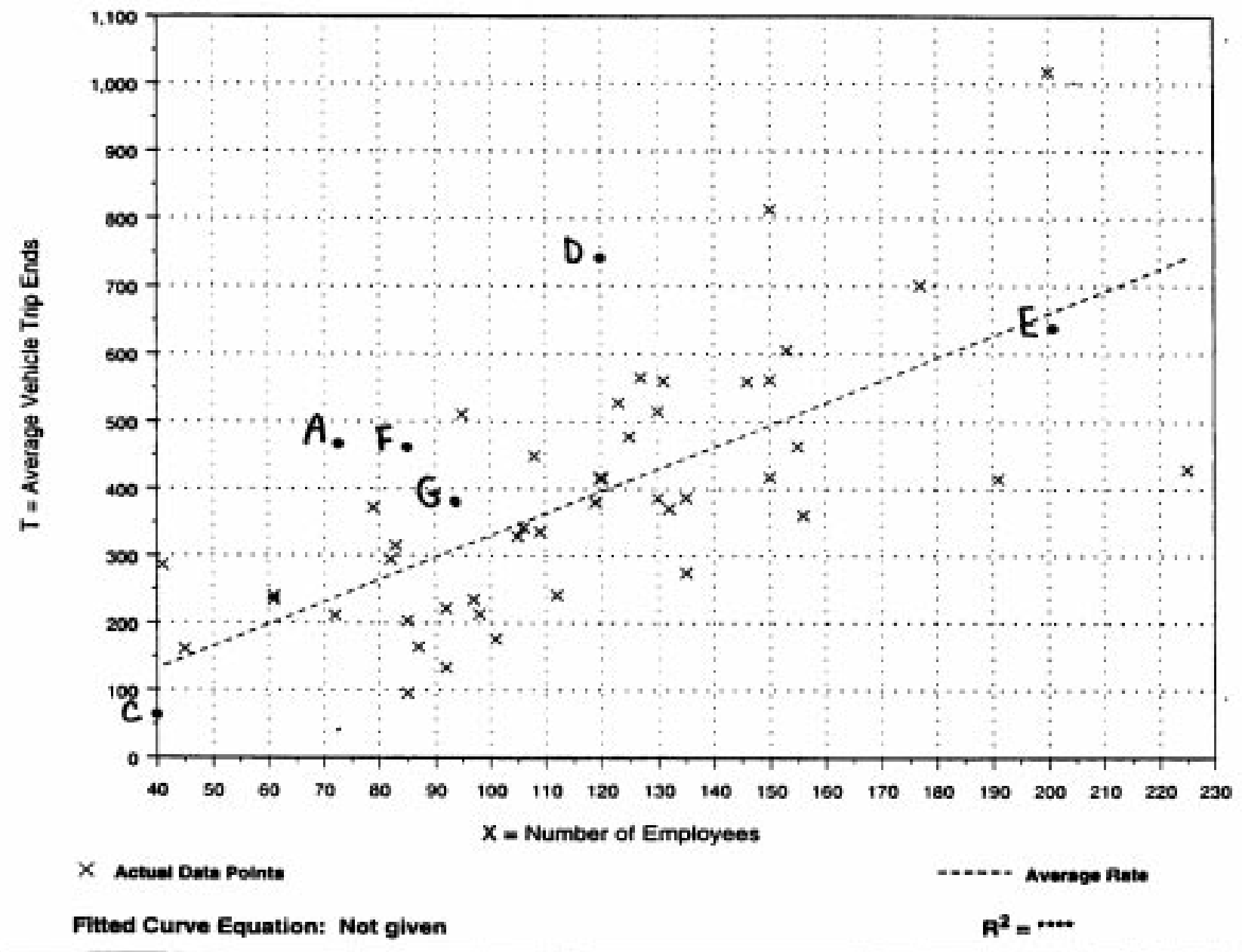




\section{High School}

(530)

\section{Average Vehicle Trip Ends vs: Employees \\ On a: Weekday, \\ A.M. Peak Hour of Generator}

Number of Studies: $\mathbf{4 5}$

Avg. Number of Employees: 117

Directional Distribution: $72 \%$ entering, $28 \%$ exiting

\section{Trip Generation per Employee}

\begin{tabular}{|ccc|}
\hline Average Rate & Range of Rates & Standard Deviation \\
\hline 4.68 & $0.54-10.20$ & 2.92 \\
\hline
\end{tabular}

\section{Data Plot and Equation}

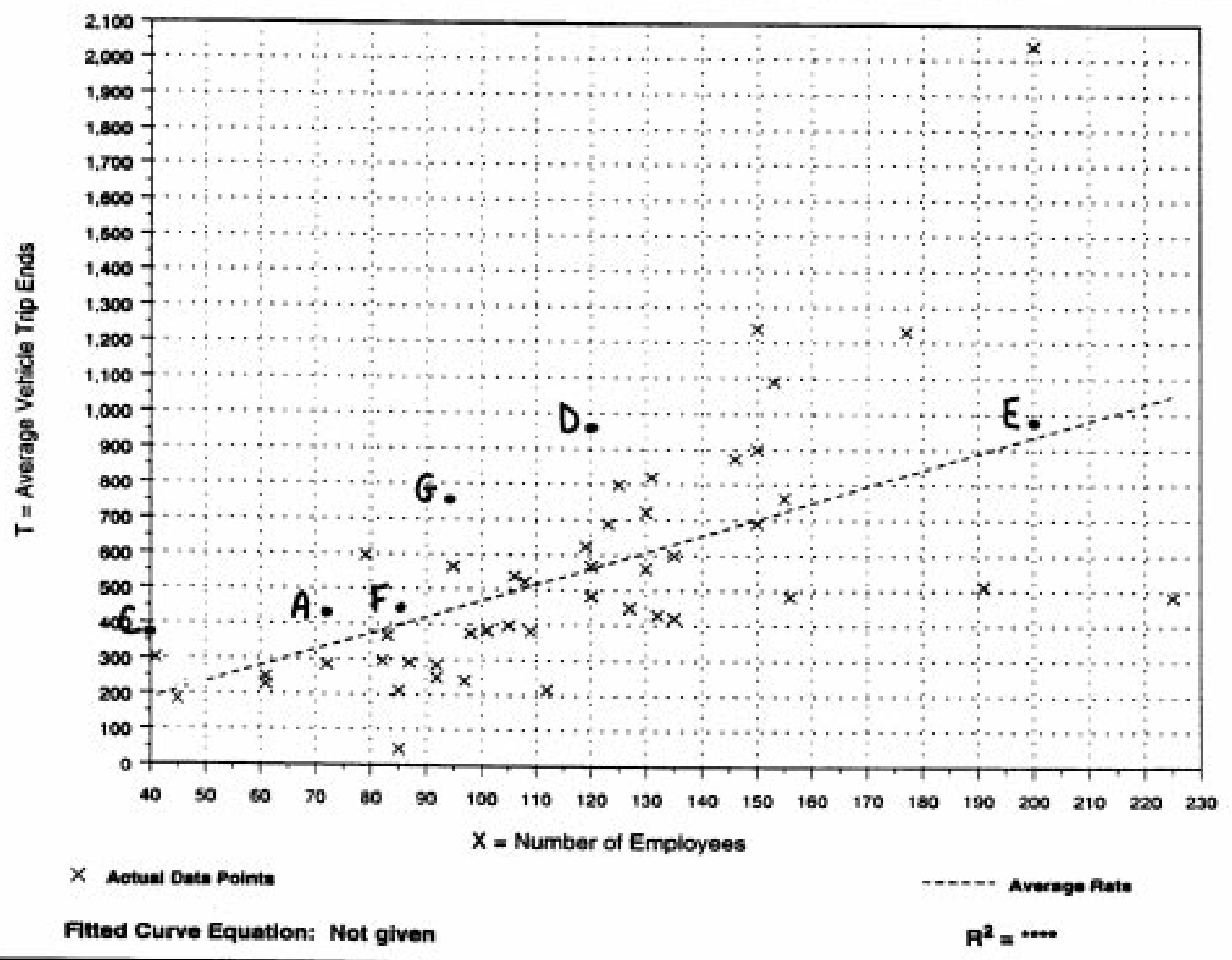




\section{High School \\ (530)}

\section{Average Vehicle Trip Ends vs: Employees \\ On a: Weekday}

Number of Studies: 45

Avg. Number of Employees: 117

Directional Distribution: $50 \%$ entering, $50 \%$ exiting

\section{Trip Generation per Employee}

\begin{tabular}{|ccc|}
\hline Average Rate & Range of Rates & Standard Deviation \\
\hline 19.98 & $4.28-35.26$ & 8.30 \\
\hline
\end{tabular}

\section{Data Plot and Equation}

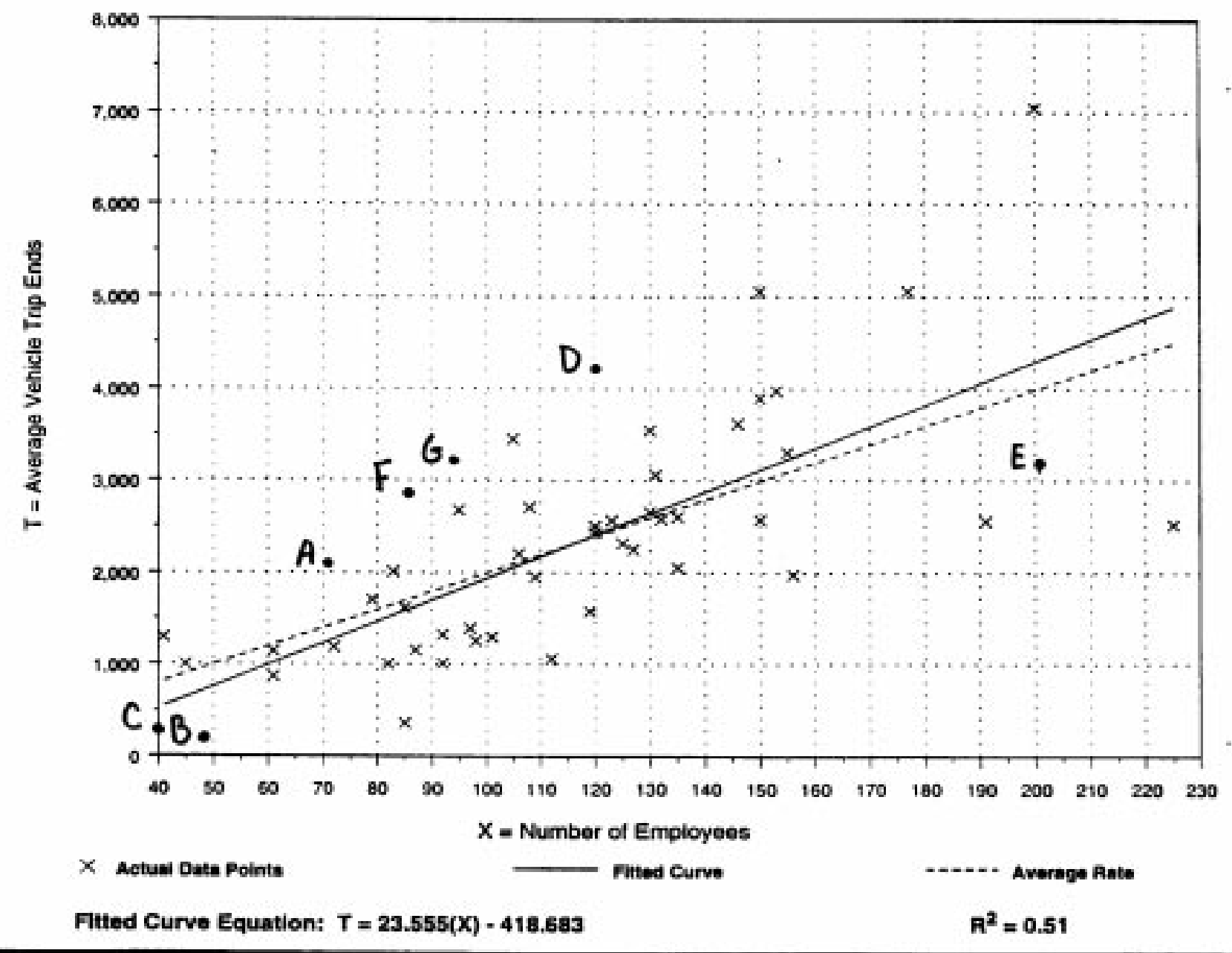




\section{Appendix IV \\ Study Data Points Plotted on ITE (1997) Graphs \\ For Middle Schools}




\title{
Middle School/Junior High School (522)
}

\section{Average Vehicle Trip Ends vs: 1000 Sq. Feet Gross Floor Area \\ On a: Weekday, \\ P.M. Peak Hour of Generator}

\begin{abstract}
Number of Studies: 16
Average $1000 \mathrm{Sq}$. Feet GFA: 96

Directional Distribution: $51 \%$ entering, $49 \%$ exiting
\end{abstract}

Trip Generation per 1000 Sq. Feet Gross Floor Area

\begin{tabular}{|ccc|}
\hline Average Rate & Range of Rates & Standard Deviation \\
\hline 2.45 & $0.68 \cdot 10.88$ & 2.45 \\
\hline
\end{tabular}

Data Plot and Equation

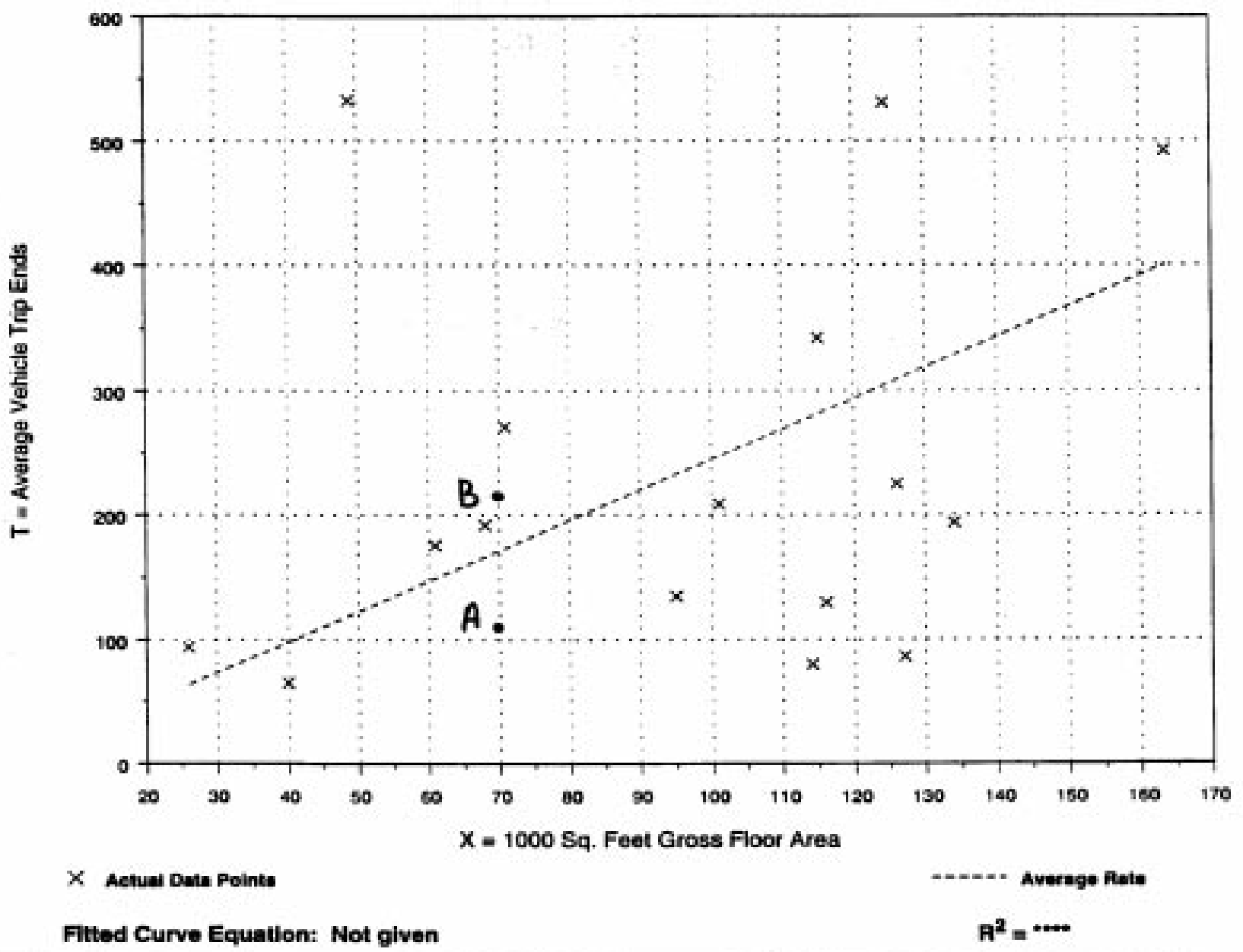




\section{Middle School/Junior High School (522)}

\section{Average Vehicle Trip Ends vs: 1000 Sq. Feet Gross Floor Area \\ On a: Weekday, \\ A.M. Peak Hour of Generator}

Number of Studies: 16

Average 1000 Sq. Feet GFA: 96

Directional Distribution: $57 \%$ entering, $43 \%$ exiting

Trip Generation per 1000 Sq. Feet Gross Floor Area

\begin{tabular}{|cccc|}
\hline Average Pate & Range of Rates & Standard Deviation \\
\hline 3.68 & 0.98 & -22.16 & 4.45 \\
\hline
\end{tabular}

Data Plot and Equation

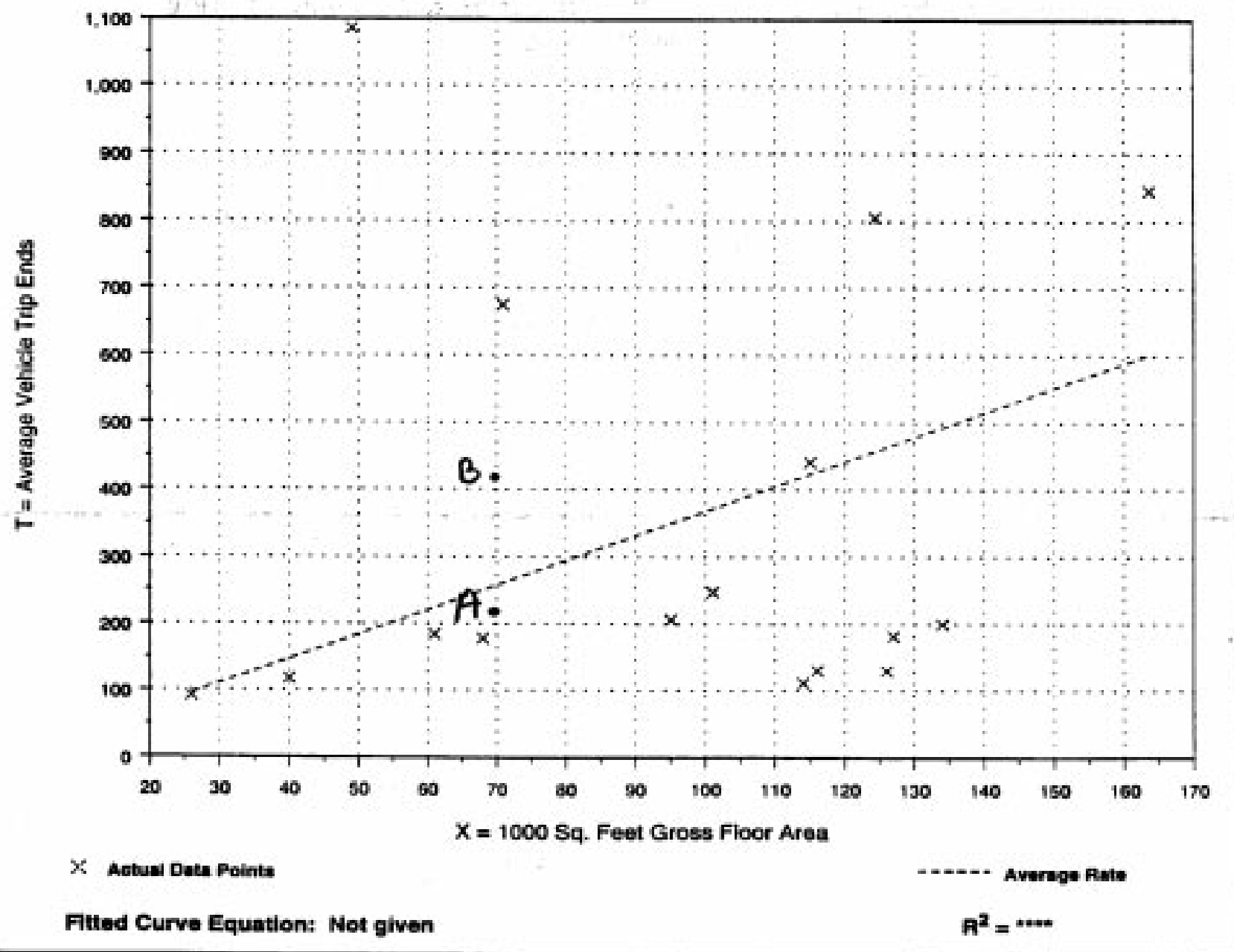




\title{
Middle School/Junior High School (522)
}

\section{Average Vehicle Trip Ends vs: 1000 Sq. Feet Gross Floor Area On a: Weekday}

\author{
Number of Studies: 16 \\ Average 1000 Sq. Feet GFA: 96 \\ Directional Distribution: $50 \%$ entering, $50 \%$ exiting
}

Trip Generation per 1000 Sq. Feet Gross Floor Area

\begin{tabular}{|c|c|c|}
\hline Average Rate & Pange of Rates & Standard Deviation \\
\hline 11.92 & $3.89=48.31$ & 9.35 \\
\hline
\end{tabular}

\section{Data Plot and Equation}

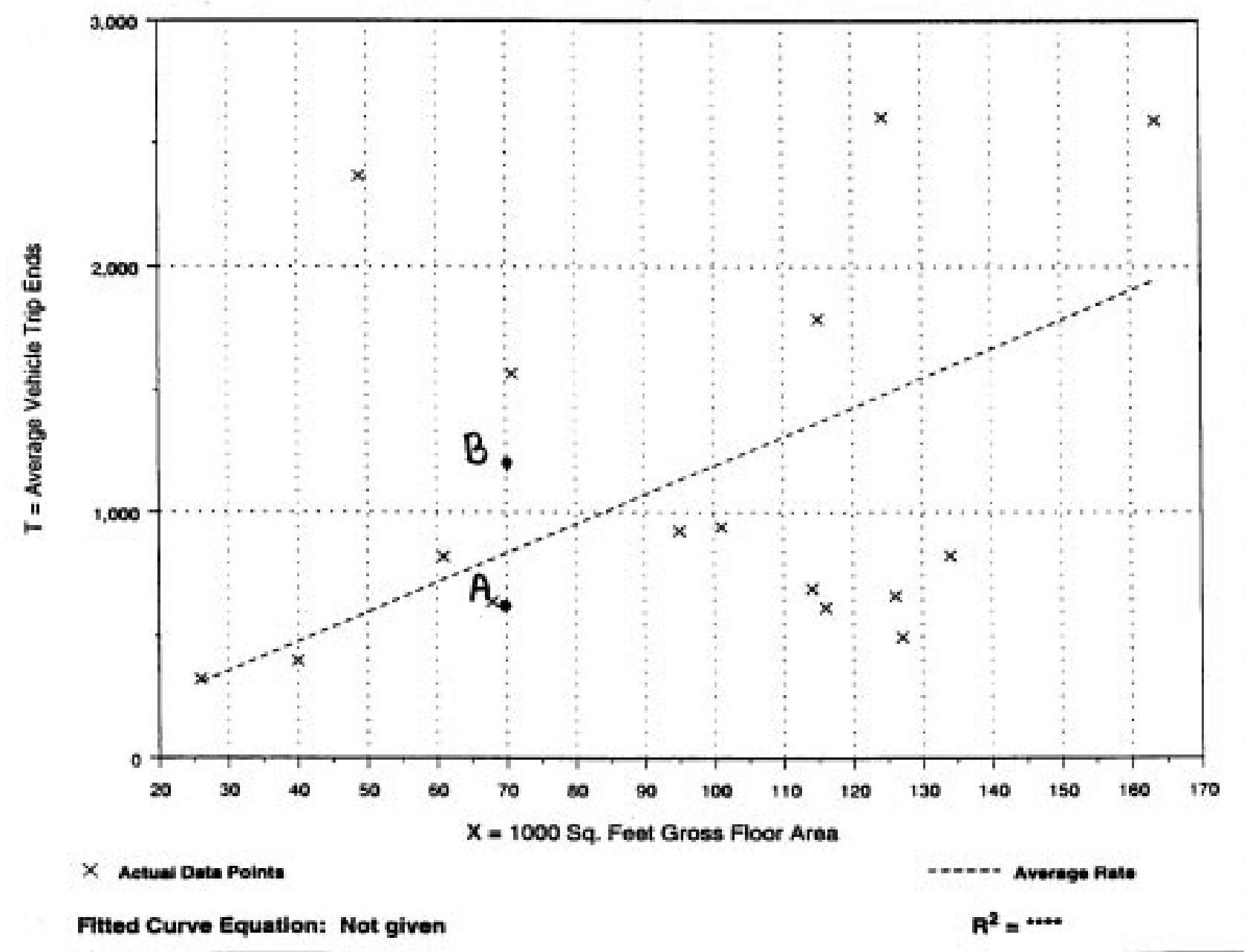




\section{Middle School/Junior High School (522)}

\section{Average Vehicle Trip Ends vs: Students \\ On a: Weekday, \\ P.M. Peak Hour of Generator}

Number of Studies: 18

Average Number of Students: 752

Directional Distribution: $51 \%$ entering, $49 \%$ exiting

\section{Trip Generation per Student}

\begin{tabular}{|cccc|}
\hline Average Rate & Range of Rates & Standard Deviation \\
\hline 0.29 & 0.12 & 0.63 & 0.56 \\
\hline
\end{tabular}

\section{Data Plot and Equation}

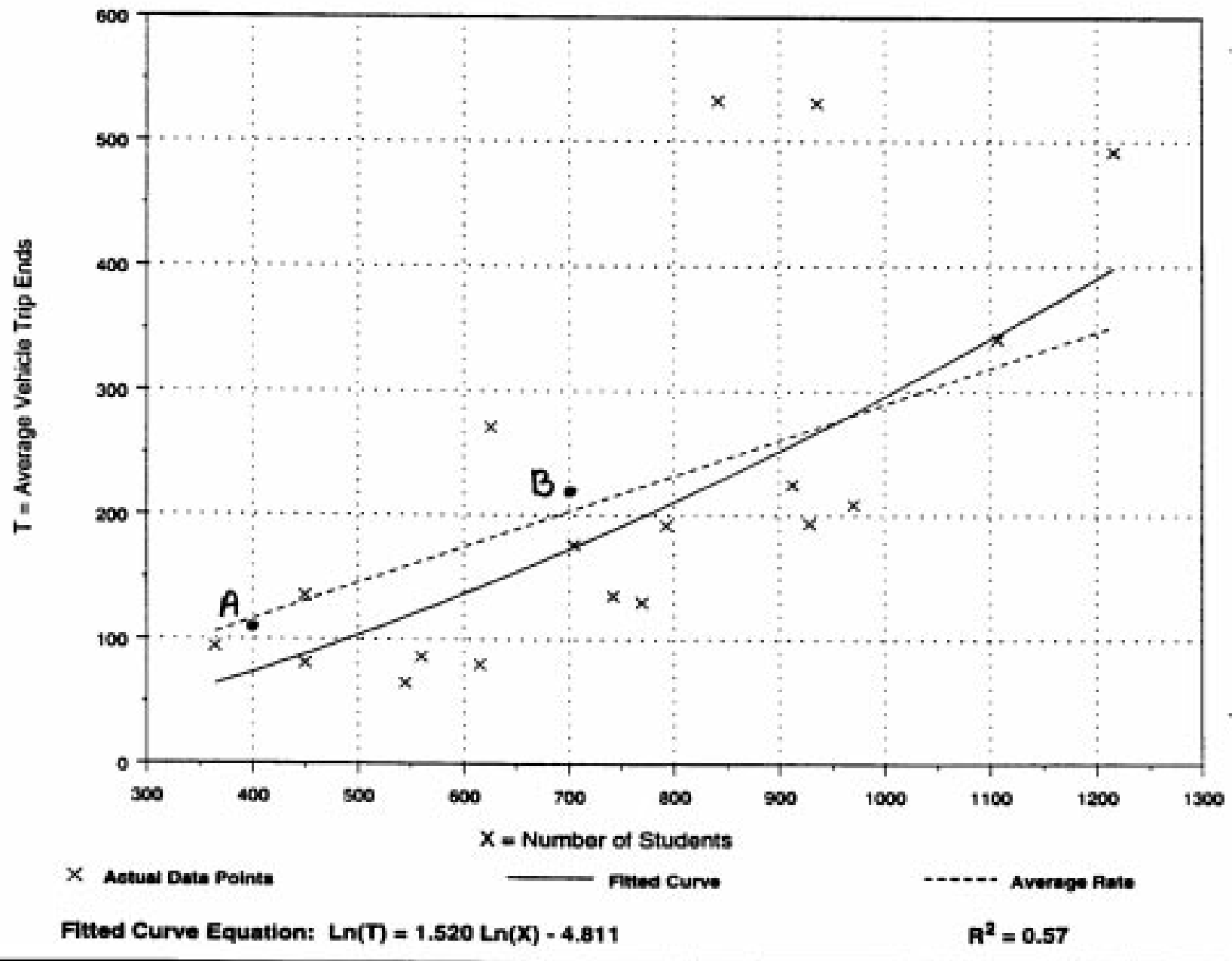




\title{
Middle School/Junior High School (522)
}

\section{Average Vehicle Trip Ends vs: Students \\ On a: Weekday, \\ A.M. Peak Hour of Generator}

\author{
Number of Studies: 16 \\ Average Number of Students: 789 \\ Directional Distribution: $57 \%$ entering, $43 \%$ exiting
}

\section{Trip Generation per Student}

\begin{tabular}{|clcc|}
\hline Average Rate & \multicolumn{2}{l|}{ Range of Rates } & Standard Deviation \\
\hline 0.45 & $0.14 \quad 1.29$ & 0.75 \\
\hline
\end{tabular}

\section{Data Plot and Equation}

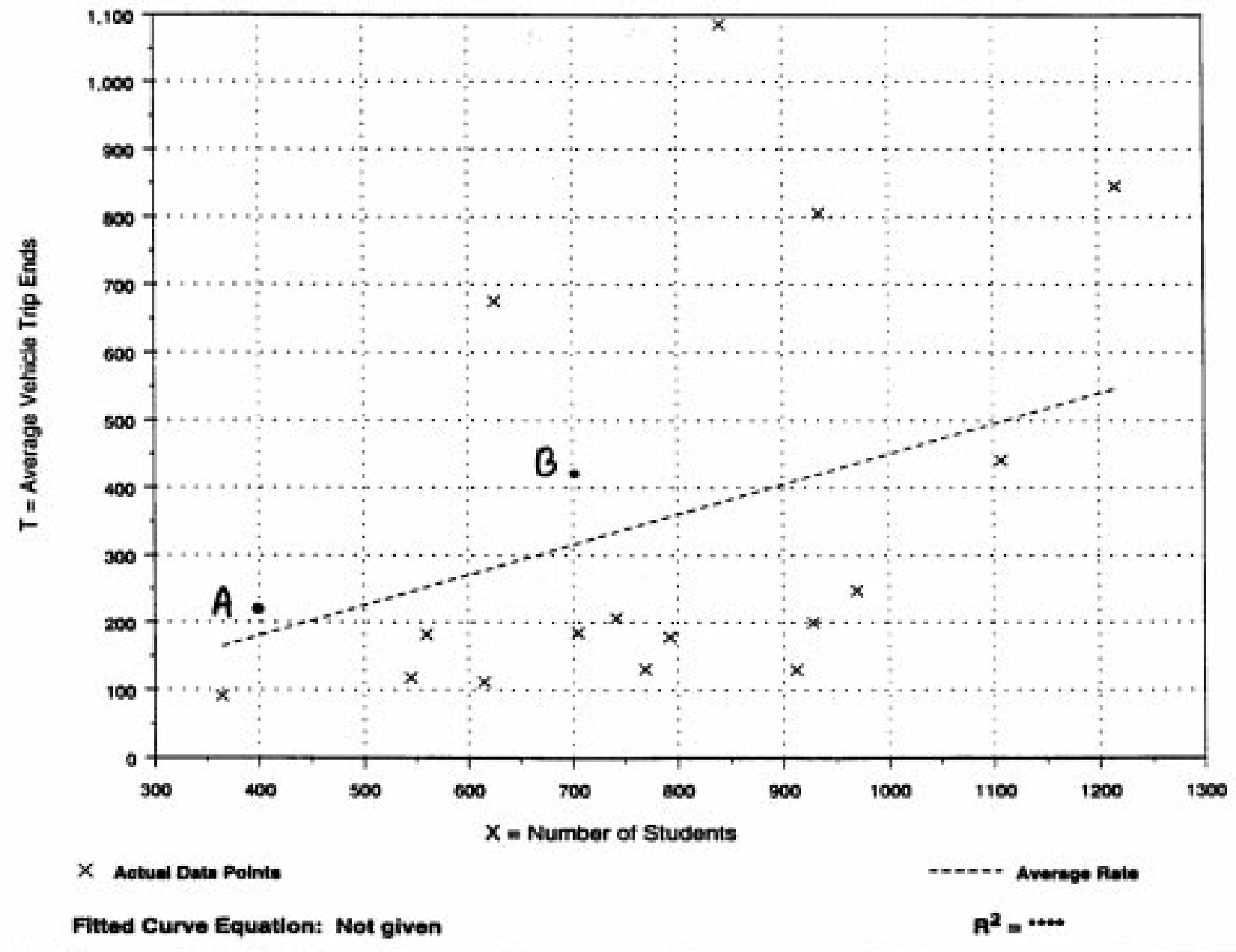




\section{Middle School/Junior High School (522)}

Average Vehicle Trip Ends vs: Students

On a: Weekday

Number of Studies: 16

Average Number of Students: 789

Directional Distribution: $50 \%$ entering, $50 \%$ exiting

Trip Generation per Student

\begin{tabular}{|ccc|}
\hline Average Rate & Range of Rates & Standard Deviation \\
\hline 1.45 & $0.72-2.81$ & 1.41 \\
\hline
\end{tabular}

\section{Data Plot and Equation}

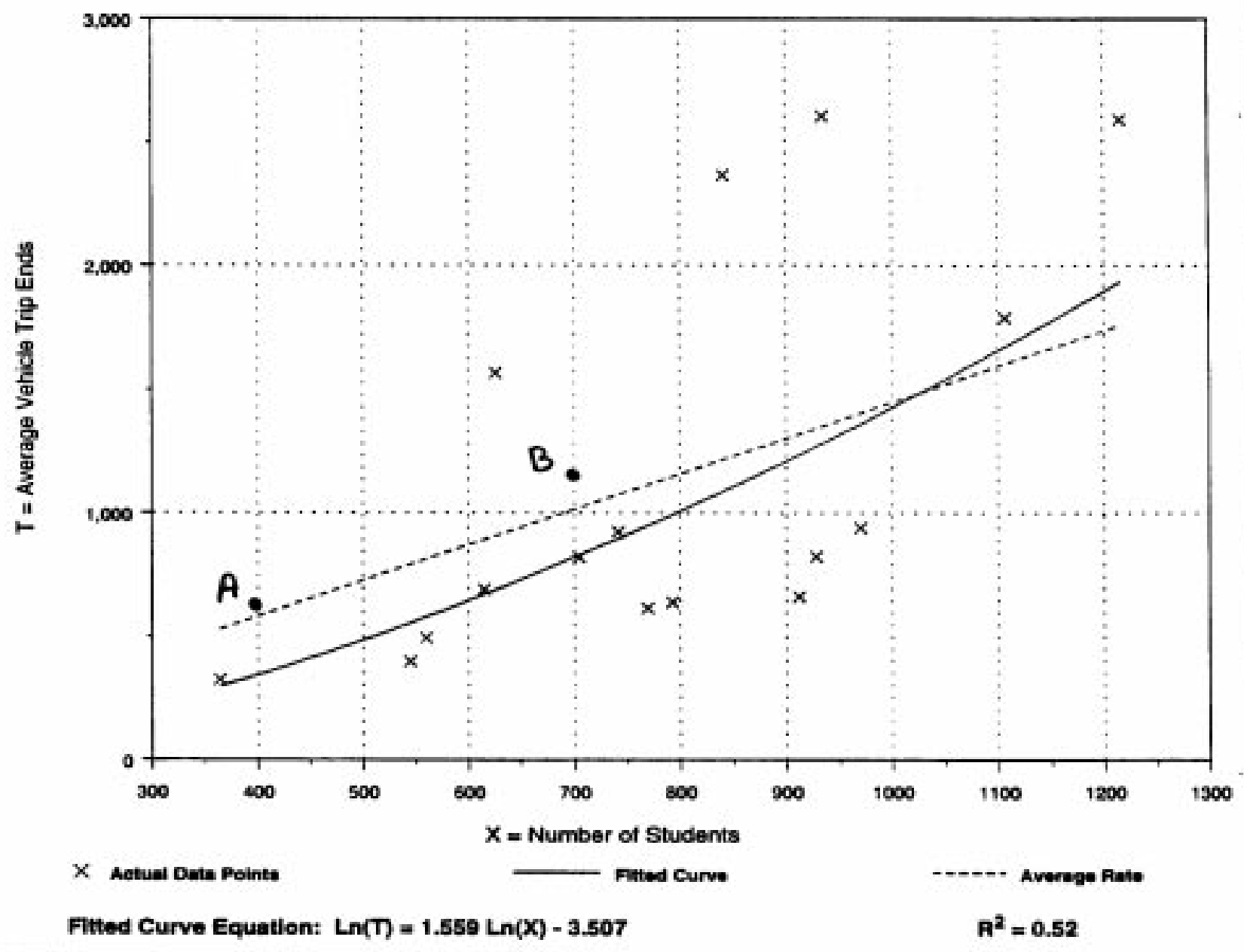


Appendix V

Study Data Points Plotted on ITE (1997) Graphs

For Elementary Schools 


\section{Elementary School \\ (520)}

\section{Average Vehicle Trip Ends vs: Employees \\ On a: Weekday}

Number of Studies: 25

Avg. Number of Employees: 43

Directional Distribution: $50 \%$ entering, $50 \%$ exiting

\section{Trip Generation per Employee}

\begin{tabular}{|ccc|}
\hline Average Rate & Range of Rates & Standard Deviation \\
\hline 13,13 & $4.47 \quad-26.37$ & 6.10 \\
\hline
\end{tabular}

\section{Data Plot and Equation}

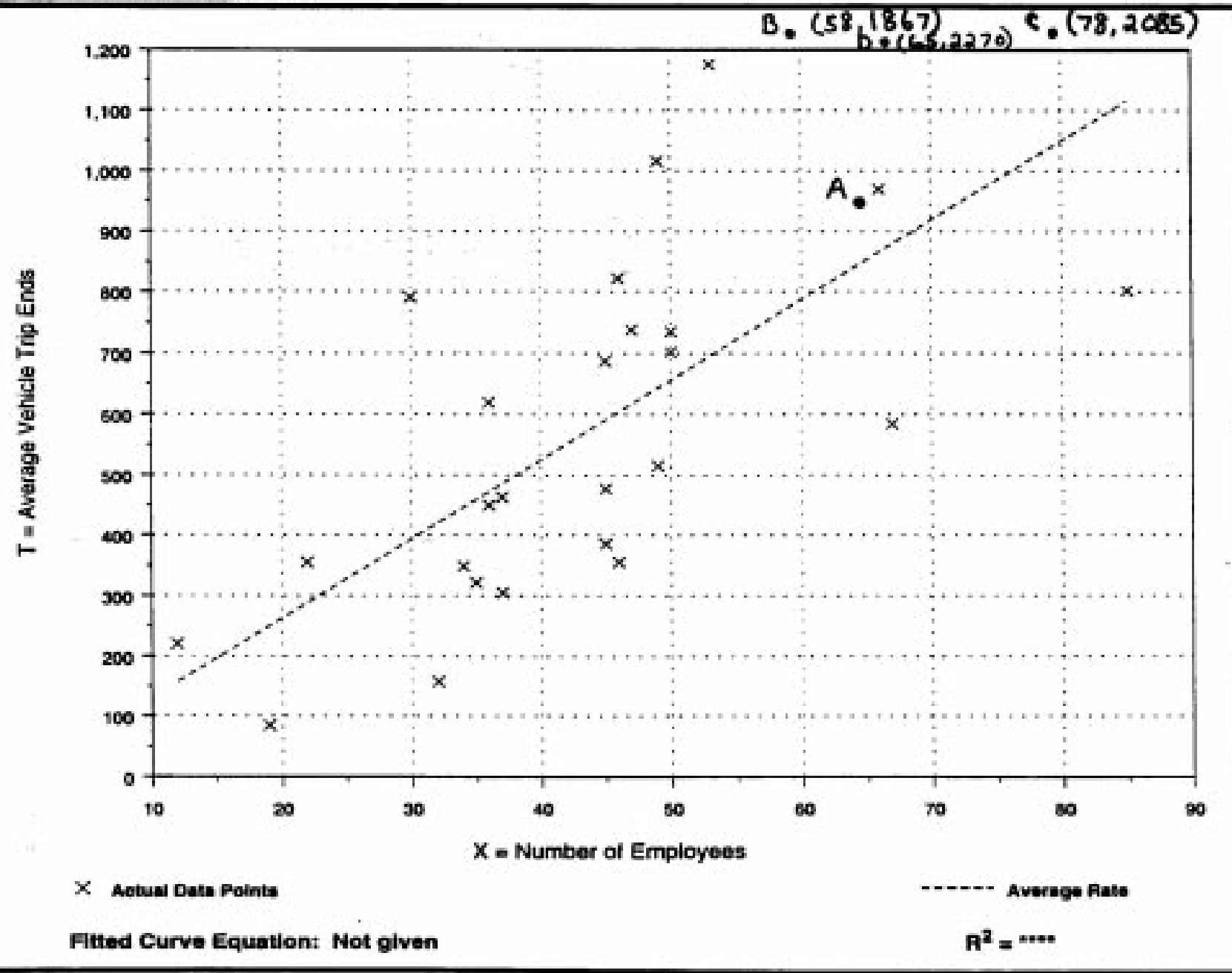




\section{Elementary School \\ (520)}

\section{Average Vehicle Trip Ends vs: Employees \\ On a: Weekday, \\ A.M. Peak Hour of Generator}

Number of Studies: 25

Avg. Number of Employees: 43

Directional Distribution: Not available

\section{Trip Generation per Employee}

\begin{tabular}{|ccc|}
\hline Average Rate & Range of Pates & Standard Deviation \\
\hline 3.71 & $1.22-7.59$ & 2.34 \\
\hline
\end{tabular}

\section{Data Plot and Equation}

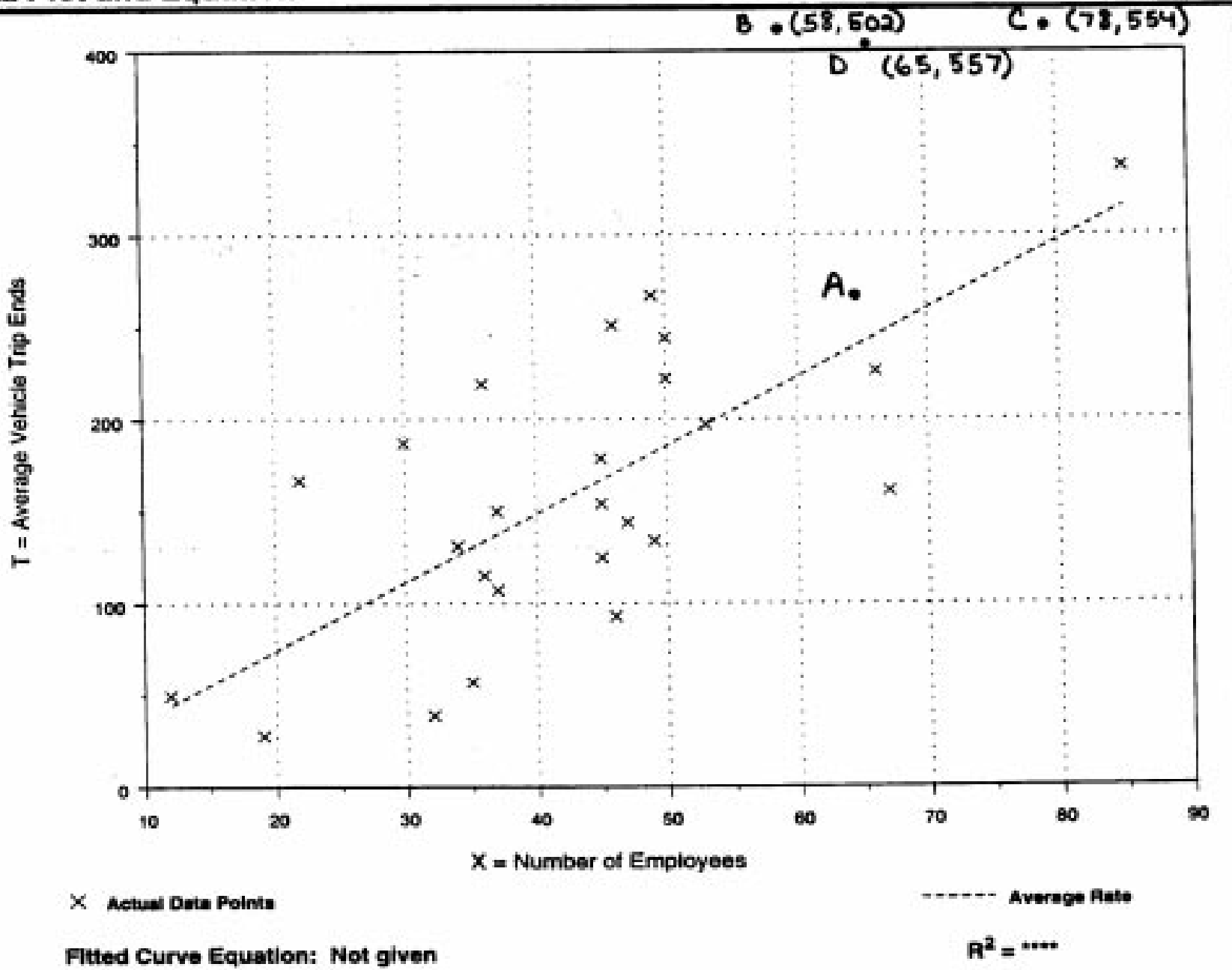




\section{Elementary School \\ (520)}

\section{Average Vehicle Trip Ends vs: Employees \\ On a: Weekday, \\ P.M. Peak Hour of Generator}

Number of Studies: 25

Avg. Number of Employees: 43

Directional Distribution: Not available

Trip Generation per Employee

\begin{tabular}{|ccc|}
\hline Average Rate & Range of Pates & Standard Deviation \\
\hline 3.50 & $1.03-10.28$ & 2.73 \\
\hline
\end{tabular}

Data Plot and Equation

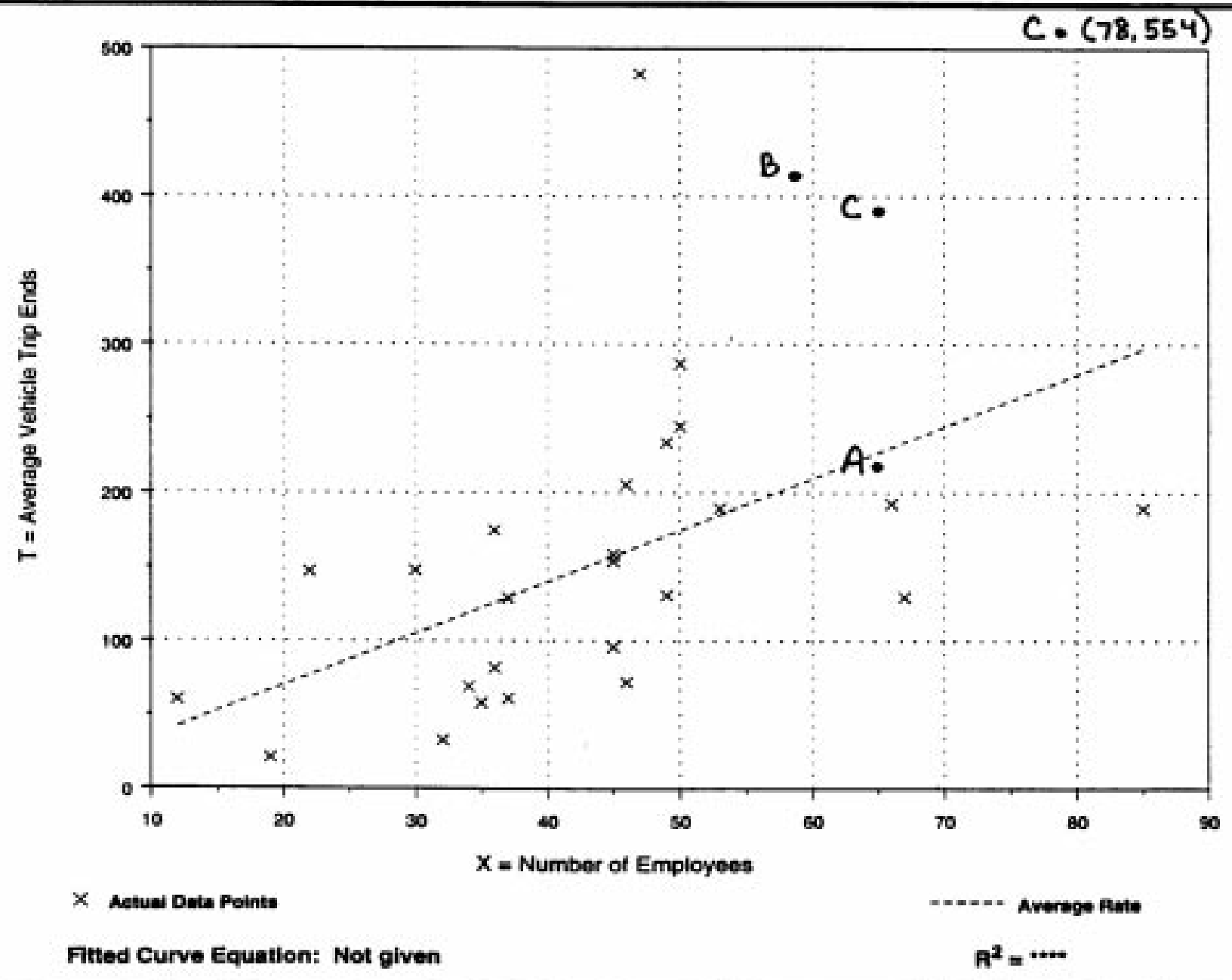




\section{Elementary School \\ (520)}

\section{Average Vehicle Trip Ends vs: Students \\ On a: Weekday}

Number of Studies: 26

Average Number of Students: 562

Directional Distribution: $50 \%$ entering, $50 \%$ exiting

\section{Trip Generation per Student}

\begin{tabular}{|clcc|}
\hline Average Pate & Range of Rates & Standard Deviation \\
\hline 1.02 & $0.45-2.12$ & 1.07 \\
\hline
\end{tabular}

\section{Data Plot and Equation}

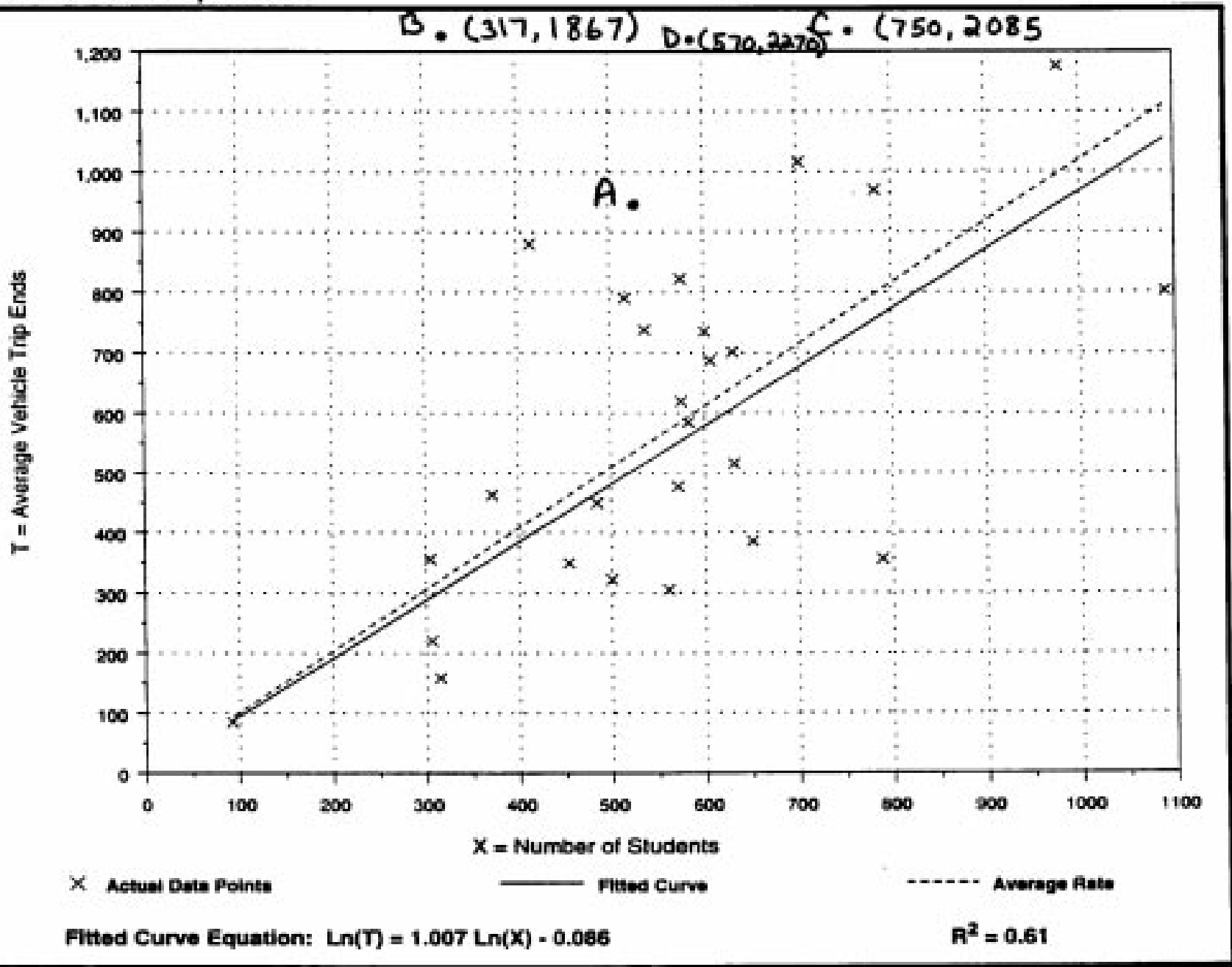




\section{Elementary School \\ (520)}

\section{Average Vehicle Trip Ends vs: Students \\ On a: Weekday, \\ A.M. Peak Hour of Generator}

Number of Studies: 31

Average Number of Students: 565

Directional Distribution: $58 \%$ entering, $42 \%$ exiting

Trip Generation per Student

\begin{tabular}{|ccc|}
\hline Average Rate & Range of Rates & Standard Deviation \\
\hline 0.30 & $0.11 \quad 0.71$ & 0.56 \\
\hline
\end{tabular}

\section{Data Plot and Equation}

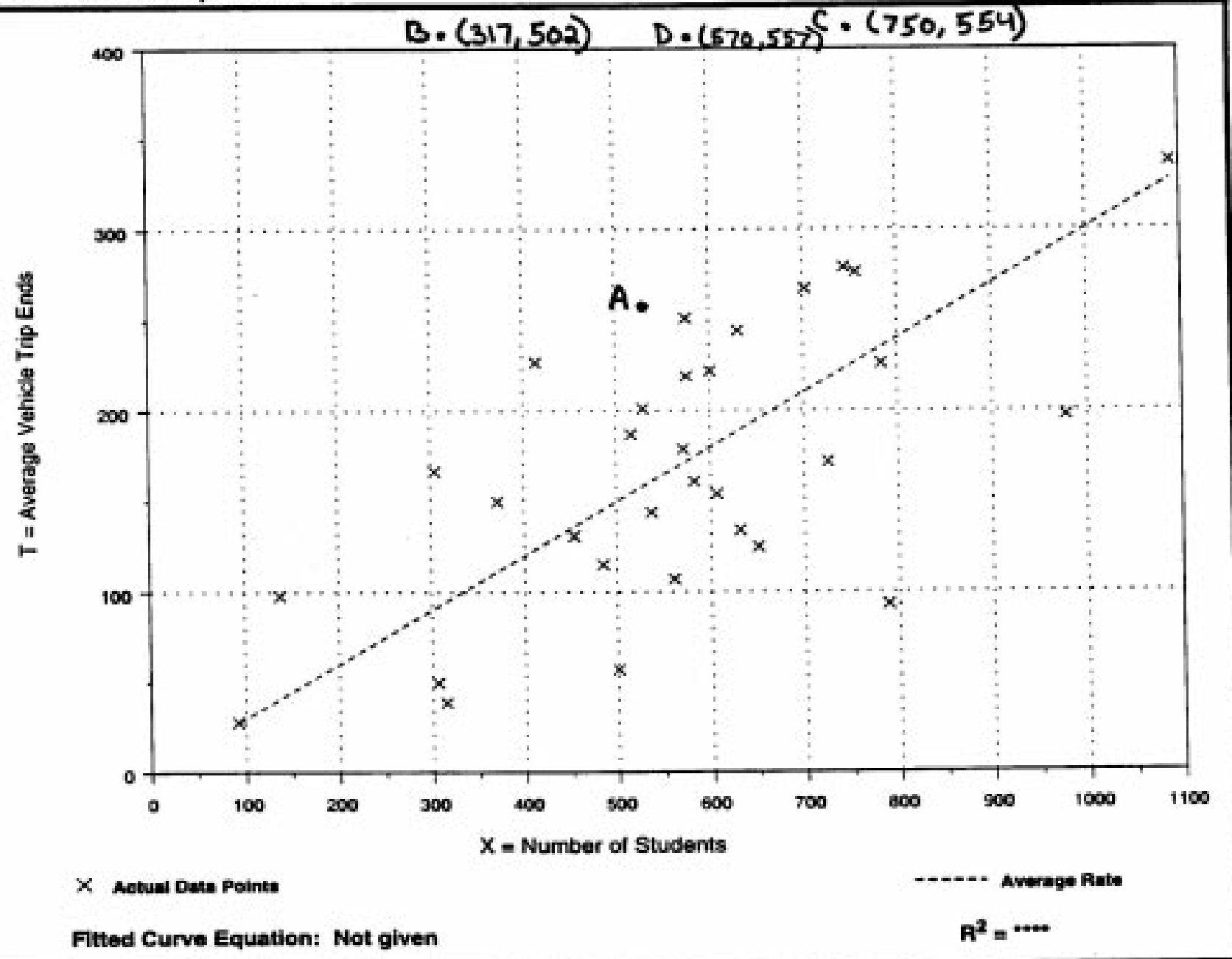




\section{Elementary School (520)}

\section{Average Vehicle Trip Ends vs: Students \\ On a: Weekday, \\ P.M. Peak Hour of Generator}

Number of Studies: 30

Average Number of Students: $\mathbf{5 7 9}$

Directional Distribution: $46 \%$ entering, $54 \%$ exiting

Trip Generation per Student

\begin{tabular}{|cccc|}
\hline Average Pate & Range of Rates & Standard Deviation \\
\hline 0.26 & 0.09 & 0.90 & 0.53 \\
\hline
\end{tabular}

\section{Data Plot and Equation}

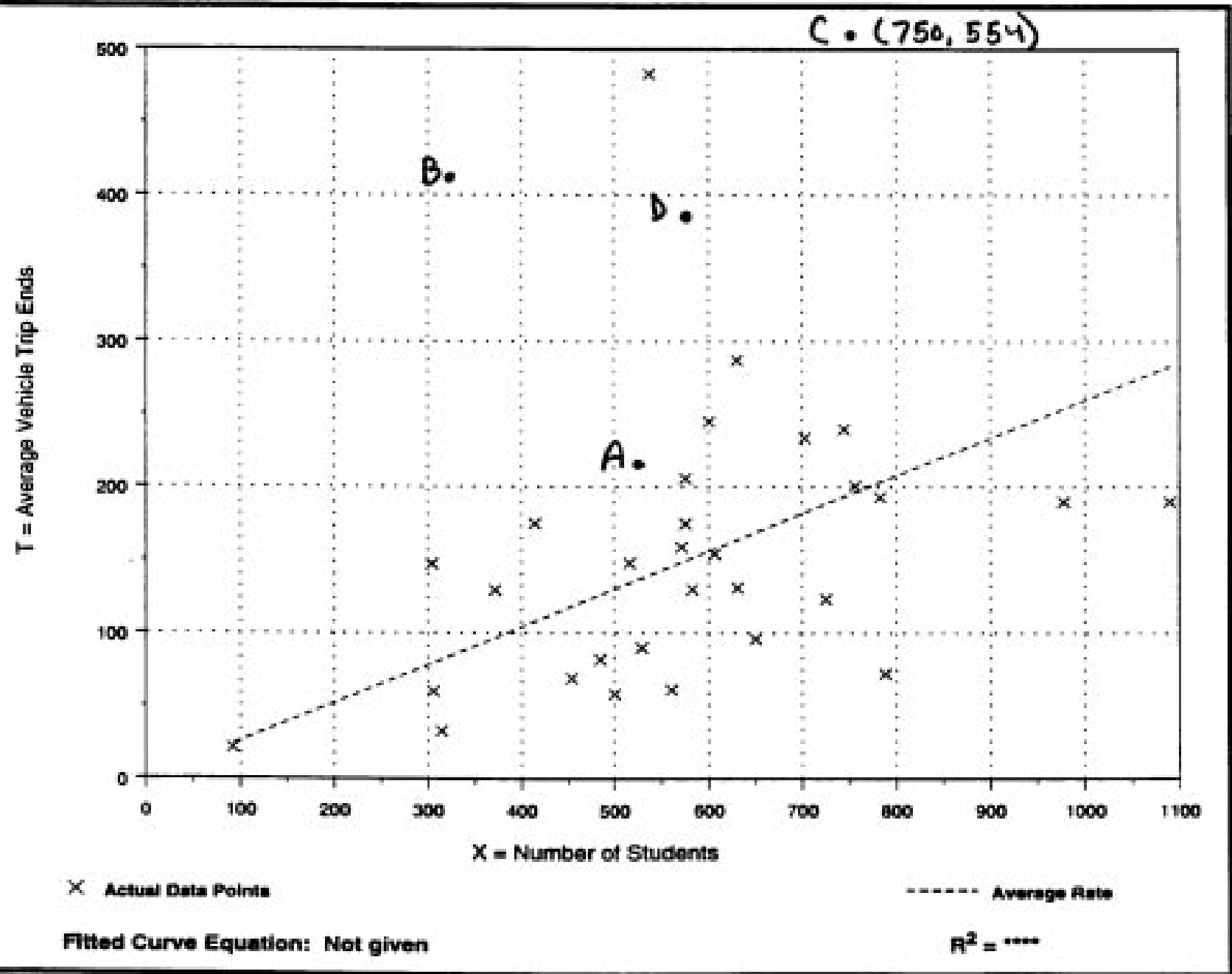




\title{
Elementary School (520)
}

\section{Average Vehicle Trip Ends vs: 1000 Sq. Feet Gross Floor Area \\ On a: Weekday}

\author{
Number of Studies: 25 \\ Average $1000 \mathrm{Sq}$. Feet GFA: 47 \\ Directional Distribution: $50 \%$ entering, $50 \%$ exiting
}

Trip Generation per 1000 Sq. Feet Gross Floor Area

\begin{tabular}{|cccc|}
\hline Average Rate & Range of Rates & Standard Deviation \\
\hline 12.03 & 4.69 & 30.15 & 7.02 \\
\hline
\end{tabular}

Data Plot and Equation

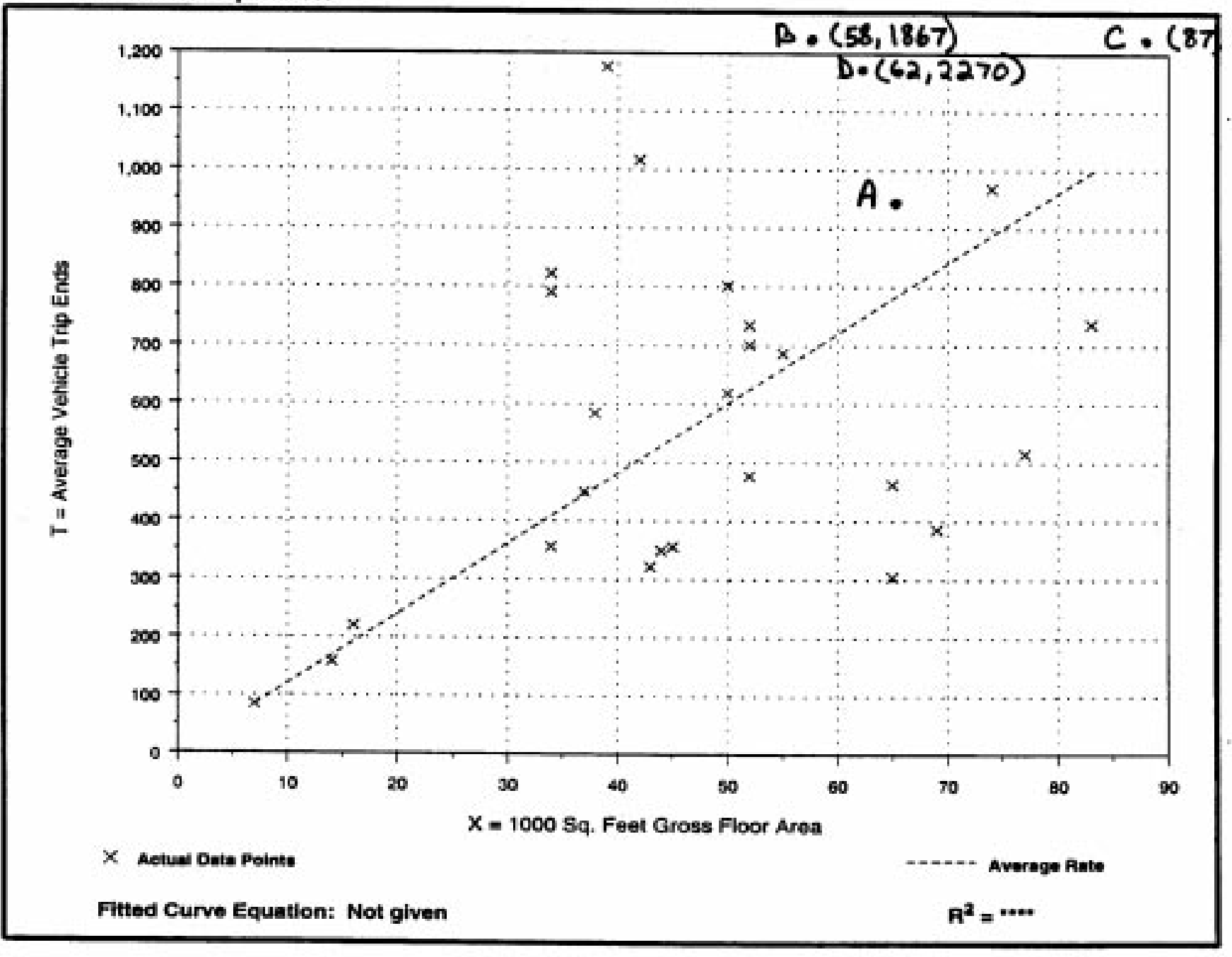




\section{Elementary School \\ (520)}

\section{Average Vehicle Trip Ends vs: $1000 \mathrm{Sq}$. Feet Gross Floor Area \\ On a: Weekday, \\ A.M. Peak Hour of Generator}

Number of Studies: 26

Average $1000 \mathrm{Sq}$. Feet GFA: 49

Directional Distribution: $61 \%$ entering, $39 \%$ exiting

\section{Trip Generation per 1000 Sq. Feet Gross Floor Area}

\begin{tabular}{|ccc|}
\hline Average Pate & Pange of Rates & Standard Deviation \\
\hline 3.36 & $1.33-7.38$ & 2.42 \\
\hline
\end{tabular}

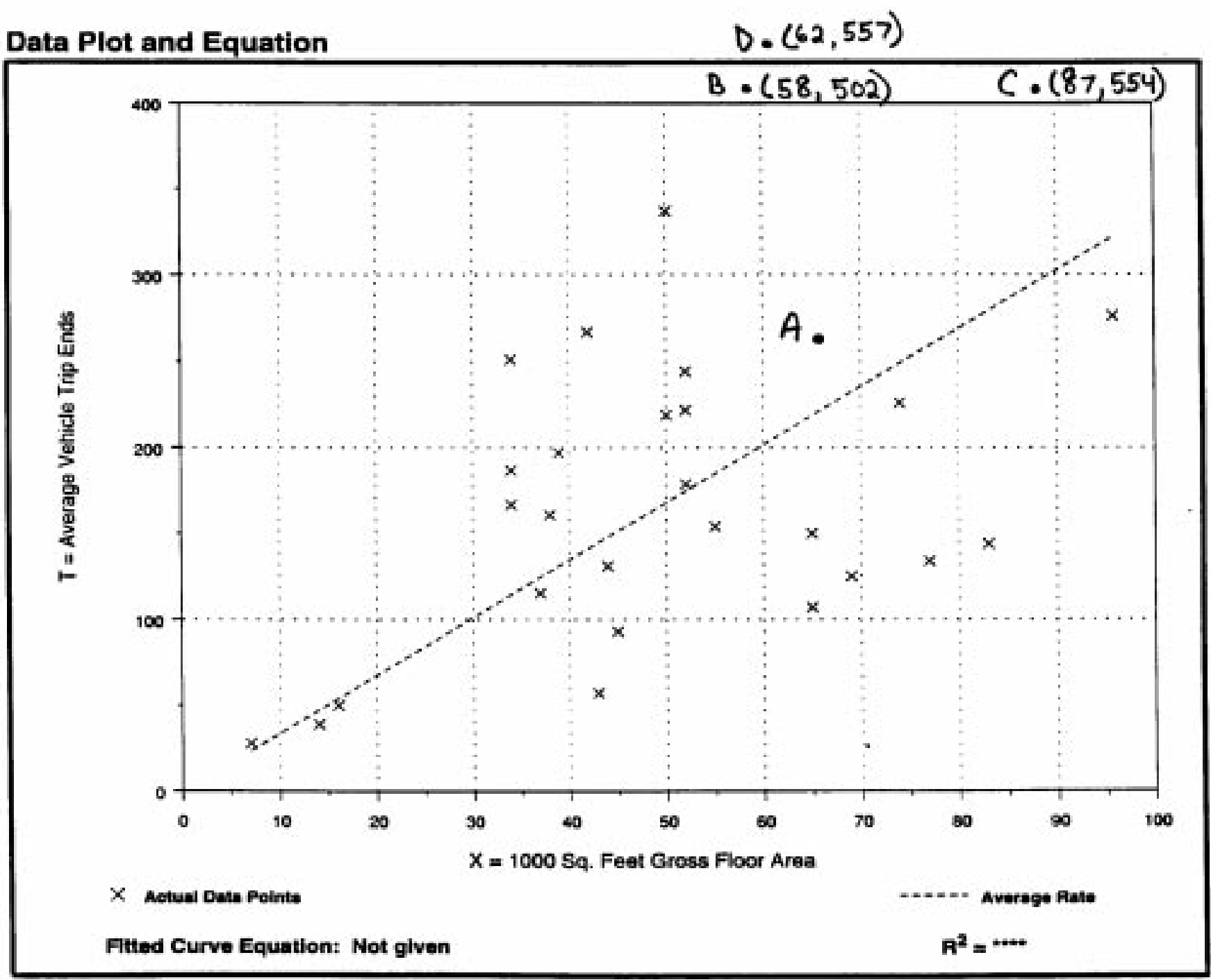




\section{Elementary School \\ (520)}

\section{Average Vehicle Trip Ends vs: 1000 Sq. Feet Gross Floor Area \\ On a: Weekday, \\ P.M. Peak Hour of Generator}

Number of Studies: 26

Average $1000 \mathrm{Sq}$. Feet GFA: 49

Directional Distribution: $26 \%$ entering, $74 \%$ exiting

Trip Generation per 1000 Sq. Feet Gross Floor Area

\begin{tabular}{|ccc|}
\hline Average Rate & Range of Rates & Standard Deviation \\
\hline 3.12 & $0.94-6.06$ & 2.35 \\
\hline
\end{tabular}

\section{Data Plot and Equation}

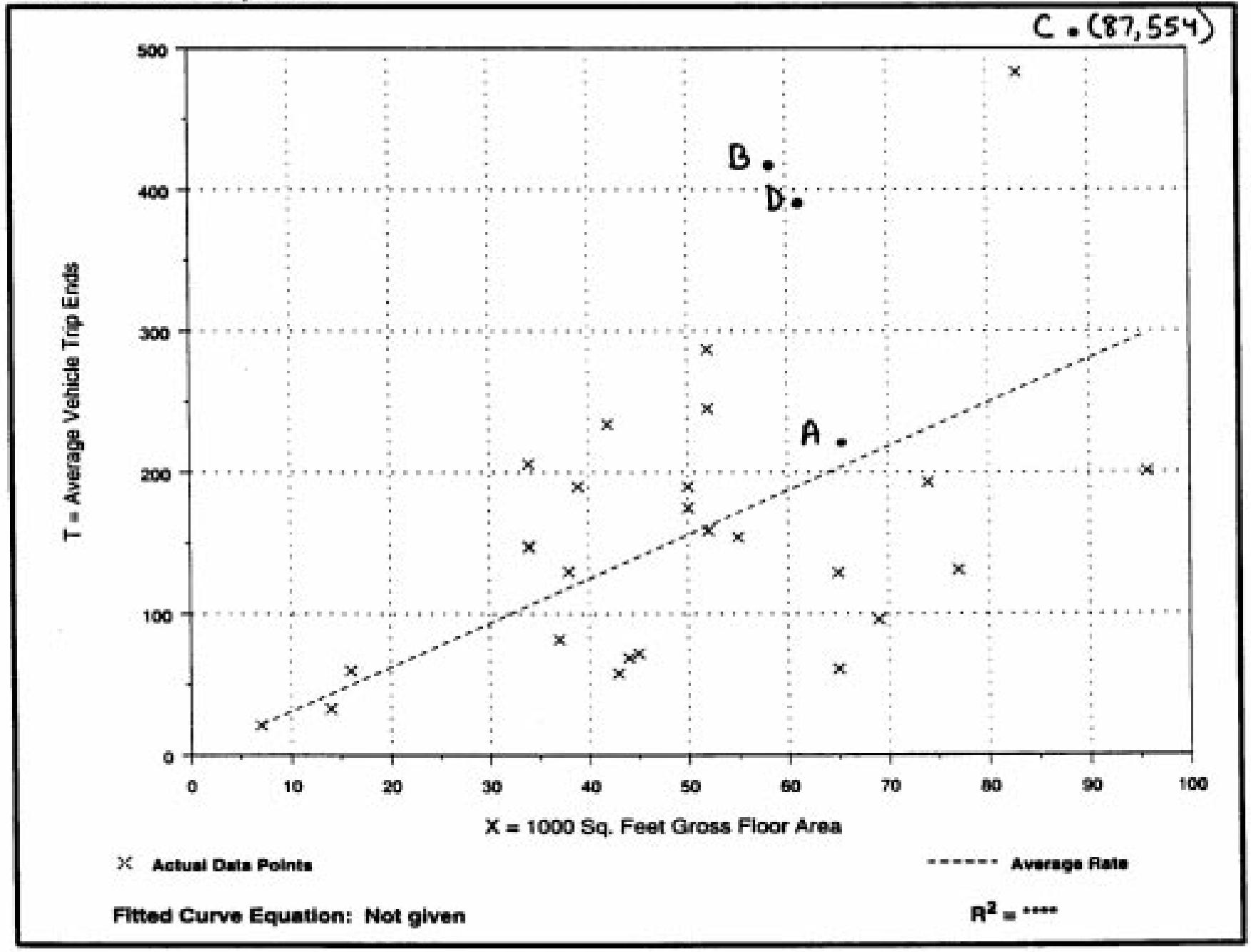


Appendix VI

Study Data Points Plotted on ITE (1997) Graphs

For Elementary-Middle Schools 


\section{Elementary School \\ (520)}

\section{Average Vehicle Trip Ends vs: Employees \\ On a: Weekday}

Number of Studies: 25

Avg. Number of Employees: 43

Directional Distribution: $50 \%$ entering, $50 \%$ exiting

\section{Trip Generation per Employee}

\begin{tabular}{|cccc|}
\hline Average Rate & Range of Rates & Standard Deviation \\
\hline 13.13 & 4.47 & -26.37 & 6.10 \\
\hline
\end{tabular}

\section{Data Plot and Equation}

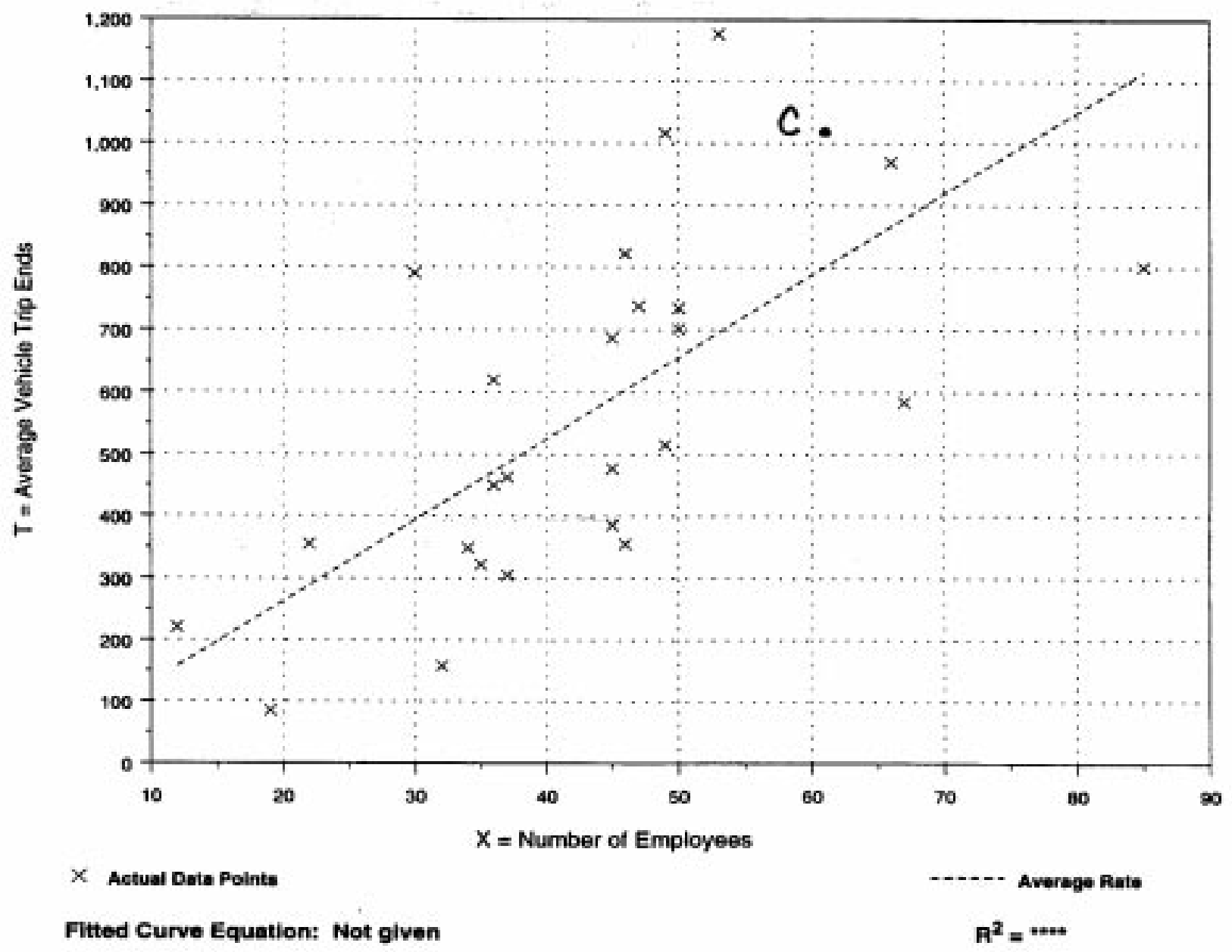




\section{Elementary School \\ (520)}

\section{Average Vehicle Trip Ends vs: Employees \\ On a: Weekday, \\ A.M. Peak Hour of Generator}

Number of Studies: 25

Avg. Number of Employees: 43

Directional Distribution: Not available

\section{Trip Generation per Employee}

\begin{tabular}{|cccc|}
\hline Average Rate & Range of Rates & Standard Deviation \\
\hline 3.71 & 1.22 & 7.59 & 2.34 \\
\hline
\end{tabular}

\section{Data Plot and Equation}

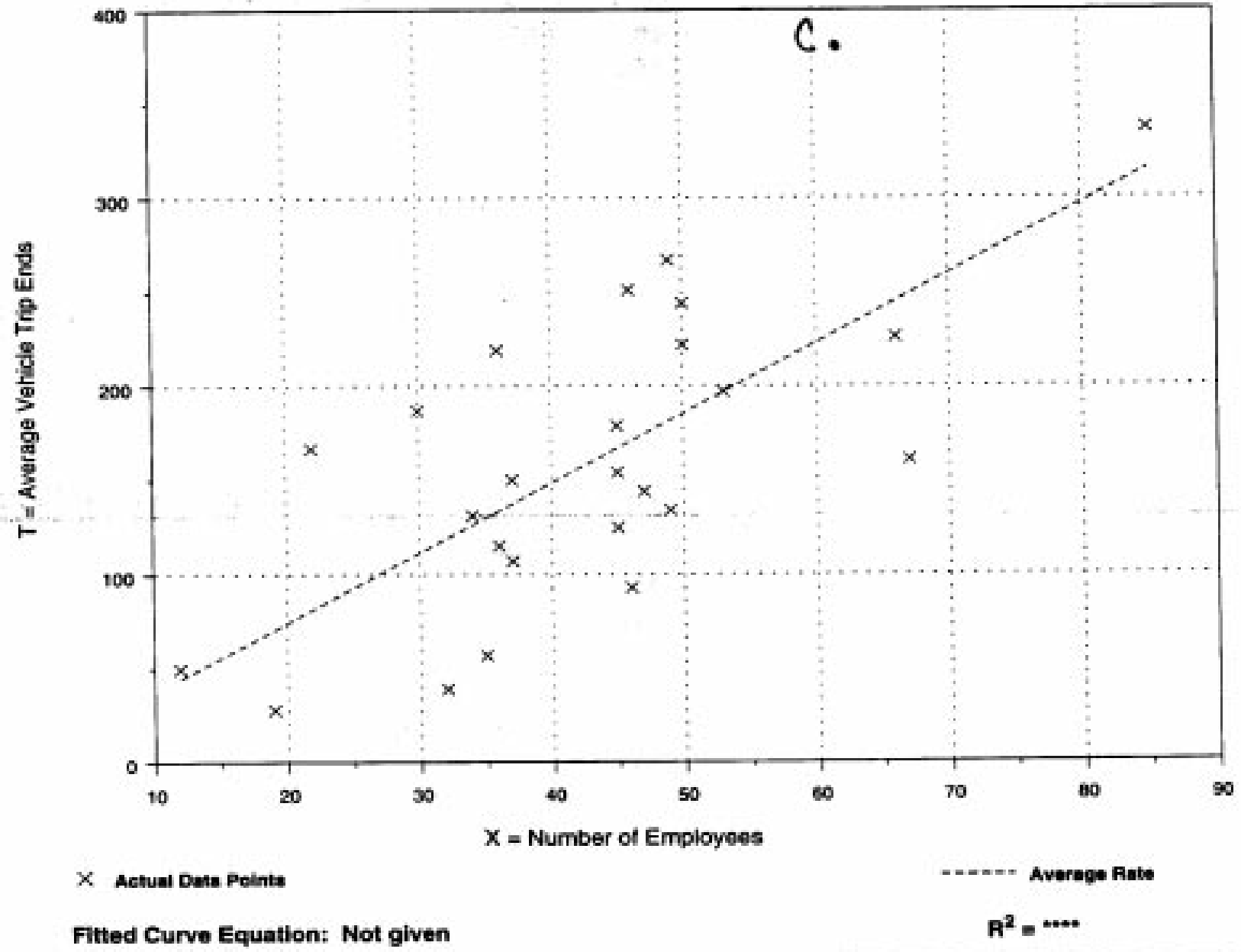




\section{Elementary School \\ (520)}

\section{Average Vehicle Trip Ends vs: Employees \\ On a: Weekday, \\ P.M. Peak Hour of Generator}

Number of Studies: 25

Avg. Number of Employees: 43

Directional Distribution: Not available

Trip Generation per Employee

\begin{tabular}{|ccc|}
\hline Average Rate & Range of Rates & Standard Deviation \\
\hline 3.50 & $1.03 \cdot 10.28$ & 2.73 \\
\hline
\end{tabular}

\section{Data Plot and Equation}

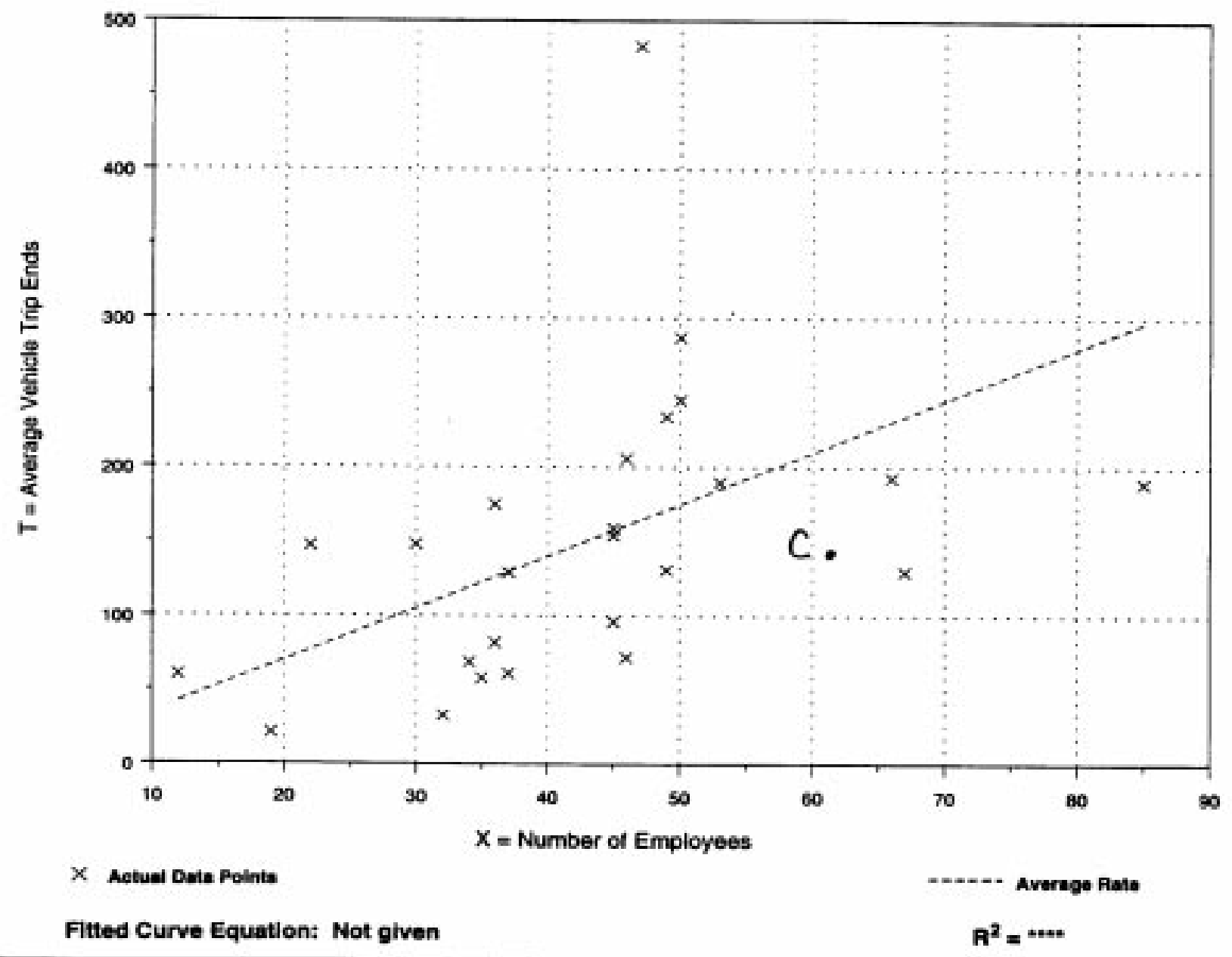




\section{Elementary School (520)}

\section{Average Vehicle Trip Ends vs: Students \\ On a: Weekday}

Number of Studies: 26

Average Number of Students: 562

Directional Distribution: $50 \%$ entering, $50 \%$ exiting

\section{Trip Generation per Student}

\begin{tabular}{|ccc|}
\hline Average Rate & Range of Rates & Standard Deviation \\
\hline 1.02 & $0.45-2.12$ & 1.07 \\
\hline
\end{tabular}

\section{Data Plot and Equation}

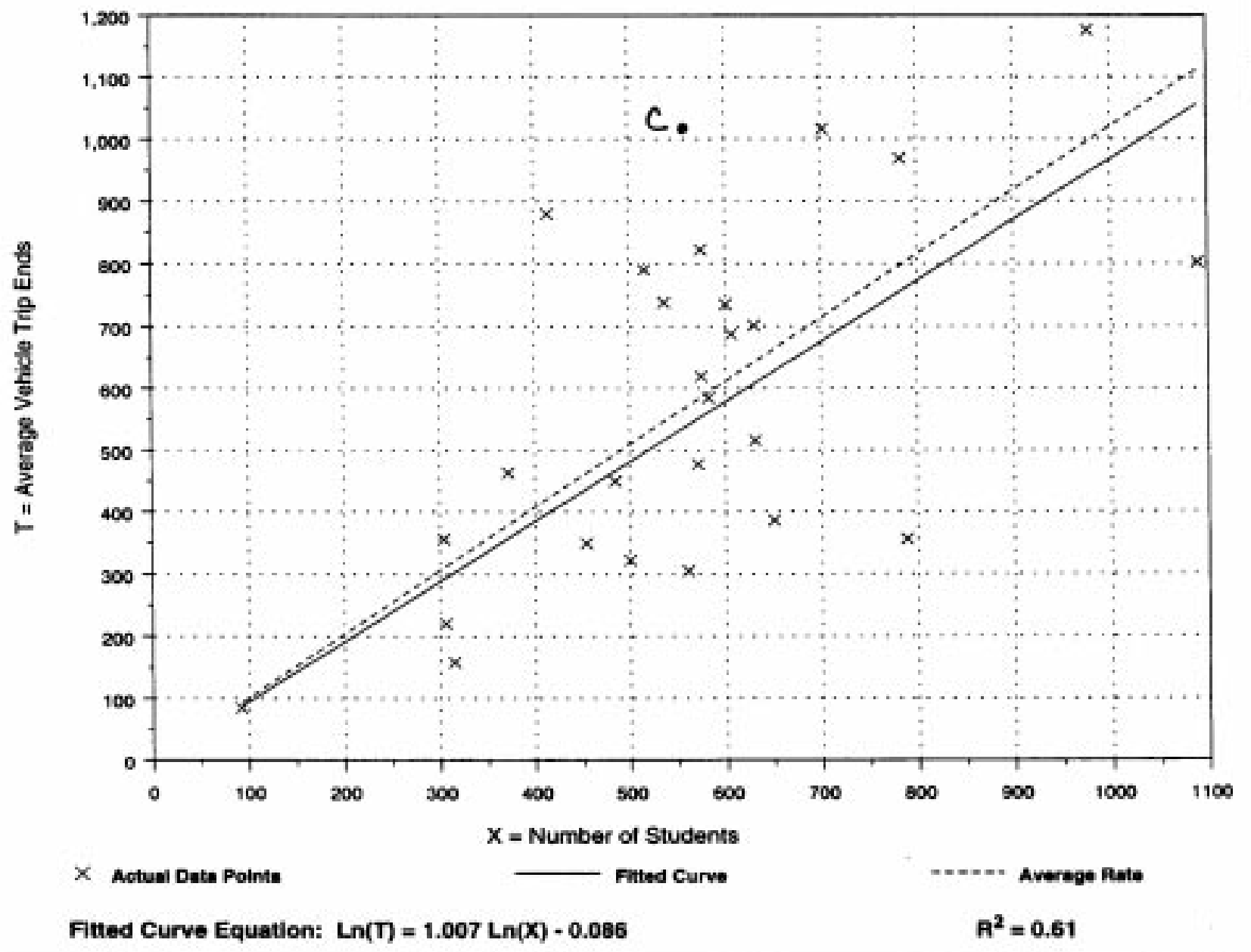




\section{Elementary School \\ (520)}

\section{Average Vehicle Trip Ends vs: Students \\ On a: Weekday,}

A.M. Peak Hour of Generator

Number of Studies: 31

Average Number of Students: 565

Directional Distribution: $58 \%$ entering, $42 \%$ exiting

Trip Generation per Student

\begin{tabular}{|cccc|}
\hline Average Rate & \multicolumn{2}{c|}{ Range of Rates } & Standard Deviation \\
\hline 0.30 & 0.11 & 0.71 & 0.56 \\
\hline
\end{tabular}

\section{Data Plot and Equation}

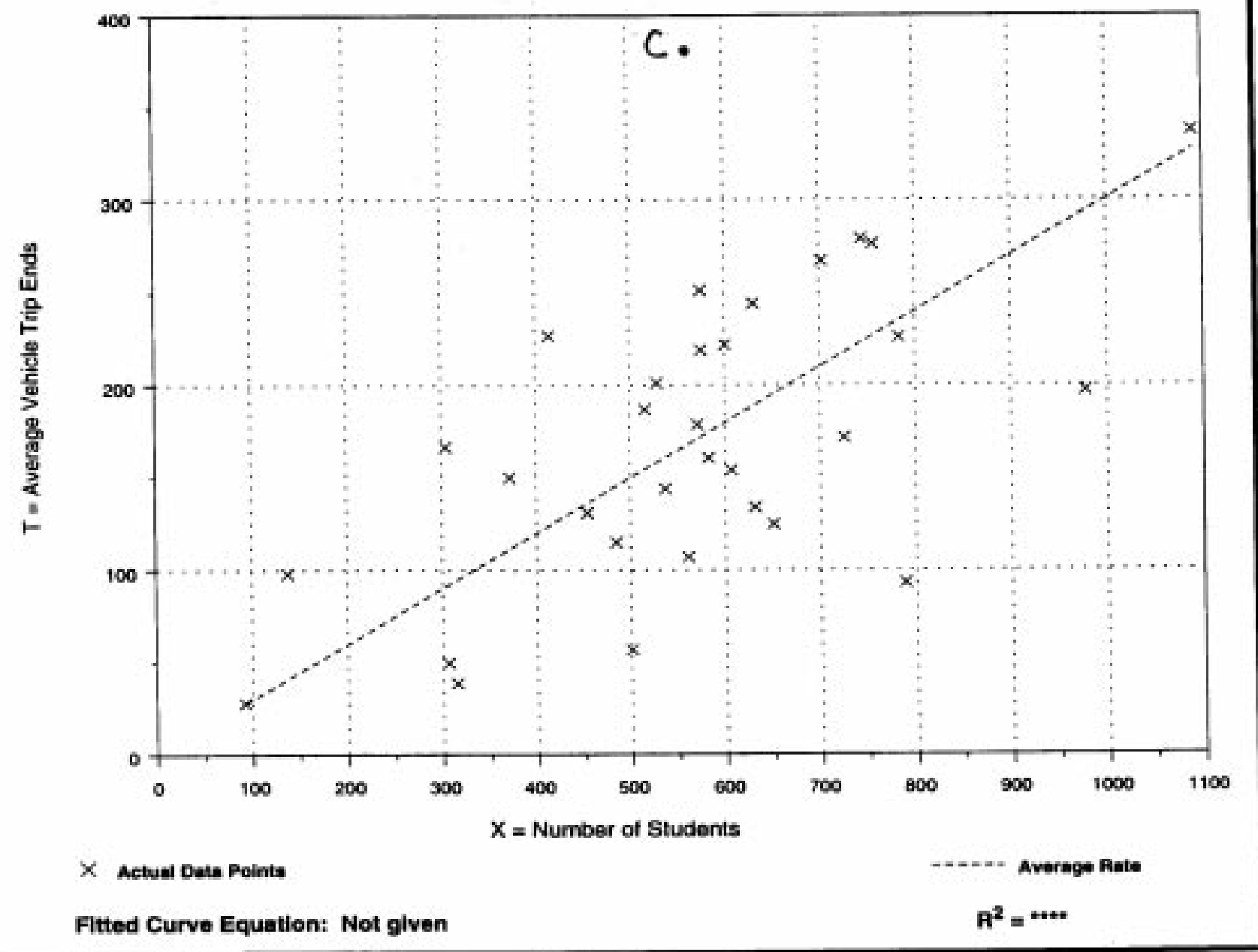




\section{Elementary School \\ (520)}

\section{Average Vehicle Trip Ends vs: Students \\ On a: Weekday, \\ P.M. Peak Hour of Generator}

Number of Studies: 30

Average Number of Students: $\mathbf{5 7 9}$

Directional Distribution: $46 \%$ entering, $54 \%$ exiting

\section{Trip Generation per Student}

\begin{tabular}{|clc|}
\hline Average Rate & Range of Rates & Standard Deviation \\
\hline 0.26 & $0.09-0.90$ & 0.53 \\
\hline
\end{tabular}

\section{Data Plot and Equation}

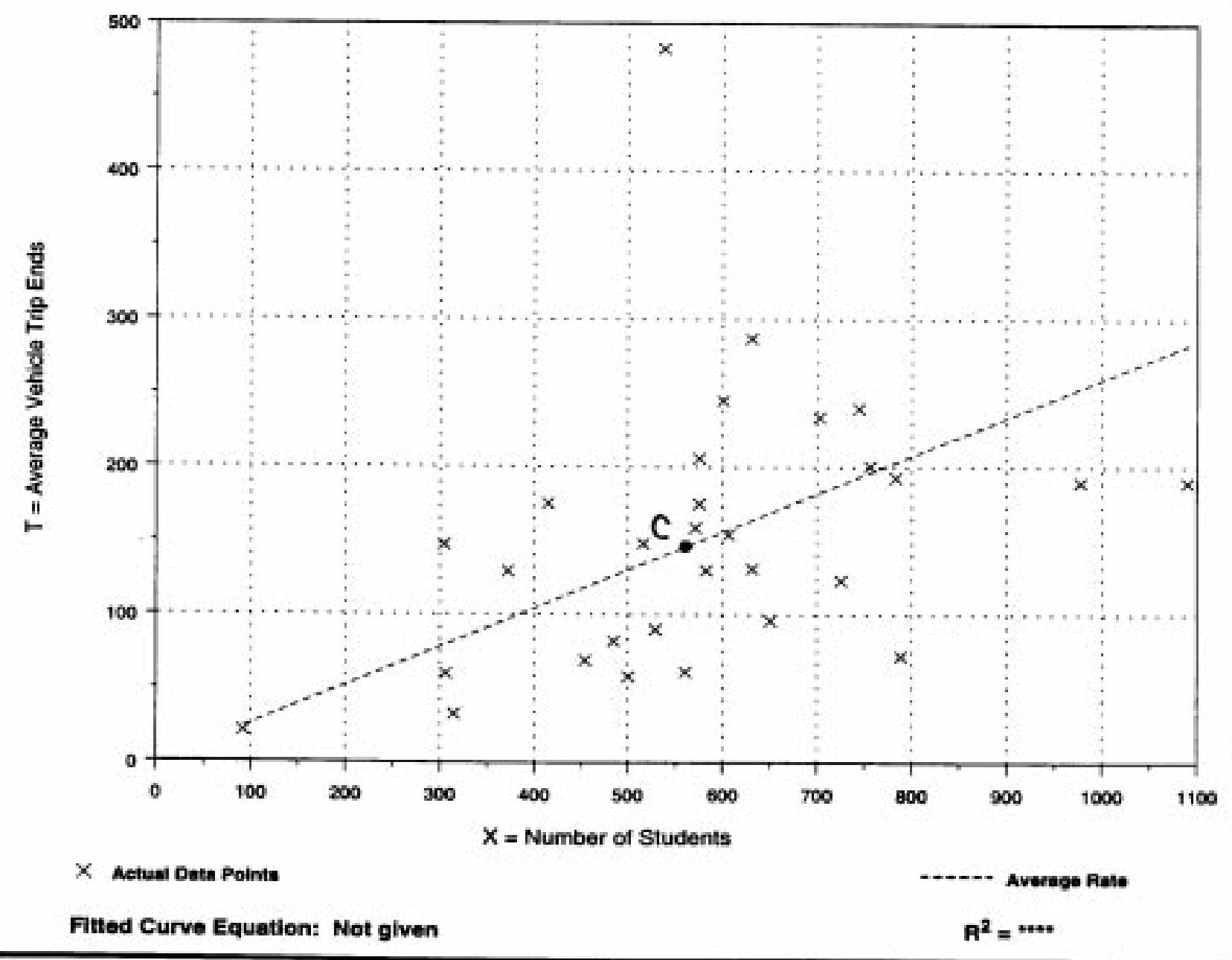




\title{
Elementary School \\ (520)
}

\section{Average Vehicle Trip Ends vs: 1000 Sq. Feet Gross Floor Area \\ On a: Weekday}

\author{
Number of Studies: 25 \\ Average $1000 \mathrm{Sq}$. Feet GFA: 47 \\ Directional Distribution: $50 \%$ entering, $50 \%$ exiting
}

\section{Trip Generation per 1000 Sq. Feet Gross Floor Area}

\begin{tabular}{|c|c|c|}
\hline Average Rate & Range of Rates & Standard Deviation \\
\hline 12.03 & $4.69-30.15$ & 7.02 \\
\hline
\end{tabular}

\section{Data Plot and Equation}

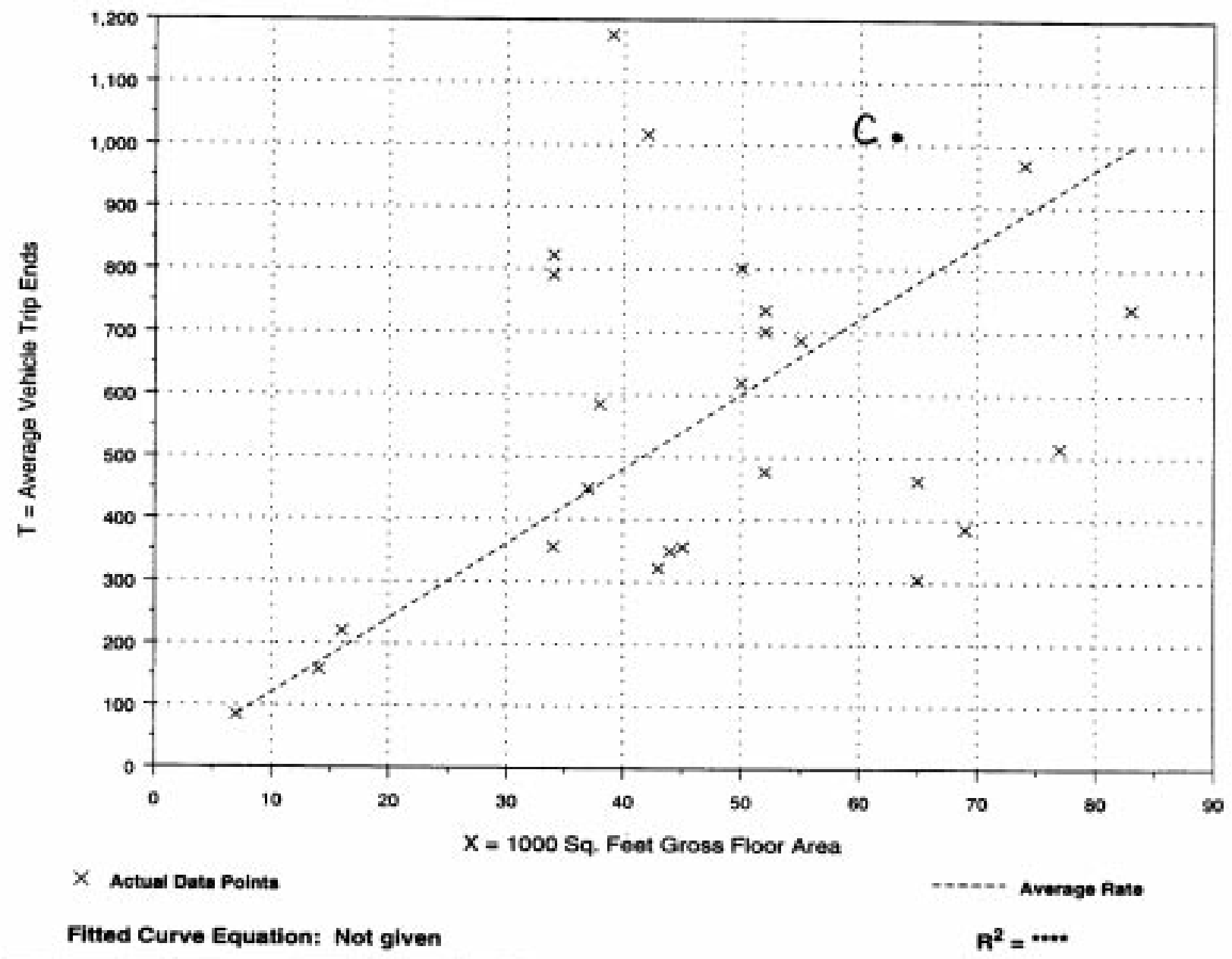




\section{Elementary School \\ (520)}

\section{Average Vehicle Trip Ends vs: 1000 Sq. Feet Gross Floor Area \\ On a: Weekday,}

A.M. Peak Hour of Generator

Number of Studies: 26

Average $1000 \mathrm{Sq}$. Feet GFA: 49

Directional Distribution: $61 \%$ entering, $39 \%$ exiting

Trip Generation per 1000 Sq. Feet Gross Floor Area

\begin{tabular}{|cccc|}
\hline Average Rate & Pange of Rates & Standard Deviation \\
\hline 3.36 & $1.33-7.38$ & 2.42 \\
\hline
\end{tabular}

\section{Data Plot and Equation}

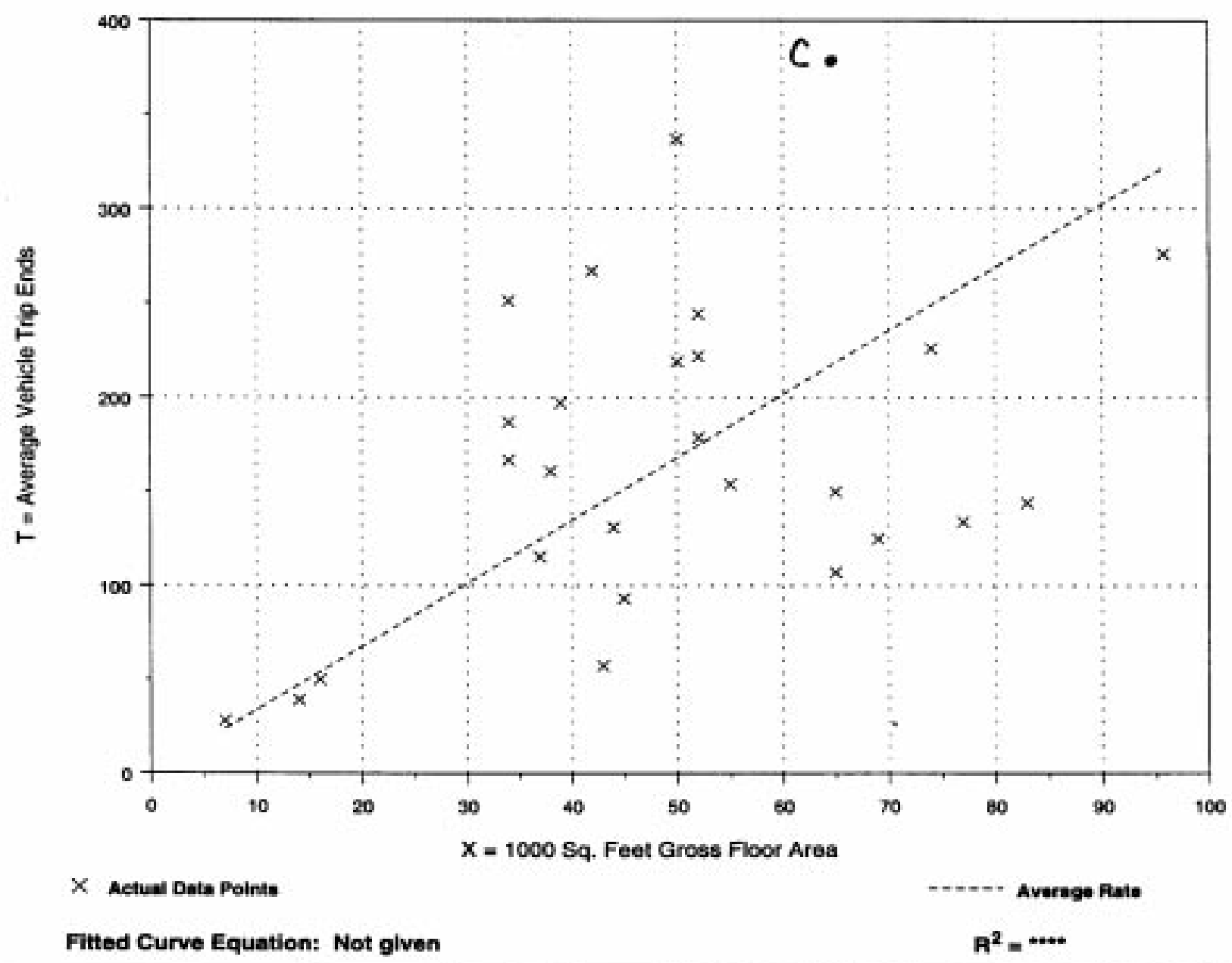




\section{Elementary School (520)}

\section{Average Vehicle Trip Ends vs: 1000 Sq. Feet Gross Floor Area \\ On a: Weekday, \\ P.M. Peak Hour of Generator}

Number of Studies: 26

Average $1000 \mathrm{Sq}$. Feet GFA: 49

Directional Distribution: $26 \%$ entering, $74 \%$ exiting

Trip Generation per 1000 Sq. Feet Gross Floor Area

\begin{tabular}{|cccc|}
\hline Average Rate & \multicolumn{2}{c|}{ Range of Rates } & Standard Deviation \\
\hline 3.12 & $0.94 \quad 6.06$ & 2.35 \\
\hline
\end{tabular}

Data Plot and Equation

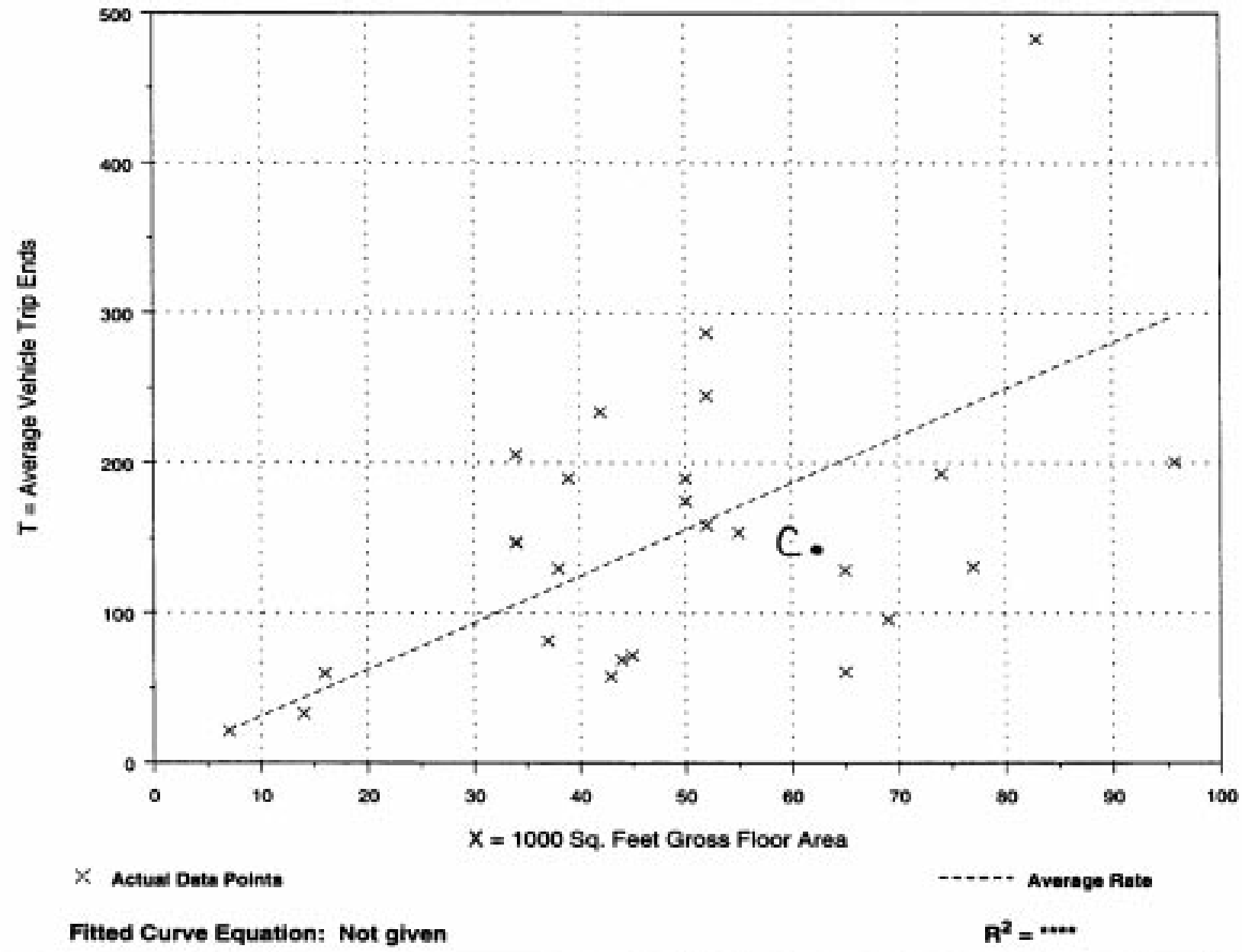




\section{Middle School/Junior High School (522)}

\section{Average Vehicle Trip Ends vs: Students \\ On a: Weekday}

Number of Studies: 16

Average Number of Students: 789

Directional Distribution: $50 \%$ entering, $50 \%$ exiting

\section{Trip Generation per Student}

\begin{tabular}{|clc|}
\hline Average Rate & Range of Rates & Standard Deviation \\
\hline 1.45 & $0.72-2.81$ & 1.41 \\
\hline
\end{tabular}

\section{Data Plot and Equation}

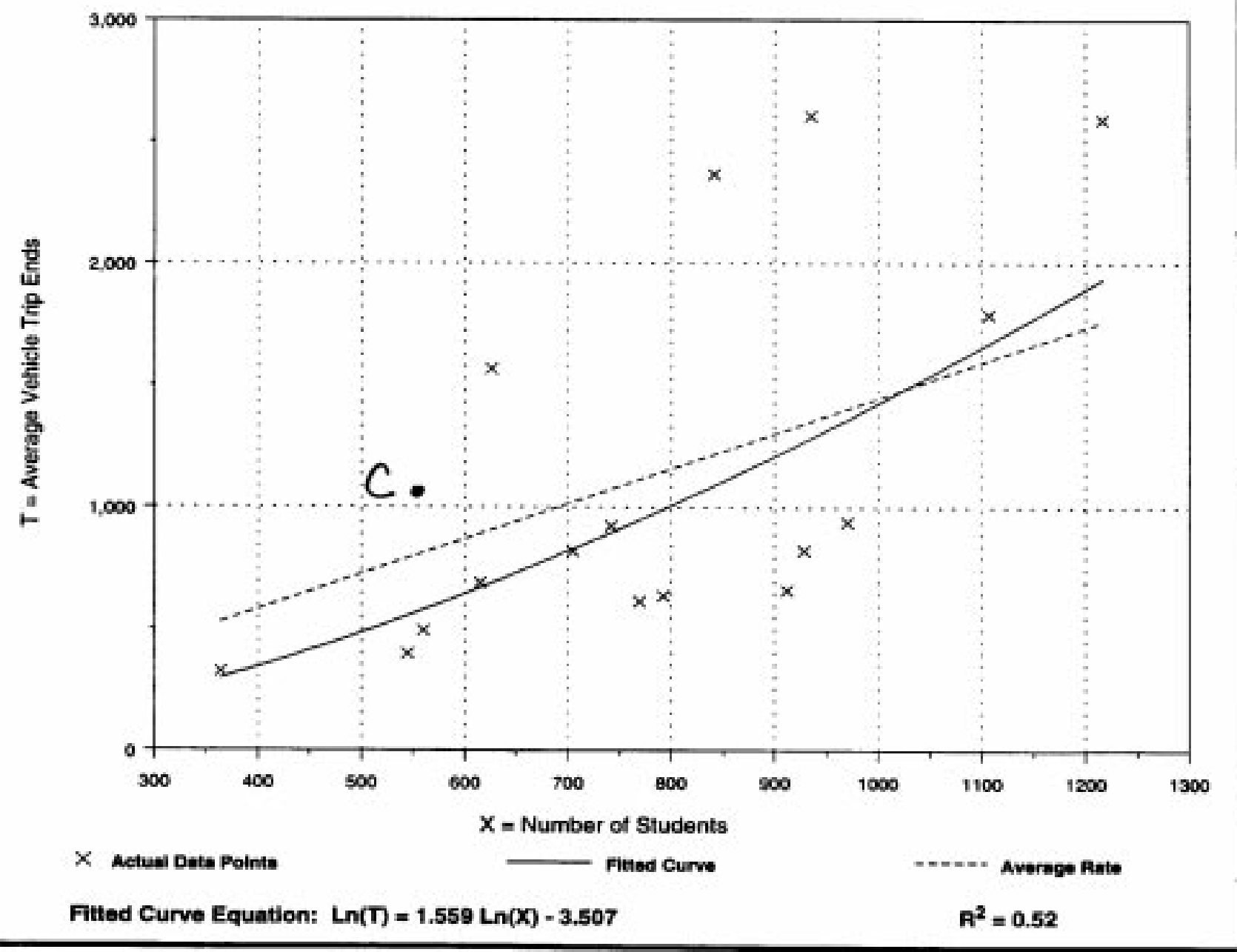




\section{Middle School/Junior High School (522)}

\section{Average Vehicle Trip Ends vs: Students \\ On a: Weekday, \\ A.M. Peak Hour of Generator}

Number of Studies: 16

Average Number of Students: 789

Directional Distribution: $57 \%$ entering, $43 \%$ exiting

Trip Generation per Student

\begin{tabular}{|c|c|c|}
\hline Average Rate & Range of Rates & Standard Deviation \\
\hline 0.45 & $0.14-1.29$ & 0.75 \\
\hline
\end{tabular}

\section{Data Plot and Equation}

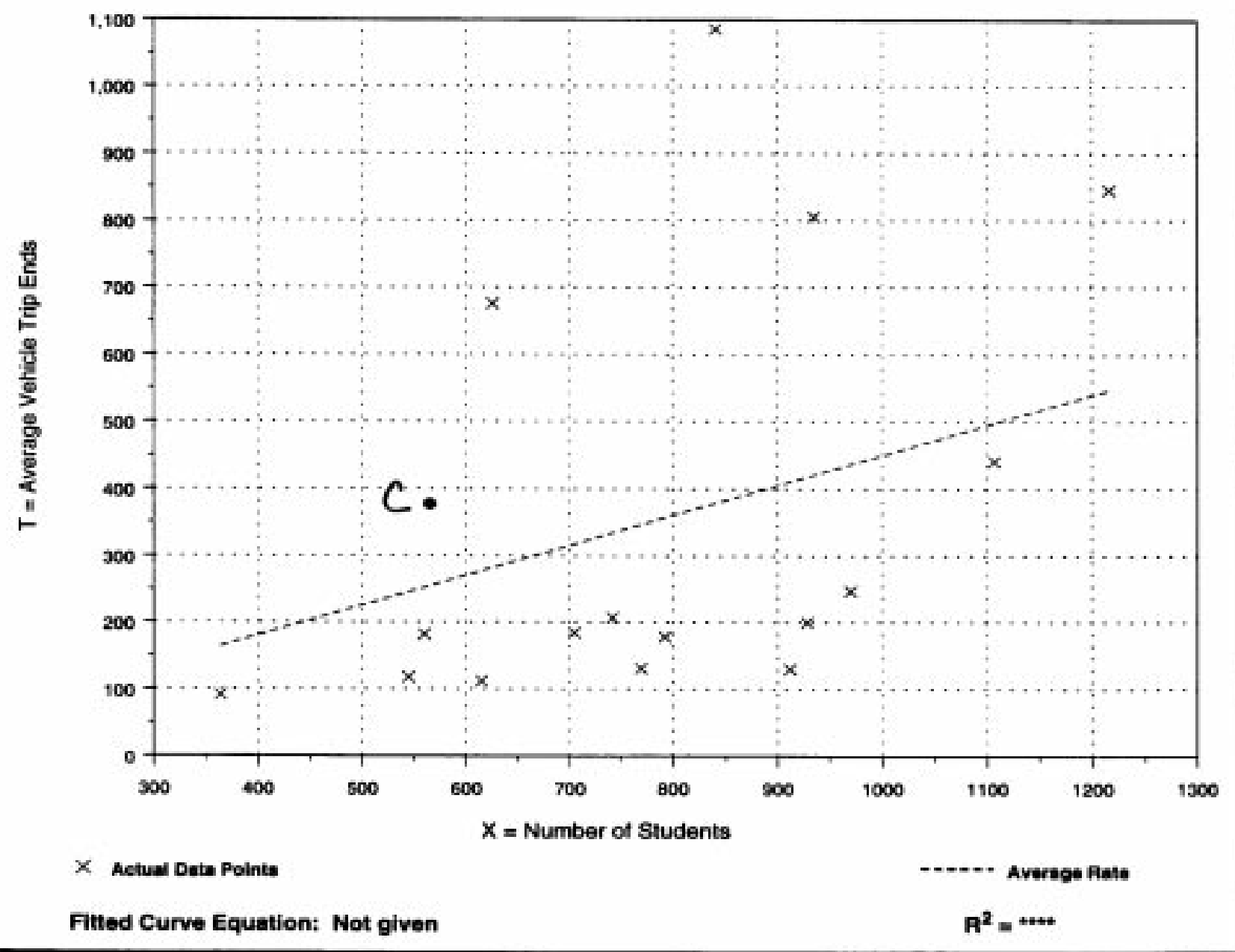




\section{Middle School/Junior High School (522)}

\section{Average Vehicle Trip Ends vs: Students \\ On a: Weekday, \\ P.M. Peak Hour of Generator}

Number of Studies: 18

Average Number of Students: 752

Directional Distribution: $51 \%$ entering, $49 \%$ exiting

\section{Trip Generation per Student}

\begin{tabular}{|cccc|}
\hline Average Rate & \multicolumn{1}{c|}{ Range of Rates } & Standard Deviation \\
\hline 0.29 & $0.12 \quad 0.63$ & 0.56 \\
\hline
\end{tabular}

\section{Data Plot and Equation}

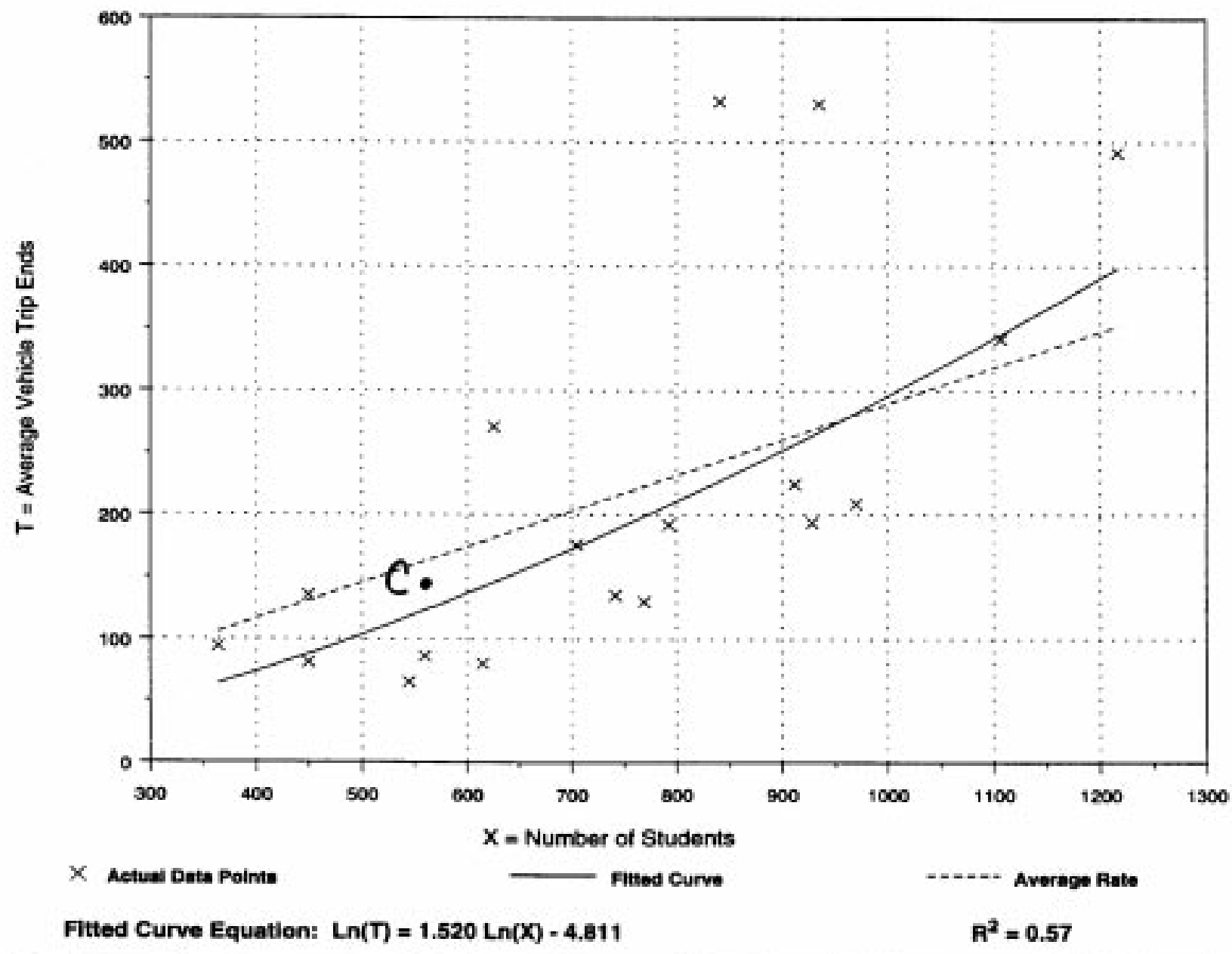




\title{
Middle School/Junior High School (522)
}

\section{Average Vehicle Trip Ends vs: 1000 Sq. Feet Gross Floor Area \\ On a: Weekday}

\author{
Number of Studies: 16 \\ Average $1000 \mathrm{Sq}$. Feet GFA: 96 \\ Directional Distribution: $50 \%$ entering, $50 \%$ exiting
}

Trip Generation per 1000 Sq. Feet Gross Floor Area

\begin{tabular}{|c|c|c|}
\hline Average Rate & Range of Rates & Standard Deviation \\
\hline 11.92 & $3.89-48.31$ & 9.35 \\
\hline
\end{tabular}

\section{Data Plot and Equation}

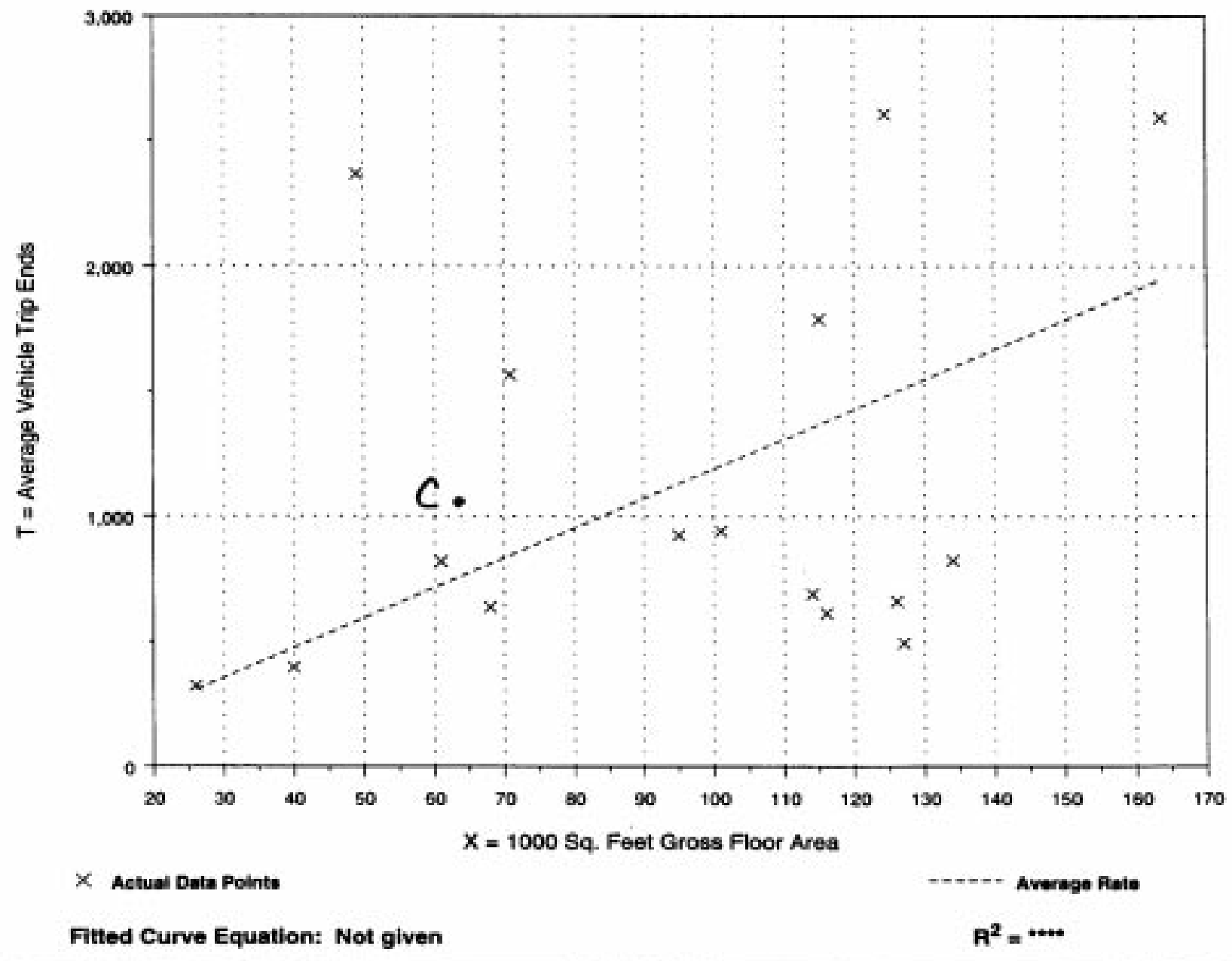




\section{Middle School/Junior High School (522)}

\section{Average Vehicle Trip Ends vs: 1000 Sq. Feet Gross Floor Area \\ On a: Weekday,}

A.M. Peak Hour of Generator

Number of Studies: 16

Average $1000 \mathrm{Sq}$. Feet GFA: 96

Directional Distribution: $57 \%$ entering, $43 \%$ exiting

Trip Generation per 1000 Sq. Feet Gross Floor Area

\begin{tabular}{|c|c|c|c|}
\hline Average Rate & Ran & Rates & Standard Deviation \\
\hline 3.68 & 0.98 & 22.16 & 4.45 \\
\hline
\end{tabular}

\section{Data Plot and Equation}

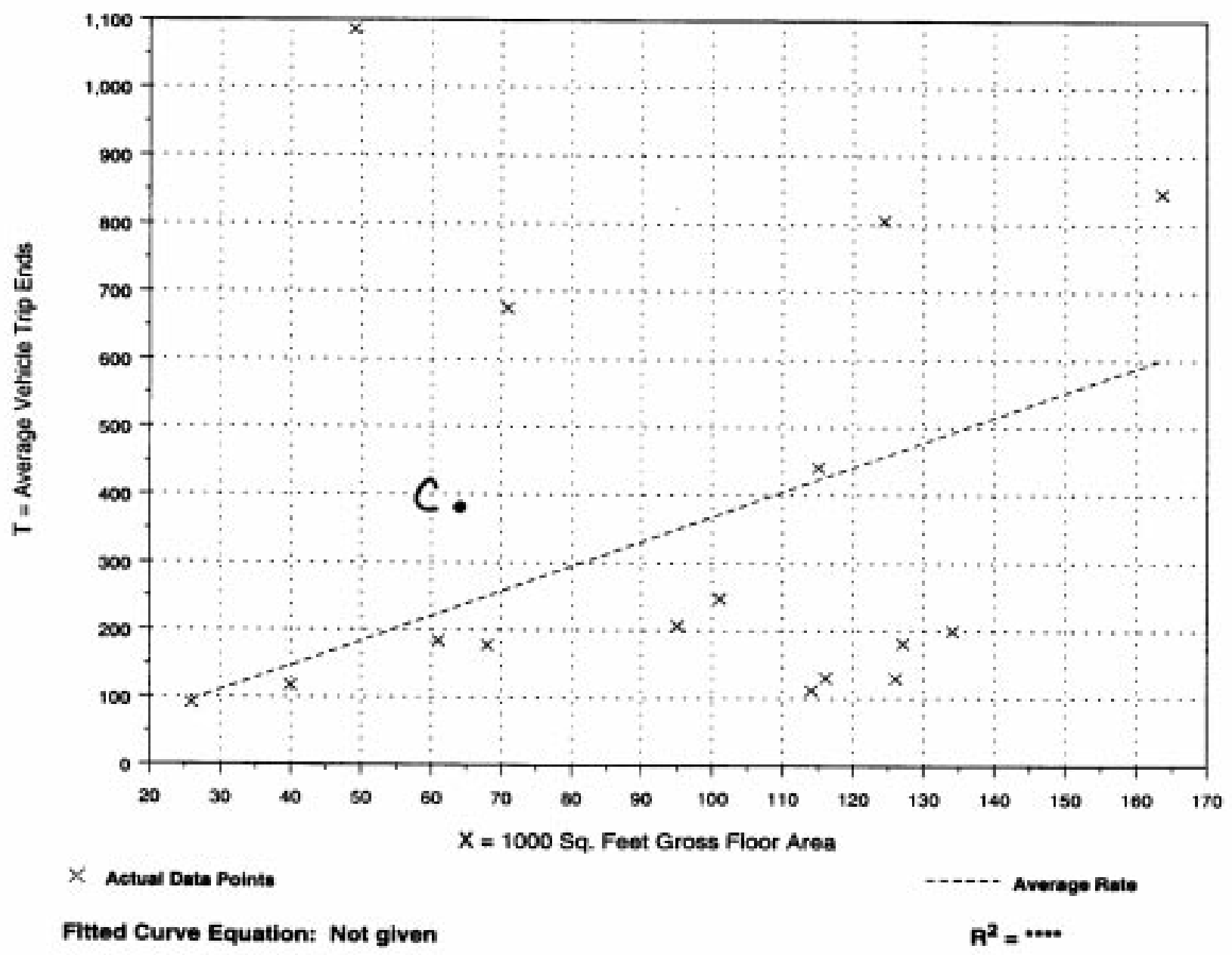




\section{Middle School/Junior High School (522)}

\section{Average Vehicle Trip Ends vs: 1000 Sq. Feet Gross Floor Area \\ On a: Weekday,}

P.M. Peak Hour of Generator

Number of Studies: 16

Average $1000 \mathrm{Sq}$. Feet GFA: 96

Directional Distribution: $51 \%$ entering, $49 \%$ exiting

Trip Generation per 1000 Sq. Feet Gross Floor Area

\begin{tabular}{|ccc|}
\hline Average Rate & Range of Rates & Standard Deviation \\
\hline 2.45 & $0.68-10.88$ & 2.45 \\
\hline
\end{tabular}

\section{Data Plot and Equation}

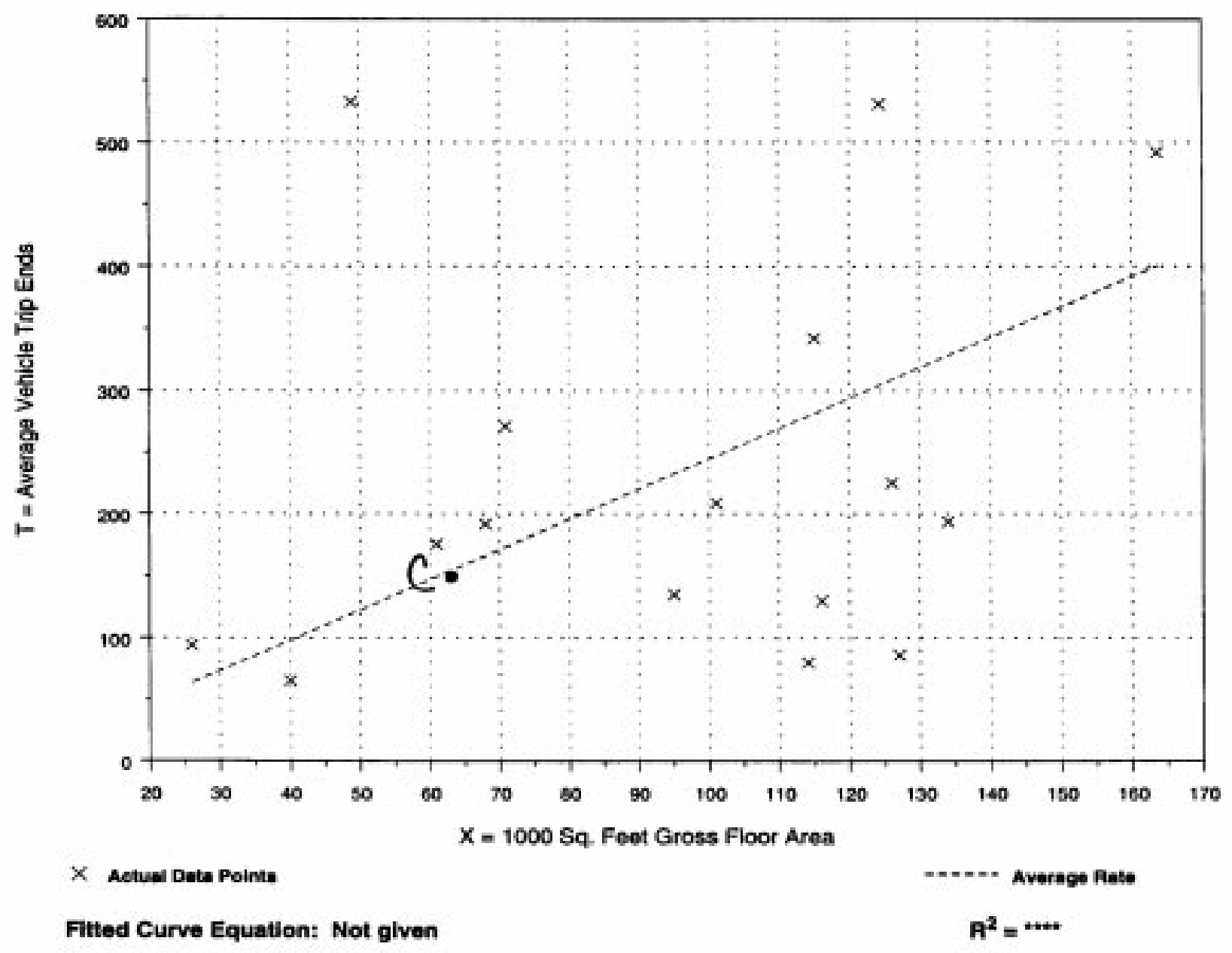


Appendix VII

Study Data Points Plotted on ITE (1997) Graphs

For Middle-High Schools 


\title{
High School
}

(530)

\section{Average Vehicle Trip Ends vs: Employees \\ On a: Weekday}

\author{
Number of Studies: 45 \\ Avg. Number of Employees: 117 \\ Directional Distribution: $50 \%$ entering, $50 \%$ exiting
}

\section{Trip Generation per Employee}

\begin{tabular}{|ccc|}
\hline Average Rate & Range of Rates & Standard Deviation \\
\hline 19.98 & $4.28-35.26$ & 8.30 \\
\hline
\end{tabular}

\section{Data Plot and Equation}

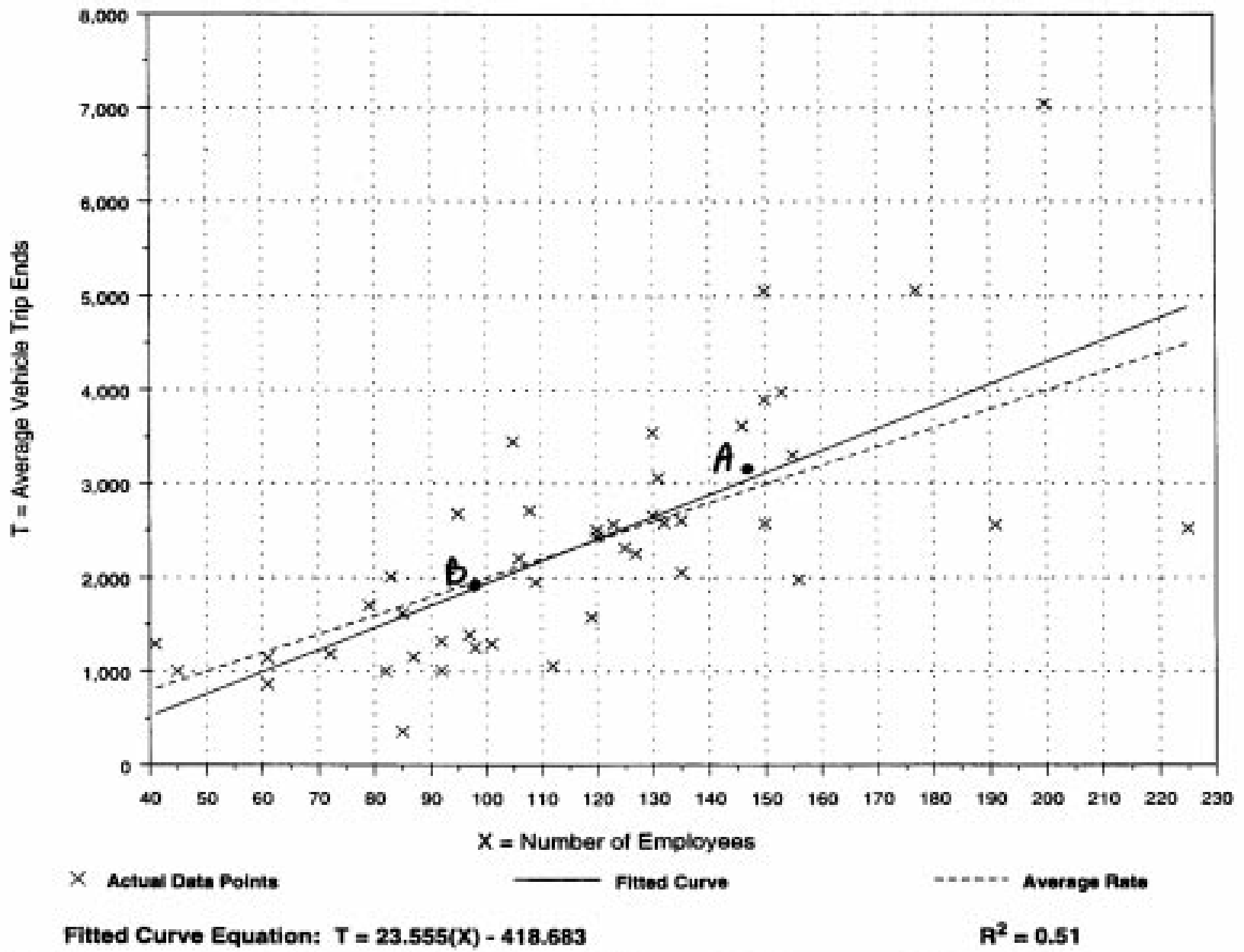




\section{High School}

(530)

\section{Average Vehicle Trip Ends vs: Employees \\ On a: Weekday,}

A.M. Peak Hour of Generator

Number of Studies: 45

Avg. Number of Employees: 117

Directional Distribution: $72 \%$ entering, $28 \%$ exiting

\section{Trip Generation per Employee}

\begin{tabular}{|c|c|c|}
\hline Average Pate & Range of Rates & Standard Deviation \\
\hline 4.68 & $0.54=10.20$ & 2.92 \\
\hline
\end{tabular}

\section{Data Plot and Equation}

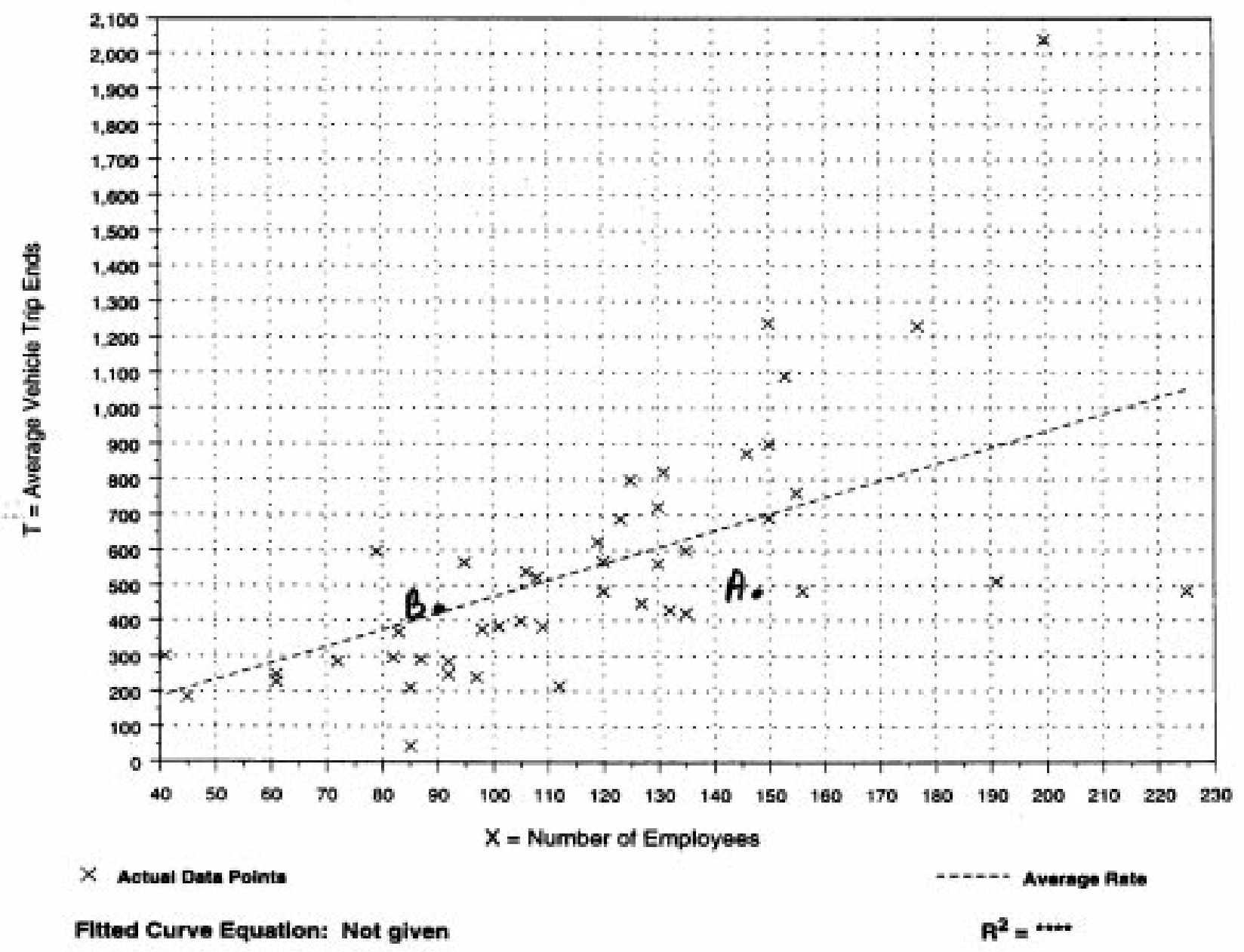




\section{High School \\ (530)}

\section{Average Vehicle Trip Ends vs: Employees \\ On a: Weekday, \\ P.M. Peak Hour of Generator}

Number of Studies: 45

Avg. Number of Employees: 117

Directional Distribution: $30 \%$ entering, $70 \%$ exiting

\section{Trip Generation per Employee}

\begin{tabular}{|ccc|}
\hline Average Rate & Range of Rates & Standard Deviation \\
\hline 3.30 & $1.13-6.98$ & 2.10 \\
\hline
\end{tabular}

\section{Data Plot and Equation}

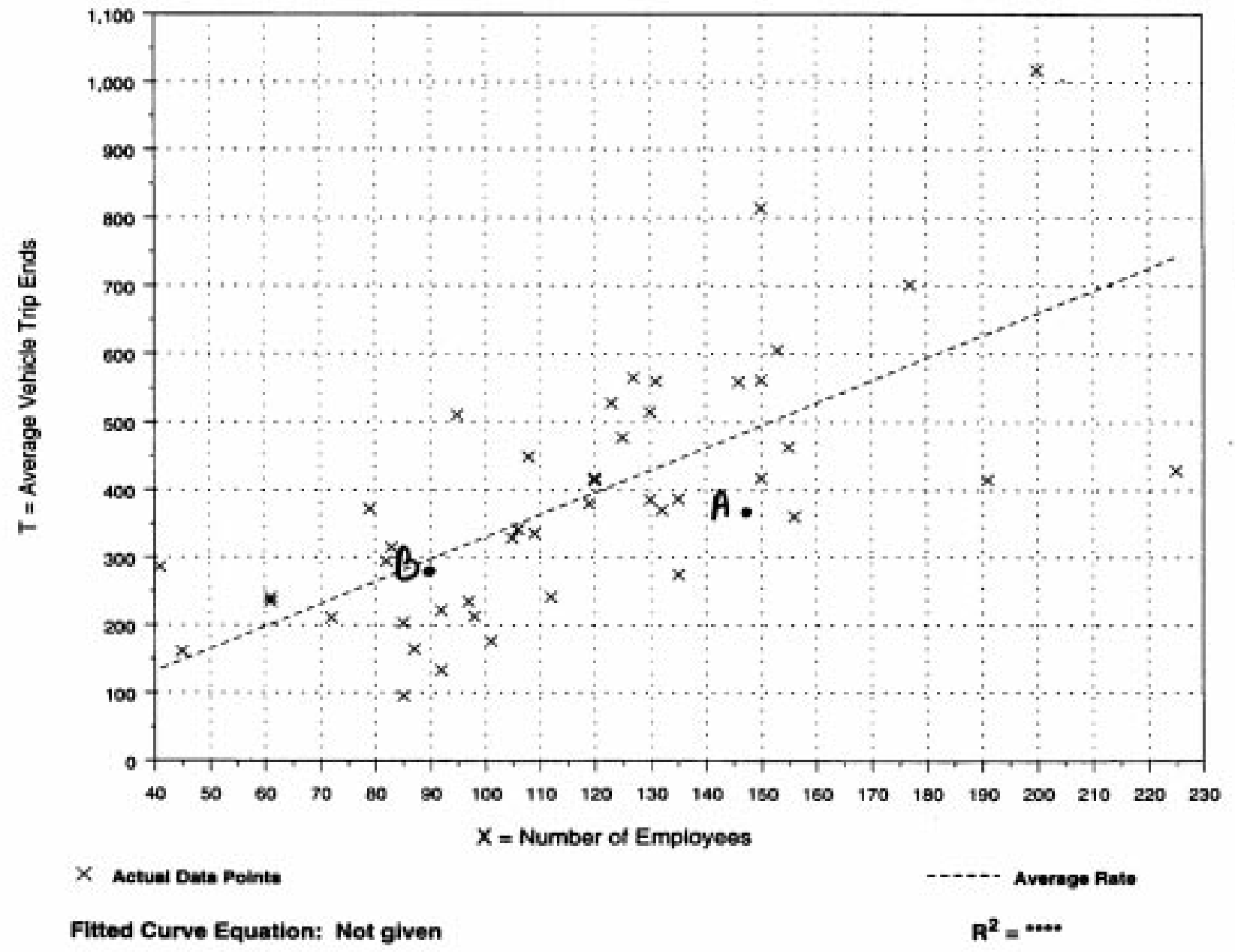




\section{Average Vehicle Trip Ends vs: Employees \\ On a: Saturday}

Number of Studies: 18

Avg. Number of Employees: 142

Directional Distribution: $50 \%$ entering, $50 \%$ exiting

\section{Trip Generation per Employee}

\begin{tabular}{|cccc|}
\hline Average Rate & Range of Rates & Standard Deviation \\
\hline 6.65 & $0.75 \cdot 19.95$ & 5.42 \\
\hline
\end{tabular}

\section{Data Plot and Equation}

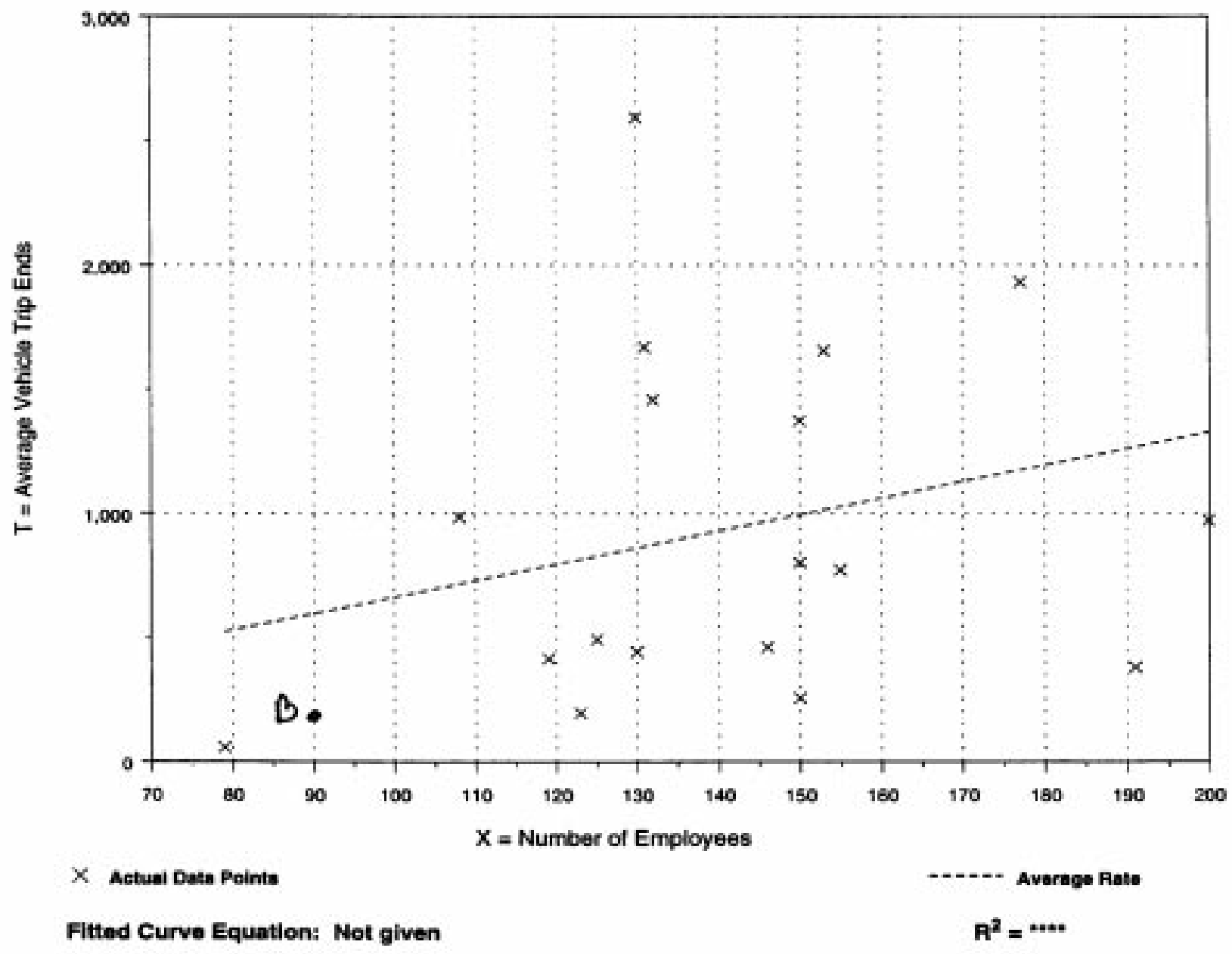




\section{High School (530)}

\section{Average Vehicle Trip Ends vs: Employees \\ On a: Saturday, \\ Peak Hour of Generator}

Number of Studies: 18

Avg. Number of Employees: 142

Directional Distribution: $74 \%$ entering, $26 \%$ exiting

Trip Generation per Employee

\begin{tabular}{|clcc|}
\hline Average Rate & Pange of Rates & Standard Deviation \\
\hline 1.23 & 0.19 & -2.72 & 1.41 \\
\hline
\end{tabular}

\section{Data Plot and Equation}

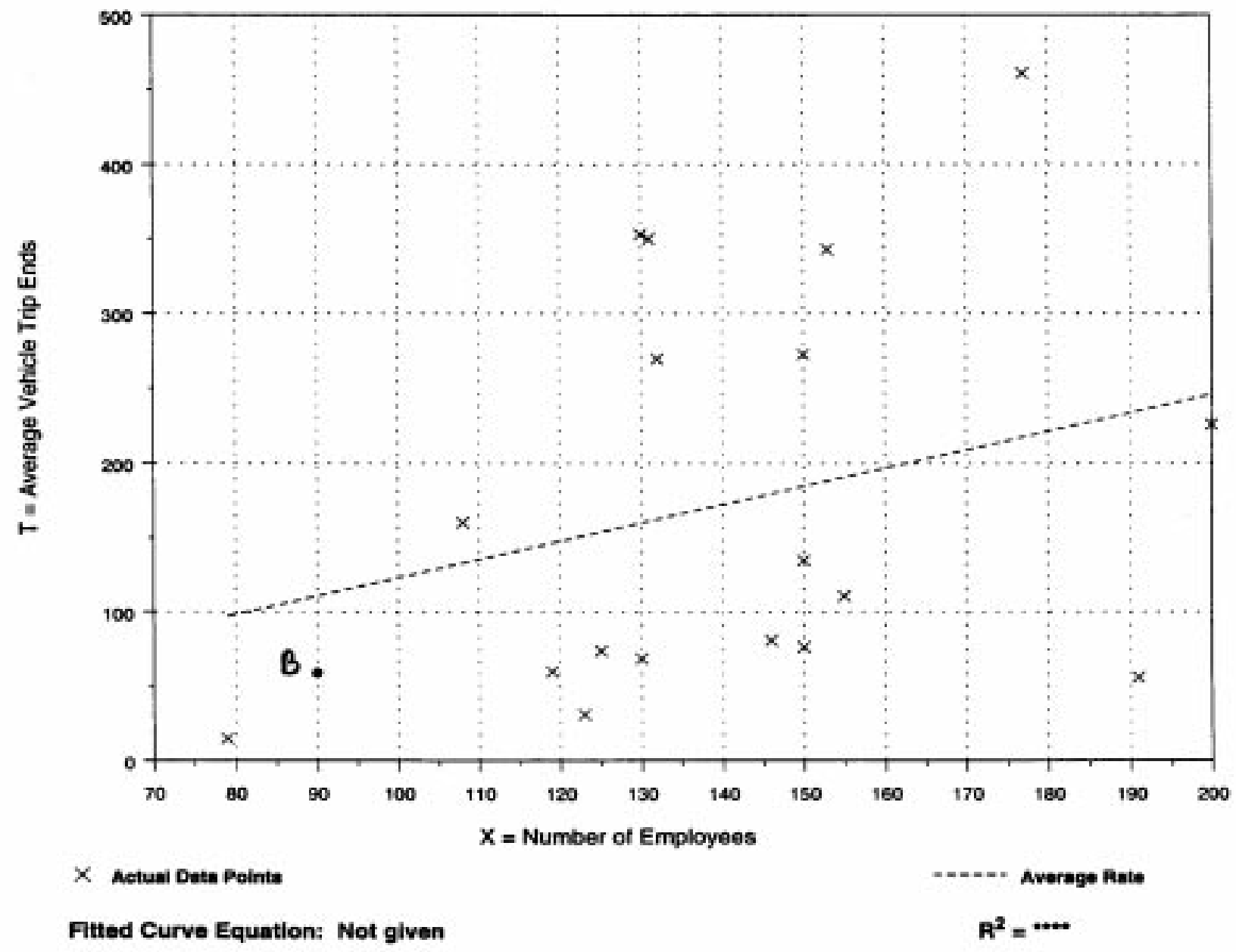




\section{High School \\ (530)}

\section{Average Vehicle Trip Ends vs: Employees \\ On a: Sunday}

Number of Studies: 18

Avg. Number of Employees: 142

Directional Distribution: $50 \%$ entering, $50 \%$ exiting

\section{Trip Generation per Employee}

\begin{tabular}{|c|c|c|}
\hline Average Rate & Range of Rates & Standard Deviation \\
\hline 2.64 & $0.45-10.27$ & 2.88 \\
\hline
\end{tabular}

\section{Data Plot and Equation}

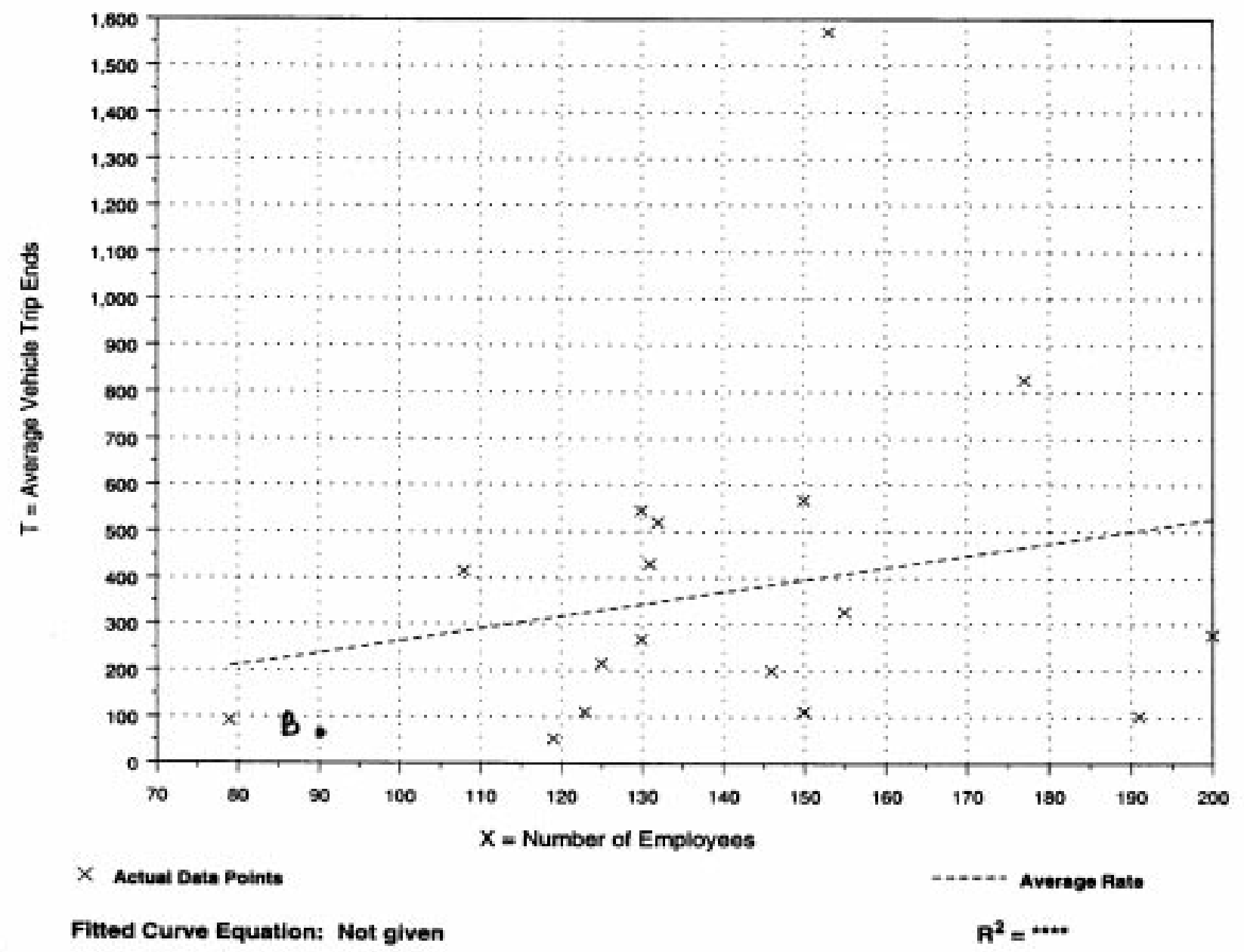


Average Vehicle Trip Ends vs: Employees

On a: Sunday,

Peak Hour of Generator

Number of Studies: 18

Avg. Number of Employees: 142

Directional Distribution: $33 \%$ entering, $67 \%$ exiting

\section{Trip Generation per Employee}

\begin{tabular}{|c|c|c|}
\hline Average Rate & Range of Rates & Standard Deviation \\
\hline 0.47 & $0.09-2.25$ & 0.84 \\
\hline
\end{tabular}

\section{Data Plot and Equation}

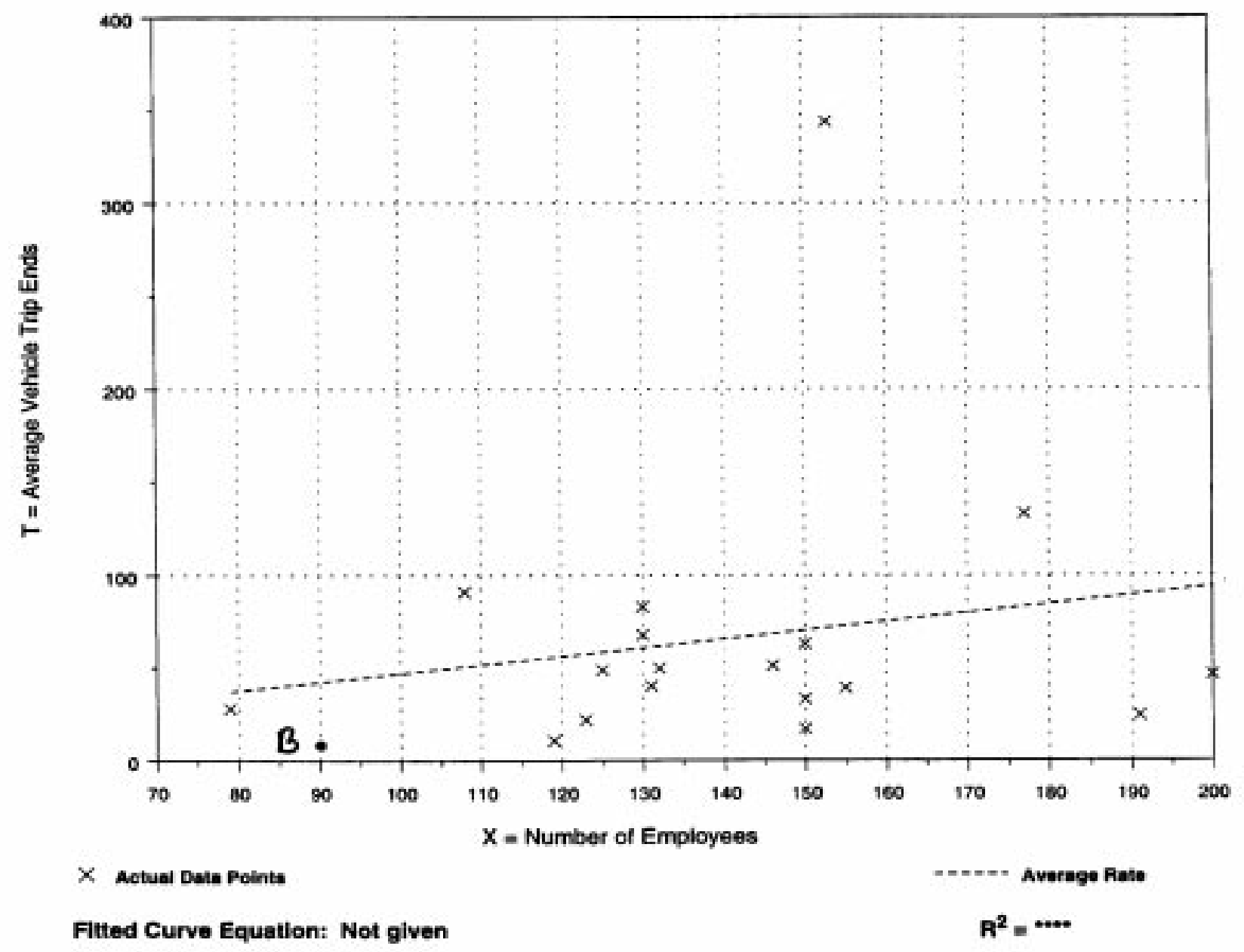




\section{High School \\ (530)}

\section{Average Vehicle Trip Ends vs: Students \\ On a: Weekday}

Number of Studies: 45

Average Number of Students: 1,309

Directional Distribution: $50 \%$ entering, $50 \%$ exiting

\section{Trip Generation per Student}

\begin{tabular}{|clc|}
\hline Average Rate & Range of Pates & Standard Deviation \\
\hline 1.79 & $0.71-3.96$ & 1.54 \\
\hline
\end{tabular}

\section{Data Plot and Equation}

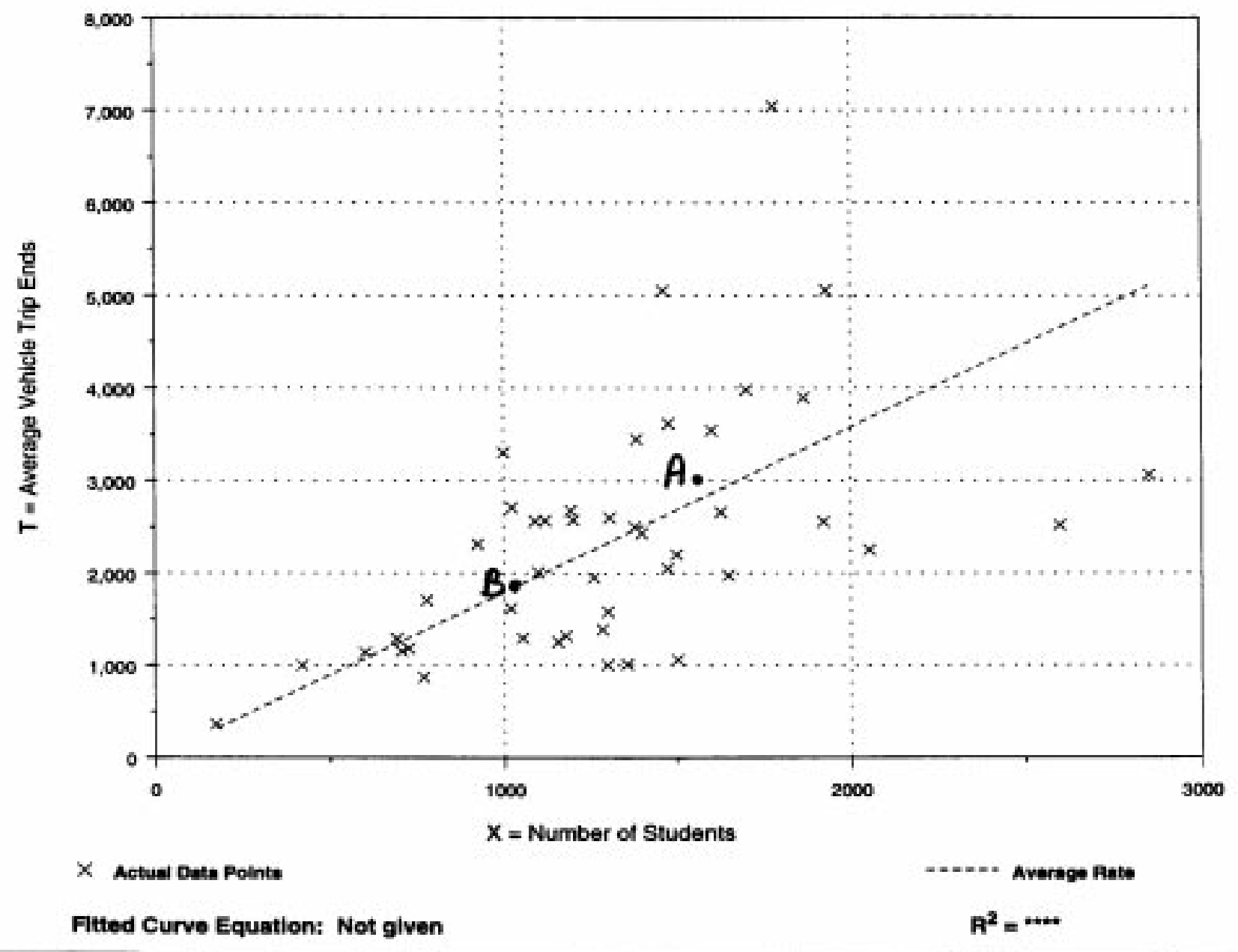




\section{High School}

(530)

\section{Average Vehicle Trip Ends vs: Students \\ On a: Weekday, \\ A.M. Peak Hour of Generator}

Number of Studies: 54

Average Number of Students: 1,253

Directional Distribution: $71 \%$ entering, $29 \%$ exiting

Trip Generation per Student

\begin{tabular}{|clc|}
\hline Average Rate & Range of Rates & Standard Doviation \\
\hline 0.42 & $0.14-1.15$ & 0.68 \\
\hline
\end{tabular}

\section{Data Plot and Equation}

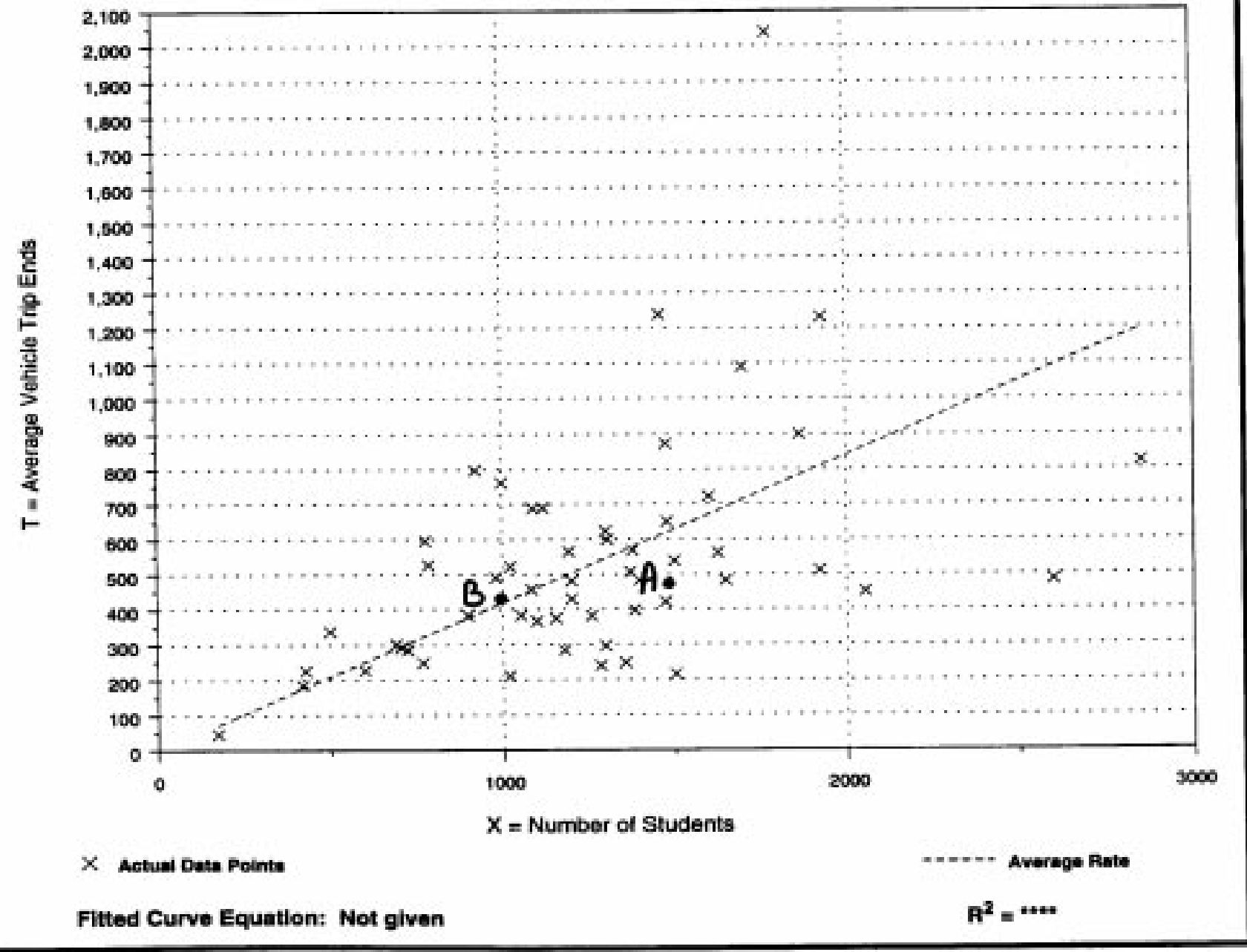




\section{High School \\ (530)}

\section{Average Vehicle Trip Ends vs: Students \\ On a: Weekday, \\ P.M. Peak Hour of Generator}

Number of Studies: 54

Average Number of Students: 1,253

Directional Distribution: $31 \%$ entering, $69 \%$ exiting

\section{Trip Generation per Student}

\begin{tabular}{|cccc|}
\hline Average Rate & Range of Rates & Standard Deviation \\
\hline 0.30 & 0.10 & -0.57 & 0.56 \\
\hline
\end{tabular}

\section{Data Plot and Equation}

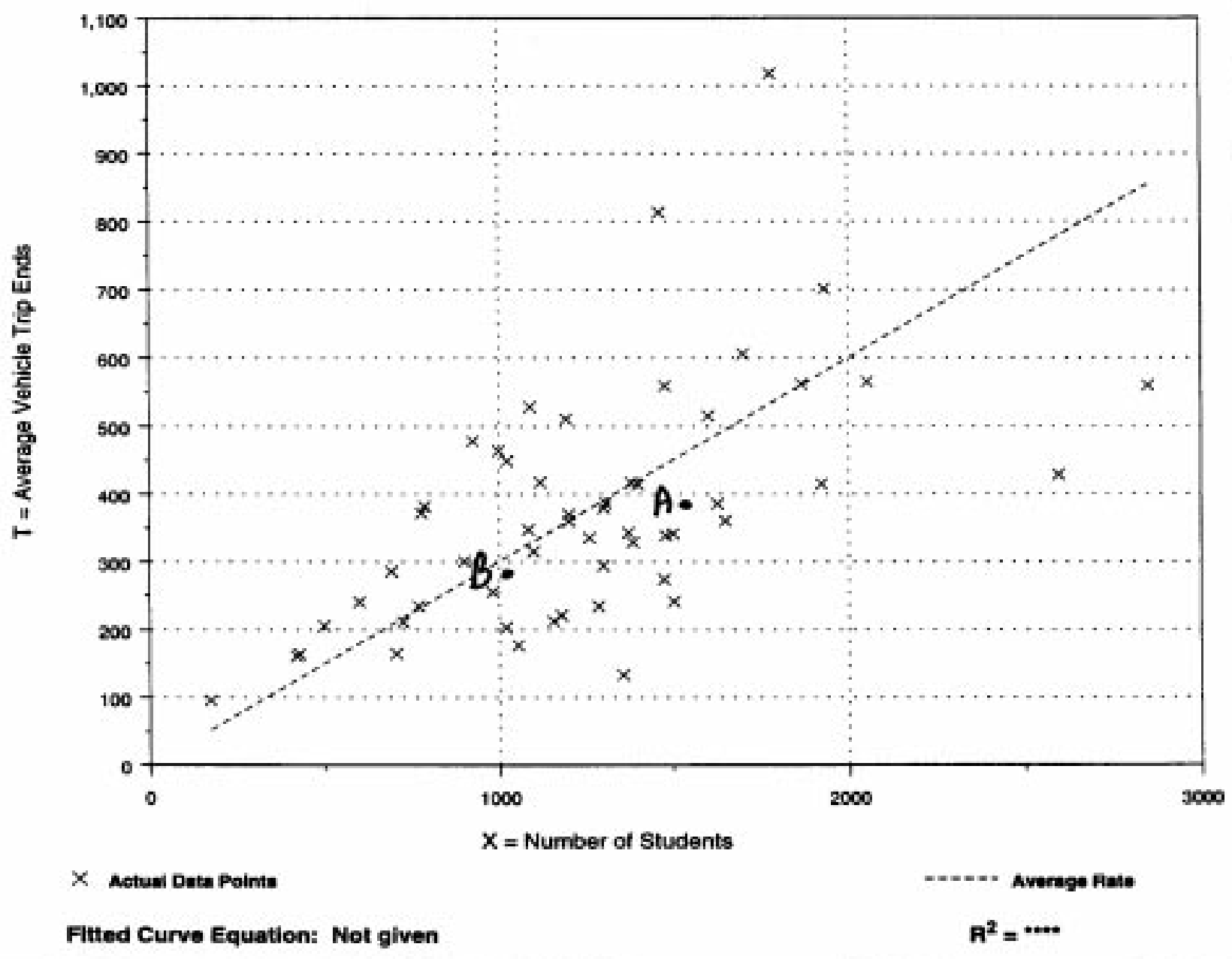




\section{High School}

(530)

\section{Average Vehicle Trip Ends vs: Students \\ On a: Saturday}

Number of Studies: 18

Average Number of Students: 1,481

Directional Distribution: $50 \%$ entering, $50 \%$ exiting

\section{Trip Generation per Student}

\begin{tabular}{|cccc|}
\hline Average Rate & Range of Rates & Standard Deviation \\
\hline 0.64 & $0.08 \quad 1.62$ & 0.90 \\
\hline
\end{tabular}

\section{Data Plot and Equation}

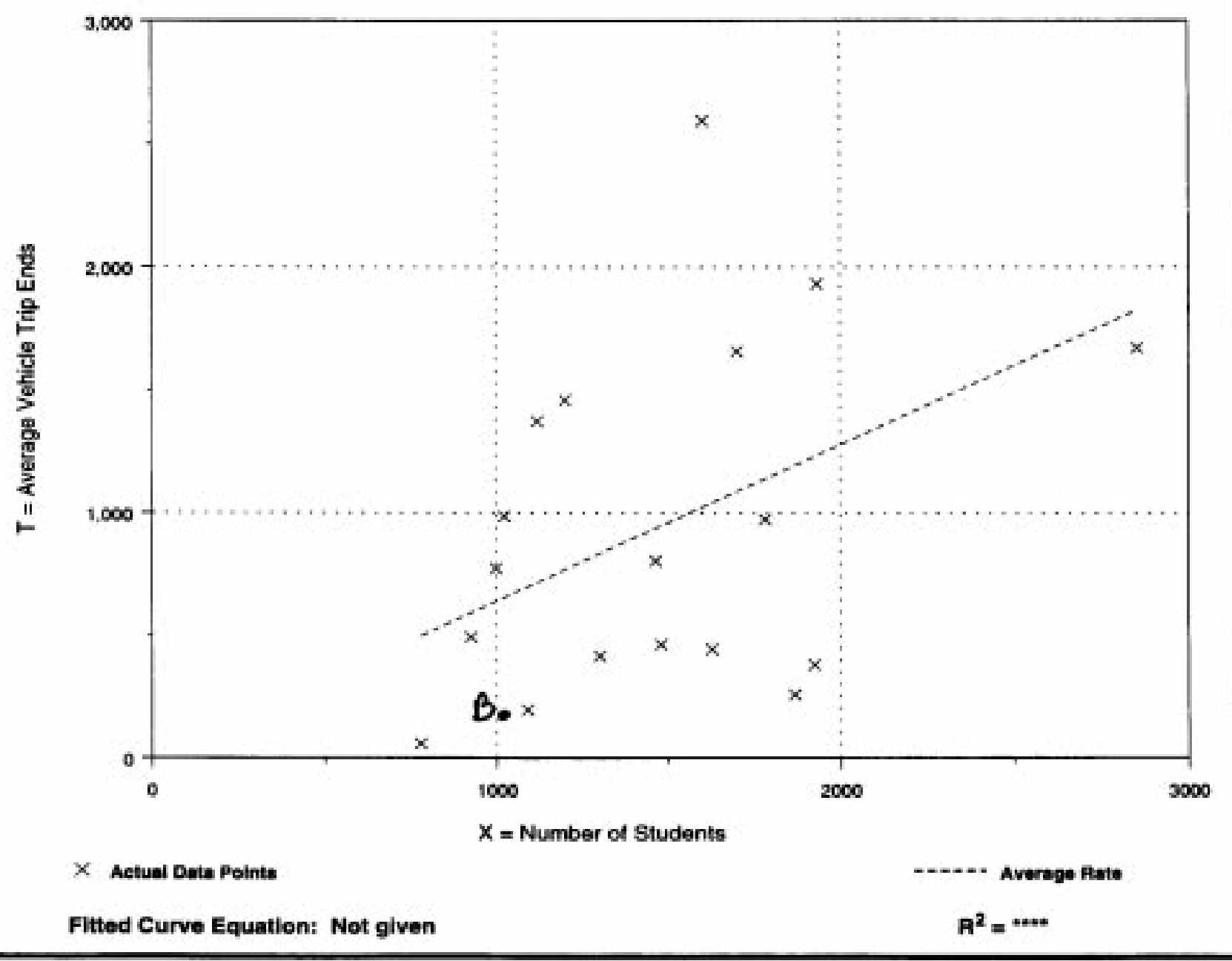




\section{High School \\ (530)}

\section{Average Vehicle Trip Ends vs: Students \\ On a: Saturday, \\ Peak Hour of Generator}

Number of Studies: 18

Average Number of Students: 1,481

Directional Distribution: $74 \%$ entering, $26 \%$ exiting

Trip Generation per Student

\begin{tabular}{|cccc|}
\hline Average Rate & Range of Rates & Standard Deviation \\
\hline 0.12 & $0.02 \cdot 0.24$ & 0.35 \\
\hline
\end{tabular}

\section{Data Plot and Equation}

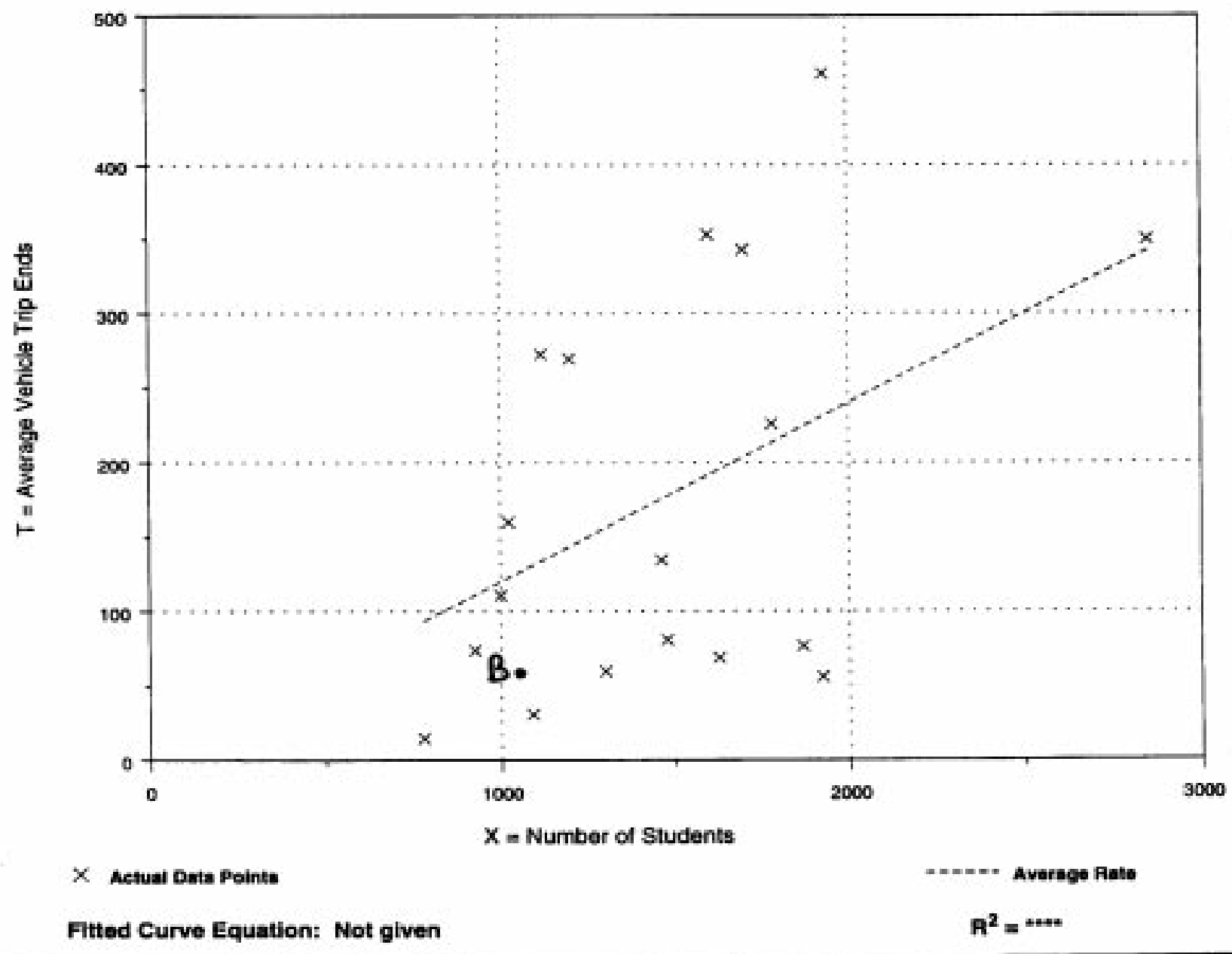




\title{
High School \\ (530)
}

\section{Average Vehicle Trip Ends vs: Students \\ On a: Sunday}

\author{
Number of Studies: 18 \\ Average Number of Students: 1,481 \\ Directional Distribution: $50 \%$ entering, $50 \%$ exiting
}

\section{Trip Generation per Student}

\begin{tabular}{|clc|}
\hline Average Rate & Range of Rates & Standard Deviation \\
\hline 0.25 & $0.04-0.92$ & 0.55 \\
\hline
\end{tabular}

\section{Data Plot and Equation}

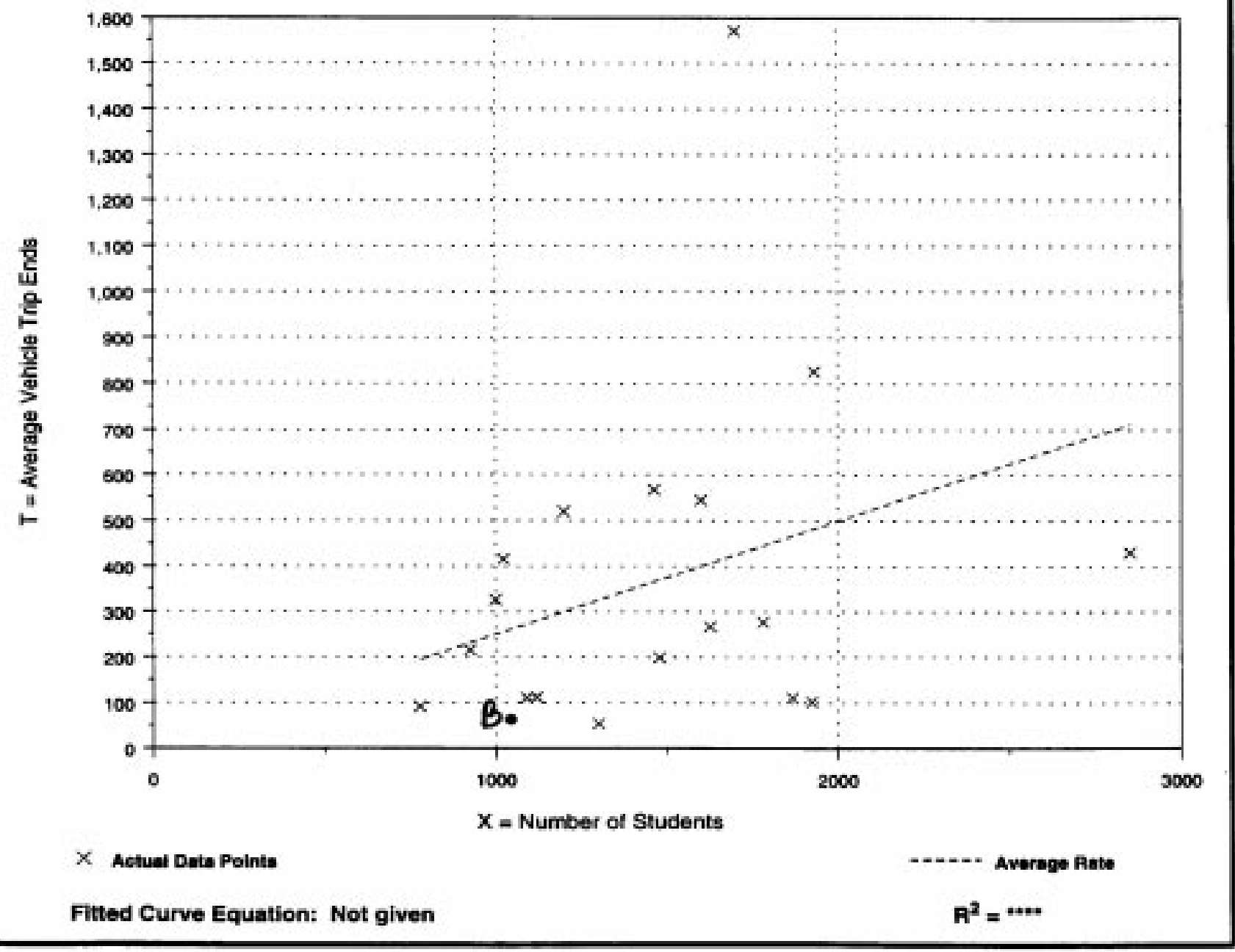




\title{
High School \\ (530)
}

\section{Average Vehicle Trip Ends vs: Students \\ On a: Sunday, \\ Peak Hour of Generator}

\author{
Number of Studies: 18 \\ Average Number of Students: 1,481 \\ Directional Distribution: $33 \%$ entering, $67 \%$ exiting
}

Trip Generation per Student

\begin{tabular}{|clcc|}
\hline Average Rate & Pange of Rates & Standard Deviation \\
\hline 0.04 & $0.01 \cdot 0.20$ & 0.22 \\
\hline
\end{tabular}

\section{Data Plot and Equation}

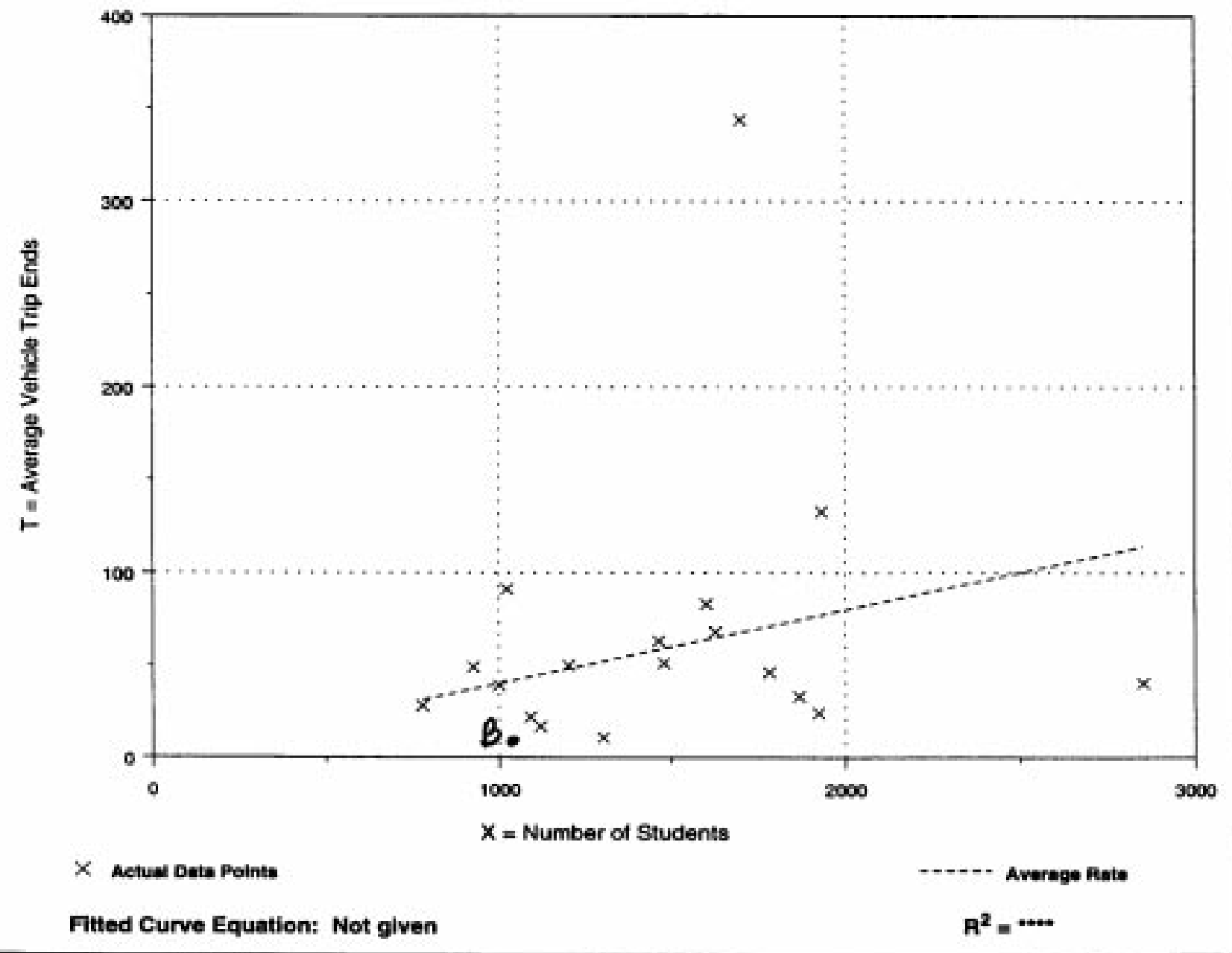




\title{
High School
}

(530)

\section{Average Vehicle Trip Ends vs: 1000 Sq. Feet Gross Floor Area \\ On a: Weekday}

\author{
Number of Studies: 38 \\ Average $1000 \mathrm{Sq}$. Feet GFA: 187 \\ Directional Distribution: $50 \%$ entering, $50 \%$ exiting
}

Trip Generation per 1000 Sq. Feet Gross Floor Area

\begin{tabular}{|c|c|c|}
\hline Average Rate & Range of Rates & Standard Deviation \\
\hline 13.27 & $4.00 \cdot 34.06$ & 7.51 \\
\hline
\end{tabular}

\section{Data Plot and Equation}

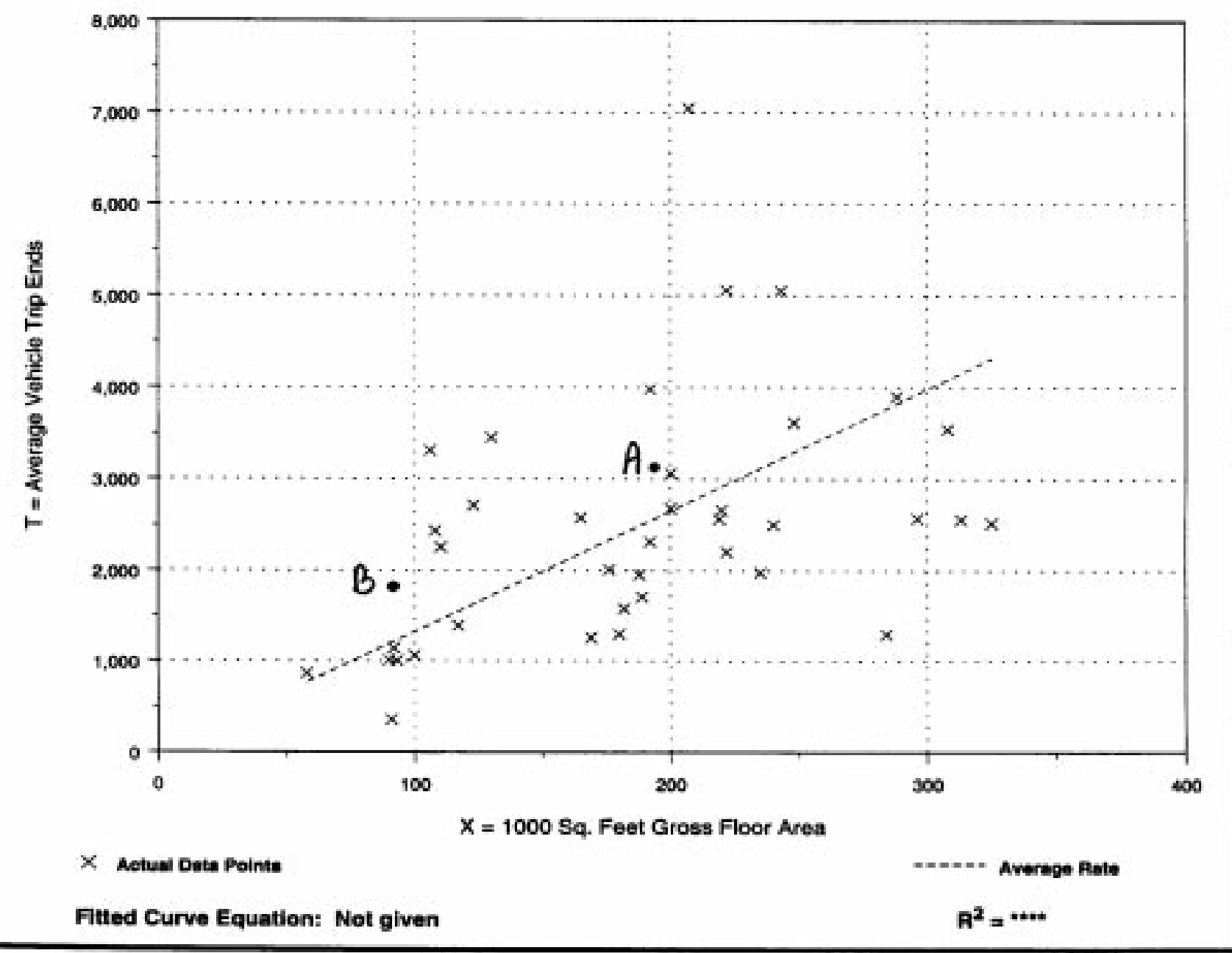




\section{High School}

(530)

\section{Average Vehicle Trip Ends vs: 1000 Sq. Feet Gross Floor Area \\ On a: Weekday, \\ A.M. Peak Hour of Generator}

Number of Studies: 38

Average 1000 Sq. Feet GFA: 187

Directional Distribution: $72 \%$ entering, $28 \%$ exiting

\section{Trip Generation per 1000 Sq. Feet Gross Floor Area}

\begin{tabular}{|ccc|}
\hline Average Rate & Pange of Rates & Standard Deviation \\
\hline 3.15 & $0.51-9.86$ & 2.47 \\
\hline
\end{tabular}

\section{Data Plot and Equation}

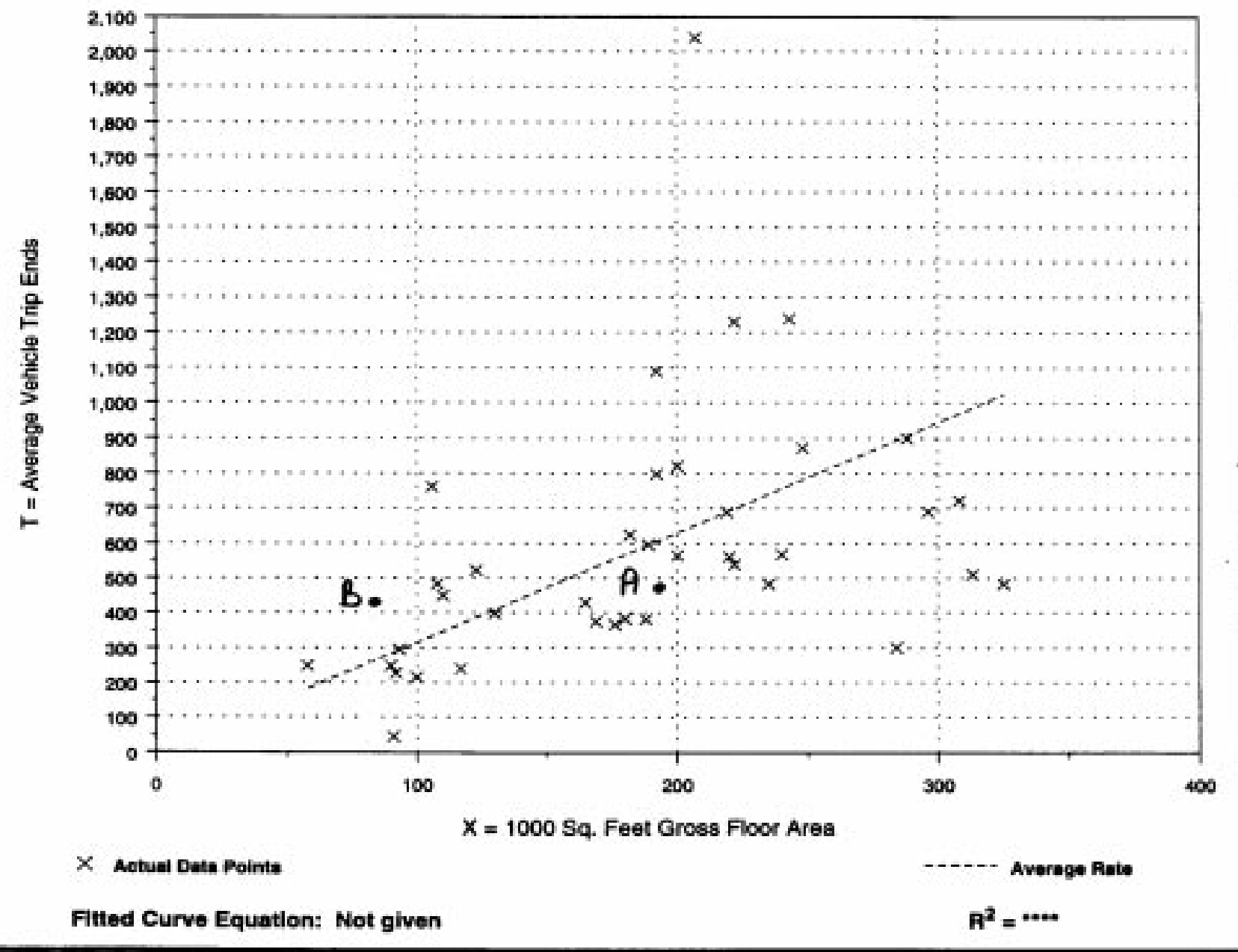




\section{High School \\ (530)}

\section{Average Vehicle Trip Ends vs: 1000 Sq. Feet Gross Floor Area \\ On a: Weekday, \\ P.M. Peak Hour of Generator}

Number of Studies: 38

Average $1000 \mathrm{Sq}$. Feet GFA: 187

Directional Distribution: $30 \%$ entering, $70 \%$ exiting

Trip Generation per 1000 Sq. Feet Gross Floor Area

\begin{tabular}{|ccc|}
\hline Average Pate & Range of Rates & Standard Deviation \\
\hline 2.21 & $0.98-5.14$ & 1.78 \\
\hline
\end{tabular}

\section{Data Plot and Equation}

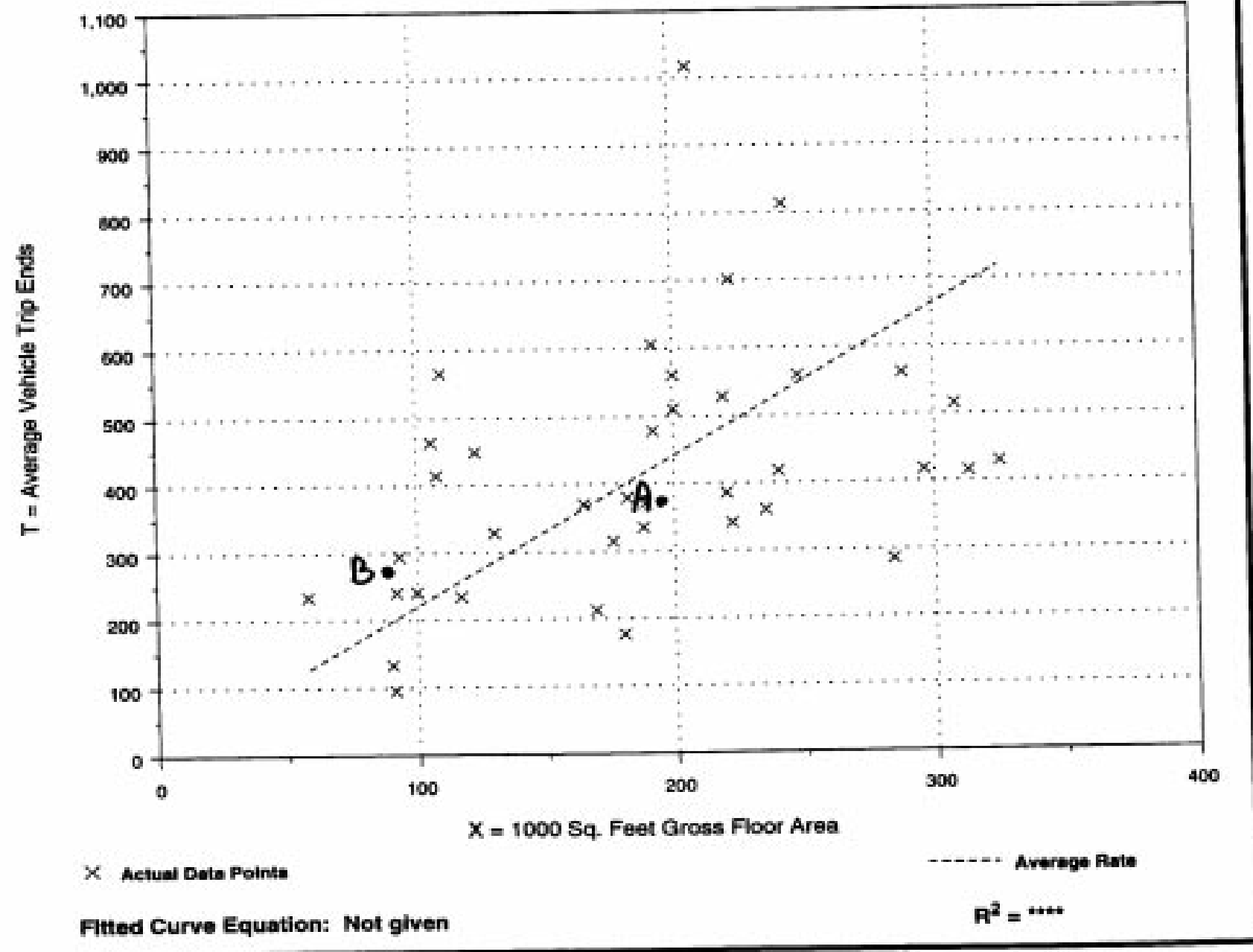




\section{High School \\ (530)}

\section{Average Vehicle Trip Ends vs: 1000 Sq. Feet Gross Floor Area \\ On a: Saturday}

Number of Studies: 18

Average $1000 \mathrm{Sq}$. Feet GFA: 217

Directional Distribution: $50 \%$ entering, $50 \%$ exiting

Trip Generation per 1000 Sq. Feet Gross Floor Area

\begin{tabular}{|cccc|}
\hline Average Rate & Range of Rates & Standard Deviation \\
\hline 4.33 & $0.31 \cdot 8.85$ & 3.76 \\
\hline
\end{tabular}

\section{Data Plot and Equation}

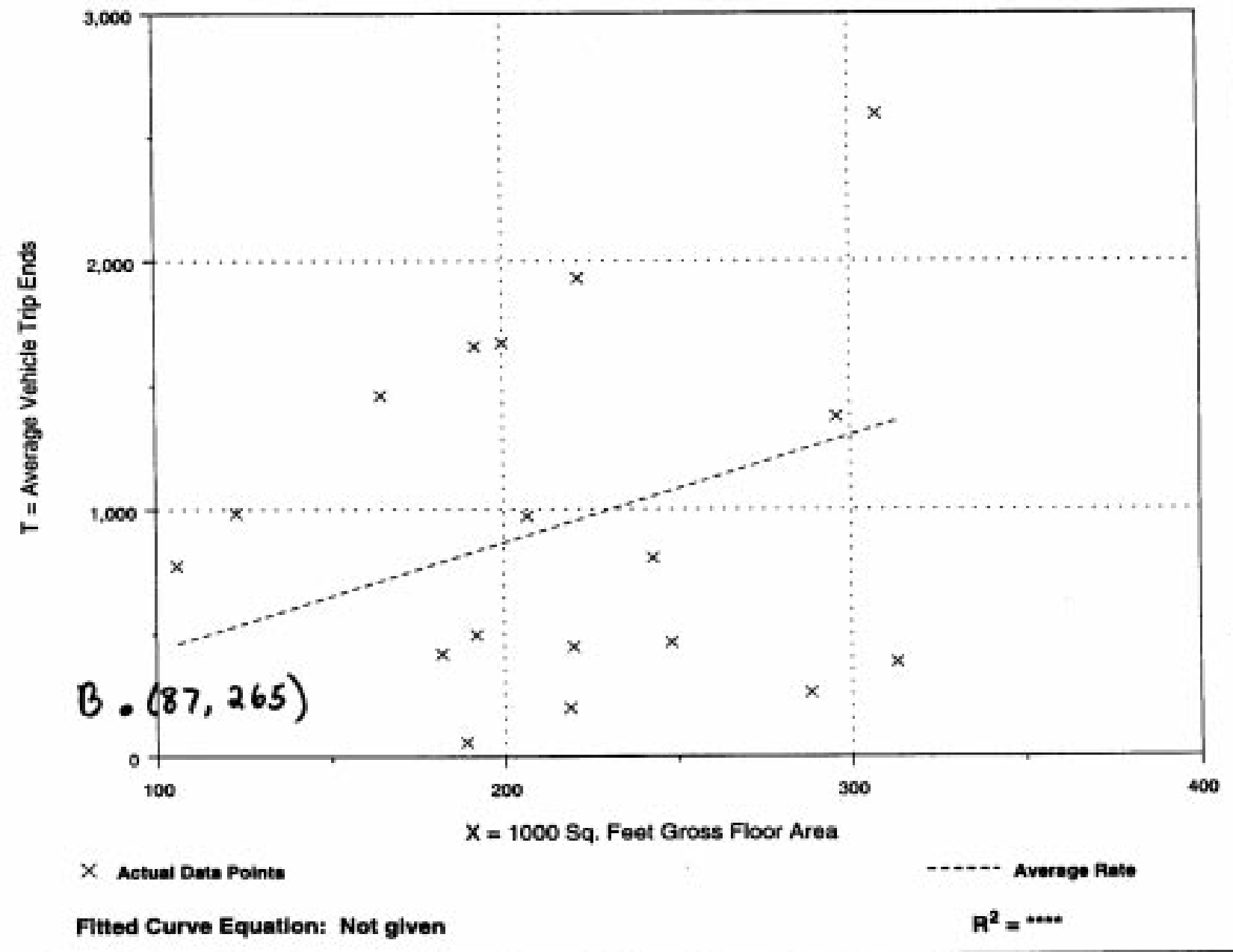




\section{High School \\ (530)}

\section{Average Vehicle Trip Ends vs: 1000 Sq. Feet Gross Floor Area \\ On a: Saturday, \\ Peak Hour of Generator}

Number of Studies: 18

Average 1000 Sq. Feet GFA: 217

Directional Distribution: $74 \%$ entering, $26 \%$ exiting

Trip Generation per 1000 Sq. Feet Gross Floor Area

\begin{tabular}{|clc|}
\hline Average Rate & Range of Rates & Standard Deviation \\
\hline 0.80 & $0.08 \cdot 2.08$ & 1.09 \\
\hline
\end{tabular}

\section{Data Plot and Equation}

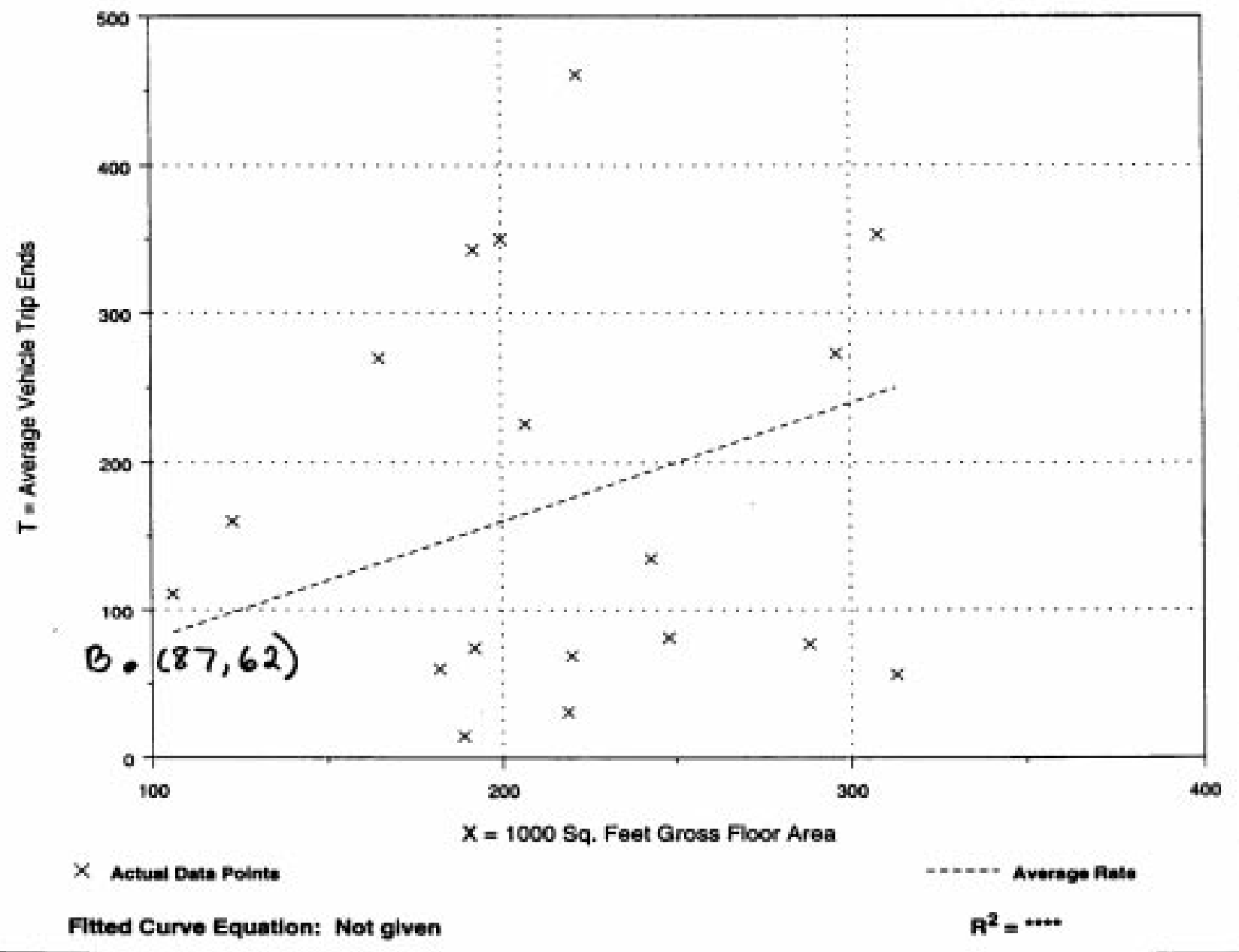




\title{
Average Vehicle Trip Ends vs: 1000 Sq. Feet Gross Floor Area On a: Sunday
}

\author{
Number of Studies: 18 \\ Average 1000 Sq. Feet GFA: 217 \\ Directional Distribution: $\mathbf{5 0 \%}$ entering, $\mathbf{5 0} \%$ exiting
}

Trip Generation per 1000 Sq. Feet Gross Floor Area

\begin{tabular}{|cccc|}
\hline Average Rate & Range of Rates & Standard Deviation \\
\hline 1.72 & 0.30 & -8.19 & 2.24 \\
\hline
\end{tabular}

\section{Data Plot and Equation}

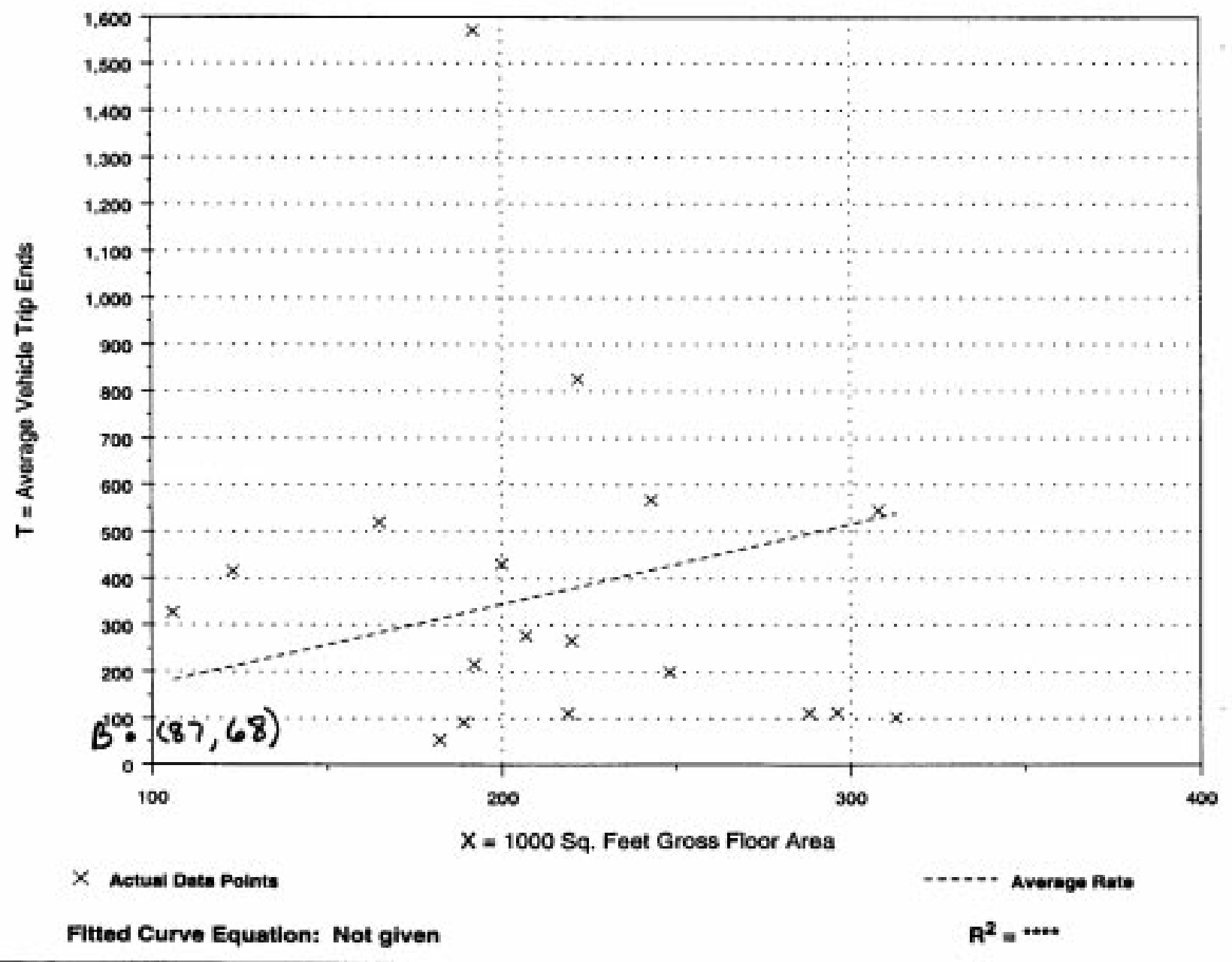




\section{High School \\ (530)}

\section{Average Vehicle Trip Ends vs: 1000 Sq. Feet Gross Floor Area \\ On a: Sunday, \\ Peak Hour of Generator}

Number of Studies: 18

Average $1000 \mathrm{Sq}$. Feet GFA: 217

Directional Distribution: $33 \%$ entering, $67 \%$ exiting

Trip Generation per 1000 Sq. Feet Gross Floor Area

\begin{tabular}{|ccc|}
\hline Average Rate & Range of Rates & Standard Deviation \\
\hline 0.30 & $0.06 \cdot 1.79$ & 0.67 \\
\hline
\end{tabular}

\section{Data Plot and Equation}

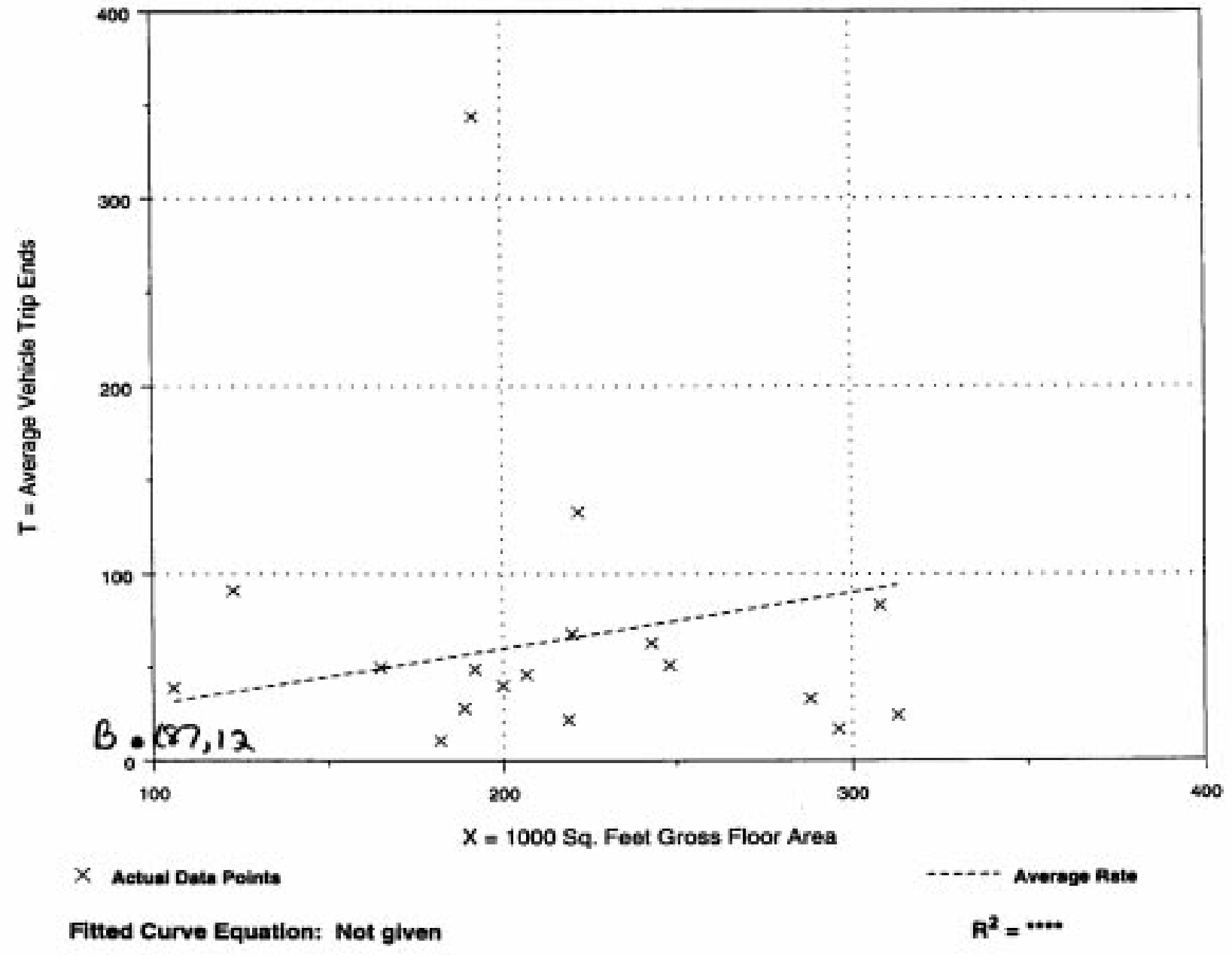




\title{
Middle School/Junior High School (522)
}

\section{Average Vehicle Trip Ends vs: Students \\ On a: Weekday}

\author{
Number of Studies: 16 \\ Average Number of Students: 789 \\ Directional Distribution: $50 \%$ entering, $50 \%$ exiting
}

\section{Trip Generation per Student}

\begin{tabular}{|cccc|}
\hline Average Rate & Range of Rates & Standard Doviation \\
\hline 1.45 & 0.72 & -2.81 & 1.41 \\
\hline
\end{tabular}

\section{Data Plot and Equation}

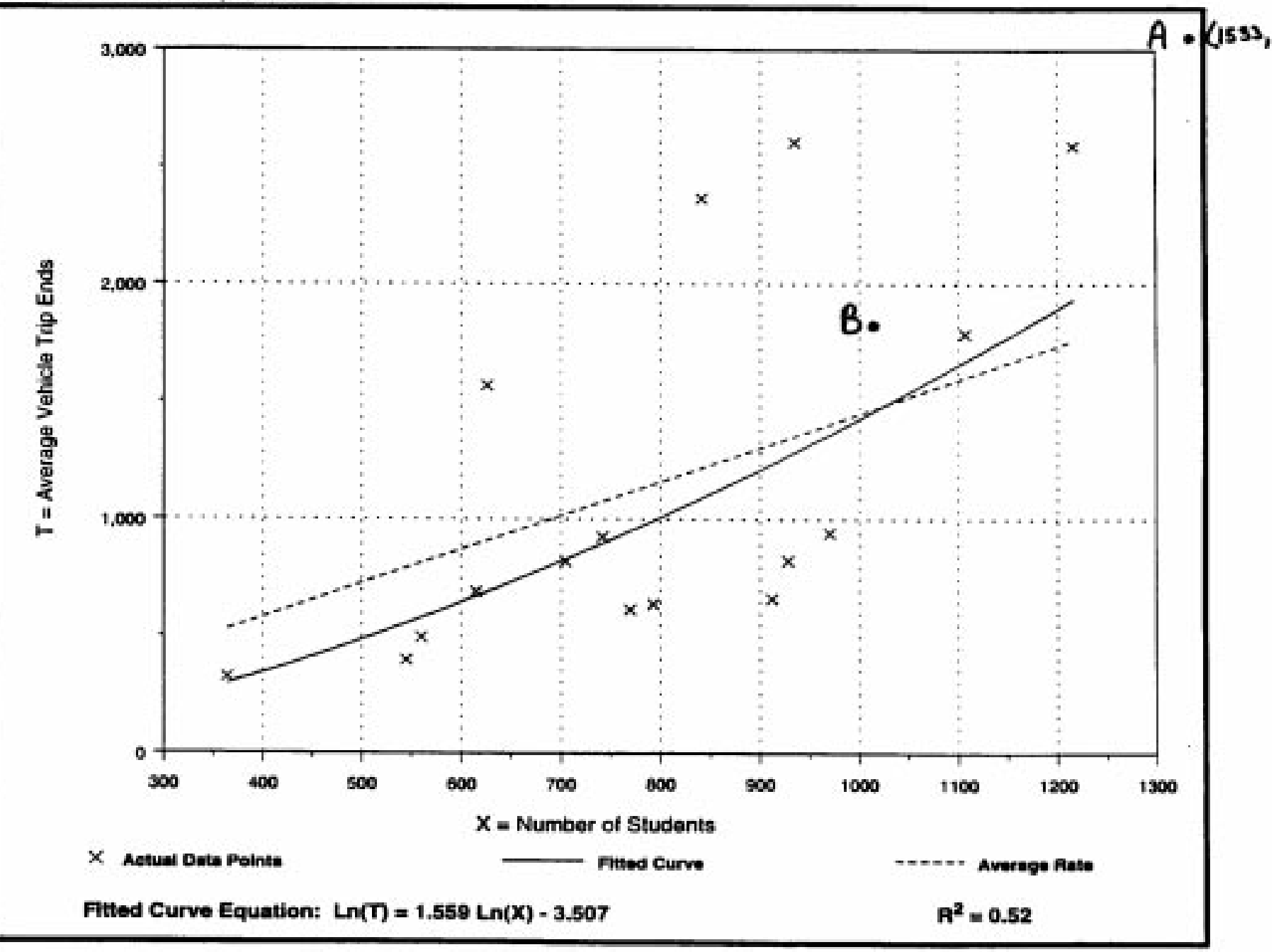




\section{Middle School/Junior High School (522)}

\section{Average Vehicle Trip Ends vs: Students \\ On a: Weekday, \\ A.M. Peak Hour of Generator}

Number of Studies: 16

Average Number of Students: 789

Directional Distribution: $57 \%$ entering, $43 \%$ exiting

\section{Trip Generation per Student}

\begin{tabular}{|ccc|}
\hline Average Rate & Range of Rates & Standard Deviation \\
\hline 0.45 & $0.14 \cdot 1.29$ & 0.75 \\
\hline
\end{tabular}

\section{Data Plot and Equation}

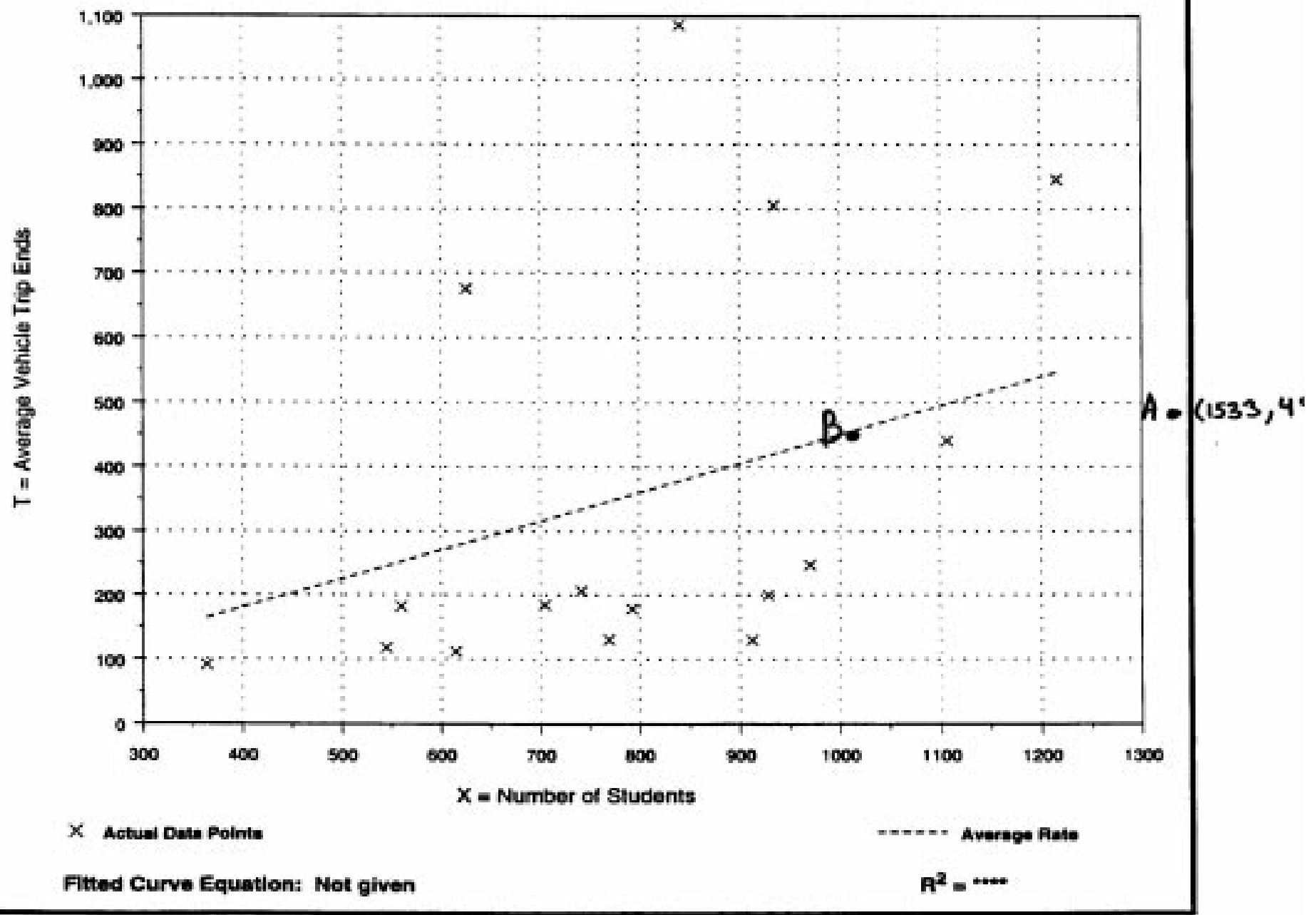




\title{
Middle School/Junior High School (522)
}

\section{Average Vehicle Trip Ends vs: Students \\ On a: Weekday, \\ P.M. Peak Hour of Generator}

\author{
Number of Studies: 18 \\ Average Number of Students: 752 \\ Directional Distribution: $51 \%$ entering, $49 \%$ exiting
}

Trip Generation per Student

\begin{tabular}{|clcc|}
\hline Average Rate & Range of Rates & Standard Deviation \\
\hline 0.29 & $0.12 \quad 0.63$ & 0.56 \\
\hline
\end{tabular}

\section{Data Plot and Equation}

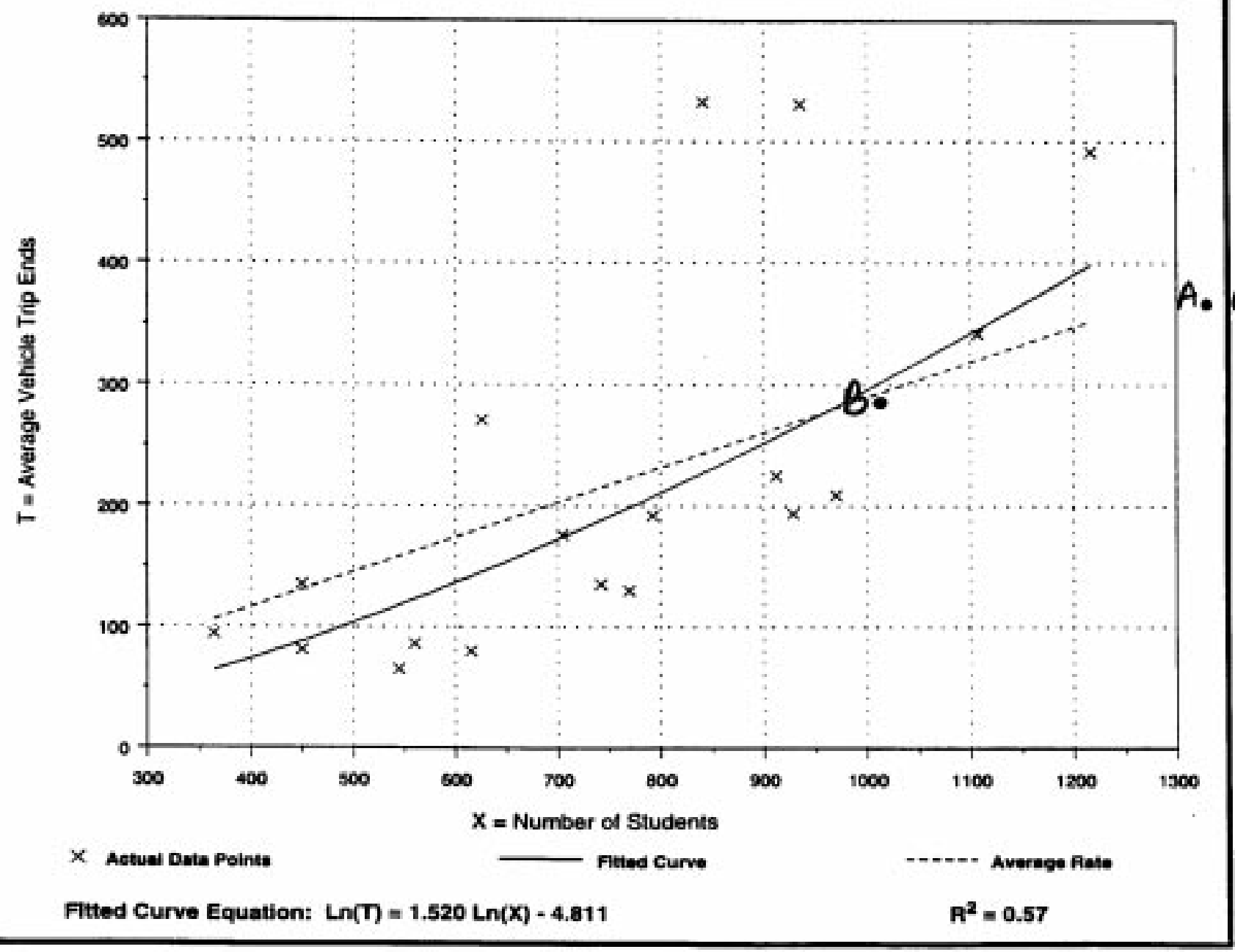




\section{Middle School/Junior High School \\ (522)}

Average Vehicle Trip Ends vs: 1000 Sq. Feet Gross Floor Area

On a: Weekday

Number of Studies: 16

Average $1000 \mathrm{Sq}$. Feet GFA: 96

Directional Distribution: $50 \%$ entering, $50 \%$ exiting

Trip Generation per 1000 Sq. Feet Gross Floor Area

\begin{tabular}{|c|c|c|}
\hline Average Rate & Range of Rates & Standard Deviation \\
\hline 11.92 & $3.89-48.31$ & 9.35 \\
\hline
\end{tabular}

\section{Data Plot and Equation}

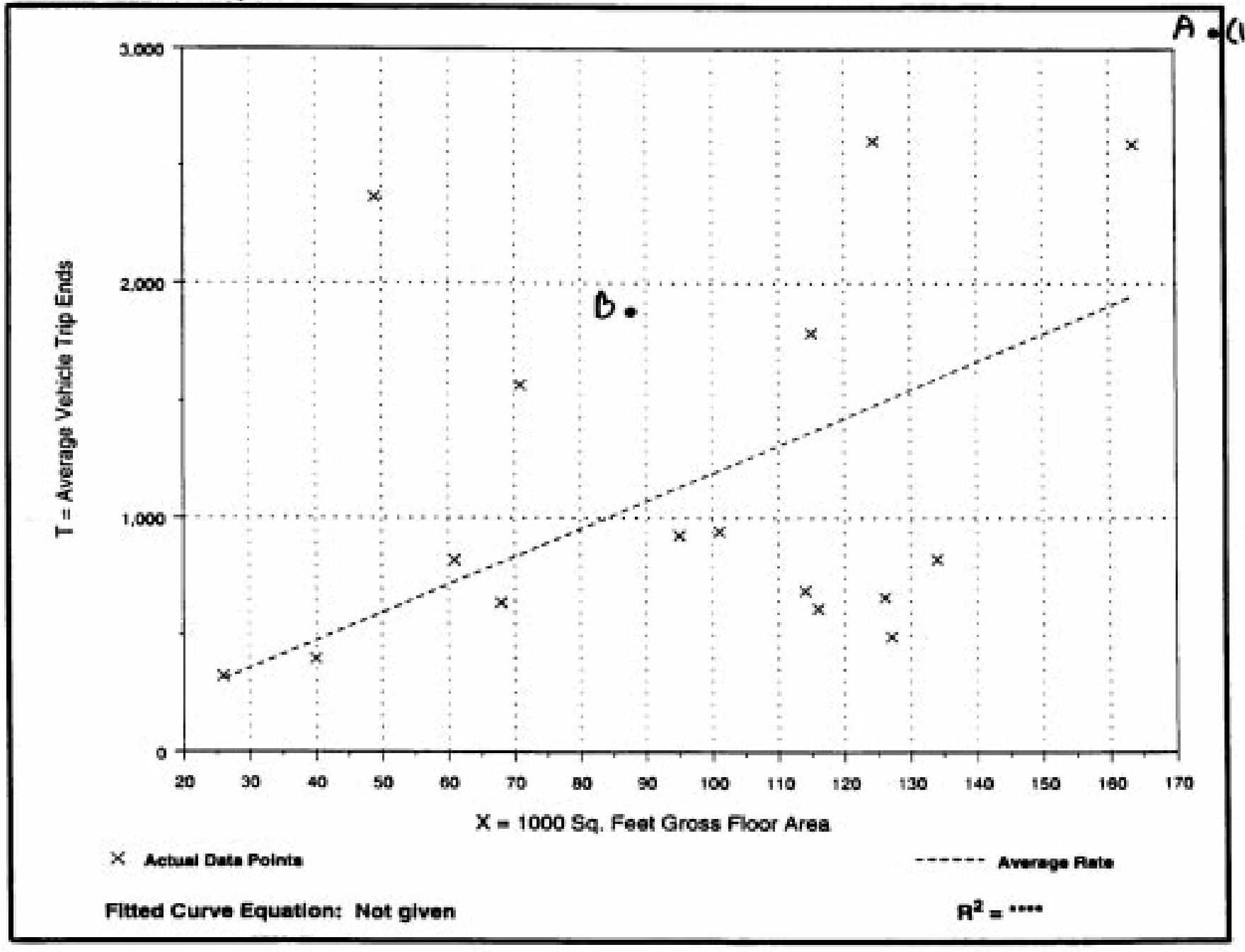




\section{Middle School/Junior High School (522)}

\section{Average Vehicle Trip Ends vs: 1000 Sq. Feet Gross Floor Area \\ On a: Weekday,}

\section{A.M. Peak Hour of Generator}

Number of Studies: 16

Average $1000 \mathrm{Sq}$. Feet GFA: 96

Directional Distribution: $57 \%$ entering, $43 \%$ exiting

Trip Generation per 1000 Sq. Feet Gross Floor Area

\begin{tabular}{|ccc|}
\hline Average Rate & Range of Rates & Standard Deviation \\
\hline 3.68 & $0.98-22.16$ & 4.45 \\
\hline
\end{tabular}

\section{Data Plot and Equation}

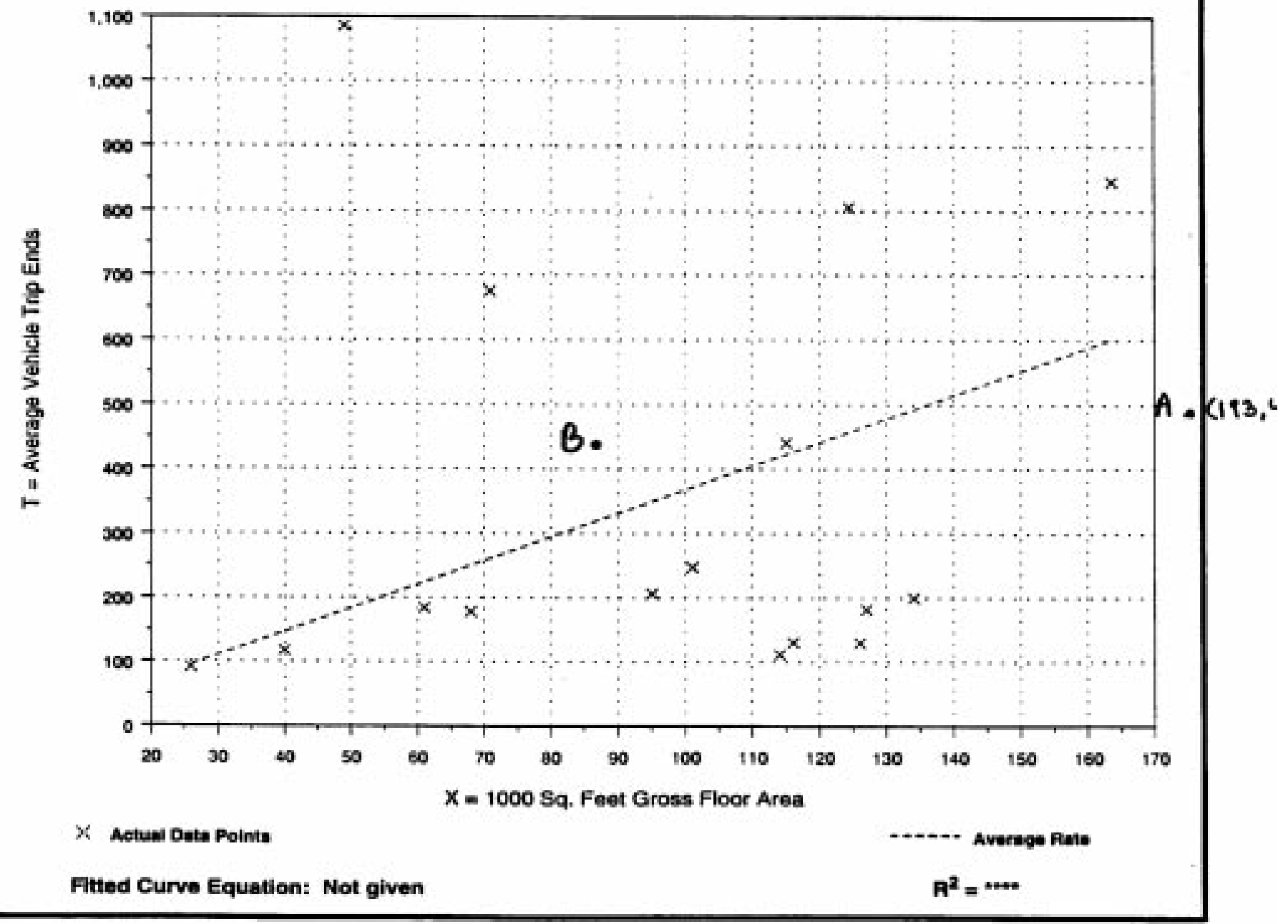




\section{Middle School/Junior High School (522)}

\section{Average Vehicle Trip Ends vs: 1000 Sq. Feet Gross Floor Area \\ On a: Weekday, \\ P.M. Peak Hour of Generator}

Number of Studies: 16

Average $1000 \mathrm{Sq}$. Feet GFA: 96

Directional Distribution: $51 \%$ entering, $49 \%$ exiting

\section{Trip Generation per 1000 Sq. Feet Gross Floor Area}

\begin{tabular}{|ccc|}
\hline Average Rate & Range of Rates & Standard Deviation \\
\hline 2.45 & $0.68-10.88$ & 2.45 \\
\hline
\end{tabular}

\section{Data Plot and Equation}

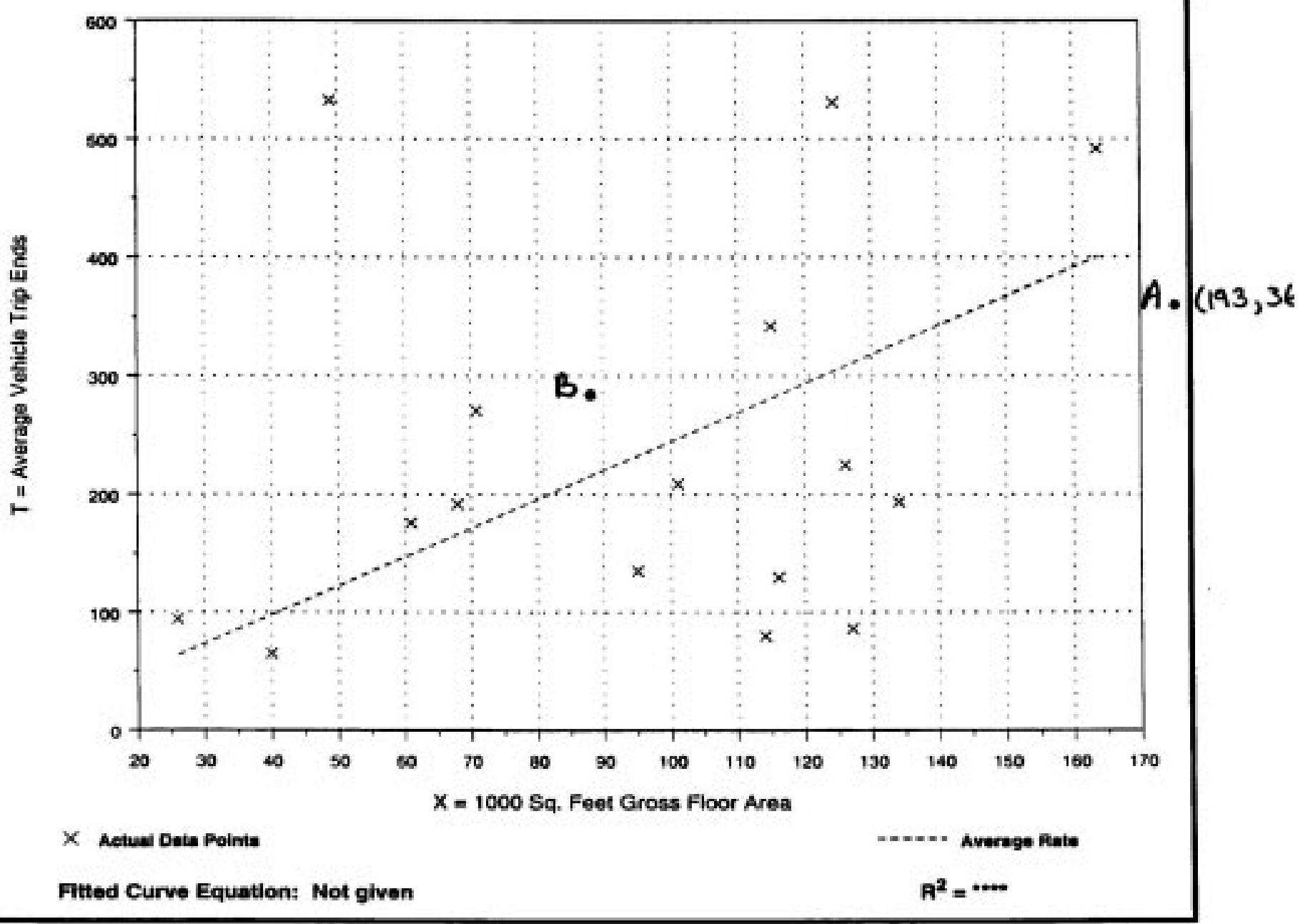




\section{Vita}

Amy Marie Balmer was born in New Brighton, PA on March 20, 1975. She was raised in nearby Beaver Falls, PA, attended Blackhawk High School, and graduated in 1993. She received her Bachelor of Science in Civil Engineering in 1997 from West Virginia University. Currently, she is a Masters candidate specializing in Transportation Engineering at West Virginia University. 